Aus der Abteilung Membranbiophysik

(Prof. Dr. rer. nat. E. Neher)

des Max-Planck-Instituts für biophysikalische Chemie in Göttingen

\title{
Klonieren und Charakterisieren von P/Q-Typ-Calciumkanälen \\ für Mikroskopie an lebenden Zellen
}

\author{
INAUGURAL-DISSERTATION \\ zur Erlangung des Doktorgrades \\ der Medizinischen Fakultät der \\ Georg-August-Universität zu Göttingen
}

vorgelegt von

Martin Juha

aus

Wilhelmshaven

Göttingen 2013 
Dekan:

I. Berichterstatter:

II. Berichterstatter:

Promotor:
Prof. Dr. Kroemer

Prof. Dr. rer. nat. Neher

Prof. Dr. Wouters

Prof. Dr. med. Oppermann

Tag der mündlichen Prüfung: 03.09.2013 


\section{Inhalt}

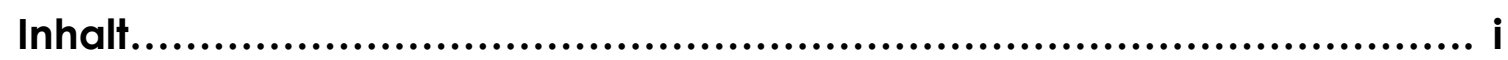

Abbildungsverzeichnis............................................................. iv

Tabellenverzeichnis..................................................................... v

Abkürzungsverzeichnis......................................................... viii

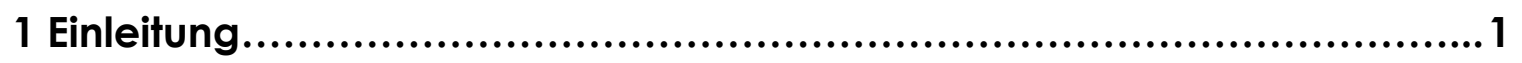

1.1 Calciumkanäle.................................................................. 1

1.2 Synaptische Transmission ............................................... 7

1.2.1 Der synaptische Vesikelzyklus........................................... 8

1.2.2 Am synaptischen Vesikelzyklus beteiligte Proteine .................... 10

1.3 Die Rolle des Calciums bei der Regulation der Transmitterfreisetzung. 12

1.4 Örtliche Anordnung der P/Q-Typ-Calciumkanäle und weitere

Ursachen für die Heterogenität der Fusionsgeschwindigkeit............. 13

1.5 P/Q-Typ-Calciumkanal-bedingte Erkrankungen......................... 17

1.5.1 Lambert-Eaton-Rooke-Syndrom und paraneoplastische

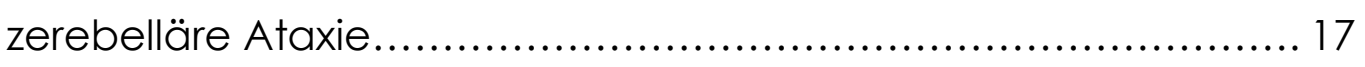

1.5.2 Familiäre hemiplegische Migräne, episodische Ataxie und

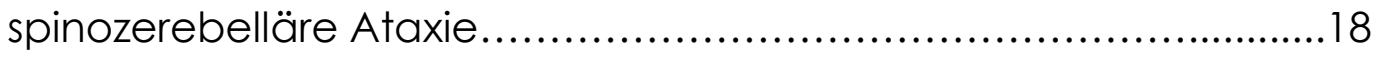

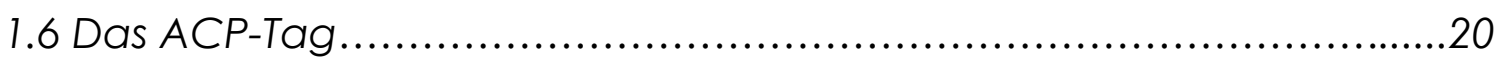

1.7 Potentielle Alternativen zum ACP-Tag: Weitere Färbemethoden........23

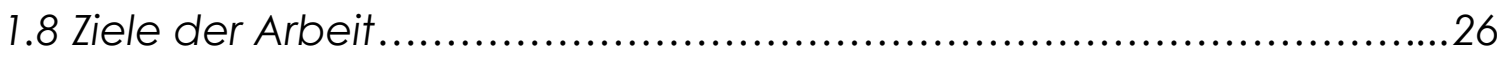

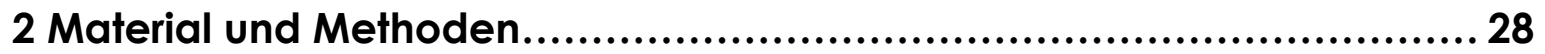

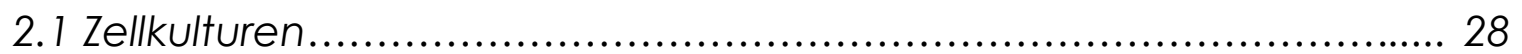


2.1.1 Kultivierung von HEK293-Zellen...........................................28

2.1.2 Kultivierung von ErbB 1-Zellen.......................................... 29

2.1.3 Kultivierung von E2T-HEK-Zellen......................................... 29

2.1.4 Vorbereitungen zum Messen der Ströme und zum Labeling.........29

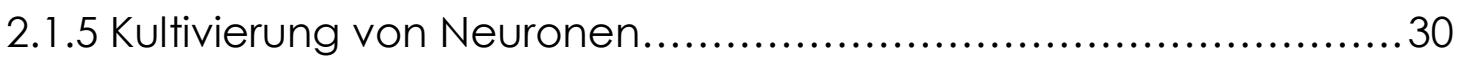

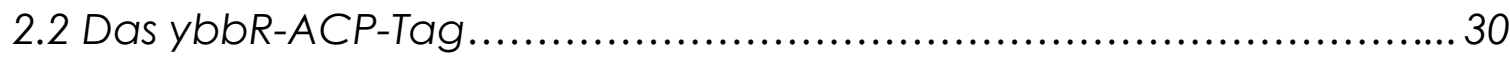

2.2.1 Identifikation geeigneter Regionen zur Integration des ACP-

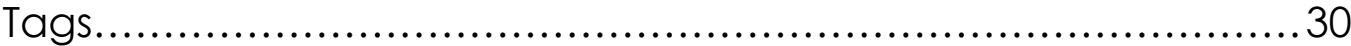

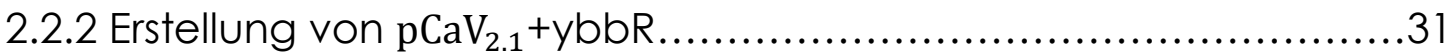

2.3 Messung von P/Q-Typ-Calciumkanalströmen mittels der Patch-Clamp-

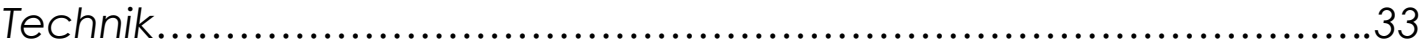

2.3.1 Transfektion der zu messenden Zellen....................................33

2.3.2 Elektrophysiologie der Patch-Clamp-Technik.......................... 33

2.3.3 Messplatz für die Patch-Clamp-Ableitungen..........................35

2.3.4 Datenakquisition und -analyse..................................... 35

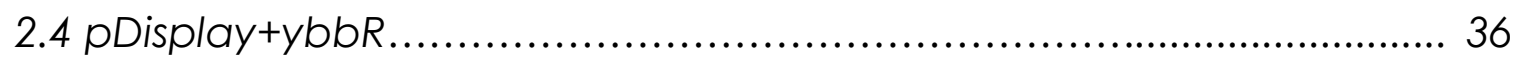

2.4.1 Einbau der benötigten Schnittstellen..................................36

2.4.2 Einbau des GFP und Hybridisierung des ybbR-Tags................... 36

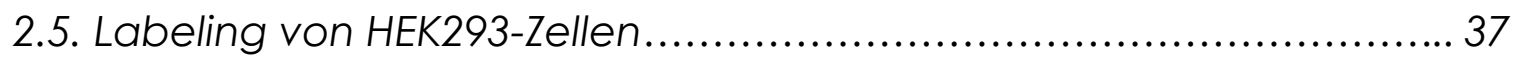

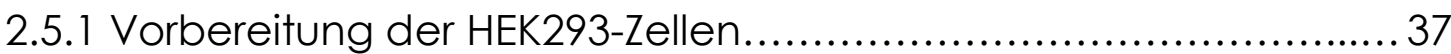

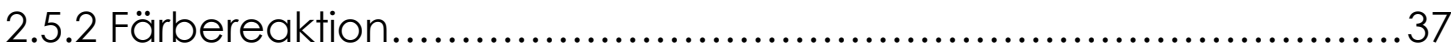

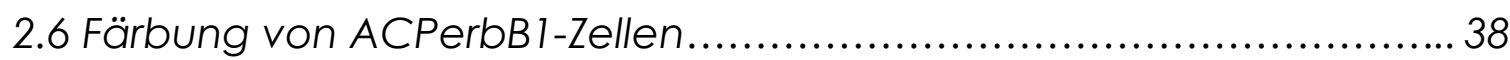

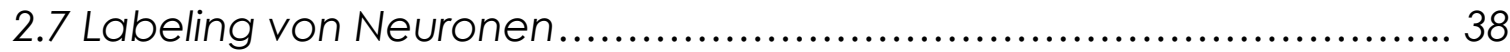




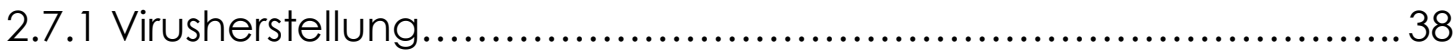

2.7.2 Infektion.............................................................. 41

2.7.3 Färbung der mit dem ybbR-ACP-Tag infizierten Neuronen...........41

2.7.4 Zusätzliches Labeling mithilfe des VGlut1-Antikörpers................ 41

2.7.5 Labeling der Neuronen für STED-Mikroskopie...........................4 42

2.8. Konfokale Mikroskopie.......................................................42

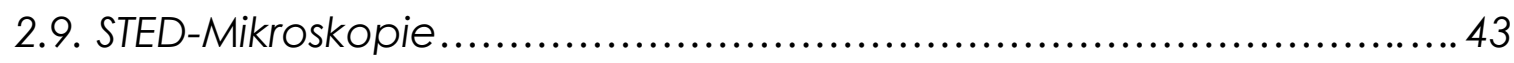

2.10 Lösungen, Puffer, Medien ......................................................4

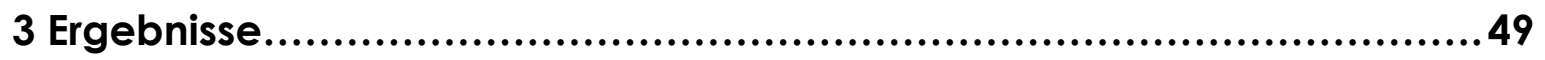

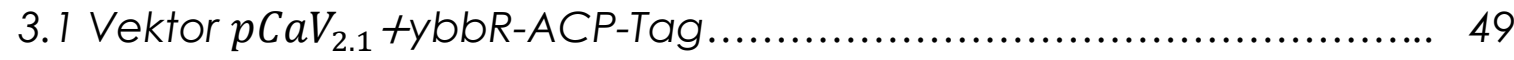

3.2 Vektor pDisplay+ybbR-ACP-Tag ...................................... 51

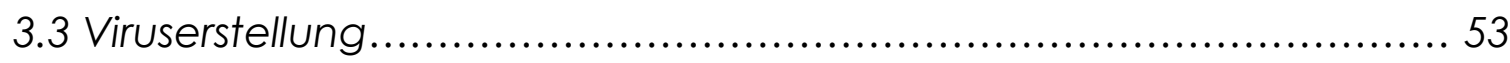

3.4 Messung von P/Q-Typ-Calciumkanalströmen mittels der Patch-

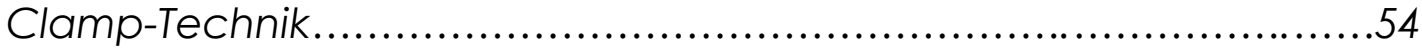

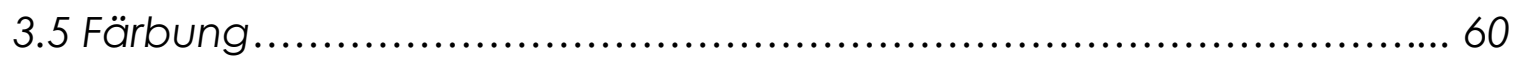

3.5.1 Labeling der mit dem Vektor ACPerbB1 transfizierten HEK293Zellen und der Zelllinie ACPerbB 1 unter Verwendung des Enzyms

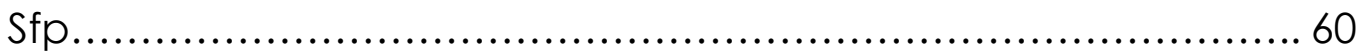

3.5.2 ybbR-Tag bei Verwendung des Vektors pDisplay und Sfp...........67

3.5.3 HEK293-Zellen, tranfiziert mit $\mathrm{pCaV}_{2.1}+\mathrm{ybbR-Insert} \mathrm{unter}$

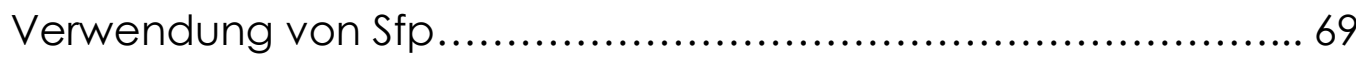

3.5.4 ybbR-Tag im Vektor pDisplay und AcpS............................... 71

3.5.5 HEK293-Zellen, tranfiziert mit $\mathrm{pCaV}_{2.1}+\mathrm{ybbR}$-Insert unter

Verwendung von AcpS................................................ 72

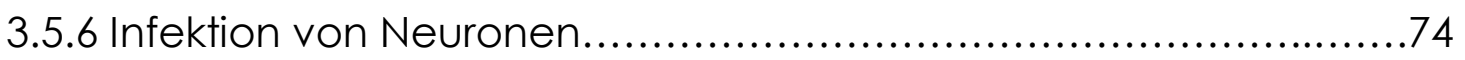

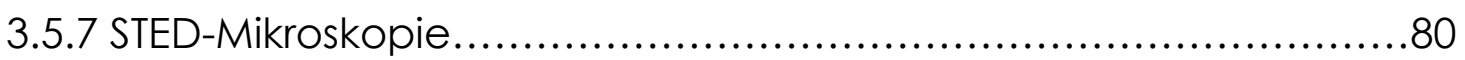




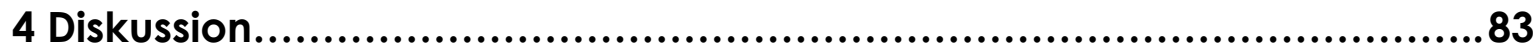

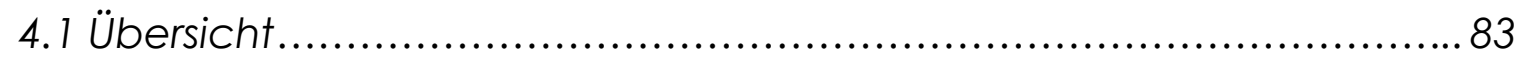

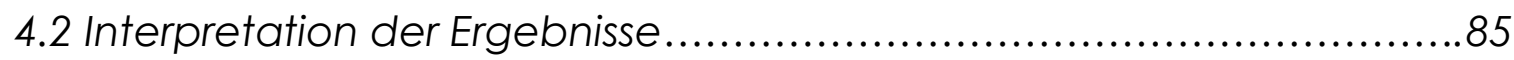

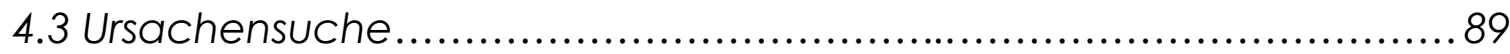

4.3.1 Inaktivierung und Konfirmationsänderung..........................89

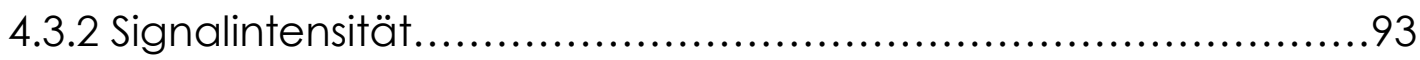

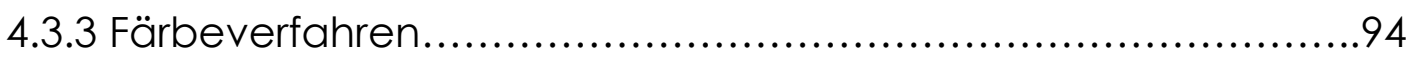

4.3.4 Wahl der Position zur Tag-Integration................................96

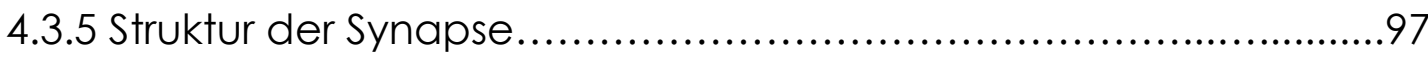

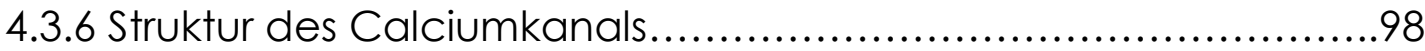

4.4 Bewertung der Ergebnisse im Kontext mit Arbeiten anderer

Arbeitsgruppen................................................................ 100

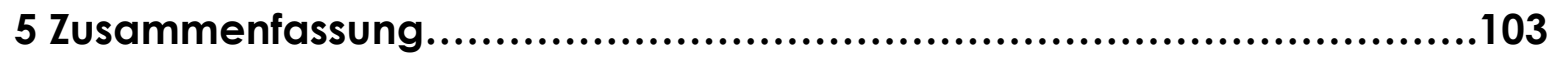

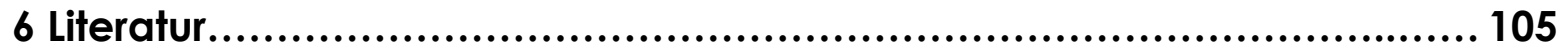




\section{Abbildungsverzeichnis}

Abb. 1.1 Übersicht über die Calciumkanaluntereinheiten in der Zellmembran.. 2

Abb. 1.2 Anordnung der Calciumkanaluntereinheiten................................. 2

Abb. 1.3 Aufbau der $\alpha_{1}$-Untereinheit...............................................

Abb. 1.4 Einteilung der Calciumkanäle............................................... 4

Abb. 1.5 Mechanismus der Transmitterfreisetzung an der präsynaptischen Endigung.............................................9

Abb. 1.6 Proteine des synaptischen Vesikelzyklus I .................................. 11

Abb. 1.7 Proteine des synaptischen Vesikelzyklus II .................................. 12

Abb. 1.8 Angenommene topographische Beziehung zwischen synaptischen Vesikeln und Calciumkanälen innerhalb der aktiven Zone..................15

Abb. 1.9 Präsynaptische Endigung ............................................. 16

Abb. 1.10 Ausschnitt aus dem Vesikelzyklus .............................................. 16

Abb. 1.11 Konvertierung des ACP von der inaktiven Apoform in die aktive Holoform........................................................................ 21

Abb. 1.12 ACP-Labeling-Reaktion................................................... 21

Abb. 3.1 Gelelektrophorese pUC19+ybbR......................................... 49

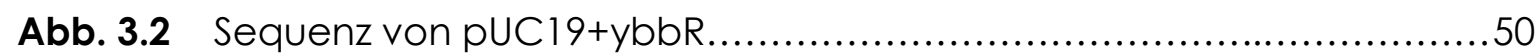

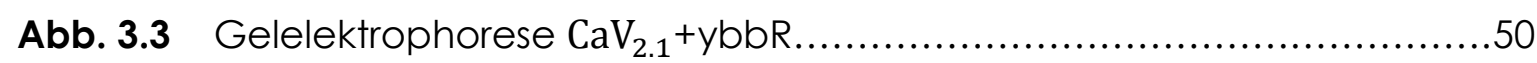

Abb. 3.4 Gelelektrophorese pDisplay+ybbR...................................... 52

Abb. 3.5 Sequenz von pDisplay+ybbR ........................................ 53

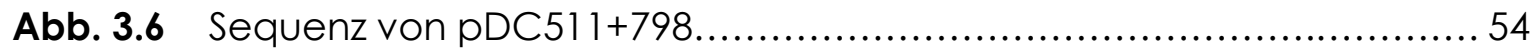

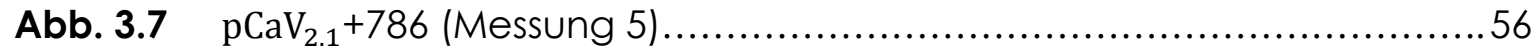

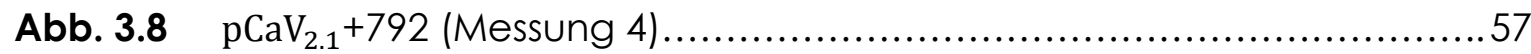

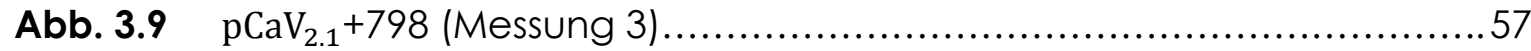

Abb. $3.10 \mathrm{pCaV}_{2.1}+810$ (Messung 1) ................................................ 58

Abb. 3.11 pCaV 2.1 -Wildtyp (Messung 1) .............................................. 58

Abb. 3.12 Maximalströme und Durchschnitt der Maximalströme......................59

Abb. 3.13 Anteil der Zellen mit $\mathrm{V}_{\mathrm{Ca} 2+}$ an der Gesamtzahl der gemessenen Zellen.59

Abb. 3.14 bis 3.16: HEK293-Zellen transfiziert mit ACPerbB 1 und pEGFP-N1

Abb. 3.14: Inkubation 70 min, $12,5 \mu \mathrm{M}$ Substrat, $0,5 \mu \mathrm{M} \mathrm{Sfp}, 37^{\circ} \mathrm{C} \ldots \ldots \ldots \ldots \ldots \ldots \ldots . . . \ldots 2$

Abb. 3.15: Inkubation 70 min, $12,5 \mu \mathrm{M}$ Substrat, $0,5 \mu \mathrm{M} \mathrm{Sfp}, 20^{\circ} \mathrm{C} \ldots \ldots \ldots \ldots \ldots \ldots . . . . . . . .62$

Abb. 3.16: Inkubation 70 min, $12,5 \mu \mathrm{M}$ Substrat, $0,5 \mu \mathrm{M} \mathrm{Sfp}, 4^{\circ} \mathrm{C} \ldots \ldots \ldots \ldots \ldots \ldots . . . . . . . . .63$ 
Abb. 3.17 bis 3.24: ACPerbB1-CHO Zellen

Abb. 3.17 Inkubation $30 \mathrm{~min}, 12,5 \mu \mathrm{M}$ Substrat, $0,5 \mu \mathrm{M} \mathrm{Sfp}, 20^{\circ} \mathrm{C} \ldots \ldots \ldots \ldots \ldots \ldots . . . . . . .63$

Abb. 3.18 Inkubation $30 \mathrm{~min}, 2,5 \mu \mathrm{M}$ Substrat, $0,5 \mu \mathrm{M} \mathrm{Sfp}, 20^{\circ} \mathrm{C} \ldots \ldots \ldots \ldots \ldots \ldots . . . . . . . . .63$

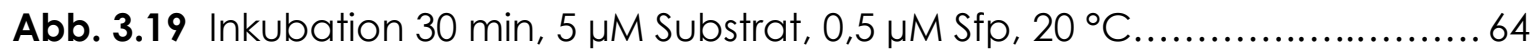

Abb. 3.20 Inkubation 30 min, $25 \mu \mathrm{M}$ Substrat, $0,5 \mu \mathrm{M} \mathrm{Sfp}, 20^{\circ} \mathrm{C} \ldots \ldots \ldots \ldots \ldots \ldots . . . . . . . . . . .64$

Abb. 3.21: Inkubation 30 min, $5 \mu \mathrm{M}$ Substrat, $0,15 \mu \mathrm{M} \mathrm{Sfp}, 20^{\circ} \mathrm{C} \ldots \ldots \ldots \ldots \ldots \ldots . . . . . . . . . .64$

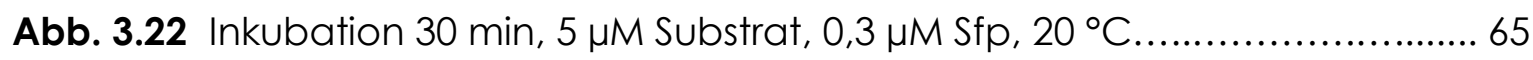

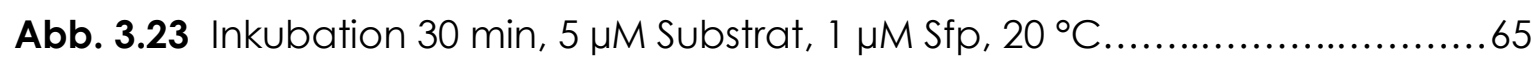

Abb. 3.24 Zellmembran, Inkubation 30 min, $5 \mu \mathrm{M}$ Substrat, 0,5 $\mu \mathrm{M} \mathrm{Sfp}, 20^{\circ} \mathrm{C} \ldots \ldots . .67$

Abb. 3.25 bis 3.28: HEK293-Zellen transfiziert mit pDisplay

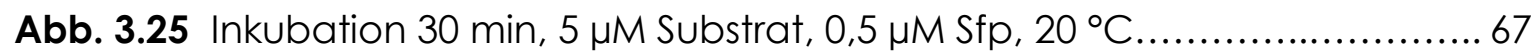

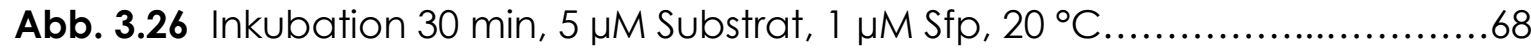

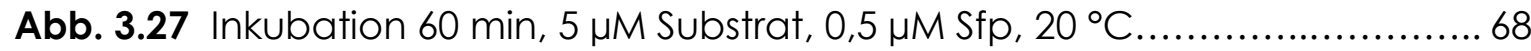

Abb. 3.28 Inkubation $30 \mathrm{~min}, 12,5 \mu \mathrm{M}$ Substrat, $0,5 \mu \mathrm{M} \mathrm{Sfp}, 20^{\circ} \mathrm{C} \ldots \ldots \ldots \ldots \ldots \ldots . . . . . . . . .68$

Abb. $3.29 \mathrm{pCaV}_{2.1}+786$ : Inkubation 30 min, $5 \mu \mathrm{M}$ Substrat, 0,5 $\mu \mathrm{M} \mathrm{Sfp}, 20^{\circ} \mathrm{C} \ldots \ldots . .69$

Abb. 3.30 $\mathrm{pCaV}_{2.1}+792$ : Inkubation $30 \mathrm{~min}, 5 \mu \mathrm{M}$ Substrat, $0,5 \mu \mathrm{M} \mathrm{Sfp}, 20^{\circ} \mathrm{C} \ldots \ldots . . .70$

Abb. 3.31 $\mathrm{pCaV}_{2.1}+798$ : Inkubation $30 \mathrm{~min}, 5 \mu \mathrm{M}$ Substrat, $0,5 \mu \mathrm{M} \mathrm{Sfp}, 20^{\circ} \mathrm{C} \ldots \ldots . .70$

Abb. $3.32 \mathrm{pCaV}_{2.1}+810$ : Inkubation $30 \mathrm{~min}, 5 \mu \mathrm{M}$ Substrat, 0,5 $\mu \mathrm{M}$ Sfp, $20^{\circ} \mathrm{C} \ldots \ldots . . .70$

Abb. 3.33 Inkubation 30 min, $5 \mu \mathrm{M}$ Substrat, $0,5 \mu \mathrm{M}$ Acps, $20^{\circ} \mathrm{C} \ldots \ldots \ldots \ldots \ldots \ldots . . . . . . . .71$

Abb. 3.34 $\mathrm{pCaV}_{2.1}+786$ : Inkubation $30 \mathrm{~min}, 5 \mu \mathrm{M}$ Substrat, $0,5 \mu \mathrm{M}$ Acps, $20^{\circ} \mathrm{C} \ldots . .72$

Abb. 3.35 $\mathrm{pCaV}_{2.1}+792$ : Inkubation $30 \mathrm{~min}, 5 \mu \mathrm{M}$ Substrat, $0,5 \mu \mathrm{M}$ AcpS, $20^{\circ} \mathrm{C} \ldots . .72$

Abb. $3.36 \mathrm{pCaV}_{2.1}+798$ : Inkubation $30 \mathrm{~min}, 5 \mu \mathrm{M}$ Substrat, $0,5 \mu \mathrm{M}$ AcpS, $20^{\circ} \mathrm{C} \ldots . .73$

Abb. 3.37 $\mathrm{pCaV}_{2.1}+810$ : Inkubation $30 \mathrm{~min}, 5 \mu \mathrm{M}$ Substrat, 0,5 $\mu \mathrm{M}$ AcpS, $20{ }^{\circ} \mathrm{C} \ldots . .73$

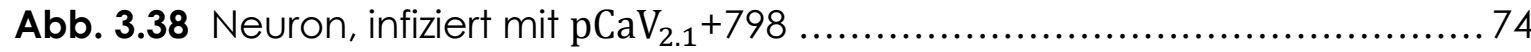

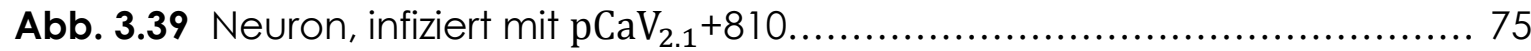

Abb. 3.40 Neuron, nicht infiziert........................................................ 75

Abb. 3.41 Neuron, infiziert mit pCaV $\mathrm{V}_{2.1}+798$ sowie Applikation des Antikörpers

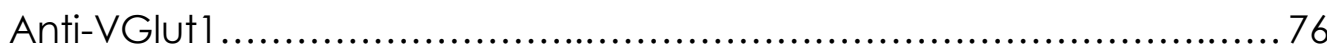

Abb. 3.42 Überlagerung der Aufnahmen bei $547 \mathrm{~nm}$ und $647 \mathrm{~nm}$....................77

Abb. 3.43 Neuron, infiziert mit $\mathrm{pCaV}_{2.1}+810$ sowie Applikation des Antikörpers

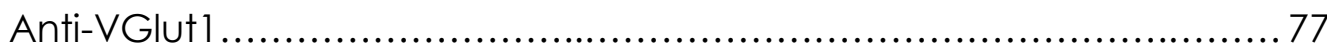

Abb. 3.44 Überlagerung der Aufnahmen bei $547 \mathrm{~nm}$ und $647 \mathrm{~nm} \ldots \ldots \ldots \ldots \ldots . . . . . . . . .78$

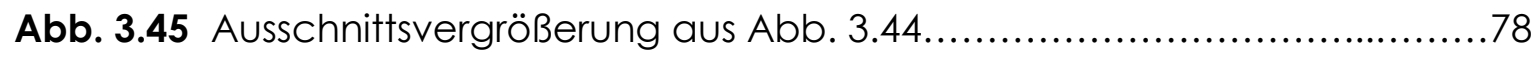

Abb. 3.46 Neuron, nicht infiziert, nicht gefärbt, Anti-VGlutl .......................... 79 
Abb. 3.47 Überlagerung der Aufnahmen bei $547 \mathrm{~nm}$ und $647 \mathrm{~nm} \ldots \ldots \ldots \ldots \ldots \ldots . . . . . . .79$

Abb. 3.48 Primärneuronen, gefärbt, konfokalmikroskopische Aufnahme ............ 80

Abb. 3.49 Überlagerung der Aufnahmen bei $488 \mathrm{~nm}$ und $647 \mathrm{~nm}$................... 80

Abb. 3.50 Ausschnittsvergrößerungen aus Abb. 3.49 ................................. 81

Abb. 3.51 Überlagerung der Ausschnittsvergrößerungen bei $488 \mathrm{~nm}$ und $647 \mathrm{~nm}$ im STED-Mikroskop ....................................................... 81

Abb. 3.52 Farbstoffkonglomerate im dendritischen Dornfortsatz.................... 82

Abb. 4.1 Schematische Darstellung der Inaktivierung eines Calciumkanals........ 90

Abb. 4.2 Schematische Anordnung der Untereinheiten des L-TypCalciumkanals.

\section{Tabellenverzeichnis}

Tab. 3.1 Maximalströme, Durchschnittsstrom und Standardfehler je Tag .59

Tab. 3.2 Anteil der Zellen mit $\mathrm{V}_{\mathrm{Ca} 2+}$ zur Gesamtzahl der gemessenen Zellen 


\section{Abkürzungsverzeichnis}

ACh Acetylcholin

ACP Acyl-Carrier-Protein

Acps ACP-Synthase

AGT $\quad 0^{6}$-Alkylguanin-DNA-Alkyltransferase

AMPA $\quad \alpha$-Amino-3-hydroxy-5-methyl-4-isoxazolepropionat

AP

Aktionspotential

ATP

Adenosintriphosphat

CAMP Zyklisches Adenosinmonophosphat

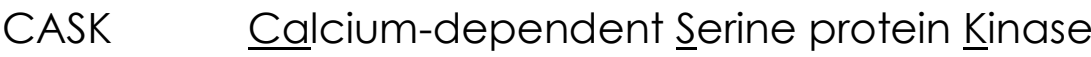

CAZ Cytoskeletal Matrix of Active Zone

$\mathrm{CHO} \quad$ Chinese Hamster Ovary Cells

CoA Coenzym A

CPE Cytopathologic Effect

DMEM Dulbecco's Modified Eagle's Medium

DNA Deoxyribonucleic Acid

dNTP Desoxyribonukleosidtriphosphat

EA Episodische Ataxie

E. coli Escherichia coli

EDTA Ethylendiamintetraacetat

EGFR Epidermal Growth Factor Receptor

EGTA Ethylene Glycol Tetraacetic Acid

EM Elektronenmikroskopie

EPSP Exzitatorisches postsynaptisches Potential

FAS Fettsäure-Synthase

FBS Fetal Bovine Serum 


$\begin{array}{ll}\text { FHM } & \text { Familiäre hemiplegische Migräne } \\ \text { FKBP } & \text { FK506-bindendes Protein } \\ \text { GFP } & \text { Green Fluorescent Protein } \\ \text { GTP } & \text { Guanosintriphosphat } \\ \text { HA } & \text { Hämagglutinin } \\ \text { HBS } & \text { HEPES Buffered Saline } \\ \text { HEK } & \text { Human Embryonic Kidney } \\ \text { HEPES } & \text { 2-(4-[2-Hydroxyethyl]-1-piperazinyl)-ethansulfonsäure } \\ \text { IPSP } & \text { Inhibitorisches postsynaptisches Potential } \\ \text { k } & \text { Wechselzahl } \\ \text { Km } & \text { Michaelis-Menten-Konstante } \\ \text { LB } & \text { Lysogeny Broth } \\ \text { LEMS } & \text { Lambert-Eaton Myasthenic Syndrome } \\ \text { LSM } & \text { Laser-Scanning-Mikroskop } \\ \text { LTP } & \text { Langzeit-Potenzierung } \\ \text { Mint } & \text { Munc-18 interacting Protein } \\ \text { Munc } & \text { Mammalian Homolog of unc } \\ \text { NRPS } & \text { Nicht-ribosomale Peptid-Synthetasen } \\ \text { ORF } & \text { Open Reading Frame } \\ \text { PBS } & \text { Phosphate Buffered Saline } \\ \text { PCA } & \text { Paraneoplastic Cerebellar Ataxia } \\ \text { PCR } & \text { Polymerasekettenreaktion } \\ \text { PDGFR } & \text { Platelet Derived Growth Factor Receptor } \\ \text { PKS } & \text { Polyketide-Synthasen } \\ \text { PPant } & \text { 4'-Phosphopantethein } \\ \text { PPTase } & \text { Phosphopantetheinyl-Transferase } \\ & \end{array}$




$\begin{array}{ll}\text { PSD } & \text { Postsynaptic Density } \\ \text { PTP } & \text { Posttetanische Potenzierung } \\ \text { RIM } & \text { Rab3 Interacting Molecule } \\ \text { RRP } & \text { Readily Releasable Pool } \\ \text { SCA } & \text { Spino-Cerebellar Ataxia } \\ \text { SCLC } & \text { Small Cell Lung Cancer } \\ \text { Sfp } & \text { Surfactinproduzierendes Peptid } \\ \text { SNAP-25 } & \text { Soluble NSF Attachment Protein 25 } \\ \text { SNARE } & \text { Soluble N-ethylmaleimide Sensitive Factor Attachment Receptor } \\ \text { SOC } & \text { Super Optimal Broth } \\ \text { SSC } & \text { Saline-Sodium Citrate } \\ \text { STED } & \text { Stimulated Emission Depletion } \\ \text { TAE-Puffer } & \text { Tris-Acetat-EDTA-Puffer } \\ \text { UV } & \text { Ultraviolett } \\ \text { VGCC } & \text { Voltage-gated Calciumchannel } \\ \text { VGlut } & \text { Vesicular Glutamate Transporter }\end{array}$




\section{$1 \quad$ Einleitung}

Als Zellmembran bezeichnet man jene Biomembran, die alle lebenden Zellen umgibt und so das innere Milieu einer jeden Zelle aufrechterhält.

Die Zellmembran setzt sich aus einer Doppellipidschicht zusammen, in die unter anderem eine große Anzahl an unterschiedlichen Membranproteinen eingebettet ist. Diese Membranproteine erfüllen ihre Aufgaben als Strukturproteine, Adhäsionsproteine, Membranrezeptoren bzw. als Transport- und Kanalproteine.

Zu den Kanalproteinen gehören die Ionenkanäle. Diese Transmembranproteine ermöglichen Ionen das Durchqueren der Zellmembran. Der Ionentransport erfolgt dabei entlang eines bestehenden elektrochemischen Gradienten zwischen dem Zelläußeren und dem Zellinneren.

Ionenkanäle spielen eine bedeutende Rolle bei der Regulation osmotischer Aktivitäten sowie des Säure-Basen-Haushalts, der Aufnahme bzw. Ausscheidung von Stoffen und der Erregungsleitung in Nerven und Muskelzellen.

Sie werden unter anderem anhand ihrer Selektivität für bestimmte lonen unterschieden. Dabei wird zum einen zwischen Kationenkanälen, wie z.B. Kalium-, Natrium- und Calciumkanälen, und zum anderen zwischen Anionenkanälen, wie z.B. Chlorid-, Nitrat- oder Malatkanälen, differenziert. Außerdem existiert eine Reihe von Transmembranproteinen, die Kanäle durch die Zellmembran bilden, z.B. die Aquaporine, die den Durchtritt von Wasser durch die Membran katalysieren.

Die meisten Ionenkanäle werden durch das sie umgebende Milieu oder durch gerichtete Signale in ihrer Leitfähigkeit beeinflusst. Man unterscheidet zwischen spannungsabhängigen lonenkanälen und ligandengesteverten Ionenkanälen. Bei Letzteren erfolgte die Aktivierung der Kanäle nicht durch eine Spannungsänderung, sondern durch Botenstoffe, z.B. Neurotransmitter.

Der thematische Fokus dieser Arbeit liegt auf der Charakterisierung und optischen Darstellung von spannungsabhängigen Calciumkanälen vom P/Q-Typ. Dazu werden zunächst Calciumkanäle allgemein und ihre Rolle bei der Signalübertragung vorgestellt. Danach folgen die Beschreibung der P/Q-TypCalciumkanäle im Besonderen und eine Erläuterung der Hypothesen bezüglich ihrer Verteilung innerhalb der Zellmembran sowie der durch sie bedingten Erkrankungen. Die zu ihrer optischen Darstellung benötigten Verfahren werden abschließend erläutert.

\subsection{Calciumkanäle}

Als Calciumkanäle werden Ionenkanäle bezeichnet, die eine selektive Permeabilität für Calcium aufweisen.

Man unterscheidet zwischen ligandengesteverten und spannungsabhängigen Calciumkanälen. Letztere werden weiter unterteilt in L-Typ-, P/Q-Typ-, N- 
Typ-, R-Typ- und T-Typ-Calciumkanäle [STRIGGOW und EHRLICH 1996].

Ligandengesteverte Calciumkanäle sind unter anderem ein Teil des $\mathrm{IP}_{3}$ - und des Ryanodin-Rezeptors oder finden sich als sog. "Zwei-Poren-Kanäle" bzw. als Kationenkanäle unter anderem in Spermien, in Neuronen bzw. PurkinjeZellen des Cerebellum sowie in Myozyten der Skelett- bzw. Herzmuskulatur [ZUCCHI und RONCA-TESTONI 1997; FERRIS und SNYDER 1992].

Die spannungsabhängigen Calciumkanäle vermitteln den Calciumeinstrom als Antwort auf eine Depolarisation der Zellmembran und regulieren dadurch intrazelluläre Prozesse, wie Sekretion, Neurotransmission und Genexpression. Ihre Aktivität ist essentiell, um elektrische Signale an der Zelloberfläche mit physiologischen Ereignissen innerhalb der Zelle zu koppeln. Zusammenfassend lässt sich sagen, dass die Präsenz von Calciumkanälen eine erregbare Zelle definiert [HILLE 2001].

Calciumkanäle sind Mitglieder einer übergeordneten Familie von transmembranen lonenkanal-Proteinen, welche auch die spannungsabhängigen Natrium- und Kaliumkanäle einschließt [YU und CATTERALL 2004].

Die Entdeckung der Calciumkanäle erfolgte im Jahre 1953 durch Paul Fatt und Bernard Katz [FATT und KATZ 1953].

Es handelt sich um komplexe Proteine, die sich aus vier bis fünf verschiedenen Untereinheiten zusammensetzen, welche von einer Vielzahl von Genen codiert werden [CATTERALL 2000]. Man unterscheidet $\alpha_{1^{-}}, \alpha_{2} \delta-, \beta-$ und $\gamma-$ Untereinheiten (zur Anordnung der Untereinheiten siehe Abbildung 1.1 und 1.2).

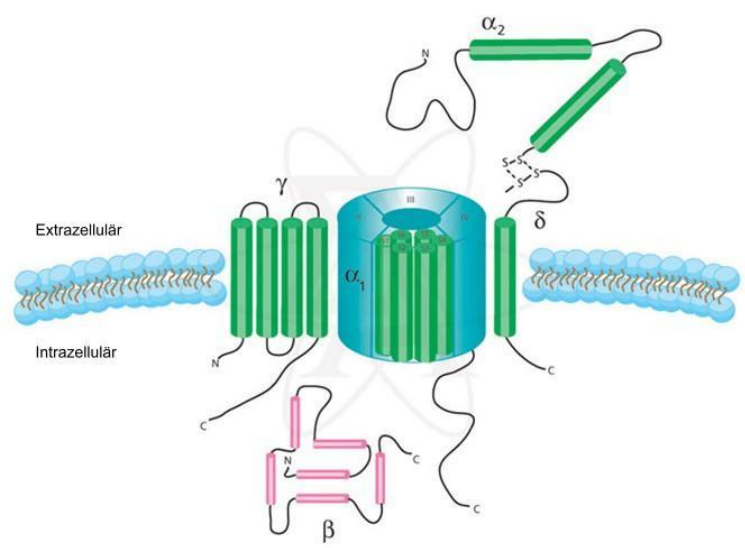

Abb. 1.1 Übersicht über die Calciumkanaluntereinheiten in der Zellmembran [adaptiert nach http://www.sigmaaldrich.com/lifescience/cell-biology/learning-center/ pathway-slides-and/calcium-pore-region.html; aufgerufen am 25.11.2011]

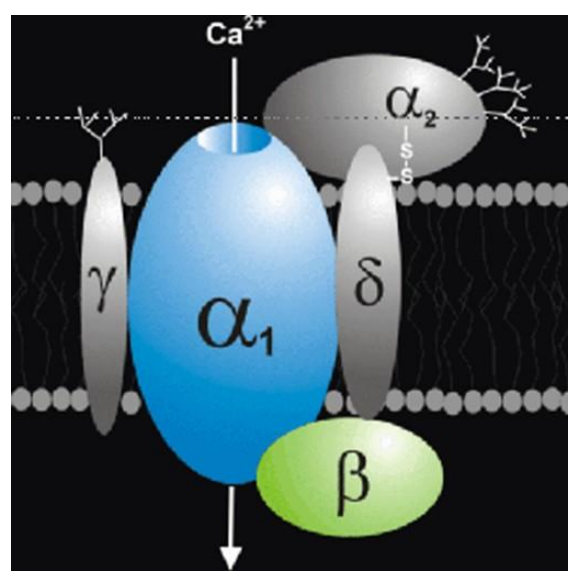

Abb. 1.2 Anordnung der Calciumkanaluntereinheiten [http://calcium.ion.ucl.ac.uk/ subunits-overview.html aufgerufen am $25.11 .2011]$ 
$\alpha_{1}$ ist mit 190 bis $250 \mathrm{kDa}$ die schwerste und größte Untereinheit. Sie vereint die Pore für die $\mathrm{Ca}^{2+}$-Ionen mit dem Spannungssensor, dem sog. "GatingApparat", sowie der Mehrzahl der heute bekannten Rezeptoren für Second Messenger, Medikamente und Toxine.

Die Aktivität des Calciumkanals wird vor allem durch die $\alpha_{1}$-Untereinheit bestimmt, wohingegen die übrigen Untereinheiten an der Regulation dieser Aktivität beteiligt sind [HOFMANN et al. 1994].

Die $\alpha_{1}$-Untereinheit ist weiter in vier homologe Domänen (I-IV) mit jeweils sechs transmembranen Segmenten (S1-S6) unterteilt. Das S4-Segment dient aufgrund des Aufbaus aus positiv geladenem Lysin bzw. Arginin als Spannungssensor. Der Loop zwischen den Segmenten S5 und S6, welcher u.a. aus negativ geladener Glutaminsäure besteht, bestimmt die Ionenleitfähigkeit und Selektivität des Calciumkanals (Abb. 1.3).

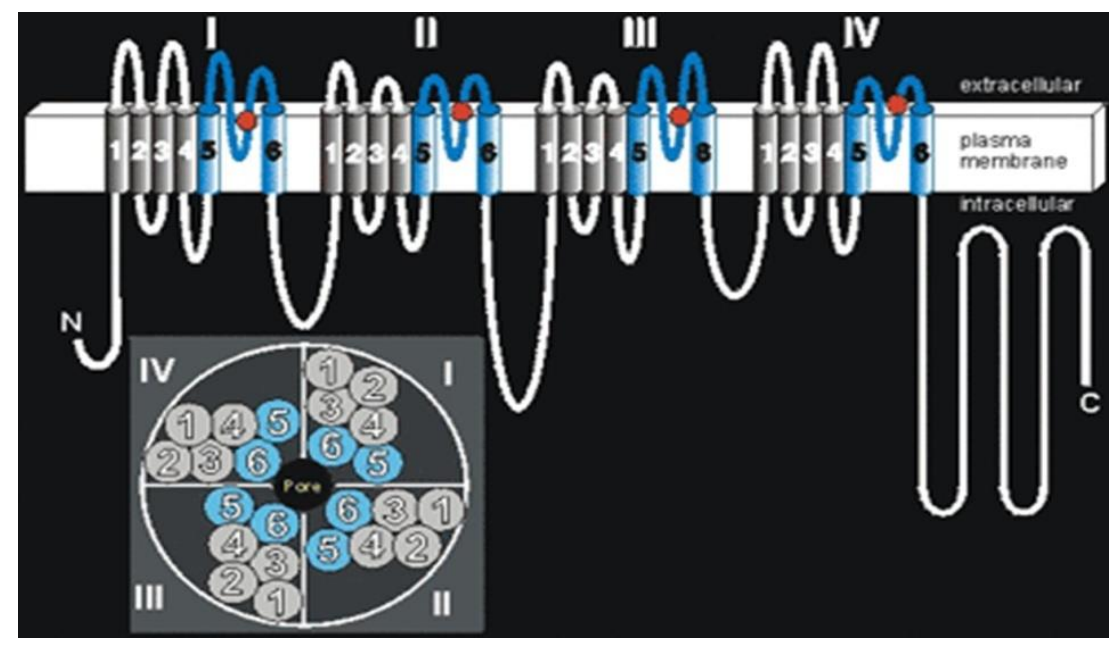

Abb. 1.3 Aufbau der $\alpha_{1}$-Untereinheit [http://calcium.ion.ucl.ac.uk/subunits-overview.html, aufgerufen am 25.11.2011]

Der Komplex aus der intrazellulären $\beta$ - und der transmembranösen $\alpha_{2} \delta$ Untereinheit ist ebenfalls ein Bestandteil der meisten Calciumkanäle.

Die $\beta$-Untereinheit enthält eine Guanylat-Kinase-Domäne, welche sie mit dem intrazellulären Loop zwischen der Domäne I und II der $\alpha_{1}$-Untereinheit verbindet. Dadurch wird die $\alpha_{1}$-Untereinheit stabilisiert. Des Weiteren hilft die $\beta$ Untereinheit der $\alpha_{1}$-Untereinheit, an die Zellmembran zu gelangen, und sorgt für eine Erhöhung der Öffnungswahrscheinlichkeit des Kanals [FANNING et al. 1999; DOLPHIN 2003].

Für die $\beta$-Untereinheit (Größe $52 \mathrm{kDa}$ ) codieren vier verschiedene Gene ( $\beta 1$ $\beta 4$ ), von denen verschiedene Spleiß-Varianten (z.B. $\beta 1 \mathrm{a}, \beta 1 \mathrm{~b}, \beta 2 \mathrm{a}$ etc.) existieren [HELTON et al. 2002]. Die Isoform $\beta 1$ a kommt z.B. vor allem in der Skelettmuskulatur und $\beta 1 \mathrm{~b}$ vor allem in Neuronen und Kardiomyozyten vor.

Das Vorliegen von $\beta 1 \mathrm{a}$ bzw. $\beta 1 \mathrm{~b}$ fördert eine Inaktivierung der betroffenen Kanäle, wohingegen Kanäle, in welchen die Isoform $\beta 2$ a exprimieren wird, 
deutlich seltener inaktiviert werden [QIN et al. 1998].

$\alpha_{2} \delta$ besteht aus der glykolysierten, extrazellulären Untereinheit $\alpha_{2}(120 \mathrm{kDa})$ und der transzellulären Untereinheit $\delta(17-25 \mathrm{kDa})$. Dieser Komplex sorgt für eine größere Amplitude der durch den Calciumeinstrom induzierten elektrischen Ströme, beschleunigt die Kinetik des Kanals und führt zu einer hyperpolarisierenden Verschiebung des Schwellenwertes der spannungsabhängigen Inaktivierung und beschleunigt diese dadurch. Des Weiteren beeinflusst er die Dichte der Calciumkanäle an der Zellmembran, da er den Transport des Calciumkanals an die Zelloberfläche fördert [CANTI et al. 2005].

Außerdem scheint die $\alpha_{2} \delta$-Untereinheit eine tragende Rolle bei der Entstehung neuropathischer Schmerzen sowie der Allodynie zu spielen [DAVIES et al. 2007]. Gabapentin und Pregabalin, zwei Antiepileptika, binden selektiv an die $\alpha_{2} \delta$-Untereinheit und können so für die Behandlung neuropathischer Schmerzen eingesetzt werden [PEREZ-REYES 2003]. Die Bindung des Gabapentins an die $\alpha_{2} \delta$-Untereinheit führt z.B. höchstwahrscheinlich zU einer Herunterregulation dieser Untereinheit und bewirkt somit eine herabgesetzte Dichte der Calciumkanäle an der Zellmembran, bedingt durch einen verminderten Transport in Richtung Membran [HENDRICH et al. 2008].

Die transmembranöse $\gamma$-Untereinheit kommt nicht in allen Calciumkanaltypen vor. Sie findet sich vor allem in Kanälen der Skelettmuskulatur sowie des ZNS. Ihre Hauptfunktion besteht dort in der Interaktion mit AMPA-Glutamatrezeptoren [MOSS et al. 2002].

Die charakterisierenden Eigenschaften der unterschiedlichen Calciumkanäle werden durch die unterschiedlichen Isoformen A bis $S$ der $\alpha_{1}$-Untereinheit determiniert, welche durch 10 Gene codiert werden. Nach einer im Jahre 2000 entwickelten, an die Einteilung der Kaliumkanäle angelehnten Nomenklatur, werden die $\alpha_{1}$-Isoformen zU Calciumkanal-Unterfamilien $\mathrm{CaV}_{1.1}$ bis $\mathrm{CaV}_{3.3} \quad \mathrm{ZU}$ sammengefasst [CATTERRAL et al. 2005]. Die Abbildung 1.4 verdeutlicht diese Einteilung sowie die Übereinstimmung ihrer Sequenzen.

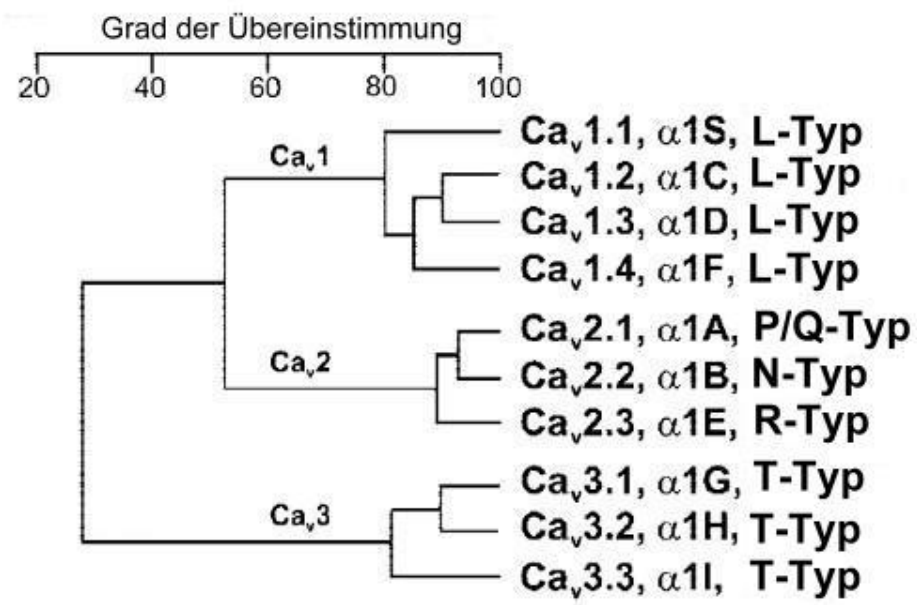

Abb. 1.4 Einteilung der Calciumkanäle [aus CATTERRAL et al. 2005, S. 413] 
L-Typ-Calciumkanäle (L für "long-lasting"), welche entweder aus der $\alpha_{1}$ Untereinheit $\mathrm{CaV}_{1.1}, \mathrm{CaV}_{1.2}, \mathrm{CaV}_{1.3}$ oder $\mathrm{CaV}_{1.4}$ zusammengesetz† sind, benötigen zur Aktivierung typischerweise eine stärkere Depolarisation, bleiben dann jedoch lange aktiviert und werden von Dihydropyridinen wie Nifedipin, Phenylalkylaminen wie Verapamil sowie von Benzothiazepinen wie Diltiazem blockiert [HESS et al. 1984]. Diese Blockade findet an drei verschiedenen, aber allosterisch verbundenen Rezeptoren statt [GLOSSMANN und STRIESSNIG 1990].

Dihydropyridine haben die Eigenschaft, den Kanal entweder zu aktivieren oder auch zu deaktivieren. Dies erreichen sie durch eine Konformationsänderung des Kanals zum geschlossenen bzw. geöffneten Zustand. Der Dihydropyridin-Rezeptor liegt zum einen gemeinsam mit dem Phenylalkylamin-Rezeptor im Segment S6 der Domänen III und IV, zum anderen im Segment S5 der Domäne III.

Phenylalkylamine sind intrazelluläre Blocker der Pore des Kanals. Sie blockieren diese von ihrer zytoplasmatischen Seite aus [HOCKERMANN et al. 1997]. Der korrespondierende Rezeptor findet sich im Segment S6 der Domänen III und IV.

Diltiazem und verwandte Benzothiazepine binden an einen dritten Rezeptor und führen zu einer Inaktivierung des Kanals [CATTERRAL et al. 2005].

L-Typ-Calciumkanäle finden sich vor allem im Skelettmuskel $\left(\mathrm{CaV}_{1.1}\right)$, in der glatten Muskulatur und der Herzmuskulatur $\left(\mathrm{CaV}_{1.2}, \mathrm{CaV}_{1.3}\right)$, in sensorischen Zellen v.a. der Retina $\left(\mathrm{CaV}_{1.3}, \mathrm{CaV}_{1.4}\right)$, in endokrinen Zellen $\left(\mathrm{CaV}_{1.2}, \mathrm{CaV}_{1.3}\right)$ und in geringerer Anzahl auch im lymphatischen Gewebe $\left(\mathrm{CaV}_{1.4}\right)$.

Andere L-Typ-Calciumkanäle, die bereits durch eine schwächere Depolarisation aktiviert werden, treten in Neuronen $\left(\mathrm{CaV}_{1.2}\right)$ und kardiogenen Schrittmacherzellen $\left(\mathrm{CaV}_{1.3}\right)$ auf [FLUCHER und FRANZINI-ARMSTRONG 1996; CATTERALL 2001; TAKIMOTO et al. 1997; BECH-HANSEN et al. 1998; NAYLOR et al. 2000]. Hauptaufgabe der L-Typ-Calciumkanäle ist folglich vor allem die Steverung der Muskelkontraktion und die Aufrechterhaltung des Sinusrhythmus im Herzmuskel. Sie stellen die Calcium-Homöostase im Skelettmuskel sicher, bewirken die Neurotransmittersekretion an den Synapsen der Retina sowie die Sekretion in neuroendokrinen Zellen und sorgen außerdem für eine verlängerte Depolarisation der Kardiomyozyten [RIOS et al. 1992; STRIESSNIG 1999; MANGONI et al. 2003; SINNEGGER-BRAUNS et al. 2004].

P/Q-Typ-Calciumkanäle ( $P$ für Purkinje) setzten sich aus der $\alpha_{1}$-Untereinheit $\mathrm{CaV}_{2.1}$ zusammen. Auch sie benötigen für ihre Aktivierung eine starke Depolarisation. Ihr Vorkommen beschränkt sich auf die Dendriten und präsynaptischen Endigungen von Purkinje-Zellen und Neuronen sowie auf endokrine Zellen (v.a. Pankreas). Sie werden nicht durch dieselben Toxine bzw. Pharmaka wie die L-Typ-Calciumkanäle gehemmt, jedoch durch $\omega$-Agatoxin, einem Gift der Trichternetzspinne Agelenopsis aperta [MILJANICH und RAMACHANDRAN 1995].

P/Q-Typ-Calciumkanäle spielen eine tragende Rolle im synaptischen Vesikelzyklus, genauer gesagt der Neurotransmitterfreisetzung, sowie der Steverung der Sekretion in pankreatischen $\beta$-Zellen [CATTERALL 2005]. 
Eine ähnliche Funktion üben die N-Typ-Calciumkanäle aus, welche aus der $\alpha_{1}$-Untereinheit $\mathrm{CaV}_{2.2}$ bestehen. Sie haben allerdings eine geringere Bedeutung für die Neurotransmitterfreisetzung als die P/Q-Typ-Calciumkanäle [WU et al. 1999].

$\mathrm{N}$-Typ-Calciumkanäle sind zum größten Teil an den präsynaptischen Endigungen von Neuronen im ZNS und PNS bzw. dem vegetativen Nervensystem zU finden [WESTENBROEK et al. 1992; DUNLAP et al. 1995].

Sie können selektiv durch $\omega$-Conotoxin, einem Gift der Kegelschnecke Conus geographus, blockiert werden [HILLYARD et al. 1992].

Die N-Typ-Calciumkanäle scheinen v.a. bei sich entwickelnden Geweben und Organismen von besonderer Bedeutung zU sein, während P/Q-TypCalciumkanäle wohl eine wichtigere Rolle bei reifen Geweben und Organismen spielen [REID et al. 2003].

Die Verteilung der R-Typ-Calciumkanäle ( $R$ für „residual"), welche die $\alpha_{1}$ Untereinheit $\mathrm{CaV}_{2.3}$ beinhalten, ist vor allem auf das Soma und die Dendriten von Neuronen beschränkt. Ihre Funktion ist neben der Neurotransmitterfreisetzung auch die posttetanische Potenzierung (PTP) sowie die LangzeitPotenzierung (LTP) der Synapsen [DIETRICH et al. 2003].

Die Blockade dieser Kanäle kann durch das synthetische Protein SNX-482, ein Derivat des Giftes der Tarantel, erreicht werden [NEWCOMBE et al. 1998].

T-Typ-Calciumkanäle setzten sich entweder aus der $\alpha_{1}$-Untereinheit $\mathrm{CaV}_{3.1}$, $\mathrm{CaV}_{3.2}$ oder $\mathrm{CaV}_{3.3}$ zusammen [RANG 2003]. Sie werden durch eine schwache Depolarisation aktiviert. Eine selektive Blockierung dieser Kanäle ist nicht möglich [HEADY et al. 2001].

Diese Kanäle werden zum einen im ZNS (vor allem im Soma bzw. den Dendriten des Bulbus olfactorius, der Amygdala, des Kortex, des Hippocampus, des Thalamus, des Hypothalamus, des Cerebellum sowie des Stammhirns), zum anderen in der Niere, Nebenniere, Leber $\left(\mathrm{CaV}_{3.2}\right)$ und dem Sinusknoten des Herzens $\left(\mathrm{CaV}_{3.1}, \mathrm{CaV}_{3.2}\right)$ gefunden [CRIBBS et al. 1998; BOHN et al. 2000; TALLEY et al. 1999].

Ihre Hauptaufgabe ist die Aufrechterhaltung des Sinusrhythmus im Herzmuskel $\left(\mathrm{CaV}_{3.1}, \mathrm{CaV}_{3.2}\right)$ sowie der thalamischen Oszillationen $\left(\mathrm{CaV}_{3.1}, \mathrm{CaV}_{3.3}\right)$, die eine Voraussetzung für die synchronisierte Aktivität des thalamo-kortikalen Systems im Schlaf darstellt, sowie die Aldosteron- und Cortisolsekretion $\left(\mathrm{CaV}_{3.2}\right)$ [PEREZ-REYES 2003; ROSSIER et al. 1998].

Calciumkanäle stehen ferner in einer engen Beziehung zu dem Mint-Protein Mintl. Die Kanäle sind mit ihrem C-terminalen Ende an einen Komplex aus Mintl und CASK (CAlcium-dependent Serine protein Kinase) gebunden.

Dieser Dreierkomplex ist wiederum mit Neurexin assoziiert, einem präsynatischen Protein, welches durch seine Interaktion mit dem postsynatischen Protein Neuroligin eine direkte Verbindung zwischen zwei komunizierenden Neuronen herstellt [SCHEIFFELE et al. 2000; Ll et al. 2006]. Das Neurexin und das Neuroligin sind demnach entscheidend an der Transmitterfreisetzung beteiligt 
und helfen zudem, die Calciumkanäle in der Zellmembran zu verankern [MISSLER et al. 2003; MAXIMOV und BEZPROZVANNY 2002].

\subsection{Synaptische Transmission}

Unter synaptischer Transmission versteht man die Signalübertragung zwischen zwei erregbaren Zellen.

Die Synapse, der Ort der Signalübertragung, lässt sich in drei Kompartimente einteilen: die präsynaptische Endung, die postsynaptische Zelle sowie den zwischen beiden liegenden synaptischen Spalt.

Ein Aktionspotential, welches seinen Ursprung im Soma präsynatischer Neuronen hat, erreicht über das Axon die präsynaptische Endung, führt dort zu einer Öffnung spannungsabhängiger Calciumkanäle und zu einem dadurch bedingten Einstrom von $\mathrm{Ca}^{2+}$-Ionen. Pro Aktionspotential öffnen sich ca. $70 \%$ der spannungsabhängigen präsynaptischen Calciumkanäle [BORST und SAKMANN 1999; BISCHOFBERGER et al. 2002]. Dieser loneneinstrom, die hierdurch bedingte Erhöhung der intazellulären Calciumkonzentration und die Bindung von Calciumionen an "Calciumsensoren", wie z.B. Synaptotagmin, führen zunächst in den aktiven Zonen zu einer Fusion der Vesikelmembran mit der Zellmembran. Auf diese Weise können die Vesikel ihren Inhalt, die Neurotransmitter, in den synaptischen Spalt freisetzten. Diese binden daraufhin an ligandengesteverte lonenkanäle der postsynaptischen Membran der Zielzelle.

Diese Bindung führt in der Zielzelle zu einer Öffnung der Ionenkanäle und dadurch zu einer Generierung von exzitatorischen bzw. inhibitorischen postsynaptischen Potentialen (EPSPs bzw. IPSPs). Somit kommt es zu einer Konvertierung des chemischen Signals in ein elektrisches. Die Gesamtdaver dieser Transmission beträgt nur wenige Millisekunden [zur Übersicht siehe WANG et al. 2009].

An der postsynaptische Zelle entsteht entweder eine Hyper- oder eine Depolarisation. Welche Reaktion eintritt, hängt dabei maßgeblich vom Transmitter und dem Umkehrpotential der beeinflussten Leitfähigkeit ab.

Man unterscheidet zwischen inhibitorischen und exzitatorischen Transmittern. Einer der wichtigsten exzitatorischen Neurotransmitter ist das Glutamat. Dieses bewirkt durch die Bindung an Glutamat-Rezeptoren den Einstrom von Natrium- und Kalium-Ionen und führt damit zu einer Depolarisation.

$\gamma$-Aminobuttersäure (GABA) und Glycin sind wichtige inhibitorische Neurotransmitter. An ihre korrespondierenden Rezeptoren gebunden, bewirken sie einen Chlorid-Einstrom, wodurch es zu einer Hyperpolarisation kommt.

Zwar läuft die Signalübertragung an elektrischen Synapsen schneller ab als an chemischen, jedoch bieten die chemischen Synapsen den Vorteil, dass sie in ihrer Sensitivität moduliert werden können. Diese Modulierbarkeit bezeichnet 
man als Plastizität. Diese Plastizität ermöglicht einer einzelnen kleinen Synapse, das Potential einer viel größeren postsynaptischen Zelle zu modulieren.

\subsubsection{Der synaptische Vesikelzyklus}

In den Synapsen durchlaufen die Vesikel einen kompletten Zyklus, bei dem die Freisetzung der Transmitter nur einen von mehreren Schritten darstellt.

Im präsynaptischen Terminal gelangen die Vesikel zu den aktiven Zonen an der Plasmamembran. Diese Zonen sind elektronenmikroskopisch deutlich an der hohen Vesikeldichte erkennbar.

Die aktiven Zonen liegen gegenüber der postsynaptischen Dichte (PSD = postsynaptic density) und stellen jene Region dar, in der die synaptischen Vesikel mit der Membran fusionieren und Neurotransmitter in den synaptischen Spalt ausschütten. Mit der aktiven Zone assoziiert ist die proteinreiche Zytomatrix der aktiven Zone (CAZ = cytoskeletal matrix of active zone).

Die CAZ besteht aus mehreren präsynaptischen Proteinen, die ein Gerüst für alle synaptischen Vesikel bilden und damit einen wichtigen Teil des Freisetzungsapparates darstellen [Übersicht: GARNER et al. 2000; GUNDELFINGER et al. 2003]. Des Weiteren liegen im Bereich der aktiven Zone spannungsabhängige Calciumkanäle.

In der postsynaptischen Dichte finden sich vor allem Rezeptoren, welche die postsynaptische Signalweiterleitung ermöglichen [zur Übersicht siehe SHENG 2001; SHENG und KIM 2002].

Die Kontaktaufnahme zwischen Vesikel und aktiver Zone wird als Docking bezeichnet. Im darauf folgenden Schritt, dem Priming, werden die Vesikel in einen fusionskompetenten Zustand versetzt.

Kommt es zu einem $\mathrm{Ca}^{2+}$-Einstrom, fusionieren im nächsten Schritt die Vesikel mit der präsynaptischen Membran und schütten die Neurotransmitter in den synaptischen Spalt aus (Abb.1.3). Die Transmitterfreisetzung läuft innerhalb von 0,5 bis $1 \mathrm{~ms}$ ab [BORST und SAKMANN 1996].

Nach dieser schnellen Exozytose folgt die Wiederverwertung der Vesikel. Es gibt zwei vorherrschende Theorien, wie dieses Recycling in der Synapse durchgeführt wird.

Nach der ersten Hypothese erfolgt während der Exozytose zunächst die Fusion der Vesikel mit der Zellmembran und die Freisetzung der gesamten Transmittermenge. Daraufhin werden die Vesikel durch eine Clathrin-vermittelt Endozytose wieder aufgenommen und verschmelzen mit frühen Endosomen innerhalb des präsynaptischen Terminals.

Danach schüren sich neve Vesikel von den Endosomen ab (Budding) und werden mit Wasserstoffionen beladen. Anschließend werden sie entlang des $\mathrm{pH}-G$ radienten erneut mit den jeweiligen Neurotransmittern gefüllt und stehen 


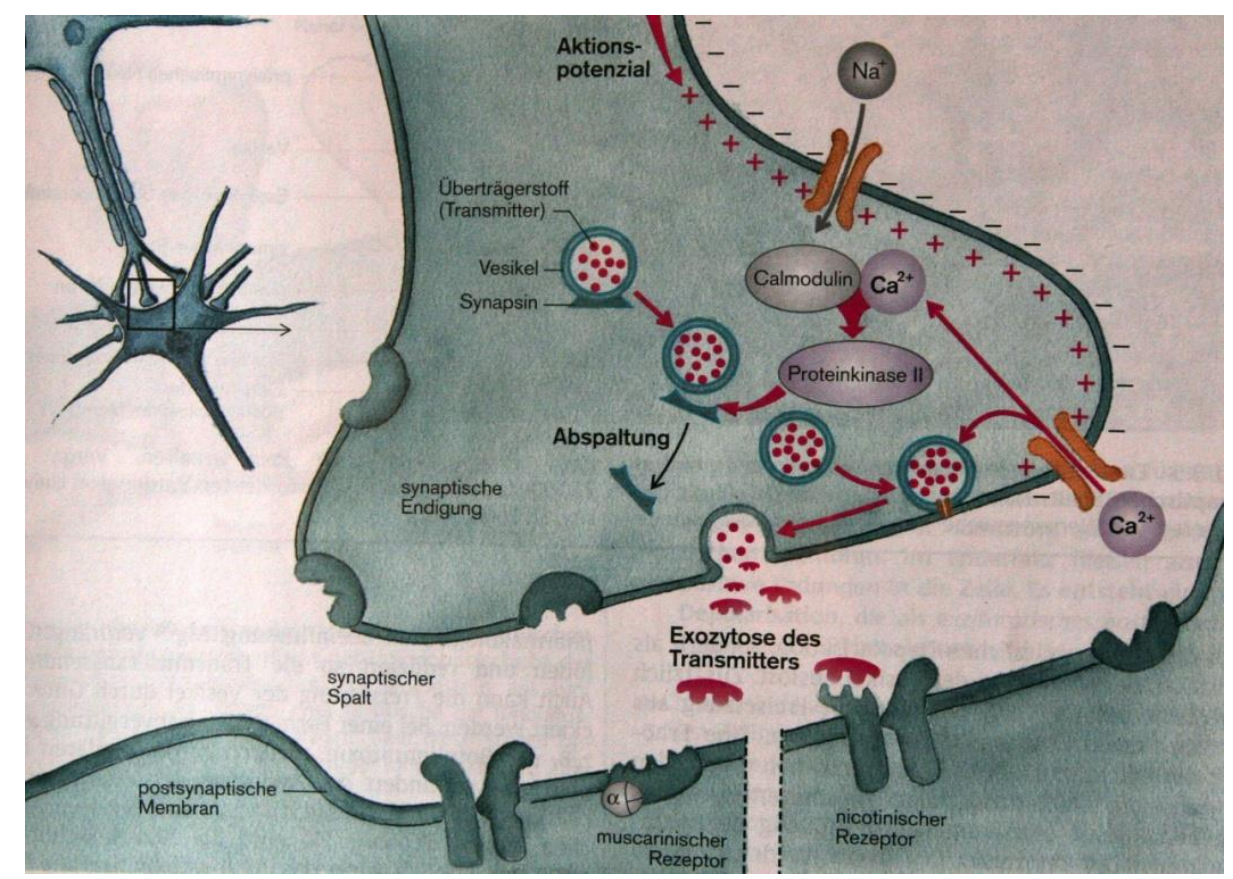

Abb. 1.5 Mechanismus der Transmitterfreisetzung an der präsynaptischen Endigung [aus KLINKE und SILBERNAGEL 2001, S. 65]

Die zweite Hypothese ist die sogenannte "Kiss-and-run"-Hypothese, nach welcher nicht der gesamte Inhalt der Vesikel in den synaptischen Spalt entleert wird.

Vielmehr wird nur ein Teil des Inhaltes ausgeschüttet und die Vesikel treten unter Beibehaltung der Membran wieder in den Zyklus ein, wobei das frühe Endosom umgangen wird. Diese etwas komplexere Form der Transmitterfreisetzung wird als die effizientere und ökonomischere Variante angesehen, vor allem für den Fall, dass ein Mangel an transmitterbeladenen Vesikeln besteht [HEUSER und REESE 1973, MELDOLESI und CECCARELLI 1981; FESCE et al. 1994; WIGHTMAN und HAYNES 2004; HE et al. 2006; XUE L und MEl 2011].

Die fusionskompetenten Vesikel bilden den schnellen Freisetzungsvorrat (readily releasable pool $=$ RRP). Sie stehen dort sofort zur Exozytose bereit und können innerhalb von Millisekunden nach Stimulation freigesetzł werden.

Neben diesem RRP, der meist nur wenige fusionskompetente Vesikel enthält [MURTHY und STEVENS 1999], existiert ein weitaus größerer Reserve-Pool an nicht sofort fusionskompetenten Vesikeln [SCHIKORSKI und STEVENS 1997; RIZZOLI und BETZ 2005].

Die meisten Synapsen besitzen in der Regel nur eine aktive Zone. Jedoch geht man davon aus, dass sich in großen Synapsen, z.B. im präterminalen Ende der Held'schen Calyx, ca. 500 aktive Zonen befinden, an denen jeweils 6 Vesikel pro ankommendem Aktionspotential fusionieren können, sodass pro Aktionspotential maximal ca. 3.000 Vesikel ihre Neurotransmitter ausschütten könn- 
ten, bis der Vesikelpool erschöpft wäre [zur Übersicht siehe NEHER 2006].

\subsubsection{Am synaptischen Vesikelzyklus beteiligte Proteine}

Bevor es im Rahmen der calciuminduzierten Exozytose zu einer Neurotransmitterfreisetzung kommen kann, sind einige wichtige Schritte nötig, welche die synaptischen Vesikel so weit vorbereiten, dass die Exozytose mit Eintreffen des Aktionspotentials und anschließendem $\mathrm{Ca}^{2+}$-Einstrom rasch ablaufen kann. Die Proteine, welche diesen Vorgang unterstützen, sind entweder mit der Vesikelmembran assoziiert oder finden sich in den aktiven Zonen der prösynaptischen Endung.

Im Ruhezustand sind die Vesikel über das Synapsin I an das Aktinskelett der präsynaptischen Endigung gebunden und dadurch immobilisiert. Kommt es zU einem Calciumeinstrom, erfolgt eine calcium-calmodulinabhängige Phosphorylierung des Synapsins I durch die Proteinkinase II. Dies führt dazu, dass sich die Vesikel vom Synapsin I lösen und dadurch nicht mehr am Zytoskelett fixiert sind [SCHULMAN und GREENGARD 1978; KRUEGER et al. 1977] (Abb. 1.5).

Die Entfernung des Synapsins I führt höchstwahrscheinlich auch dazu, dass die Vesikel des Reserve-Pools in den RRP überführt werden. Auf diese Weise wirkt ein nicht-phosphoryliertes Synapsin inhibitorisch auf die Neurotransmission [AKBERGENOVA und BYKHOVSKAIA 2010].

Das Priming der Vesikel wird während des Dockings initiiert, indem die Moleküle RIM1 (Rab3 Interacting Molecule) und Rab3 miteinander in Kontakt treten. RIMI interagiert sowohl mit der aktiven Zone als auch mit den synaptischen Vesikeln und nimmt damit eine besondere Stellung im Vesikelzyklus ein.

Mithilfe von Munc-13 wird während des Primings aus SNARE-Proteinen (soluble $\mathrm{N}$-ethylmaleimide sensitive factor attachment receptor) der SNARE-Komplex gebildet.

Die SNARE-Proteine setzen sich u.a. aus Synaptobrevin, Syntaxin und SNAP-25 zusammen (siehe Abb. 1.6, S. 11 und 1.7, S. 12) [zur Übersicht siehe JAHN und SUDHOF 1999, CHEN YA und SCHELLER 2001]. Während Syntaxin an der Plasmamembran verankert ist, findet sich Synaptobrevin in der Vesikelmembran. Zusammen mit SNAP-25, welches eine Doppelhelixstruktur besitzt, bilden diese Proteine eine Vierfachhelixstruktur, welche die beiden Membranen miteinander verbindet.

Synaptotagmin, ein weiterer Bestandteil des SNARE-Komplexes, spielt eine entscheidende Rolle als Calciumsensor des Freisetzungsapparats, da es in der Lage ist, Calcium und SNARE-Proteine zU binden (Abb. 1.7) [GEPPERT et al. 1994; FERNANDEZ-CHACON et al. 2001; zur Übersicht siehe CHAPMAN 2002]. Des Weiteren beeinflusst Synaptotagmin den RRP, indem es das Zusammenspiel zwischen Calciumeinstrom und Transmitterfreisetzung zu stevern scheint 
[YOUNG und NEHER 2009]. Im SNARE-Komplex sorgt es für die abschließende Verbindung zwischen Syntaxin und Synaptobrevin, wenn eine weitere Annäherung dieser beiden Proteine aufgrund von Zugkräften durch die Verankerung in ihrer jeweiligen Membran nicht mehr möglich ist [zur Übersicht siehe NEHER 2010].

Munc-13-Proteine ermöglichen die Umformung des SNARE-Komplexes, indem sie Munc-18 aus der Bindung zu Syntaxin verdrängen. Dies träg† grundlegend zur Bereitstellung fusionskompetenter Vesikel bei [BETZ et al. 1998; ARAVAMUDAN et al. 1999; AUGUSTIN et al. 1999].

Am Munc-18 binden wiederum Mint-Proteine (Munc-18 interacting protein) und es übt einen hemmenden Einfluss auf Syntaxin aus [zur Übersicht siehe GARNER et al. 2000; ZHANG W et al. 2000; HO et al. 2003]. MINT-Proteine sollen auch eine entscheidende Rolle in Bezug auf die Interaktion zwischen Calciumkanälen, synaptischen Vesikeln und postsynaptischen Rezeptoren einnehmen (s.u.).

Zusammenfassend lässt sich festhalten, dass es sich beim Freisetzungsapparat der Vesikel um ein relativ vielschichtiges System handelt. Unterschiedliche Sekretionsleistungen in verschiedenen Geweben sind vor allem in unterschiedlichen Isoformen der Proteine (z.B. Synaptotagmin 1 vs. Synaptotagmin 2) begründet [XU et al. 2007; XUE MS et al. 2008; SORENSEN et al. 2003; ROSENMUND et al. 2002].

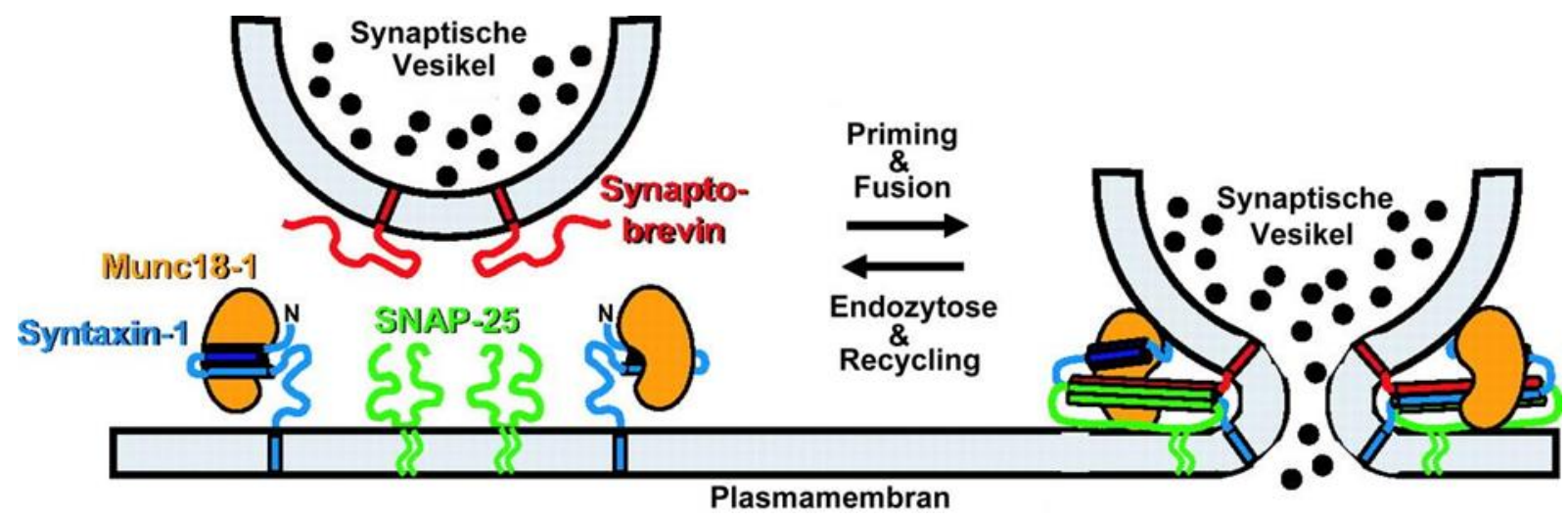

Abb. 1.6 Proteine des synaptischen Vesikelzyklus I [adaptiert nach DULUBOVA et al. 2007, S. 2700] 


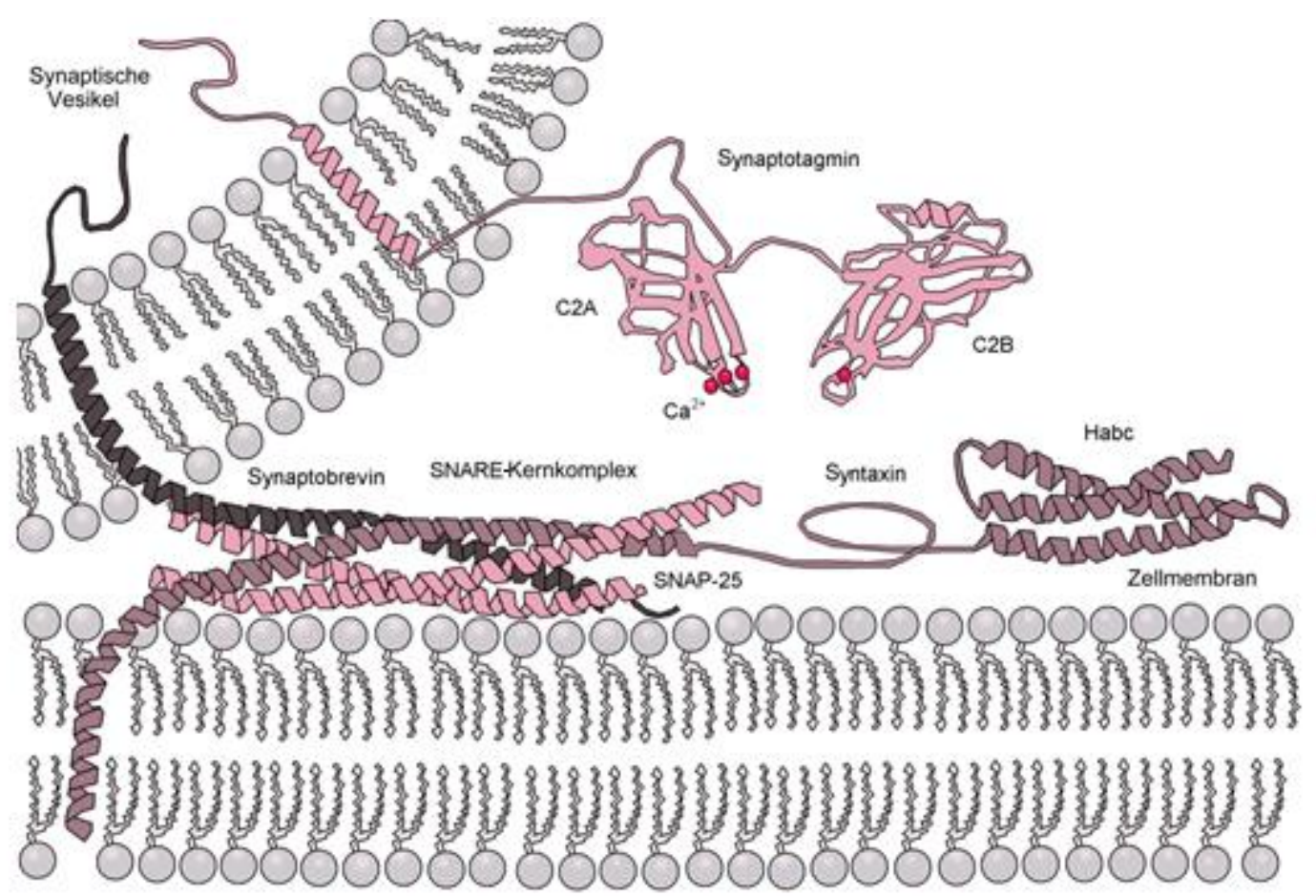

Abb. 1.7 Proteine des synaptischen Vesikelzyklus II [adaptiert nach GEORGIEV und GLAZEBROOK 2007, S. 425]

\subsection{Die Rolle des Calciums bei der Regulation der Trans- mitterfreisetzung}

Neben der Funktion des intrazellulären Calciums bei der Transmitterfreisetzung, für die eine relativ hohe Calciumkonzentration in den sogenannten "microdomains" benötigt wird, spielt Calcium eine entscheidende Rolle bei der Regulation der synaptischen Plastizität, indem es Einfluss auf die Zusammensetzung des RRP nimmt und die Rekrutierung fusionskompetenter Vesikel unterstütz†. Als „microdomain" bezeichnet man eine Einheit aus mehreren Calciumkanälen mit den von ihnen kontrollierten Vesikeln.

Eine beschleunigte Freisetzung wird durch ein vermehrtes Docking der fusionskompetenten Vesikel in der unmittelbaren Nähe der Calciumkanäle erreicht. Hierfür wird ein langsamer Anstieg der Calciumkonzentration benötigt, da hier die Sensoren für Calcium sensitiver sind als jene, welche die Transmitterfreisetzung initiieren [STEVENS und WESSELING 1998; WANG und KACZMAREK 1998].

Ein verstärkter Calciumeinstrom führt bei Eintreffen eines Aktionspotentials zU einem stärkeren Anstieg der Calciumkonzentration in den "microdomains" und damit auch zu einer Erhöhung der Freisetzungswahrscheinlichkeit der Transmitter.

Kommt es nun durch eine schnelle Abfolge von Aktionspotentialen zu einem weiteren Anstieg des Calciumeinstroms, führt dieser zu einer Erhöhung des Calciums in der gesamten präsynaptischen Endigung. 
Diese Erhöhung des sog. globalen Calciums führt wahrscheinlich zu einer Beschleunigung der Wiederbeladung der sogenannten „schnell freisetzenden Vesikel" (s.u.). Da sich jedoch gleichzeitig die Freisetzungswahrscheinlichkeit in einem stärkeren Maße erhöht, führen zU hohe Calciumspiegel zU einer Erschöpfung fusionskompetenter Vesikel [zur Übersicht siehe NEHER und SAKABA 2008].

\section{4 Örtliche Anordnung der P/Q-Typ-Calciumkanäle und weitere Ursachen für die Heterogenität der Fusionsge- schwindigkeit}

Die genaue örtliche Anordnung der P/Q-Typ-Calciumkanäle in Bezug zu den synaptischen Vesikeln ist nicht bekannt. Es gibt jedoch einige Hypothesen, wie sie angelegt sein könnte.

Es wird angenommen, dass die Vesikel des RRP in zwei verschiedene, etwa gleich große Populationen eingeteilt werden können. Eine dieser Populationen, die "schnell freisetzenden Vesikel“, fusioniert innerhalb von 2-3 ms mit der Zellmembran der aktiven Zone der präterminalen Endigung, die andere Population, die "langsam freisetzenden Vesikel", benötigt für diesen Schritt etwa zehnmal mehr Zeit [WU und BORST 1999; SAKABA und NEHER 2001b].

Im Gegensatz dazu werden die "langsam freisetzenden Vesikel" jedoch deutlich schneller (innerhalb von ca. 200 ms) wieder mit Neurotransmittern beladen als die "schnell freisetzenden Vesikel", welche für diesen Vorgang einige Sekunden benötigen [WU und BORST 1999; SAKABA und NEHER 2001b].

Bei der Transmitterfreisetzung nehmen die „schnell freisetzenden Vesikel" die Hauptfunktion wahr, da die "langsam freisetzenden Vesikel" vor allem asynchron während hochfrequenter, repetitiver Aktionspotential-Salven APunabhängig ausgeschüttet werden [SAKABA 2006].

Eine Erhöhung des Gesamtcalciums führt bei den „schnell freisetzenden Vesikel" zu einer Beschleunigung der Wiederbeladung, übt jedoch diesen Effekt nicht auf die "langsam freisetzenden Vesikel" aus. Calmodulin übernimmt in Gegenwart von CAMP, welches das Recruitment der "schnell freisetzenden Vesikel" erhöht [SAKABA und NEHER 2001b], eine regulatorische Funktion bei der Transmitterfreisetzung [SAKABA und NEHER 2003]. Demnach üben Calcium, Calmodulin und CAMP einen direkten Einfluss auf das Priming der Vesikel aus [SAKABA und NEHER 2001c].

Als Grund für die unterschiedliche Transmitterfreisetzungsgeschwindigkeit werden zwei Ursachen diskutiert.

Zum einen ist es denkbar, dass die sog. "release machinery", die alle Prozesse einschließt, welche die Transmitterfreisetung stevern (s.o.), unterschiedlich 
sensitiv auf Calcium reagiert [WU und BORST 1999; WÖLFEL et al. 2007].

Die zweite Annahme besteht darin, dass sich die Vesikelpopulationen hinsichtlich ihrer örtlichen Beziehung zu den Calciumkanälen unterscheiden. Dies würde bedeuten, dass sich die Populationen nicht in ihren intrinisischen Eigenschaften (Sensitivität dem Calcium gegenüber) unterscheiden, sondern dass sich z.B. die „langsam freisetzenden Vesikel" in einer größeren Distanz zu den Calciumkanälen befinden [SAKABA und NEHER 2001a; WADEL et al. 2007].

Dies würde bedeuten, dass sich in der Umgebung jener Vesikel, die weiter entfernt von den Kanälen positioniert sind, die Calciumkonzentration aufgrund der längeren Diffusionsstrecke deutlich langsamer erhöhen würde als in der Umgebung der näher positionierten Vesikel, was die Freisetzungswahrscheinlichkeit deutlich herabsetzen würde (siehe S.15 Abb. 1.8).

Frühere, vor allem elektronenmikroskopische Untersuchungen an der neuromuskulären Endplatte des Frosches legten die Vermutung nahe, dass die Anordnung der Calciumkanäle linear über die gesamte präsynaptische Membran erfolgt (siehe S. 16 Abb. 1.9) [HEUSER et al. 1974].

Aufgrund neverer Untersuchungen an weiteren, vor allem zentralen Synapsen wird nun angenommen, dass Calciumkanäle höchstwahrscheinlich überwiegend in "Clustern" angeordnet sind, sie also an wenigen Stellen innerhalb der aktiven Zonen konzentriert sind, wo ihre Dichte ca. zehnmal höher ist als in der übrigen Zellmembran. Von hier aus kontrollieren sie die Vesikelfreisetzung [ROBERTS et al. 1990; LLINAS et al. 1992; MEINRENKEN et al. 2002; KHANNA et al. 2007; BUCURENCIU et al. 2008]. Dabei wird jeweils ein Vesikel des RRP durch mehrere (mindestens 10) Calciumkanäle kontrolliert (Abb. 1.8) [BORST und SAKMANN 1999; WU et al. 1999; MEINRENKEN et al. 2002].

Als Entfernung zwischen den Vesikeln des RRP und den jeweiligen Calciumkanälen wird eine Distanz von 30 bis $300 \mathrm{~nm}$ angenommen, mit einem Durchschnitt von $118 \mathrm{~nm}$ vom Zentrum eines "Clusters" [MEINRENKEN et al. 2002]. Dies bedeutet, dass es höchstwahrscheinlich keine direkten Interaktionen zwischen den Calciumkanälen und den Vesikeln gibt. Als theoretischer Mindestabstand zwischen den Calciumkanälen und den jeweiligen Vesikeln wird eine Strecke von $20 \mathrm{~nm}$ definiert, da der SNARE-Komplex von sich aus schon eine zirkuläre Ausdehnung von ca. $20 \mathrm{~nm}$ besitz† [CHO et al. 2005; WANG et al. 2009].

Die Distanz zwischen zwei Clustern von Calciumkanälen wird mit mindestens $200 \mathrm{~nm}$ und der Durchmesser eines solchen Clusters mit ca. $50 \mathrm{~nm}$ angegeben. Da eine aktive Zone als eine runde Struktur mit einen Radius von ungefähr $125 \mathrm{~nm}$ definiert wird, die unterschiedlichen aktiven Zonen jedoch 200$800 \mathrm{~nm}$ entfernt voneinander liegen, würde dies bedeuten, dass es pro aktiver Zone in den meisten Fällen nur ein Cluster von Calciumkanälen geben sollte und dass dieses nur die Vesikel der nächstgelegenen aktiven Zone kontrolliert [MEINRENKEN et al. 2002].

Es wird weiter angenommen, dass die Zuordnung der Vesikel zu der jeweiligen 
Population durch das sog. „positional priming“ erfolgt, das auf das „,molecular priming" folgt, welches die Vesikel auf molekularer Ebene fusionskompetent macht (siehe S. 16 Abb. 1.10) [NEHER und SAKABA 2008].

Das "molecular priming" wird außer durch Calcium auch durch das Muncl3 des Vesikelfreisetzungsapparats und durch einige Proteine in der aktiven Zone, z.B. den RIM-Proteinen, unterstütz† [ASHERY et al. 2000; DULUBOVA et al. 2005; ANDREWS-ZWILLING 2006].

Eine weitere Erklärung für die unterschiedlichen Fusionsgeschwindigkeiten ist ebenfalls in Abb. 1.10 dargestellt. Nach der Transmitterfreisetzung muss sich eine Vesikel wieder von der aktiven Zone lösen, bevor an dieselbe Stelle eine weitere Vesikel andocken kann. Geschieht diese Ablösung zu langsam, kann dies zu einer verzögerten Transmitterfreisetzung der nachfolgenden Vesikel führen (Schritt 5a in Abb. 1.10) [DITTMAN und REGEHR 1998; WIENISCH und KLINGAUF 2006].

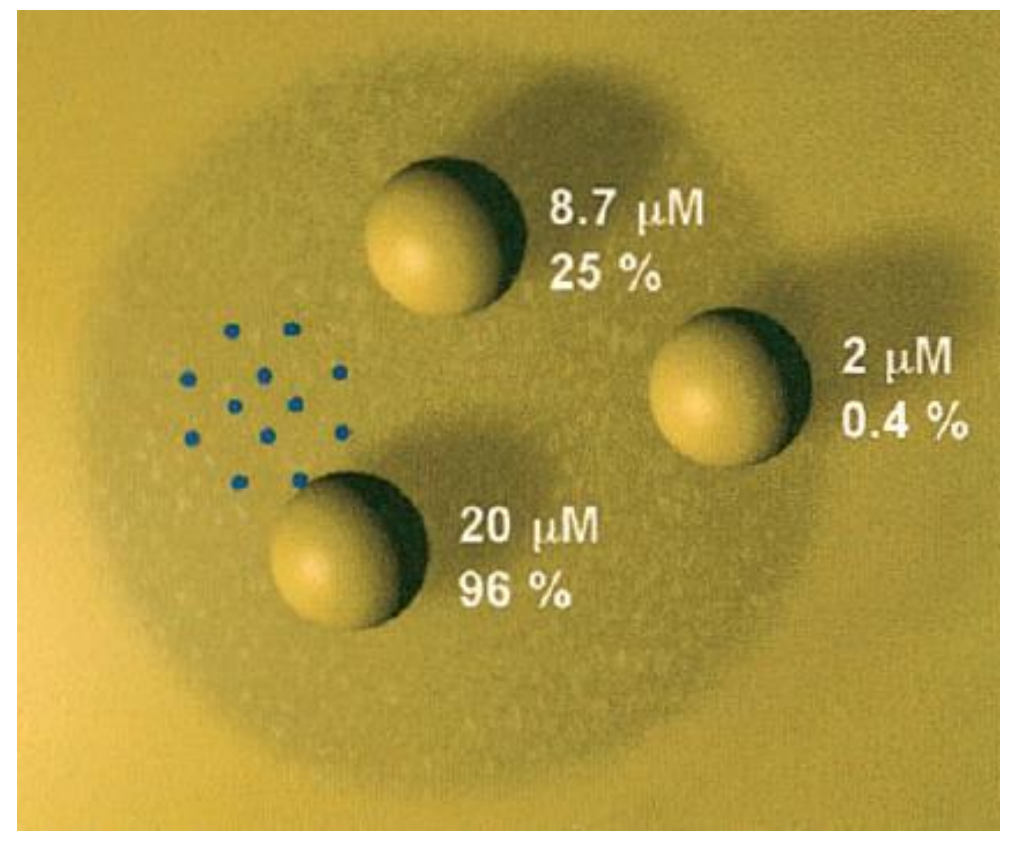

Abb. 1.8 Angenommene topographische Beziehung zwischen synaptischen Vesikeln und Calciumkanälen innerhalb der aktiven Zone. Es sind exemplarisch drei Vesikel abgebildet. Calciumkanäle sind als blaue Punkte, die aktive Zone als Kreis dargestellt. Angegeben ist die Calciumkonzentration in der Umgebung des jeweiligen Vesikels und dessen Freisetzungswahrscheinlichkeit [nach MEINRENKEN 2002, S.1660] 


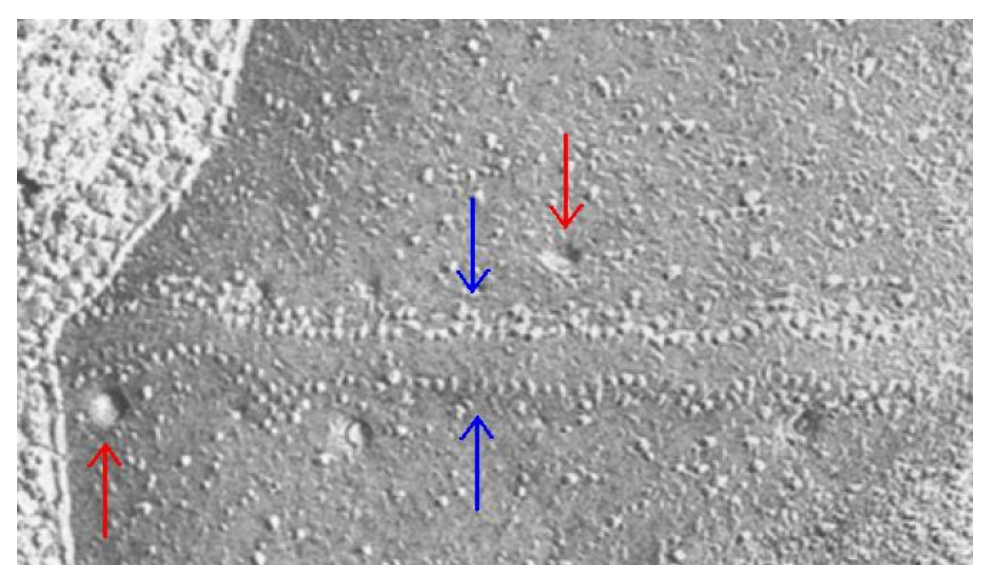

Abb. 1.9 Präsynaptische Endigung (90.000-fache Vergrößerung): mutmaßliche Darstellung der synaptischen Vesikel (rote Pfeile) sowie der Calciumkanäle (blave Pfeile) [HEUSER et al. 1974, S. 117]

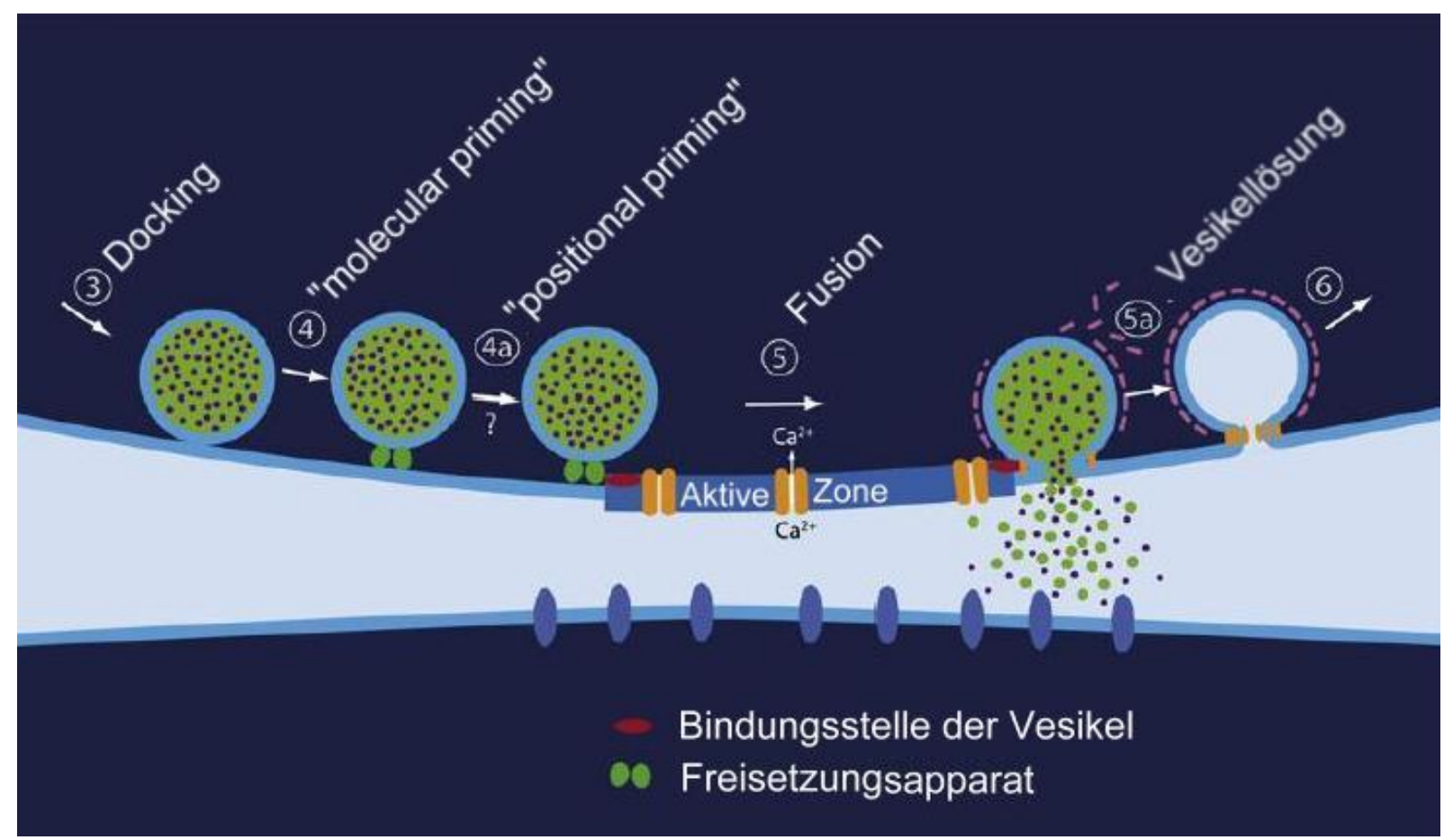

Abb. 1.10 Ausschnitt aus dem Vesikelzyklus mit hypothetischem, zweigeteiltem Ablauf des Primings. Zur einfacheren Darstellung ist hier die "Kiss-and-run"-Hypothese dargestellt. Das Prinzip lässt sich jedoch auch auf die klassische Endozyłose übertragen [adaptiert nach NEHER und SAKABA 2008, S. 868]. 


\subsection{P/Q-Typ-Calciumkanal-bedingte Erkrankungen}

\subsubsection{Lambert-Eaton-Rooke-Syndrom und paraneoplastische zerebelläre Ataxie}

Das Lambert-Eaton-Rooke-Syndrom (LEMS) zeichnet sich in erster Linie durch eine proximal betonte Muskelschwäche aus. Es kommt zu einer zeitlichen Verzögerung der vollständigen Kraftentwicklung bei Willkürbewegungen von einigen Sekunden. Dies führt bei fortgeschrittener Kraftanstrengung zu einer Ermüdung der betreffenden Muskulatur [MARESKA und GUTMANN 2004].

Begründet ist diese Schwäche in einer gestörten Signalübertragung zwischen Nervenzellen und Muskel. Es handelt sich dabei um einen präsynaptischen Defekt. Im Rahmen dieser Autoimmunerkrankung werden in der Regel Antikörper gegen präsynaptische spannungsabhängige P/Q- und N-Typ-Calciumkanäle (VGCC) gebildet [PELUCCHI et al. 1993]. Dies führt zwangsläufig zU einer Behinderung der Neurotransmitterfreisetzung, was im Falle des Acetylcholins (ACh) in einer Behinderung der neuromuskulären Koppelung resultiert.

Ursächlich für die Bildung der Antikörper ist in ca. $60 \%$ der Fälle eine tumoröse Erkrankung, vor allem das kleinzellige Bronchialkarzinom (SCLC) [EATON, LAMBERT 1957; SATOYOSHI et al. 1973]. Das LEMS zählt zU den paraneoplastischen Syndromen und kann schon vor Entdeckung des Tumors auftreten.

Auch ohne die Existenz eines Tumors kann das LEMS vorkommen. Bei dieser Form besteht eine Korrelation mit dem Genotyp HLA-DR3-B8.

Insgesamt besitzen ca. $15 \%$ der Patienten mit LEMS keine Antikörper gegen VGCC. Als Pathomechanismus wird bei dieser Form das Vorkommen von Antikörpern gegen Synaptotagmin diskutiert [TAKAMORI 2008].

Diagnostisch lässt sich das LEMS U.a. anhand des Lambert-Zeichens diagnostizieren, bei dem eine graduelle Zunahme der Muskelkraft mit andauerndem Nervenreiz zu verzeichnen ist. Diese Zunahme ist in der Akkumulation des ACh im synaptischen Spalt bei der andauernden Reizung begründet [MARESKA und GUTMANN 2004; POURMAND 2009].

Das LEMS hat eine Inzidenz von ca. 1/100.000. Da das Bronchialkarzinom zurzeit deutlich häufiger bei Männern als bei Frauen vorkommt, erkranken Männer zwei- bis fünfmal häufiger am LEMS.

Bei der paraneoplastischen zerebellären Ataxie (PCA) kommt es zur subakuten Entwicklung einer schweren, generalisierten zerebellären Dysfunktion. Initial entstehen meist eine Gang- bzw. eine symmetrische Extremitätenataxie sowie Schwindel, Übelkeit, Erbrechen und Sehstörungen (Doppelbilder, Oszillopsien), welche sich innerhalb von Wochen bis Monaten verschlechtern. Zusätzlich können ein Nystagmus und eine Dysarthrie auftreten. Diese Symptome entwickeln sich deutlich schneller als die oben genannten, häufig innerhalb weniger Stunden bis Tage. Wegen der zunehmenden Progredienz dieser Erkrankung werden die Patienten meist nach ca. 3 Monaten bettlägerig. 
Am häufigsten assoziierte Tumoren sind Ovarial- und Mammakarzinome, das SCLC sowie Hodgkin-Lymphome. Das SCLC besitzt in diesem Zusammenhang jedoch die größte Bedeutung [siehe zur Übersicht SHAMS'ILI et al. 2003; PETERSON K et al. 1992].

Ursächlich für die PCA sind neben Anti-Hu-Antikörpern (Antikörper gegen HuProteine, die für die RNA-Bindung verantwortlich sind) auch D-III-Antikörper, welche sich gegen den Loop zwischen den Transmembransegmenten S5 und S6 der Domäne III in P/Q-Typ-Calciumkänalen richten. Beide Antikörper werden überwiegend im Rahmen des SCLC gebildet. Diese Antikörper führen zU einer Inhibierung spannungsabhängiger Calciumkanäle sowie zu einer Beeinträchtigung der synaptischen Transmission [GRAUS et al. 2002, LIAO et al. 2008].

\subsubsection{Familiäre hemiplegische Migräne, episodische Ataxie und spinozerebelläre Ataxie}

Allen drei Erkrankungen ist gemein, dass sie in verschiedene Subtypen unterteilt werden können, wobei jeweils ein Subtyp durch Mutationen im CACNAIA-Gen, welches für die $\alpha_{1}$-Untereinheit $\mathrm{CaV}_{2.1}$ in P/Q-Typ-Calciumkanälen codiert, charakterisiert wird und zu einer Funktionseinschränkung dieser Kanäle führt [DUCROS et al. 2001; JOUVENCEAU et al. 2001, WAPPL et al. 2002].

Diese Mutationen sind ursächlich für die familiäre hemiplegische Migräne vom Typ 1, die episodische Ataxie vom Typ 2 sowie für die spinozerebelläre Ataxie vom Typ 6.

Außerdem folgen alle drei Erkrankungen einem autosomal-dominanten Erbgang.

Ein charakteristisches Symptom der familären hemiplegischen Migräne (FHM) ist eine Hemiparese während der Auraphase, welche die sonstigen Beschwerden einer Migräne begleitet. Des Weiteren sind Ataxien und epileptische Anfälle bis hin zum Koma möglich [DUCROS et al. 2001].

Die Prävalenz dieser Erkrankung liegt bei ca. 10/100.000, wobei das Verhältnis zwischen Männern und Fraven 1:2,5 beträg† [LYKKE THOMSEN et al. 2002]. Man unterscheidet insgesamt 3-4 Subtypen der FHM. Typ 1, der häufigste Subtyp, beruht auf einer Mutation des CACNAlA-Gens, wohingegen bei Typ 2 eine Mutation des Gens ATP1A2 vorliegt, welches für die $\mathrm{Na}^{+} / \mathrm{K}^{+}-$ATPase codiert. Beim Typ 3 liegt eine Mutation des SCN1A-Gens vor, was zu einer Funktionsänderung der Natriumkanäle der betroffenen Zelle führt [OPHOFF et al. 1996].

Da sich jedoch einige der Symptome der FHM mit den drei oben genannten Mutationen nicht erklären lassen, geht man davon aus, dass es noch einen vierten Subtyp geben muss.

Die FHM kann auch mit einer zerebellären Degeneration einhergehen 
[OPHOFF et al. 1998].

Zum Symptombild der episodischen Ataxie (EA) gehören sporadische ataktische Anfälle sowie Myokymien (wellenartig fibrilläre Muskelzuckungen). Weitere Symptome können ein Nystagmus, Schwindel, Tinnitus, Dysarthrie oder Doppelbilder sein [BALOH et al. 1997]. Diese Beschwerden können, je nach Subtyp der Erkrankung, Sekunden bis Tage andavern [VON BREDERLOW et al. 1995].

Die Ataxie kann durch eine Schreckreaktion, Stress oder größere Anstrengungen, jedoch auch durch Kaffee oder Alkohol ausgelöst werden [SUBRAMONY et al. 2003].

Man geht davon aus, dass mindestens sechs Genloci für die EA verantwortlich sind, wobei vier Gene bekannt sind.

Einige Patienten leiden neben der EA auch an einer Migräne bzw. einer FHM sowie zerebellären degenerativen Störungen [DENIER et al. 1999; JEN et al. 1999].

Die episodische Ataxie vom Typ 1 (EAl) ist in einer Mutation des Gens KCNAl begründet, welches für die Untereinheit $\mathrm{K}_{\mathrm{V} 1.1}$ eines spannungsabhängigen Kaliumkanals codiert.

Ursächlich für die EA2 isł wiederum eine Mutation des CACNA1A-Gens. Die Genloci, deren Mutation zu einer EA3 und EA4 führt, sind unbekannt, wohingegen die Mutationen, die eine EA5 bzw. EA6 hervorrufen, in CACNB4, einem Gen, welches für die Calciumkanaluntereinheit $\beta 4$ codiert, bzw. in SCLC1A3, verantwortlich für die Glutamataufnahme durch den exzitatorischen Aminosäuretransporter 1 (EAAT1), liegen [OPHOFF et al. 1996; DENIER et al. 1999; JEN et al. 1999].

Bei der spinozerebellären Ataxie (SCA) unterscheidet man 29 Subtypen, wobei der Typ 6 wiederum auf eine Mutation im CACNAlA-Gen zurückzuführen ist. Zu den Symptomen zählen aufgrund der zerebellären Dysfunktion neben einer Gangataxie eine Dysarthrie, Störungen der Okulomotorik, Inkontinenz sowie eine periphere Neuropathie [YABE et al. 2003].

Im Gegensatz zu anderen Subtypen dieser Erkrankung ist die SCA6 nicht tödlich. Die Abgrenzung zur episodischen Ataxie erfolgt aufgrund der Tatsache, dass die zerebelläre Dysfunktion nicht sporadisch auftritt, sondern daverhaft und progredient ist.

Bei der SCA6 zeigt CACNA1A eine polymorphe Gestalt, welche in der unterschiedlichen Ausgestaltung der (CAG) ${ }_{n}$-Repeats zu finden ist. Eine Vermehrung dieser Repeats von einem Normalwert von 4-16 auf Werte von 21-28 gilt als Auslöser einer spinozerebellären Ataxie [ZHUCHENKO et al. 1997].

Die Prävalenz der SCA6 beträgt 0,06 bis 0,31/100.000 [GESCHWIND et al. 1997; JIANG et al. 2005]. 


\subsection{Das ACP-Tag}

Das ACP-Tag ermöglicht eine spezifische Färbung von Proteinen.

Es ist ein 8 kD schweres Polypeptid-Tag, welches auf dem Acyl-Carrier-Protein (ACP) basiert. Da das ACP ein essentieller Baustein der Fettsäure-Synthase (FAS) ist, spielt es eine entscheidende Rolle im Fettstoffwechsel.

Die Fettsäure-Synthase besteht aus zwei identischen Untereinheiten, die Cförmig gebogen sind und ein Homodimer bilden. Jede Untereinheit enthält alle sieben für die Fettsäuresynthese nötigen katalytischen Zentren. Die Substrate werden als Thioester gebunden, wobei die Schwefelatome aus zwei SHGruppen stammen. Die zentrale SH-Gruppe bildet einen Teil einer prosthetischen Gruppe, das 4'-Phosphopantethein (Ppant). Dieses organische Molekül besitzł eine Länge von ungefähr $2 \mathrm{~nm}$, trägt an einem Ende die entscheidende SH-Gruppe und ist mit dem anderen Ende über eine Phosphatgruppe mit der Fettsäure-Synthase verbunden.

Des Weiteren ist das ACP ein Bestandteil der nichtribosomalen PeptidSynthetasen (NRPS) und der Polyketide-Synthasen (PKS) [CANE und WALSH 1999; HOPWOOD 1997; KLEINKAUF 2000; WALSH et al. 1997]. Die NRPS sorgen in Prokaryonten und Pilzen für eine DNA-unabhängige Möglichkeit, bioaktive Substrate wie Vancomycin, Ciclosporin oder Surfactin zu produzieren, wohingegen die PKS die Produktion von Polyketiden wie Erythromycin oder Tetracyklin katalysieren [LAMBALOT et al. 1996].

Ähnlich wie die Fettsäure-Synthase bilden die PKS aus Coenzym-A-aktivierten Acyl-Gruppen Vorstufen der Polyketide, welche dann im Rahmen einer schrittweisen Kettenverlängerung zum Endprodukt zusammengesetz† werden.

Das ACP, welches einen Serylrest der FAS, PKS bzw. NRPS darstellt, ist jene Domäne dieser Enzyme, in der das Phosphopantethein verankert ist. Es liegt im carboxyterminalen Abschnitt jeder Untereinheit der Fettsäure-Synthase.

In der FAS überträgt Phosphopantethein die Zwischenprodukte der Fettsäuresynthese (die Acylgruppen) in Form eines langgestreckten Armes von einem Reaktionszentrum zum nächsten. Die Länge des Phosphopantethein-Moleküls reicht dabei aus, um innerhalb der C-förmigen Untereinheiten auch die Domänen der gegenüberliegenden Seite zU erreichen [SMITH 1994].

Die periphere SH-Gruppe ist Teil eines Cysteins des Enzyms. Sie liegt in der Nterminalen Domäne jeder Untereinheit und nimmt in der Reaktionssequenz kurzzeitig die zu verlängernde Fettsäure auf, während der Phosphopantethein-Arm mit einer neuen Malonylgruppe beladen wird [zur Übersicht siehe LAI und CRONAN 2004; SHARMA et al. 2005].

Während der posttranslationellen Modifikation der ACP-Domäne in PKS bzW. NRPS wird das Ppant durch eine Phosphopantetheinyl-Transferase (PPTase) vom COA an einen konservierten Serin-Rest des ACP transferiert. 
Dieser Schritt führt in Prokaryonten und Pilzen zur essentiellen Überführung der inaktiven Apoform in die aktive Holoform und damit zu einer Aktivierung der NRPS und PKS [WALSH et al. 1997; MOFID et al. 2002] (Abb. 1.11).

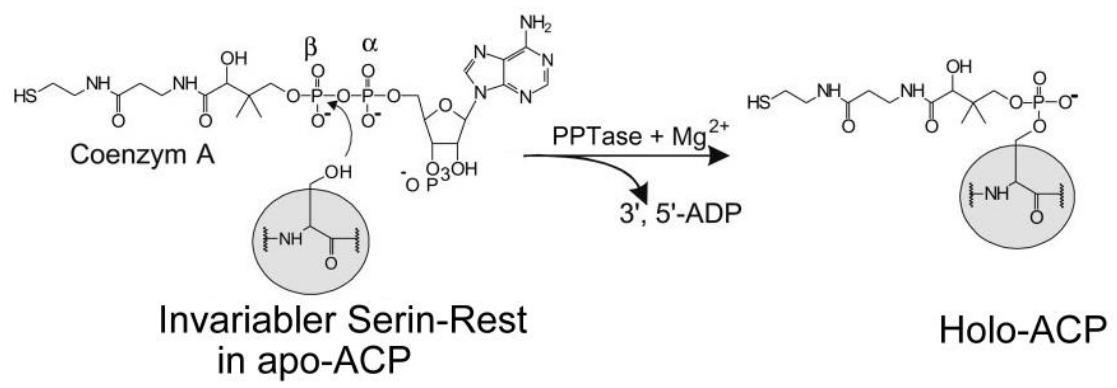

Abb. 1.11 Konvertierung des ACP von der inaktiven Apoform in die aktive Holoform [adaptiert nach MOFID et al. 2002, S. 17025]

Mit dem auf dem Acyl-Carrier-Protein basierenden ACP-Tag ist es nun möglich, eine Vielzahl von Molekülen kovalent an das zu analysierende Protein zu binden. Die Substrate für diese Reaktion sind Thiol-modifizierte Abkömmlinge des Coenyzms A. In der Färbereaktion (Labeling-Reaktion) wird die 4'Phosphopantethein-Gruppe des CoA kovalent an den Serin-Rest des ACPTags gebunden [LAMBALOT et al. 1996; GEORGE et al. 2004] (Abb. 1.2). Diese Reaktion wird analog durch eine Phosphopantethein-Transferase wie beispielsweise das Surfactinproduzierendes Peptid (Sfp) oder ACP-Synthase (AcpS) katalysiert.

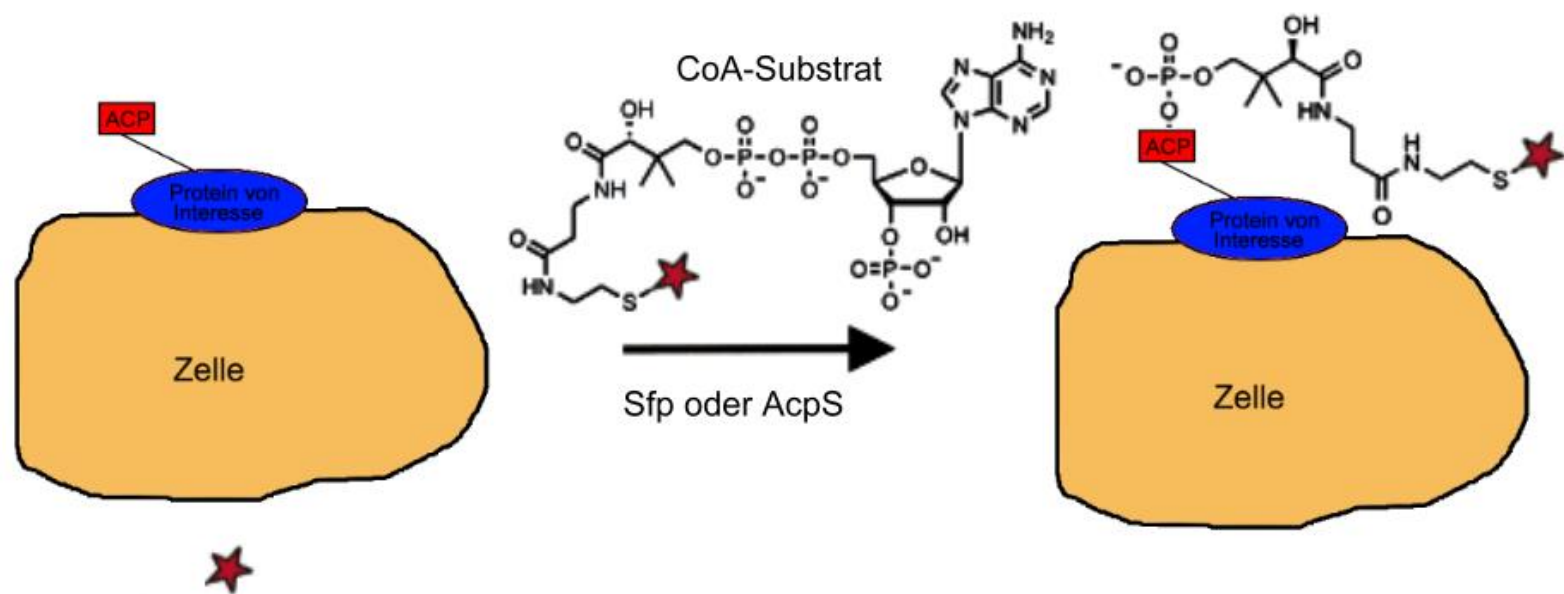

Fluoreszenzfarbstoff

Abb. 1.12 ACP-Labeling-Reaktion [adaptiert nach GEORGE et al. 2004, S. 8896]

Im Falle des Sfp, welches aus 220-240 Aminosäuren besteht, erfolgt dieser Transfer sowohl an NRPS als auch an PKS, z.B. in Bacillus subtilis [QUADRI et al. 1998]. Das Sfp ist ein essentieller Bestandteil der Surfactinproduktion in Bacillus 
subtilis (daher die Namensgebung) [NAKANO et al. 1992].

Die 120-140 Aminosäuren lange ACP-Synthase (AcPS) ist ausschließlich mit der Fettsäure-Synthase von Prokaryonten, vor allem Escherichia coli, assoziiert und akzeptiert nur deren ACP [LAMBALOT und WALSH 1997]. Sie besitzt daher eine engere Substratspezifität [VIVERO-POL et al. 2005].

Der Grund für diese Unterschiede ergibt sich aus der Mikrostruktur dieser beiden Enzyme. Die AcpS besitz† eine rigide Helix, mit der sie am ACP-Tag bindet, das Sfp hingegen enthält für diese Bindung einen flexiblen Loop zwischen den Untereinheiten [REUTER et al. 1999; PARRIS et al. 2000; MOFID et al. 2002]. Dies bietet für die Sfp-katalysierte posttranslationale Proteinmodifikation des ACP den Vorteil, dass das Sfp mit einem größeren Substratspektrum reagiert. Beiden Enzymen ist jedoch gemein, dass sie sehr spezifisch und effizient arbeiten [YIN et al. 2005b].

Die ACP-Tags können sowohl am $\mathrm{N}$ - als auch am $\mathrm{C}$-Terminus verwendet werden und sind relativ klein (78 Aminosäuren im herkömmlichen Tag [FLUGEL et al. 2000; MOFID et al. 2002] und nur 11 Aminosäuren im modifizierten ybbR-Tag [YIN et al. 2005a]).

Des Weiteren ist es vorteilhaft, dass die Labeling-Reaktion mithilfe des ACPTags nur zwischen 10 und 60 min davert [JOHNSSON et al. 2005].

Da jedoch die an das CoA konjugierten Moleküle nicht membrangängig sind, eignet sich das ACP-Labeling-Verfahren nur für Färbungen von Zelllysaten bzw. zur Membranfärbung [LA CLAIR et al. 2004].

Das Unvermögen, die Zellmembran zu passieren, bietet jedoch den Vorteil, dass nach dem Färben der Zellen mit CoA-Fluoreszenz-Konjugaten die intrazelluläre Hintergrundfärbung sehr gering ist, wodurch ein großer Kontrast bei der Membranfärbung erreicht werden kann. Da die Auswahl an CoAFluoreszenz-Konjugaten theoretisch nahezu unbegrenzt ist, wäre es dadurch möglich, einen für das Resultat der Labeling-Reaktion optimalen Fluoreszenzfarbstoff zU wählen [GEORGE et al. 2004; VIVERO-POL et al. 2005; YIN et al. 2005a].

Das nur 11 Aminosäuren lange ybbR-Tag mit der Aminosäurensequenz DSLEFIASKLA kann sowohl am C- oder N-Terminus als auch in den flexiblen Loop eines Proteins integriert werden. Den Namen erhielt dieses Tag, da seine Sequenz vom ybbR ORF von Bacillus subtilis, dessen Funktion noch weitgehend unbekannt ist, abgeleitet worden ist. Es ist durch seine geringe Größe mit sehr vielen Proteinen kompatibel, da so die Wahrscheinlichkeit einer möglichen Funktionsstörung des analysierten Proteins durch das Tag minimiert werden kann.

Zur Erkennung des Tags durch das Enzym Sfp bzw. AcpS ist zum einen das Cterminale Ende des ybbR-Tags, zum anderen die Eigenschaft des Tags, eine $\alpha$ helikale Konformation anzunehmen, von großer Bedeutung. 
In Verbindung mit dem ybbR-Tag besitz† das Sfp eine ähnliche Wechselzahl $\left(\mathrm{k}_{\text {cat }}\right)$, jedoch eine 30-fach höhere Michaelis-Menten-Konstante $\left(\mathrm{K}_{\mathrm{m}}\right)$ verglichen mit dem 78 Aminosäuren langen herkömmlichen ACP-Tag [YIN et al. 2005a]. Es kann daher bei beiden Tags von einer vergleichbaren Reaktionsgeschwindigkeit ausgegangen werden, jedoch wird in Verbindung mit dem ybbR-Tag eine höhere Substratkonzentration benötigt.

Die spezifische Färbung eines Proteins mit dem ACP-Tag besteht aus vier Schritten. Nach Auswahl eines geeigneten Vektors muss zunächst die DNA des zu analysierenden Proteins in den Vektor integriert werden. Daraufhin wird in diese Protein-Sequenz die DNA des ACP-Tags eingefügt. Geeignete Zellen, wie z.B. HEK293-, E2T- oder CHO-Zellen, werden darauf folgend mit diesem Vektor transfiziert bzw. infiziert, sodass die Zellen schließlich das markierte Protein exprimieren. Im letzten Schritt erfolgt die eigentliche Färbereaktion mithilfe eines an Coenzym A gekoppelten Fluoreszenzfarbstoffs und des Sfp bzw. der AcpS.

\subsection{Potentielle Alternativen zum ACP-Tag: Weitere Fär- bemethoden}

Aufgrund der freien Zugänglichkeit der Zellmembran von kultivierten Zellen für chemische Reaktionen ist es das Bestreben vieler Imaging-Verfahren, synthetische Moleküle in die Proteine der Zellmembran einzubaven, um diese so näher zu charakterisieren. Hierbei ist es jedoch wichtig, ein Färbeverfahren anzuwenden, welches spezifisch mit dem zu analysierenden Protein reagiert, um dieses von den anderen Molekülen der Zellmembran zu unterscheiden.

Eine solche spezifische Reaktivität kann in wenigen Fällen auch in intrinsischen Eigenschaften des Proteins begründet sein, jedoch müssen in den meisten Fällen molekulare Modifikationen durchgeführt werden, um eine hochspezifische Färbung der beobachteten Region zu gewährleisten.

Eine dieser Methoden ist das sogenannte "metabolische OligosaccharidEngineering " zur Markierung lebender Zellen [SAXON und BERTOZZI 2000].

Bei diesem Verfahren werden dem Zellkulturmedium säurehaltige, künstliche Monosaccharide hinzugefügt. Diese werden daraufhin von den Zellen inkorporiert und werden an die Zellmembran transportiert und dort eingebaut. Diese Azido-Glykoproteine können daraufhin mithilfe von Phosphin-Derivaten modifiziert werden, was die Applikation einer relativ großen Anzahl an Fluoreszenzfarbstoffen erlaubt [PRESCHER et al. 2004]. Die Inkorporation der künstlichen Monosaccharide ist jedoch relativ unspezifisch, was zu einer Anfärbung verschiedenster Glykokonjugate und Glykoproteine führen kann [HANG et al. 2003]. 
Eine Weiterentwicklung stellt das Einbringen von künstlichen Aminosäuren in die Proteine der Zellmembran dar [NOREN et al. 1989].

Dazu wird eine t-RNA, welche eine künstliche Aminosäure geladen hat, mithilfe von Mikroinjektion, Elektroporation bzw. per Transfektion in die zu untersuchende Zelle eingebracht [MONAHAN et al. 2003]. Diese Methode besitz† jedoch einige Einschränkungen in der Auswahl der Zellen und ist daher nicht universal einsetzbar [JOHNSSON et al. 2005].

Eine weitere Alternative ist die Fusion des zu untersuchenden Proteins mit einem Protein-Tag, welches dem Protein eine neve Funktion verleiht.

Ein Rezeptorprotein wird in das zu analysierende Protein integriert. Daraufhin erfolgt eine synthetische Konjugierung eines zu diesem Rezeptor passenden Liganden mit einem Fluoreszenzfarbstoff. Durch Bindung des Liganden gelangt der Farbstoff an das Protein.

Zu dieser Gruppe gehören, neben dem ACP-Tag, z.B. das Tetracystein-Tag und das AGT-Tag.

Das Tetracystein-Tag ist ein kurzes Protein, welches vier benachbarte Cysteine besitzt, die jedoch nur mithilfe von biarsenischen Derivaten intrazellulär gefärbt werden können. Dies erfordert bei einer Anwendung an der Zellmembran eine Reduktion der sonst oxidierten und dadurch inaktivierten Cysteine [ADAMS et al. 2002].

Dies macht dieses Tag für Membranfärbungen lebender Zellen ungeeignet, da unter anderem die Reduktion des Cysteins durch 2Mercaptoethansulfonat und Trisphosphin auch zu einer Reduktion der Disulfidbrücken der meisten Zellmembranproteine führen kann und dadurch deren Funktion essentiell beeinträchtigt wird [KEPPLER et al. 2003]. Ein anderes Problem bei der Verwendung des Tetracystein-Tags stellt die relativ hohe Hintergrundfluoreszenz dar [ADAMS et al. 2002].

Eine Labeling-Reaktion mithilfe des AGT-Tags wird durch das Enzym $0^{6}$ Alkylguanin-DNA-Alkyltransferase (AGT) katalysiert.

Für diese Reaktion ist es notwendig, dass die AGT durch $0^{6}$-BenzylguaninDerivate alkyliert wird. Diese Bedingung führt zu einer ausgesprochenen Instabilität des AGT-Tags in der oxidativen Umgebung der Zellmembran [GRIFFIN et al. 1998; KEPPLER et al. 2004].

Außerdem ist dieses Tag mit 207 Aminosäuren sehr groß und kann nur in Kombination mit speziellen Zellen verwendet werden, welche entweder AGTdefizient sind oder bei denen das Wildtyp-AGT supprimiert werden muss [JUILLERAT et al. 2005].

Zu der Gruppe der Protein-Tags für das Labeling-Verfahren gehören weiterhin eine mutierte prokaryotische Dehalogenase (HaloTag-Protein) [LOS et al. 2008] oder ein Lanthanoid-bindendes Protein [SCULIMBRENE und IMPERIALI 2006].

Bei diesen Verfahren kommt es zwar genauso wie beim AGT-Tag zU einer kovalenten Bindung, jedoch sind auch hier die Tags sehr groß [DRAGULESCUANDRASI und RAO 2007]. 
Außerdem kann das zu charakterisierende Protein mit einem Polypetid-Tag, welches nur eine geringe Größe von beispielsweise 15 Aminosäuren besitzt, fusioniert werden. Dieses wird dann beispielsweise von einer Biotin-Ligase wie BirA erkannt [PARROTT und BARRY 2001; CHEN I et al. 2005].

Die Biotin-Ligase bewirkt eine Biotinylierung des Fusionsproteins. Daran wiederum können mit Fluoreszenzfarbstoffen beladene Avidine bzw. Streptavidine binden. Dadurch wird die Färbereaktion indirekter, da nun mehrere Reaktionen nacheinander ablaufen müssen. Ein Nachteil ist auch in der Tatsache begründet, dass die Bindung an das Biotin nicht kovalent erfolgt, wobei die Biotin-Streptavidin-Interaktion schon zu den stärksten bekannten nichtkovalenten Bindungen zählt [CHEN et al. 2005; JOHNSSON et al. 2005]. Diese nichtkovalenten Bindungen führen jedoch stets zu einem relativ instabilen Komplex. Dadurch kann mit der Zeit das Signal verschlechtert werden, da es zu einer Dissoziation der fluoreszenzmarkierten Moleküle von den Membranproteinen kommen kann [YIN et al. 2005b]. Des Weiteren ist das Streptavidin mit $56 \mathrm{kDa}$ wiederum sehr schwer und groß und könnte so die Proteinfunktion negativ beeinflussen [HOWARTH und TING 2008].

Weitere nichtkovalente Labeling-Methoden sind z.B. die Bindung von kleinen Molekülen an ein Oligohistidin-Tag [GUIGNET et al. 2004] oder an die PeptidylProlyl-cis-trans-Isomerase FKBP12 (FK506-bindendes Protein) [MARKS et al. 2004]. Eine weitere Möglichkeit stellt die Bindung des einkettigen Antikörperfragments Anti-c-myc, das im endoplasmatischen Retikulum, dem GolgiApparat bzw. an die Zellmembran von lebenden $\mathrm{CHO}$-Zellen bindet, an das Protein von Interesse dar [FARINAS und VERKMAN 1999]. Außerdem ist eine Färbung mithilfe einer Dihydrofolat-Reduktase [MILLER et al. 2004], welche mit dem zu untersuchenden Membranprotein fusioniert, möglich.

Proteine der Zellmembran können ferner mit dem Green Fluorescent Protein (GFP) fusioniert werden.

Das GFP wurde erstmals 1961 von Osamu Shimomura beschrieben [SHIMOMURA et al. 1961]. Es stammt aus der Qualle Aequorea victoria und fluoresziert bei Anregung mit blavem oder ultraviolettem Licht grün. Der Vorteil des GFPs liegt unter anderem in der Möglichkeit, es mit beliebigen anderen Proteinen zu fusionieren.

Die intrinsische Fluoreszenz des GFPs basiert nicht auf einem Umbau durch ein externes Enzym oder nachträglich integrierte Substanzen, es kommt vollständig ohne zellspezifische Prozessierungssysteme aus. GFP ist für nahezu alle eukaryontischen Zellen nicht toxisch und eignet sich daher gut für die Untersuchung biologischer Prozesse in vivo [zur Übersicht: TSIEN 1998; LIPPINCOTTSCHWARTZ Und PATTERSON 2003].

Die Verwendung des GFPs zum Färben von Proteinen bringt jedoch die Nachteile mit sich, dass auch das GFP mit 238 Aminosäuren und einer Masse von $26,9 \mathrm{kDa}$ relativ groß ist, nur eine limitierte Anzahl an Fluoreszenz-Varianten erhältlich ist und es eine relativ geringe intrinsische Helligkeit besitzt [YIN et al. 2005b].

Durch die Größe des GFPs kann es potentiell zu einer Funktionsänderung des Zielproteins, z.B. Dislokalisation oder Missexpression, kommen [TIAN et al. 2004]. 
Eine weitere Methode der Markierung von Proteinen stellt die Verwendung von Epitop-Tags dar. Relativ häufig verwendet wird zu diesem Zweck das HATag. Dabei handelt es sich um einen mononuklearen Antikörper, der in Verbindung mit dem Zielprotein, das eine HA-Sequenz trägt, verwendet werden kann.

Die Sequenz des HA-Tags ist vom Hämagglutinin abgeleitet. Dieses membranständige Glykoprotein der Influenzaviren bewirkt im menschlichen Organismus eine Agglutination der Erythrozyten und ermöglicht bei der Infektion der Wirtszelle die Anheftung und das Eindringen des Virus [GREEN et al. 1982]. Es zeigt eine extrem geringe Funktionseinschränkung der getaggten Proteine, da es aus nur 9 Aminosäuren besteht und damit sehr klein ist.

Das HA-Tag wird zusammen mit dem zu analysierenden Protein in einen geeigneten Vektor kloniert. Mit diesem erfolgt die Transfektion bzw. Infektion der zu untersuchenden Zellen und abschließend eine Immunofluoreszenz-Färbung mit einem an den HA-Antikörper gebundenen Farbstoff [FIELD et al. 1988].

Schließlich bietet sich auch eine klassische Antikörperfärbung an. Bei Durchführung der direkten Methode wird das zu untersuchende Protein als Antigen mit einem spezifischen Antikörper, an dem ein Fluoreszenzfarbstoff gekoppelt ist, markiert.

Alternativ wird zunächst in einem ersten Schritt ein spezifischer Antikörper (Primärantikörper) an das zu untersuchende Protein gebunden und in einem zweiten Schritt ein weiterer Antikörper hinzugegeben, der sich als Sekundärantikörper gegen den ersten Antikörper richtet und der mit einem Fluoreszenzfarbstoff gekoppelt ist (indirekte Methode).

Ein Nachteil der Antikörperfärbungen ist jedoch die Tatsache, dass es oft sehr schwierig ist, geeignete Primärantikörper zu finden, welche auch extrazellulär anwendbar sind. Des Weiteren ist für eine intrazelluläre Färbung stets eine Permeabilisierung der Zellmembran nötig.

\subsection{Ziele der Arbeit}

Das Ziel der Arbeit war in erster Linie, die Verteilung und die Anzahl von P/QTyp-Calciumkanälen in der aktiven Zone zu bestimmen.

Auf Basis der Forschungsarbeit der letzten Jahre entstand die Annahme, dass es U.a. zwei verschiedene Populationen von Vesikeln gibt, welche sich in ihrer Transmitterfreisetzungsgeschwindigkeit unterscheiden. Einige Arbeiten formulieren als mögliche Erklärung für dieses Phänomen eine Heterogenität der örtlichen Beziehung der synaptischen Vesikel zu den Calciumkanälen. Vesikel, welche dichter bei den Calciumkanälen lägen, sollten bei einem eintreffenden Aktionspotential zehnmal schneller fusionieren als jene in größerer Distanz zU den Kanälen [SAKABA und NEHER 2001a].

Im Rahmen dieser Arbeit wurde versucht eine genauere Lokalisation der Cal- 
ciumkanäle in transfizierten HEK292-Zellen, sowie Neuronen durchzuführen.

Des Weiteren formulierten u.a. Sakmann und Meinrenken vom Max-PlanckInstitut für medizinische Forschung in Heidelberg die Hypothese, dass Calciumkanäle innerhalb der aktiven Zone in Cluster organisiert seien [MEINRENKEN et al. 2002]. Durch eine genaue optische Darstellung der Calciumkanäle mit hochauflösenden Methoden wurde versucht, die Existenz dieser Cluster zu beweisen.

Bei der Wahl des Färbeverfahrens wurde vor allem Wert darauf gelegt, dass sich das gewählte Verfahren an lebenden Zellen anwenden ließ. Auf diese Weise sollte die Möglichkeit geschaffen werden, dynamische Veränderungen und Aktivitäten an den Calciumkanälen, beispielsweise nach einer Stimulation Calciumkanal-exprimierender Neuronen, darstellen zu können.

Als ein zukünftiges Ziel wurde schließlich die Herstellung von Knock-in-Mäusen, welche die getaggten Calciumkanäle in der gleichen Menge bzw. Konzentration wie auch ihre Wildtyp-Kanäle exprimieren definiert. 


\section{Material und Methoden}

\subsection{Zellkulturen}

Insgesamt wurden in den Experimenten vier Zelllinien (konventionelle HEK293Zellen, modifizierte HEK-Zellen [E2T] für die Virusproduktion, Neuronen und ACP-erbB1-Zellen) eingesetzt.

\subsubsection{Kultivierung von HEK293-Zellen}

Als HEK293-Zellen (human embryonic kidney-cells) wird eine humane Zellinie bezeichnet, die als Transformationsprodukt einer menschlichen embryonalen Nierenzelle mit DNA-Abschnitten des menschlichen Adenovirus 5 geschaffen worden ist. HEK293-Zellen enthalten $4,5 \mathrm{~kb}$ des viralen Genoms, zeigen ein adhärentes Wachstum, sind hypotriploid und können daher relativ einfach kultiviert und transfiziert werden.

Die Aufbewahrung der Zellen erfolgte bei $-80^{\circ} \mathrm{C}$ bzw. bei längerer Lagerung in flüssigem Stickstoff. Es wurde ein Aliquot entnommen, bei $37^{\circ} \mathrm{C}$ im Wasserbad aufgetaut und sofort in einer Zellkulturschale mit einem Durchmesser von $10 \mathrm{~cm}$, in der sich auf $37^{\circ} \mathrm{C}$ enwärmtes Kulturmedium befand, resuspendiert. Danach wurden die Zellen bei $37^{\circ} \mathrm{C}$ und $5 \% \mathrm{CO}_{2}$ inkubiert.

Am folgenden Tag erfolgten das Absaugen des Mediums, das vorsichtige Spülen der Zellkulturschale mit phosphatgepufferter Salzlösung (PBS) sowie das erneute Auffüllen mit frischem Nährmedium. Die Zellen wurden erneut bei $37^{\circ} \mathrm{C}$ und $5 \% \mathrm{CO}_{2}$ inkubiert.

Nach etwa 5 Tagen hatten sich die Zellen in der Zellkulturschale so weit vermehrt, dass die gesamte Oberfläche zu 80-90 \% konfluent bewachsen war.

In diesem Stadium erfolgte das Passagieren der Zellen. Dazu wurde das ursprüngliche Medium abgesaugt und die Zellen wiederum mit PBS gespült. Durch die Zugabe von $2 \mathrm{ml}$ Trypsin-Medium, gefolgt von stärkerem Schwenken und Spülen, wurden die Zellen vom Boden des Kulturgefäßes abgelöst. Das Trypsin wurde durch Zugabe von 8 ml Kulturmedium deaktiviert.

Die Suspension der gelösten Zellen wurde anschließend entweder im Verhältnis 1:5 oder 1:10 mit frischem Medium verdünnt. Nun wurden die Zellen entweder in eine neve $10 \mathrm{~cm}$ Zellkulturschale übertragen und erneut bei $37^{\circ} \mathrm{C}$ mit $5 \% \mathrm{CO}_{2}$ inkubiert oder alternativ zur weiteren Verwendung, z.B. zur Messung der Ströme oder für Labeling-Reaktionen, in eine mit Poly-D-Lysin beschichteten Deckgläschen bestückte 6-Well-Zellkulturplatte überführt [BARNES et al. 1984]. 


\subsubsection{Kultivierung von ErbB 1-Zellen}

Die ACPerbB1-Zellinie leitet sich von den $\mathrm{CHO}$-Zellen (Chinese hamster ovary cells) ab. Der Vorteil der CHO-Zellen besteht in ihrem relativ schnellen Wachstum - sie teilen sich alle $24 \mathrm{~h}$ - und in ihrer hohen und vor allen stabilen Exprimierung von Proteinen.

Da diese Zellen außerdem keinen Epidermal Growth Factor Receptor (EGFR) exprimieren, eignen sie sich sehr gut für das Einbringen von mutierten EGFR.

Diesen Umstand machte sich die Arbeitsgruppe von Dr. Arndt-Jovin aus dem Labor für Zelluläre Dynamik am Max-Planck-Institut für biophysikalische Chemie in Göttingen zunutze, indem sie das 78 Aminosäuren lange ACP-Tag genau zwischen das 24 Aminosäuren lange Signalpeptid und die Sequenz des EGFR einfügte und dieses Konstrukt in die $\mathrm{CHO}$-Zellen einbrachte.

Die Kultivierung der ACPerbB1-Zellen entsprach der weiter oben beschriebenen Kultivierung der HEK293-Zellen. Da Erstere jedoch eine deutlich höhere Wachstumsgeschwindigkeit als die HEK293-Zellen aufweisen, erfolgte das Passagieren der Zellen alle zwei Tage.

\subsubsection{Kultivierung von E2T-HEK-Zellen}

Bei den E2T-Zellen handelt es sich um modifizierte HEK293-Zellen, die sich morphologisch nicht von der Ausgangszelllinie unterscheiden. Sie besitzen jedoch die Fähigkeit einer induzierbaren Produktion von viralen Proteinen, welche von den stabil exprimierten adenoviralen Genomabschnitten El und E2a codiert werden.

Auf diese Weise ist es möglich, sichere El/E2a-defiziente Virusvektoren zu nutzen und trotzdem eine suffiziente Vektoramplifikation zu erreichen.

Die Gene für diese beiden Untereinheiten sind in den E2T-Zellen an ein G418sowie an ein Puromycin-Resistenz-Gen gekoppelt. Dadurch lässt sich durch Zugabe dieser beiden Antibiotika eine Selektion der El/E2a exprimierenden Zellen durchführen, da diese Pharmaka normalerweise toxisch für eukaryotische Zellen sind [ZHOU H und BEAUDET 2000].

Die Kultivierung der E2T-Zellen erfolgte ebenfalls nach dem oben beschriebenen Procedere, jedoch wurden für diese Kultivierung Schalen mit einem Durchmesser von $20 \mathrm{~cm}$ und ein modifiziertes Kulturmedium verwendet, welches die Antibiotika G418 und Puromycin enthielt.

\subsubsection{Vorbereitungen zum Messen der Ströme und zum Labeling}

Die Deckgläschen, auf denen die HEK293- bzw. ACPerbB1-Zellen wachsen sollten, mussten in einem ersten Schritt gründlich gereinigt werden. Dazu wurden sie zunächst für eine Stunde in $1 \mathrm{M} \mathrm{HCl}$ und anschließend für eine weitere Stunde in $1 \mathrm{M} \mathrm{NaOH}$ auf einem rotierenden Plattformschüttler (Unimax 1010, 
Heidolph Instruments, Schwabach) geschwenkt. Die Lagerung erfolgte dann in $70 \% \mathrm{EtOH}$.

Vor der Bestückung der 6-Well-Zellkulturplatten mit den gereinigten Deckgläschen wurden diese mit einer Gasflamme abgeflammt.

Diesem Trocknungsvorgang und der Positionierung der Gläschen schloss sich eine Beschichtung mit Poly-D-Lysin an, welches zuvor mit $\mathrm{H}_{2} \mathrm{O}$ im Verhältnis 1:10 verdünnt worden war. Nach einer Stunde wurde die Poly-D-Lysin-Lösung abgesaugt und die Deckgläschen wurden mehrmals mit $\mathrm{H}_{2} \mathrm{O}$ gespült. Danach folgte die Lufttrocknung.

Nach dem vollständigen Trocknungsvorgang konnte ein Teil der geernteten HEK293- bzw. ACPerbB1-Zellsuspension zusammen mit frischem Medium (Verdünnungsgrad je nach weiterer Verwendung: Patch-Clamp-Messung 1:100, Färbung 1:4) auf die Glasplättchen aufgebracht werden. Am Folgetag erfolgte die Transfektion.

\subsubsection{Kultivierung von Neuronen}

Die Kultivierung der Neuronen erfolgte mit freundlicher Unterstützung von Frau Ina Herfort. Es wurden Neuronen des Hippocampus von postnatalen Raten verwendet.

Die Kultivierung der Neuronen erfolgte im „Elevated-Coverslip“-Verfahren. Dazu lässt man zunächst den Boden eines Wells, in dem sich das mit Neuronen bewachsene Deckgläschen befindet, mit einer Schicht aus Astrozyten bewachsen. Diese unterstützen die Neuronen bei der Nährstoffversorgung. Die neuronentragenden Gläschen wurden in einem Abstand von ca. $1 \mathrm{~mm}$ mit der Zellschicht nach unten über der Astrozytenschicht platziert.

Auf diese Weise entwickelte sich nach ungefähr 14 Tagen eine zu ca. $80 \%$ konfluent bewachsene Neuronenzellschicht.

Diese Zellen konnten daraufhin mit Adenoviren, in die zuvor das ybbR-Tag integriert worden war, infiziert und anschließenden zur Färbung genutzt werden.

\subsection{Das ybbR-ACP-Tag}

\subsubsection{Identifikation geeigneter Regionen zur Integration des ACP- Tags}

Die Auswahl der Position innerhalb der DNA der $\alpha_{1}$-Untereinheit $\mathrm{CaV}_{2.1}$ des P/Q-Typ-Calciumkanals, an der das ybbR-ACP-Tag integriert werden sollte, erfolgte auf der Basis von Daten, welche Frau Dr. Pedersen am Max-Planck Institut für biophysikalische Chemie in Göttingen in vorhergehenden Experimenten ermittelt hatte und freundlicherweise zur Verfügung stellte. In diesen 
Experimenten wurden HA-Tags an verschiedenen Stellen der DNA der $\alpha_{1^{-}}$ Untereinheit von P/Q-Typ-Calciumkanälen eingebaut und die Ströme, welche durch die Kanäle flossen, mit der Patch-Clamp-Methode gemessen [PEDERSEN 2008].

Relevant bei der Auswertung dieser Messungen war zum einen das Verhältnis von HEK293-Zellen, welche mit der DNA der getaggten CalciumkanalUntereinheit transfiziert worden waren und einen Calciumstrom aufwiesen, zu der Gesamtheit aller mit dieser DNA transfizierten Zellen.

Zum anderen wurden die maximal gemessenen Stromstärken, je nach verwendeter DNA, bei der Auswahl der geeigneten Positionen zur Integration eines Tags berücksichtigt. Anhand der von Frau Dr. Pedersen gesammelten Daten bezüglich des HA-Tags wurde entschieden, vier dieser ermittelten Positionen, welche in den Experimenten die besten Resultate geliefert hatten, auch für das ybbR-ACP-Tag zu nutzen. Dies waren Insertionen hinter den Basenpaarpositionen 786, 792, 798 und 810 der $\alpha_{1}$-Untereinheit $\mathrm{CaV}_{2.1}$.

\subsubsection{Erstellung von $\mathrm{pCaV}_{2.1}+\mathrm{ybbR}$}

Im nächsten Schritt wurde das ybbR-Tag mittels Polymerasekettenreaktion (PCR) in den Vektor pUC19+CaV inseriert [SAIKI et al. 1985; SAMBROOK und RUSSELL 2001].

pUC19 ist ein künstlich hergestelltes bakterielles Plasmid und wird sehr häufig als Vektor zur Klonierung und Expression von Proteinen in E. coli eingesetzt. Es handelt sich um ein sog. "high-copy number-plasmid". Aufgrund der hohen Anzahl an Kopien pro Bakterium nach Inkorporation des Plasmids durch E. coli kann relativ einfach eine große Menge an Plasmiden isoliert werden. Das Ampicilin-Resistenzgen (ampR) dient der Selektion von pUC19-positiven Bakterien nach Einführung des Plasmids in einen Bakterienstamm mittels Transformation [YANISCH-PERRON et al. 1985].

Vor dem Beginn der Experimente wurde in diesen Vektor eine Teilsequenz des P/Q-Typ-Calciumkanals hineinkloniert. Dies geschah mit freundlicher Unterstützung durch Frau Dr. Pedersen.

Es wurden zunächst die vier passenden Primerpaare $(786,792,798,810$ - jeweils up und down) erstellt und bei IBA, Göttingen, bestellt. Danach erfolgte die PCR mit $50 \mu \mathrm{gg}$ pUC19+CaV-DNA, 0,4 $\mathrm{\mu g}$ Primer jeweils up und down, $0,2 \mathrm{mM}$ dNTPs, $1 \mu \mathrm{l}$ Pfu-Polymerase (Stratagene, La Jolla, USA) und $5 \mu \mathrm{L}$ PfuPuffer (Stratagene) mit 35,5 $\mu \mathrm{H}_{2} \mathrm{O}$. 
PCR Protokoll:

$02: 00 \mathrm{~min}$ bei $94^{\circ} \mathrm{C}$

$00: 15 \min$ bei $94^{\circ} \mathrm{C}$

$00: 30 \mathrm{~min}$ bei $74^{\circ} \mathrm{C}$

$24 x$

10:00 $\min$ bei $72^{\circ} \mathrm{C}$

10:00 $\min$ bei $68^{\circ} \mathrm{C}$

Im nächsten Schritt wurden die Transformation des PCR-Produktes sowie die DNA-Aufreinigung einzelner Bakterienkolonien mithilfe des QIAprep Spin Miniprep Kit (Qiagen, Venlo, Niederlande) und die Sequenzierung bei SeqLab in Göttingen durchgeführt.

Danach erfolgte ein Verdau der Vektoren pUC19+ybbR (786, 792, 798 bzw. 810) mit den Restriktionsenzymen Nhe I, Xho I und Pvu I (New England Biolabs [NEB]), Ipswich, USA) für 180 min. Zeitgleich wurde der Vektor pCDNA3.1, in den in einem vorhergehenden Schritt die Sequenz der $\alpha_{1}$-Untereinheit $\mathrm{CaV}_{2.1}$ integriert worden war (pCDNA3.1+CaV 2.1$)$, mithilfe der Restriktionsenzyme Nhe I und Xho I (NEB) für 180 min verdaut, wobei nach 120 min Alkalische Phosphatase (NEB) hinzugefügt wurde, um Religationen zu verhindern.

Nach Auftragen der fertig verdauten DNA-Proben von pUC19+ybbR bzw. pCDNA3.1+ $\mathrm{CaV}_{2.1}$ auf ein Agarosegel und Durchführung einer Gelelektrophorese wurden eine Bande mit 2419 bp (Verdau des Vektoren pUC19+ybbR) sowie mit ca. 10.000 bp (Verdau des Vektoren pCDNA3.1 $+\mathrm{CaV}_{2.1}$ ) isoliert [AUSUBEL et al. 2009].

Der daraufhin durchgeführten Gelreinigung mithilfe des QIAquick Gel Extraction Kits (Qiagen) der beiden ausgeschnittenen Banden schloss sich eine Ligation mit $1 \mu \mathrm{g}$ der aus pUC19+ybbR stammenden DNA mit 0,15 $\mathrm{gg}$ der aus pCDNA3.1+CaV 2.1 extrahierten DNA mithilfe des Rapid Ligase Kits (Roche, Mannheim) an. Nach Transformation und DNA-Aufreinigung (Qiagen) entstanden schließlich die vier Endprodukten $\mathrm{pCaV}_{2.1}+786$, $\mathrm{pCaV}_{2.1}+792$, $\mathrm{pCaV}_{2.1}+798$ und $\mathrm{pCaV}_{2.1}+810$. 


\subsection{Messung von P/Q-Typ-Calciumkanalströmen mittels der Patch-Clamp-Technik}

\subsubsection{Transfektion der zu messenden Zellen}

Die Transfektion der HEK293-Zellen erfolge mithilfe der CalciumphosphatPräzipitationsmethode [CHEN CA und OKAYAMA 1988].

Es wurden fünf verschiedene Ansätze hergestellt. Jeder Ansatz enthielt jeweils $0,5 \mu \mathrm{g}$ der DNA der Calciumkanal-Untereinheiten $\alpha 2 \delta$ bzw. $\beta 1 \mathrm{~b}$ und 0,05 $\mu \mathrm{g}$ des Vektors pEGFP-N 1 (GFP). Die Funktion des GFP bestand darin, im Lichtmikroskop unter ultraviolettem Licht zunächst jene Zellen zu selektieren, welche eine durch GFP verursachte Fluoreszenz aufwiesen. Diese Fluoreszenz war ein verlässlicher Marker, um erfolgreich transfizierte Zellen zu erkennen.

$\mathrm{Zu}$ jedem Ansatz wurden daraufhin jeweils $0,5 \mu \mathrm{g}$ der DNA $\mathrm{pCaV}_{2.1}+786$, $\mathrm{pCaV}_{2.1}+792$, $\mathrm{pCaV}_{2.1}+798, \mathrm{pCaV}_{2.1}+810$ bzw. pCDNA3.1+ $\mathrm{CaV}_{2.1}$ (Wildtyp-DNA der $\alpha_{1}$-Untereinheit $\mathrm{CaV}_{2.1}$ ) sowie $2,5 \mathrm{mM} \mathrm{CaCl}{ }_{2}$ hinzugeben und auf ein Volumen von 83.3 $\mu \mathrm{l}$ mit $\mathrm{H}_{2} \mathrm{O}$ aufgefüllt.

Nach sorgfältiger Auflösung der Ansätze in jeweils 83,3 $\mu$ HBS erfolgte nach 30 min eine Präzipitatbildung.

Das Präzipitat wurde auf Deckgläschen in einer 6-Well-Zellkulturplatte gegeben, die mit einigen wenigen HEK293-Zellen bewachsen waren, um von diesen Zellen durch Endozytose aufgenommen zu werden.

Die Zellen wurden ca. $18 \mathrm{~h}$ bei $37^{\circ} \mathrm{C}\left(5 \% \mathrm{CO}_{2}\right)$ inkubiert und danach dreimal mit PBS gewaschen. Anschließend erfolgte die Inkubation in den 6-WellZellkulturplatten für $24-48 \mathrm{~h}$ bei $37^{\circ} \mathrm{C}\left(5 \% \mathrm{CO}_{2}\right)$ sowie schließlich die elektrophysiologische Untersuchung der Zellen.

\subsubsection{Elektrophysiologie der Patch-Clamp-Technik}

Zur Durchführung aller elektrophysiologischen Messungen wurde die PatchClamp-Technik angewandt. Diese Methode wurde von Neher und Sakmann am Max-Planck-Institut für biophysikalische Chemie entwickelt und im Jahre 1976 vorgestellt. Mithilfe dieser Technik ist es möglich, Ströme durch einzelne Ionenkanäle zu messen [NEHER und SAKMANN 1976]. Das Anwendungsgebiet der Patch-Clamp-Technik wurde in den folgenden Jahren auf das Messen von Strömen über die Membran ganzer Zellen und schließlich auch auf weitere Anwendungsgebiete wie z.B. die Messung von Zellen in GehirnschnittPräparaten erweitert [EDWARDS et al. 1989].

Für die Durchführung der Patch-Clamp-Methode wurden Glaskapillaren mit $2 \mathrm{~mm}$ Durchmesser und $0,3 \mathrm{~mm}$ Wandstärke in einem Micropipette-Puller durch dreifache Erhitzung und gleichzeitigen Zug ausgezogen. Mit diesem Verfahren konnten Öffnungsdurchmesser von ca. einem Mikrometer erreicht werden, die einen Pipettenwiderstand von 4,0 bis 5,5 $\mathrm{M} \Omega$ ergaben. 
Im nächsten Schritt wurden die von einer Nährlösung („extrazelluläre Lösung“) bedeckten Deckgläschen unter UV-Licht auf grünfluoreszierende HEK293Zellen analysiert. Die grüne Fluoreszenz zeigte, wie oben beschrieben, an, dass diese Zellen GFP exprimierten. Es konnte folglich davon ausgegangen werden, dass in diesen fluoreszierenden Zellen auch der getaggte Calciumkanal exprimiert wurde.

Sobald die Pipette unter leichtem Sog an die Zellmembran herangeführt wurde, bildete sich sofort eine Verbindung zwischen Membran und Pipette. Es baute sich anschließend ein hoher elektrischer Widerstand (im Giga-OhmBereich, daher "Gigaseal" genannt) gegenüber der extrazellulären Lösung auf [HAMILL et al. 1981].

Zur Messung der Ströme der kompletten Zellmembran wurde daraufhin durch einen kurzen, kräftigeren Saugstoß das eingesogene Membranstück zerstört („Whole-cell“-Konfiguration). Diese Konfiguration entsprach der, welche für die vorliegende Arbeit angewandt wurde.

Auf diese Weise war es möglich, einen direkten elektrischen Zugang zum Inneren der Zelle zu erhalten. Der Widerstand dieses Zuganges betrug mit rund 10 $M \Omega$ mehr als das Doppelte des Pipettenwiderstandes in der Badlösung [MARTY und NEHER 1983].

Über diesen Zugang ließ sich das elektrische Potential an der Innenseite der Membran gegenüber der Referenzelektrode im Bad - und somit der Membranaußenseite - messen.

Durch einen Rückkoppelungsverstärker war es möglich, ein Membranpotential vorzugeben (,Haltepotential") und Änderungen dieses Potentials infolge von Ionenströmen über die Zellmembran zu kompensieren. Dadurch konnte die Zelle auf ein Potential "geklemmt" werden ("voltage-clamp"). Die Zelle wurde in den folgenden Experimenten auf ein negatives Haltepotential von $-80 \mathrm{mV}$ "geklemmt", da davernde Depolarisation im Bereich von $0 \mathrm{mV}$ zum raschen Zelltod geführt hätte und P/Q-Typ-Calciumkanäle bei positiveren Potentialen mit einer größeren Wahrscheinlichkeit spannungsabhängig inaktiviert werden würden.

Zum Öffnen der Kanäle wurden Depolarisationen für eine Dauer von jeweils $10 \mathrm{~ms}$ bei $-50 \mathrm{mV}$ bis $+40 \mathrm{mV}$ in Zehnerschritten durchgeführt.

Die maximalen Ströme wurden bei $0 \mathrm{mV}$ gemessen. Daraufhin wurde das Minimum des Calciumeinstroms während der Depolarisation, noch vor Einsetzen der spannungsabhängigen Inaktivierung, ausgewertet.

Der Strom, der für die Aufrechterhaltung des Depolarisationspotentials notwendig war, entsprach dabei genau dem Strom durch die lonenkanäle und konnte auf diese Weise gemessen werden.

Nach dem Öffnen der Zellmembran war ein Diffusionsaustausch zwischen Zy- 
toplasma und Pipettenlösung möglich. Das Volumen der Lösung in der Pipette übersteigt das Zellvolumen bei Weitem. Dies führte zu einer Auswaschung aller beweglichen Teile aus dem Zytoplasma, sodass die Lösung im Zellinneren praktisch identisch mit der Lösung der Pipette war [PUSCH und NEHER 1988]. Aus diesem Grund war es essentiell, dass die Zusammensetzung der Pipettenlösung (,intrazelluläre Lösung“) der Zusammensetzung des Zyłoplasmas möglichst entsprach. Es war darauf zu achten, dass die Osmolarität identisch war und die Pipettenlösung genügend ATP enthielt. Des Weiteren wurde $\mathrm{Ca}^{2+}$ durch $\mathrm{Ba}^{2+}$ ersetzt, um eine calciumabhängige Inaktivierung zu verhindern.

\subsubsection{Messplatz für die Patch-Clamp-Ableitungen}

Der für diesen Teil der Experimente verwendete Messplatz war wie folgt aufgebaut:

Über einen schwinungsgedämpften Tisch (EFFBE, Bad Soden) wurde ein Faraday-Käfig zur Abschirmung aufgestellt. Auf dem Tisch wurde das Forschungsmikroskop Axiovert 35 (Zeiss, Oberkochen) in invertierter Bauweise montiert. Das Mikroskop war unter anderem mit einem 20x Objektiv PH2 Neofluor 20/0,50 (unendlich)/0,17 ausgestattet. Zur Erkennung der GFP-exprimierenden Zellen wurde die Fluoreszenzleuchte VXHC 75 (Zeiss) verwendet.

Auf einem Verschiebetisch stand eine Badkammer, in der die Deckgläschen mit den HEK293-Zellen, wie oben beschrieben, mit Messpuffer („,extrazelluläre Lösung") bedeckt waren und aufgenommen werden konnten.

Durch ein kombiniertes Makro- und Mikromanipulatorensystem war es möglich, den Vorverstärker (Headstage) mit dem Halter für die Patch-Pipetten mikrometergenau zu bewegen und sich auf diese Weise der Zellmembran zu nähern. Drei über Kreuz angeordnete Verschiebetische (Narishige, Tokyo, Japan) wurden dazu mit einem 3D-Mikromanipulationsblock (Narishige) gestevert.

\subsubsection{Datenakquisition und -analyse}

Die $\mathrm{Ca}^{2+}$-Ströme wurden mit einem Patch-Clamp-Verstärker EPC 9 (HEKA, Lambrecht/Pfalz) bei Raumtemperatur $\left(20-23^{\circ} \mathrm{C}\right)$ gemessen. Die Digitalisierung erfolgte bei $20 \mathrm{kHz}$ mithilfe des EPC9. Die Steuerungs- und Akquisitionssoftware Pulse (HEKA) lief auf einem Apple Power Macintosh G3. 


\section{4 pDisplay+ybbR}

pDisplay ist ein 5,3 kb großer Vektor, mit dem Proteine auf der Zelloberfläche dargestellt und die so beispielsweise konfokal-mikroskopisch analysiert werden können.

\subsubsection{Einbau der benötigten Schnittstellen}

Im ersten Schritt wurden in den Vektor pEGFP-NI zwei neve Schnittstellen für den Restriktionsverdau mittels PCR hineinkloniert [AUSUBEL et al. 2009].

Nachdem die beiden Primer GFP-Xmal und GFP-Bglll am Computer geplant und wenig später von der Firma IBA, Göttingen, geliefert worden waren, wurde die PCR nach folgendem Protokoll durchgeführt:

02:00 $\min$ bei $94^{\circ} \mathrm{C}$

$00: 15 \mathrm{~min}$ bei $94^{\circ} \mathrm{C}$

$00: 30 \mathrm{~min}$ bei $60^{\circ} \mathrm{C} \quad 24 \mathrm{x}$

01:00 min bei $68^{\circ} \mathrm{C}$

10:00 min bei $68^{\circ} \mathrm{C}$

Anschließend erfolgte nach der Ligation des PCR-Produktes die Transformation in $\mathrm{DH} 5 \alpha$ E. coli.

\subsubsection{Einbau des GFP und Hybridisierung des ybbR-Tags}

Nach der Gewinnung der DNA pEGFP-N1+Xmal+Bglll mittels QIAprep Spin Miniprep Kit (Qiagen) aus den tranformierten E.-coli-Kolonien erfolgte ein Restriktionsverdau der DNA mit den Enzymen Bgl II und Xma I (NEB). Die mit diesen Produkten durchgeführte Gelelektrophorese resultierte in drei Banden mit den Größen 4.003 bp, 724 bp und 29 bp.

Zeitgleich erfolgte ein Restriktionsverdau des Vektors pDisplay. Die Banden in der Gelelektrophorese bestanden aus 5.319 bp bzw. 6 bp.

Die 724 bp große Bande des pEGFP-NI-Verdaus sowie die 5.319 bp große Bande des pDisplay-Verdaus wurden aus dem Agarosegel ausgeschnitten, gelgereinigt und die auf diese Weise gewonnenen DNA-Abschnitte zusammenligiert. Das Zwischenprodukt pDisplay +GFP entstand.

Danach erfolgte die Hybridisierung der beiden Oligonukleotide pDisplay-Tag- 
up und pDisplay-Tag-down, welche das ybbR-ACP-Tag beinhalteten, zur zweisträngigen DNA pDisplay+Tag.

Hierzu wurden die Oligonukleotide zunächst mithilfe des Tisch-Schüttelinkubators Thermomixer 5436 (Eppendorf, Hamburg) bei $94^{\circ} \mathrm{C}$ in SSC-Puffer denaturiert und anschließend darin langsam und kontinuierlich abgekühlt, was zur Hybridisierung der beiden Oligonukleotide führte.

Dieses Produkt wurde dann nach einem Restriktionsverdau mit Bgl II und Apa I (NEB) mit dem Vektor pDisplay+GFP zum Endprodukt pDisplay+ybbR ligiert (Roche).

Dieses Endprodukt wurde in DH5 $\alpha$ E. coli transformiert und die DNA mithilfe des Minipräp-Kits (Qiagen) gewonnen. Anschließend wurden HEK293-Zellen damit transfiziert.

Die mit pDisplay+ybbR transfizierten Zellen dienten in den nachfolgenden Experimenten als Positivkontrolle.

\subsection{Labeling von HEK293-Zellen}

\subsubsection{Vorbereitung der HEK293-Zellen}

Zunächst wurden die Zellen analog zum oben beschriebenen Vorgehen mithilfe der Calciumphosphat-Präzipitationsmethode transfiziert.

Das Präzipitationsprodukt enthielt 0,5 $\mu \mathrm{g}$ der jeweiligen Vektor-DNA (entweder ACPerbB 1, pDisplay oder $\mathrm{pCaV}_{2.1}+\mathrm{ybbR}$ ) sowie $2,5 \mathrm{mM} \mathrm{CaCl}_{2}$.

Bei Verwendung von ACPerbB 1 wurden zusätzlich 0,05 $\mu \mathrm{g}$ des Vektors pEGFP$\mathrm{N} 1$ sowie bei den Ansätzen mit $\mathrm{pCaV}_{2.1}+\mathrm{ybbR}$ analog 0,05 $\mu \mathrm{g}$ pEGFP-N1 und jeweils $0,5 \mu \mathrm{g}$ der DNA der Calciumkanal-Untereinheiten a2 $\delta$ bzw. $\beta 1 b$ hinzugegeben.

\subsubsection{Färbereaktion}

Die Färbung der HEK293-Zellen wurde 40-50 h nach der Transfektion durchgeführt.

Die CoA-Substrate CoA-547 bzw. CoA-647 (Covalys Biosciences AG, Witterswil, Schweiz) wurden zunächst in $50 \mu \mathrm{L}$ DMSO bei Dunkelheit und unter ständiger Bewegung für 10 min gelöst. Dies ergab eine Substratkonzentration von $1 \mathrm{mM}$.

Diese Lösung wurde je nach durchgeführtem Experiment im Verhältnis 1:40 bis 1:400 zum HEK293-Nährmedium hinzugeben. Dadurch entstanden verschie- 
dene Färbemedia mit Substratkonzentrationen von 2,5 $\mu \mathrm{M}$ bis $25 \mu \mathrm{M}$. Außerdem wurden $10 \mathrm{mM} \mathrm{MgCl}_{2}$ und schließlich, wiederum je nach Experiment, $0,15 \mu \mathrm{M}$ bis $1 \mu \mathrm{M}$ der Enzyme Sfp bzw. AcpS (Covalys) hinzugefügt [MOFID et al. 2004].

Im nächsten Schritt wurde das Nährmedium der auf den Deckgläschen adhärierten Zellen durch das gewählte Färbemedium ersetz† und es erfolgte eine Inkubation bei $20^{\circ} \mathrm{C}$ für 30 min bei Dunkelheit [vgl. zu diesem Vorgehen MEYER et al. 2006; YIN et al. 2005b].

Nach einem Spülschritt mit PBS konnten die Zellen im Konfokalmikroskop untersucht werden.

\subsection{Färbung von ACPerbB1-Zellen}

Die Färbereaktion erfolge analog zum oben beschriebenen Verfahren. Da diese Zellen das ACP-Tag stabil exprimierten, war im Vorfeld keine Transfektion nötig.

\subsection{Labeling von Neuronen}

\subsubsection{Virusherstellung}

Die Integration der DNA des mit dem ybbR-Tag versehenen Calciumkanals in Neuronen erfolgte mithilfe eines adenoviralen Vektors.

Die Familie der Adenoviridae umfasst Viren ohne Hülle. Ihr Genom besteht aus einer doppelsträngigen, linearen DNA. Das Kapsid dieser Viren setzł sich aus Penton- und Hexon-Kapsomeren zusammen. Die Pentone tragen Fiberproteine, die der Virusfamilie ihr typisches antennenartiges Aussehen verleihen. Diese Proteine vermitteln die Bindung an die Oberfläche der Wirtszelle und induzieren die gruppenspezifischen Antikörper.

Durch Mutationen dieser Fiberstrukturen isł es für die Adenoviren möglich, immer wieder neue Varianten zu bilden. Das komplex aufgebaute Kapsid muss, im Gegensatz zU vielen anderen unbehüllten Viren, nicht modifiziert werden.

Es existieren innerhalb der Adenovirusfamilie 47 human- und tierpathogene Virusspezies, welche bei Säugetieren, Vögeln, Reptilien und Fischen in Form von zahlreichen Subtypen vorkommen. Hauptmanifestationsorte einer Adenovirus-Infektion beim Menschen sind die Atemwege (Tonsillitis, Pharyngitis, Bronchitis, Pneumonie, Pertussissyndrom), der Urogenitalbereich (Zystitis, Genitalulzera), das Auge (Konjunktivitis, Keratokonjunktivitis) und der Gastrointestinaltrakt (v.a. Säuglingsenteritis). 
Den Namen erhielt diese Virusgruppe, weil sie bei ihrer Entdeckung im Jahre 1953 ausschließlich aus adenoidem Drüsengewebe isoliert werden konnte.

Das 26-45 kbp lange Genom der Adenoviren besitzt an beiden Enden repetitive Sequenzen (ITRs = Inverted Terminal Repeats). Es ist in mehrere Abschnitte unterteilt. Der Abschnitt El zum Beispiel codiert für zwei Proteine, welche die Transkription aktivieren, in der Wirtszelle den Eintritt in die S-Phase des Zellzyklus induzieren sowie die Apoptose dieser Zelle hemmen. Ein weiterer Abschnitt der Genoms, E2a, codiert für drei Proteine, die eine wichtige Rolle in der DNAReplikation spielen [zur Übersicht siehe: SHENK und HORWITZ 2001].

$\mathrm{Zu}$ Beginn der Virusherstellung wurden jeweils $5 \mu \mathrm{g}$ der DNA pCaV $2 . \mathrm{C}+798$ und $\mathrm{pCaV}_{2.1}+810$ mit dem Restriktionsenzym Mfe I (NEB) nach Herstellerangaben für $60 \mathrm{~min}$ bei $37^{\circ} \mathrm{C}$ verdaut.

Aus Effizienzgründen erfolgte eine Beschränkung auf die o.g. zwei Vektoren, da diese im elektrophysiologischen Experiment die besten Ergebnisse erzielt hatten.

Es folgte eine Isopropanol-Fällung [AUSUBEL et al. 2009] und anschließend ein Verdau für 90 min bei $37^{\circ} \mathrm{C}$ mit Not I (NEB).

Die anschließend durchgeführte Agarosegel-Elektrophorese zeigte eine $5.253 \mathrm{bp}$ große Bande. Diese wurde ausgeschnitten und mithilfe des Gel Extraction Kits (Qiagen) gereinigt.

Daraufhin wurde der Vektor pTracer mit dem Restriktionsenzymen Not I und ECOR I (NEB) verdaut und eine Gelelektrophorese durchgeführt. Daraufhin wurden die entstandene 6.354bp große Bande ausgeschnitten und gelgereinigt.

pTracer ist ein 6,2 kb großer, vom Säugetiervektor pCDNA3.1 abstammender Vektor, welcher mithilfe des integrierten GFPs für die visuelle Ermittlung von transformierten $E$. coli genutzt werden kann.

In diesen Vektor war bereits in einem früheren Experiment eine Hind-IIISchnittstelle mithilfe der PCR hinzugefügt worden. Die Verwendung von pTracer erfolgte aufgrund dieser Schnittstelle, da diese zuvor nicht direkt in den Vektor pCDNA3.1+ pCaV $_{2.1}$ hineinkloniert werden konnte, für die spätere Ligation mit dem Vektor pDC511 jedoch essentiell war.

Anschließend erfolgte die Ligation der erhaltenen DNA-Abschnitte von pTracer sowie $\mathrm{pCaV}_{2.1}+\mathrm{ybbR}$ mithilfe des Rapid Ligase Kits (Roche), wodurch das Zwischenprodukt „,pTracer+810" bzw. , pTracer+798“ entstand.

Es folgte nun der Verdau der DNA „pTracer+810“ und „pTracer+798“ mit den Restriktionsenzymen Xba I und Hind III sowie der DNA des Vektors pDC511 mit den Enzymen EcoR I und Hind III (NEB).

pDC51 1ist ein 3.277 bp großer Vektor, welcher eine Flp-FRT-Sequenz besitzt. Die Flp-Sequenz codiert u.a. für die Flip-Rekombinase, ein Enzym, mit dem gezielt DNA-Sequenzen in lebenden Organismen entfernt und gegen andere 
Sequenzen mit entsprechenden Erkennungsstellen ausgetauscht werden können. Dies ermöglicht eine genetische Modifikation einzelner Zellarten, ohne dass andere Gewebe davon beeinflusst werden.

Wird ein Gen nun von der FRT-Sequenz flankiert, wird dieses entfernt (Exzision) und gegen ein anderes ausgetauscht. Dies erfolgt durch die FlipRekombinase, welche die FRT-Sequenz erkennt [ZHU und SADOWSKI 1995].

Nach Gelelektrophorese sowie Ausschneiden und Reinigen der $6.657 \mathrm{bp}$ (pTracer+810 und pTracer+798) bzw. 4.069 bp (pDC511) großen Banden erfolgte die Ligation zu den Endprodukten pDC511+798 bzw. pDC511+810. Die DNA des getaggten Calciumkanals befand sich nun in der sog. „Synapsin Promoter Region" des pDC511.

Dieses Endprodukt wurde daraufhin zu SeqLab, Göttingen, zum Sequenzieren geschickt.

Nach dem Passagieren der E2T-HEK-Zellen wurden jeweils $500 \mu \mathrm{l}$ der erhaltenen Zellsuspension auf alle Wells einer 6-Well-Zellkulturplatte übertragen und bei $37^{\circ} \mathrm{C}\left(5 \% \mathrm{CO}_{2}\right)$ für $72 \mathrm{~h}$ inkubiert. Anschließend erfolgte die Transfektion dieser Zellen mithilfe der Calciumphosphat-Präzipitationsmethode mit $5 \mathrm{\mu g}$ GFP-Backbone-DNA und 2,5 $\mathrm{gg}$ pDC511+798 bzw. pDC511+810.

Die GFP-Backbone-DNA beinhaltete im Wesentlichen ein Adenovirus-Genom, dem jedoch die Sequenzen der beiden adenoviralen Genomabschnitte E1 und E2a fehlten und das durch eine GFP-Sequenz vervollständigt worden war. Dies geschah zum einen, um die Pathogenität des Virusvektors zu minimieren bzw. seine unkontrollierte Replikation zu unterbinden, und zum anderen, um durch das exprimierte GFP die infizierten Neuronen zu identifizieren [ZHOU H und BEAUDET 2000; YOUNG und NEHER 2009].

Des Weiteren besaß das GFP-Backbone-Plasmid wie pDC511 eine FRTSequenz. Dadurch konnte die von pDC511 codierte Flip-Rekombinase die korrekte Schnittstelle im GFP-Backbone-Plasmid erkennen, einen Teil der DNA entfernen und diesen durch die klonierte $\mathrm{CaV}_{2.1}$-Sequenz des pDC511+ybbR austauschen.

Da die E2T-Zellen die dem Virusvektor fehlenden Genomabschnitte El und E2a enthielten, konnte durch die o.g. Transfektion die Produktion potentiell infektiöser Adenoviren ausgelöst werden. Daher wurden die weiteren Arbeiten im S2-Labor durchgeführt.

Nach einer Inkubation bei $37^{\circ} \mathrm{C}\left(5 \% \mathrm{CO}_{2}\right)$ über $24 \mathrm{~h}$ wurde zunächst das E2TMedium ernevert. In einem Zeitraum von 14 Tagen erfolgte eine schrittweise Replikation des Virus in den transfizierten E2T-Zellen sowie eine fortschreitende Infektion, bis die Mehrzahl der Zellen einen zytopathologischen Effekt (CPE) aufwies. Dies ließ sich morphologisch an der veränderten, abgerundeten Zellform sowie der Lösung der Zellen aus dem Zellverband und der damit verbundenen aufgehobenen Adhäsion der Zellen vom Boden des Wells erkennen. Der CPE und die starke Zunahme der Fluoreszenz durch das nun vermehrt exprimierte GFP waren der Hauptindikator zur Abschätzung des Fortschritts des Infektionsprozesses. 


\subsubsection{Infektion}

Die Zellen wurden daraufhin von jedem Well separat in Falcon-Tubes (BD Biosciences, San Jose, USA) übertragen und bei $-80^{\circ} \mathrm{C}$ eingefroren. Im tiefgefrorenen Zustand wurden die Tubes zügig in einem $37^{\circ} \mathrm{C}$ warmen Bad aufgetaut und danach sofort wieder bei $-80^{\circ} \mathrm{C}$ eingefroren. Dieser Zyklus wurde insgesamt dreimal wiederholt und die Tubes dann für $10 \mathrm{~min}$ bei $10.000 \mathrm{U} / \mathrm{min}$ zentrifugiert.

Mit dem Überstand wurden weitere E2T-Zellen infiziert, welche diesmal in einer $10 \mathrm{~cm}$ Kulturschale kultiviert worden waren.

Nach ca. 5 Tagen trat auch bei diesen E2T-Zellen der CPE ein und das o.g. Procedere wurde wiederholt. Mit dem Überstand aus der Zentrifugation wurden nun E2T-Zellen einer $20 \mathrm{~cm}$ großen, konfluent bewachsenen Kulturschale infiziert. Diese Zellen wiesen wiederum nach ca. 5 Tagen mehrheitlich den CPE auf.

Im folgenden Schritt erfolgte die Extrahierung und Reinigung der Virus-DNA aus den E2T-Zellen mithilfe von Vivaspin-Zentrifugalkonzentratoren (Sartorius, Göttingen).

Schließlich wurden die Neuronen, welche zuvor auf Deckgläschen in einer 12Well-Zellkulturplatte kultiviert worden waren, mit jeweils einem der beiden Viren, Adeno798+ybbR bzw. Adeno810+ybbR, infiziert, nachdem aus jedem Well $500 \mu \mathrm{l}$ Medium entfernt worden waren. Einige Wells blieben als Kontrollen uninfiziert.

Am Folgetag wurde das entnommene Medium wieder aufgefüllt.

\subsubsection{Färbung der mit dem ybbR-ACP-Tag infizierten Neuronen}

Das Labeling der infizierten Neuronen entsprach zum größten Teil dem Verfahren zur Färbung der HEK293-Zellen. Jedoch wurde diesmal zur Herstellung des Färbemediums das Neurobasal-A Medium als Grundlage benutzt.

\subsubsection{Zusätzliches Labeling mithilfe des VGlut1-Antikörpers}

Bei dieser Reaktion wurden die Neuronen nach dem o.g. Verfahren infiziert und mithilfe des Enzyms Sfp und den CoA-Substraten CoA-547 bzw. CoA-647 (Covalys) gefärbt, jedoch anschließend mit $4 \%$ Paraformaldehyd (SigmaAldrich, St. Louis, USA) für 10 min fixiert [vgl. zum Prozess der Fixierung: YIN et al. 2005b].

Nach dreimaligem Waschen mit PBS erfolgte die Inkubation der fixierten Neuronen mit Anti-VGlut1 1:5.000 (Synaptic Systems, Göttingen), einem polyklonalen Antikörper aus Meerschweinchen gegen einen Glutamattransporter in exzitatorischen Synapsen, über Nacht. 
Am Folgetag wurden die Zellen wieder dreimal mit PBS gewaschen und danach mit dem Sekundärantikörper GaGp (goat-anti-guineapig) A647 1:500 (Invitrogen, Carlsbad, USA) für $1 \mathrm{~h}$ inkubiert. Einem weiteren Waschzyklus mit PBS folgte das sog. "Mounten" der Neuronen.

Dazu wurde ein Tropfen des Dako Fluorescence Mounting Mediums (Dako, Carpinteria, CA, USA) auf einen Objektträger aufgetragen, auf den anschlieBend ein Neuronen-tragendes Deckgläschen mit der Zellschicht nach unten gelegt wurde. Nach 30 min erfolgte eine Versiegelung mit Nagellack.

\subsubsection{Labeling der Neuronen für STED-Mikroskopie}

Auch bei diesen Experimenten kam als Primärantikörper Anti-VGlut1 1:5.000 (Synaptic Systems, Göttingen) [gegen die synaptischen Vesikel] zum Einsatz. Zusätzlich wurde als zusätzlichen Primärantikörper Anti-CaVext 1:100 (Synaptic Systems, Göttingen), einem polyklonalen Antikörper aus Kanninchen, [gegen die P/Q-Typ-Calciumkanäle] verwendet.

Dieser Antikörper basierte auf dem DIII-Antikörper, welcher u.a. die paraneoplastische zerebelläre Ataxie (PCA) verursacht (s.o.), da er Calciumkanäle reversibel inhibiert, indem er im homologen Loop der Domäne III bindet [LIAO et al. 2008].

Als Sekundärantikörper wurden Anti-Guineapig Alexa 488 1:500 (Invitrogen, Carlsbad, USA) und Anti-Rabbit Atto 647N 1:100 eingesetzt (Sigma-Aldrich, St. Louis, USA). Die o.g. Antikörper wurden mit freundlicher Unterstützung der Abteilung NanoBiophotonik von Prof. Stefan Hell am Max-Plank-Institut für biophysikalische Chemie in Göttingen zur Verfügung gestellt.

Daraufhin erfolgte wiederum das "Mounten" der Neuronen.

\subsection{Konfokale Mikroskopie}

Das im Jahre 1957 von MINSKY entwickelte Prinzip der konfokalen Mikroskopie beruht auf einer punktuellen Abtastung eines Objektes (Scan).

Durch eine Messung der Lichtintesitäten eines jeden Punktes isł die Rekonstruktion eines gesamten Bildes möglich.

Diese punktförmige Rasterung des Objektes ermöglicht es, mithilfe einer Lochblende (pinhole), welche sich direkt im Strahlengang befindet, Licht von außerhalb der Schärfeebene zu blockieren. Dies führt zu einer deutlich gesteigerten Auflösung entlang der Z-Achse.

Moderne Konfokalmikroskope arbeiten als Laser-Scanning-Mikroskope mit Lasern, die Licht mit verschiedenen Wellenlängen emittieren können. Der Laser führt zur Anregung von Fluoreszenzfarbstoffen, welche daraufhin Licht emittieren. 
Mithilfe der Lochblende gelangen nur jene Signale, welche genau aus der Fokusebene kommen, auf den lichtempfindlichen Empfänger des Mikroskops. Signalanteile aus anderen Ebenen oberhalb oder unterhalb der Fokusebene werden durch die Lochblende ausgeblendet. Der Durchmesser der Lochblende bestimmt zusammen mit dem Objektiv des Mikroskops die Dicke des optischen Schnittes. Auf diese Weise kann durch eine Summation der Bildpunkte aus der Fokusebene mithilfe des Computers eine Schichtaufnahme rekonstruiert werden.

Die Auflösung der Konfokalmikroskopie wird jedoch durch die Beugung des Lichtes (Abbe-Beugung) begrenzt, welche die Auflösung auf 1/2 (lateral) bzw. 1/4 (axial) der Wellenlänge des verwendeten Lichtes limitiert.

Für die Experimente, die dieser Arbeit zugrunde liegen, wurde das Konfokalmikroskop LSM 410 mit der Software LSM Version 3.98 (Zeiss) benutzt.

Gearbeitet wurde in einem Dunkelraum. Als Laser wurden ein Argon-Laser mit einer Wellenlänge von $488 \mathrm{~nm}$ und zwei Helium-Neon-Laser mit 543 bzw. $633 \mathrm{~nm}$ Wellenlänge eingesetzt. Als Objektive wurden ein Plan-Neofluor 40x/1,30 Oil (Zeiss) und ein Plan-APOCHROMAT 63x/1,40 Oil (Zeiss) verwendet [ähnliches Protokoll siehe MEYER et al. 2006].

\subsection{STED-Mikroskopie}

Das Stimulated-Emission-Depletion-(STED-)Mikroskop wurde von Stefan Hell am Max-Planck-Institut für biophysikalische Chemie entwickelt. Im Gegensatz zu einem gewöhnlichen Konfokalmikroskop ist die maximale Auflösung des STEDMikroskops nicht mehr durch die Abbe-Beugung begrenzt.

Bei einem konventionellen LSM-Mikroskop werden alle Moleküle, welche sich zur gleichen Zeit an der beleuchteten Stelle befinden, angeregt. Es ist daher nicht möglich zu unterscheiden, von welchem Molekül die Fluoreszenz gerade ausgeht.

Im STED-Mikroskop wird dieses Problem dadurch gelöst, dass die Moleküle zunächst durch einen fokussierten Lichtstrahl angeregt werden. Diesem ersten Strahl folgt einige Pikosekunden später, noch bevor die angeregten Farbstoffmoleküle von sich aus fluoreszieren können, ein zweiter, energieärmerer Lichtstrahl (Ausschaltestrahl).

Dieser Ausschaltestrahl führt zu einer ringförmigen „Abregung" eines Großteils der angeregten Moleküle, die am Rand des ersten Lichtstrahles liegen, noch bevor sie fluoreszieren.

Der Ring lässt sich vom Rand her dermaßen verkleinert, das eine theoretische Auflösung von nur einem Molekül, welches sich genau in der Mitte des ersten Strahls (also des Anregungsstrahls) befindet, möglich isł [zur Übersicht siehe WILLIG et al. 2006; BRETSCHNEIDER et al. 2007]. 
Für diese Versuche wurde das Mikroskop SP 5 der Firma Zeiss benutzt. Als Objektiv diente 1,4 NA 100x Oil. Es wurden ein Argon-Laser der Wellenlänge $488 \mathrm{~nm}$ sowie ein gepulster Laser der Wellenlänge $633 \mathrm{~nm}$ in Kombination mit einem Laser für den Ausschaltestrahl benutzt.

\subsection{Lösungen, Puffer, Medien}

\section{Virus storage buffer}

$\begin{array}{llll}10 & \mathrm{mM} & \mathrm{HEPES} & \text { (Sigma-Aldrich, St. Louis, USA) } \\ 250 & \mathrm{mM} & \text { Saccharose (dto.) } \\ 1 & \mathrm{mM} & \mathrm{MgCl}_{2} \quad \text { (Merck, Darmstadt) } \\ \mathrm{pH} & 7,4 & & \end{array}$

$\underline{\text { SSC-Puffer }}$

$\begin{array}{llll}3 & \mathrm{M} & \mathrm{NaCl} & \text { (Merck, Darmstadt) } \\ 0,3 & \mathrm{M} & \text { Citrat } & \text { (Sigma-Aldrich, St. Louis, USA) } \\ \mathrm{pH} & 7,00 & & \end{array}$

E. coli Agarplatten

$40 \mathrm{ml}$ LB-Medium (Lysogeny broth) (Invitrogen, Carlsbad, USA):

Hefeextrakt $(5 \mathrm{~g} / \mathrm{l})$

Trypton $(10 \mathrm{~g} / \mathrm{l})$

Natriumchlorid $(0,5-10 \mathrm{~g} / \mathrm{l})$

0,8 g Agarose (Invitrogen, Carlsbad, USA)

\section{E. coli Nährmedium}

$50 \mathrm{ml}$ LB-Medium (Invitrogen, Carlsbad, USA)

$100 \mu \mathrm{l} \quad$ Ampicilin $\quad$ (Sigma-Aldrich, St. Louis, USA) 


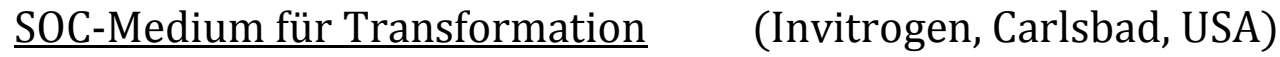

- Hefeextrakt 0,5\% (5 g/l)

- Trypton $2 \%(20 \mathrm{~g} / \mathrm{l})$

- 10 mM Natriumchlorid $(0,6 \mathrm{~g} / \mathrm{l})$

-2,5 mM Kaliumchlorid (0,2 g/l)

- 10 mM Magnesiumchlorid

- 10 mM Magnesiumsulfat

\section{Messlösungen}

${ }_{\Perp}$ Extrazelluläre Lösung“ 10x konzentriert

170 mM TEA-Cl (Fluka, Buchs, $\mathrm{CH}$ )

$5 \quad \mathrm{mM} \quad \mathrm{BaCl}_{2} \quad$ (Sigma-Aldrich, St. Louis, USA)

$1 \quad \mathrm{mM} \quad \mathrm{MgCl}_{2} \quad$ (Merck, Darmstadt)

$10 \mathrm{mM}$ HEPES (Sigma-Aldrich, St. Louis, USA)

$10 \mathrm{mM}$ Glukose (dto.)

$\mathrm{pH} \quad 7,3$

Osmolarität: 305 mosmol/l

„Intrazelluläre Lösung“ $1 \mathrm{x}$ konzentriert

$156 \mathrm{mM} \quad \mathrm{CsCl} \quad$ (Merck, Darmstadt)

10 mM TEA-Cl (Fluka, Buchs, $\mathrm{CH}$ )

10 mM EGTA (Sigma-Aldrich, St. Louis, USA)

$0,5 \quad \mathrm{mM} \quad \mathrm{GTP} \quad$ (dto.) 
$3 \quad \mathrm{mM} \quad$ MgATP $\quad$ (dto.)

10 mM HEPES (dto.)

$\mathrm{pH} \quad 7,3$

Osmolarität: 305 mosmol/l

Zur Beschichtung der Deckgläschen

Poly-D-Lysin $\quad$ (Sigma-Aldrich, St. Louis, USA)

Nährmedium für HEK293-Zellen und ACPerbB1-Zellen

$500 \mathrm{ml}$ DMEM (Dulbecco's Modified Eagle's Medium) (Gibco/Invitrogen, Grand Island, USA)

$50 \mathrm{ml}$ FBS (Fetal Bovine Serum) (dto.)

$1.000 \mu \mathrm{l} \quad$ Penicillin/Streptomycin (10.000 U Penicillin und $10 \mathrm{mg}$ Streptomycin) (Roche, Mannheim)

Zum Spülen der Zellen

PBS (Phosphate Buffered Saline 1x) (Gibco/Invitrogen, Grand Island, USA)

Nährmedium für E2T-HEK-Zellen

$500 \mathrm{ml}$ DMEM (Gibco/Invitrogen, Grand Island, USA)

$50 \mathrm{ml}$ FBS (dto.)

$1.000 \mu \mathrm{l} \quad$ Penicillin/Strepromycin (10.000 U Penicillin und $10 \mathrm{mg}$ Streptomycin) (Roche, Mannheim)

$500 \mu \mathrm{l} \quad$ Puromycin $\quad$ (Gibco/Invitrogen, Grand Island, USA)

$1.000 \mu \mathrm{l} \quad \mathrm{G} 418 \quad$ (dto.) 
Neuronenmedium (Neurobasal-A-Medium)

$500 \mathrm{ml} \quad$ Neurobasal-A (Gibco/Invitrogen, Grand Island, USA)

$10 \mathrm{ml}$ B27-bSupplement (dto.)

5 ml Gluatmax I-Stock (dto.)

$1.000 \mu \mathrm{l} \quad$ Penicillin/Streptomycin (Roche, Mannheim)

TAE-Puffer (Tris-Acetat-EDTA-Puffer) 50x

$2 \quad$ M Trizma ${ }^{\circledR}$ base $(242 \mathrm{~g} / \mathrm{l}) \quad$ (Fluka, Buchs, $\left.\mathrm{CH}\right)$

3,5 M $\quad \mathrm{H}_{3} \mathrm{COOH}$ (dto.)

0,05 M EDTA (Sigma-Aldrich, St. Louis, USA)

Agarosegel (1\%)

$50 \mathrm{ml}$ TAE-Puffer (Tris-Acetat-EDTA-Puffer)

0,5 g Agarose (Invitrogen, Carlsbad, USA)

$5 \quad \mu \mathrm{l} \quad$ Ethidiumbromid $10 \mathrm{mg} / \mathrm{ml} \quad$ (Roth, Karlsruhe)

HBS (HEPES buffered saline) $2 \mathrm{x}$

$280 \mathrm{mM} \quad \mathrm{NaCl} \quad$ (Merck (Darmstadt)

$1,5 \quad \mathrm{mM} \quad \mathrm{Na}_{2} \mathrm{HPO}_{4} \quad$ (dto.) 
50 MM HEPES

(Sigma-Aldrich, St. Louis, USA)

pH $\quad 7,05$ 


\section{Ergebnisse}

\subsection{Vektor $\mathrm{pCaV}_{2.1}+\mathrm{ybbR}-\mathrm{ACP}-\mathrm{Tag}$}

Zur Herstellung der Vektoren pCaV $2.1+y b b R ~(786,792,798$ bzw. 810) war es zunächst nötig, das ACP-ybbR-Tag in den Vektor pUC 19+CaV zu integrieren.

Dies führte im ersten Schritt zur Herstellung der vier Vektoren pUC19+786, pUC19+792, pUC19+798 und pUC19+810.

Diese Vektoren unterschieden sich in ihrer DNA-Sequenz dahingehend, dass das ACP-ybbR-Tag an unterschiedlichen Positionen der CalciumkanalSequenz, welche zuvor in den Vektor eingefügt worden war, hineinkloniert worden war.

Nach erfolgter PCR, Transformation und DNA-Aufreinigung erbrachte die Gelelektrophorese nach einem analytischen Verdau aller vier Vektoren mit dem Restriktionsenzym Hind III zwei Banden der Größe 3.479 bp bzw. 1.617 bp (Abb. 3.1). Der erste Schnitt dieses Enzyms erfolgte im Calciumkanal codierenden Bereich der pUC19+ybbR, der zweite im Bereich der Sequenzen des vorher integrierten ybbR-Tags.

a.)

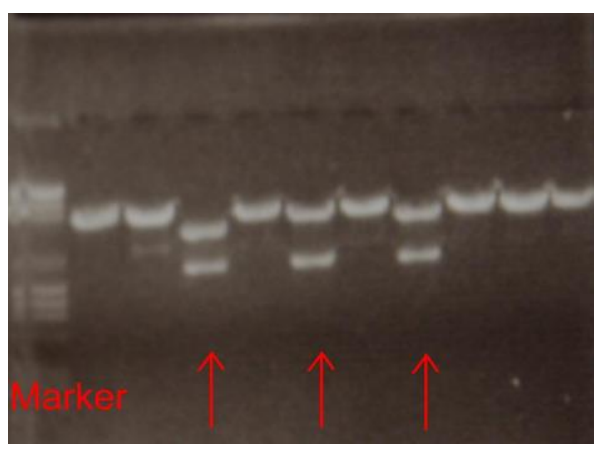

b.)

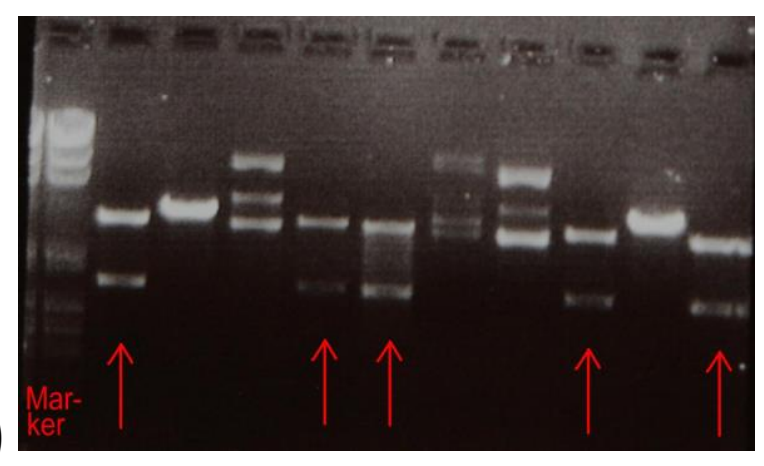

c.)

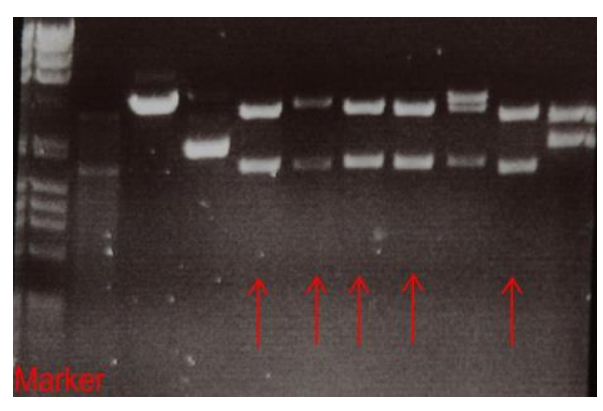

Abb. 3.1 Gelelektrophorese pUC19+ybbR

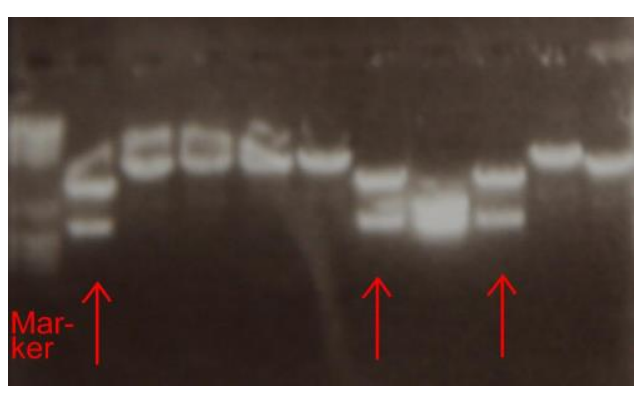

a.) $\mathrm{pUC} 19+786$

c.) $\mathrm{pUC} 19+798$

b.) $\mathrm{pUC} 19+792$

d.) $\mathrm{pUC} 19+810$

Erfolgreich integriertes ybbR-Tag ( $\uparrow$ 
Die anschließend durchgeführte Sequenzierung bestätigte, dass die jeweiligen ybbR-Tags erfolgreich in die Calciumkanal-Sequenz des Vektors pUC19+CaV integriert worden waren, sodass die weiteren Schritte zur Herstellung der Vektoren $\mathrm{pCaV}_{2.1}+\mathrm{ybbR}$ erfolgen konnten (Abb. 3.2).

ggaaatttcataccacetgetttgaagaggggacagacgacatcGATCTCTTGAATTATTGTAGTAAGCTGCGcagggtgagtcg

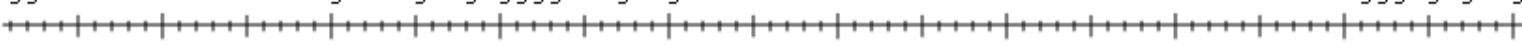
cetttaaagtatggtggacgaaactetecetgtetgetgtagCTAAGAGACTTAAATACGATCATCGAACGCgtcceactcagc

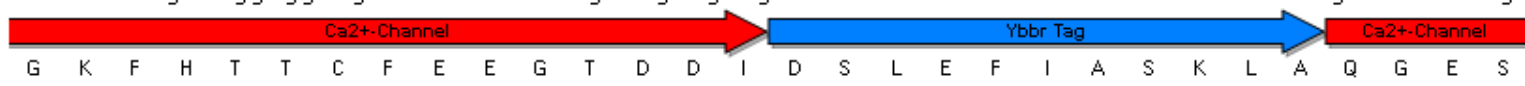
$\operatorname{Psp} 0 \mathrm{MI}$ Apa I

ceagetecgtgtgggacagaggagectgecegeacetgececaacgggaceaaatgteagecgtactgggaagggeceaacaacggeatc

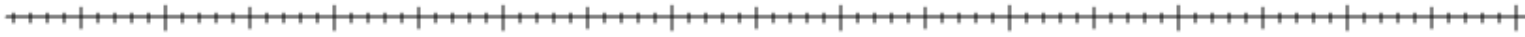
ggtegaggeacacectgtetecteggaegggegtggaeggggttgecetggtttacagteggeatgacectecegggttgttgecgtag

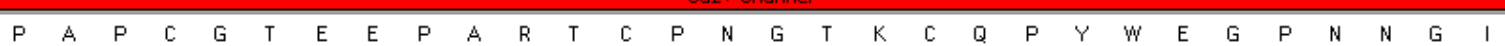

Abb. 3.2 Sequenz von pUC19+ybbR (beispielhaft pUC19+798 dargestellt)

Die Endprodukte $\mathrm{pCaV}_{2.1}+\mathrm{ybbR}$ entstanden schließlich durch Verdau der Vektoren pUC19+ybbR (786, 792, 798 bzw. 810) und pCDNA3.1+ $\mathrm{CaV}_{2.1}$ durch die Restriktionsenzyme Nhe I und Xho I und anschließender Ligation der $2.419 \mathrm{bp}$ bzw. ca. 10.000 bp großen Fragmente. pCDNA3.1+ $\mathrm{CaV}_{2.1}$ enthielt dabei unter anderem die Sequenz der $\alpha_{1}$-Untereinheit $\mathrm{CaV}_{2.1}$ des P/Q-Typ-Calciumkanals.

Nach der Transformation und DNA-Aufreinigung zeigten sich im folgenden analytischen Verdau mit dem Restriktionsenzym Hind III die erwarteten Banden, welche Fragmenten mit ca. 12.000 bzw. 900 Basenpaaren entsprachen (Abb. 3.3).

a.)

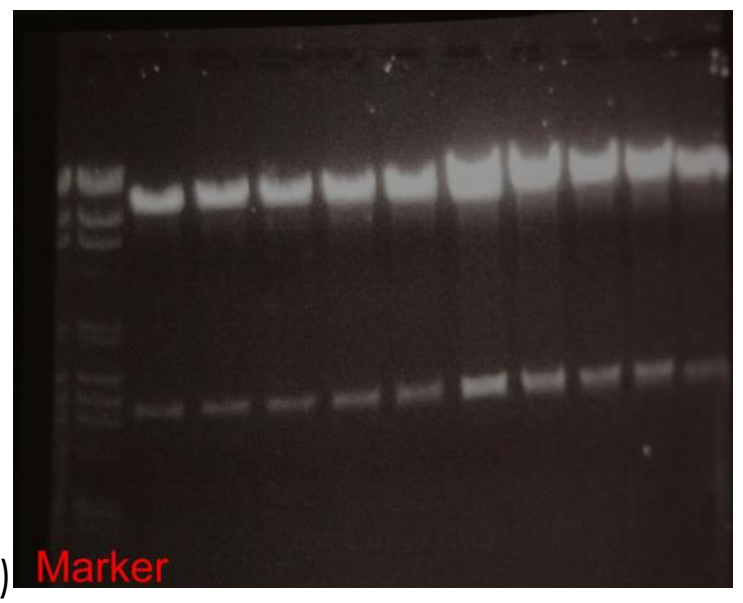

b.)

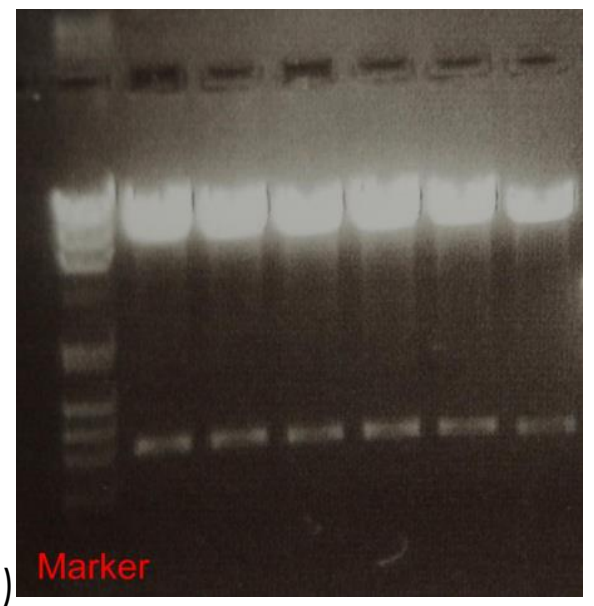




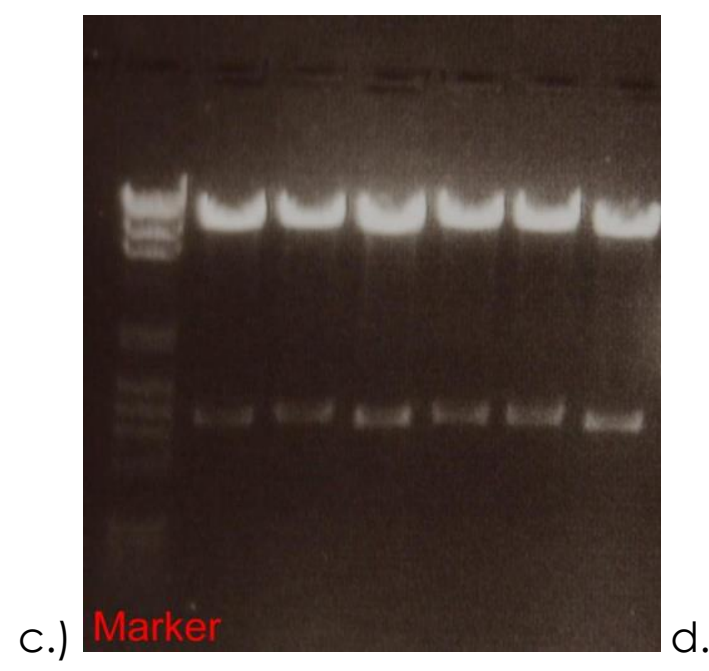

Abb. 3.3 Gelelektrophorese pCaV $_{2.1}+y b b R$

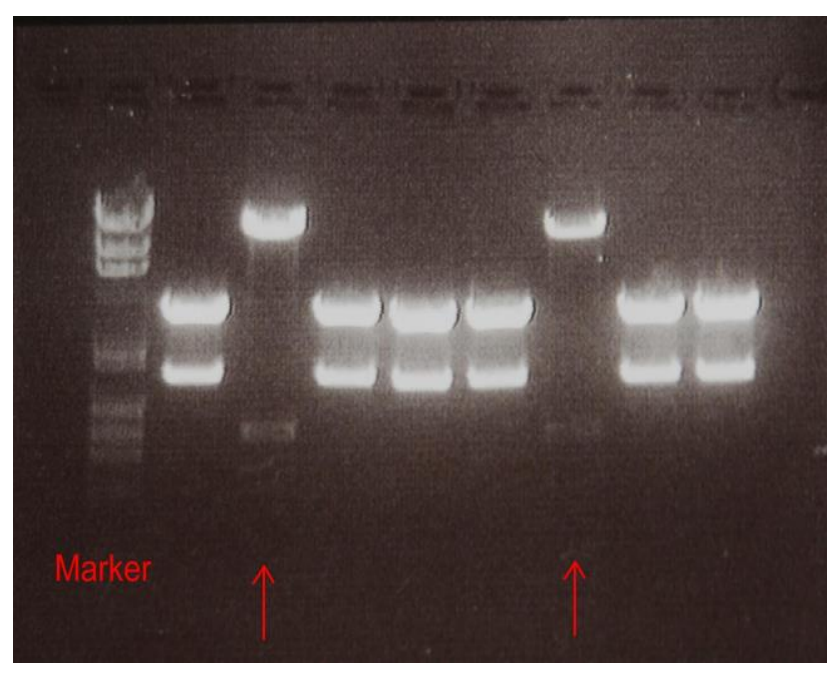
a.) $\mathrm{pCaV}_{2.1}+786$
b. $\left.\mathrm{pCaV}_{2.1}\right)+792$

c.) $\mathrm{pCaV}_{2.1}+798$

d.) $\mathrm{pCaV}_{2.1}+810$

Da durch die vorangegangene Sequenzierung der Vektoren pUC19+ybbR bewiesen worden war, dass die Sequenz des ybbR-Tags erfolgreich in diese Vektoren integriert werden konnte, war davon auszugehen, dass sich dieses Tag nun auch in den neu entstandenen Vektoren $\mathrm{pCaV}_{2.1}+\mathrm{ybbR}$ befand. Aus diesem Grund wurde auf eine nochmalige Sequenzierung verzichtet.

Es schlossen sich daraufhin Transfektionen der HEK293-Zellen mit den jeweiligen Vektoren pCaV $2.1+y b b R(786,792,798$ bzw. 810) sowie der DNA der Calciumkanal-Untereinheiten $\alpha 2 \delta$ bzw. $\beta 1 \mathrm{~b}$ an, mit dem Ziel, ybbR-ACP-Tagtragende Calciumkanäle auf der Zellmembran zu exprimieren.

Diese transfizierten Zellen wurden in den folgenden Versuchen zur Messung von P/Q-Typ-Calciumkanalströmen mittels der Patch-Clamp Technik sowie zur optischen Darstellung dieser Kanäle verwendet.

Des Weiteren dienten die Vektoren als Grundlage zur Herstellung von Viren zur Infektion von Neuronen.

\subsection{Vektor pDisplay+ybbR-ACP-Tag}

Das Ziel war es, die Sequenzen des GFP sowie des ybbR-ACP-Tags an das Nterminale Ende der murinen Ig-k-Ketten-Sequenz des Vektors pDisplay und damit gleichzeitig an das C-terminale Ende der benachbarten Sequenz des „,platelet derived growth factor receptor" (PDGFR) zu klonieren.

Auf diese Weise sollten beide Proteine über den sekretorischen Pfad an die Zellmembran gelangen, wo sie mithilfe des PDGFR an der extrazellulären Seite der Zellmembran verankert werden konnten.

Nach erfolgreicher PCR des Vektors PEGFP-N1 mit den Primern GFP-Xma I und GFP-Bgl II und dem darauf folgenden Verdau sowohl dieses Produktes als 
auch des Vektors pDisplay mit den Restriktionsenzymen Xma I und Bgl II wurden nach Durchführung der Gelelektrophorese zunächst die beiden entstandenen $724 \mathrm{bp}$ (pEGFP-N1) und $5.319 \mathrm{bp}$ (pDisplay) großen Banden isoliert und anschließend zum Zwischenprodukt pDisplay+GFP ligiert.

Zum Abschluss erfolgte die Hybridisierung zweier Oligonukleotide, welche aus der ybbR-Sequenz und korrespondierenden Schnittstellen für die Restriktionsenzyme Bgl II und Apa I zusammengesetzt worden waren, zu einem Doppelstrang und dessen Ligation mit dem vorher mithilfe von Bgl II und Apa I verdauten Vektor pDisplay+GFP zum Endprodukt pDisplay+ybbR.

Der zur Überprüfung des Resultats durchgeführte analytische Verdau mithilfe der Restriktionsenzyme BsrG I und Hind III ließ erkennen, dass die DNA

pDisplay+ybbR durch beide Enzyme insgesamt dreimal geschnitten worden war.

Hind III schnitt jeweils einmal in der Sequenz des ursprünglichen pDisplays sowie des ybbR-Tags und die Sequenz des GFPs wurde einmal durch das Restriktionsenzym BsrG I geschnitten.

Nach der Durchführung der Gelelektrophorese entstanden die drei erwarteten Banden mit einer Größe von 5.150 bp, 196 bp bzw. 73 bp (Abb. 3.4).

Die Sequenzierung bestätigte den korrekten Einbau des ybbR-Tags sowie des GFPs in den Vektor pDisplay. Das Tag befand sich nun, wie vorgesehen, zwischen den Sequenzen der Ig-K-Ketten und der GFP-Sequenz, welche wiederum C-terminal des dem PDGFR vorgelagerten Myc-Epitops lokalisiert war (Abb. 3.5).

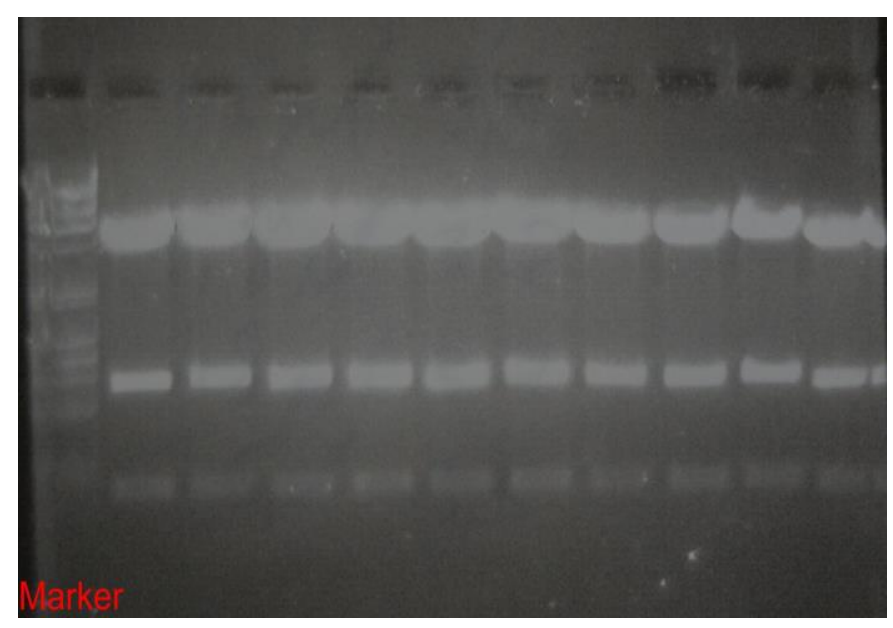

Abb. 3.4 Gelelektrophorese pDisplay+ybbR 


\section{a.)}

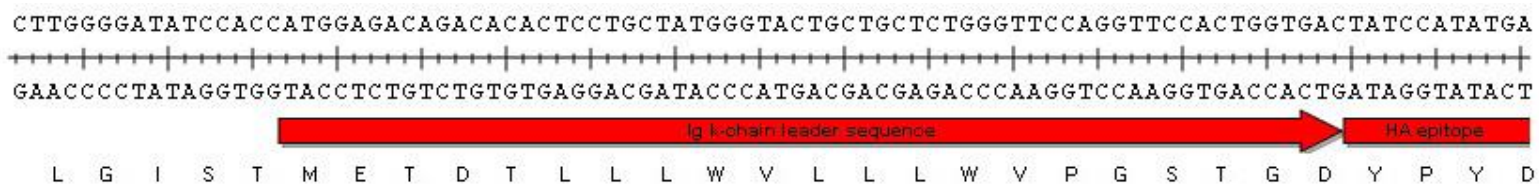

Apa I Hir dlll $B g^{\prime} \|$

TGTTCCAGATATGCTGGGGCCCttGATTCTCTTGAATTATTGCTAGTAAGCTTGCGACCGGTAGATCTATGGTGAGCAAGGGCGAGGA

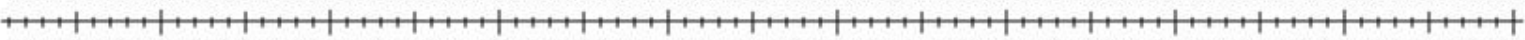
ACAAGGTCTAATAGACCCCGGGaACTAAGAGACTTAATAACGATCATTCGAACGCTGGCCATCTAGATACCACTCGTTCCCGCTCCT HA Epitope $>$ MCS

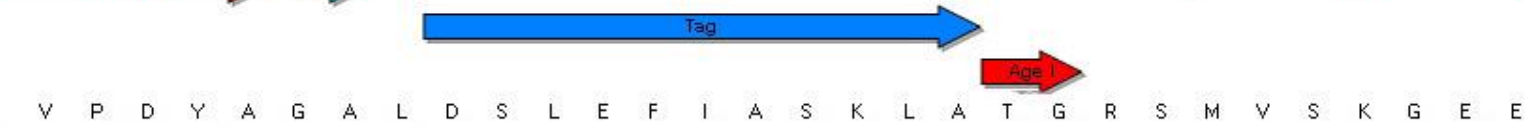

GCTGTTCACCGGGGTGGTGCCCATCCTGGTCGAGCTGGACGGCGACGTAAACGGCCACAAGTTCAGCGTGTCCGGCGAGGGCGAGGGCGA

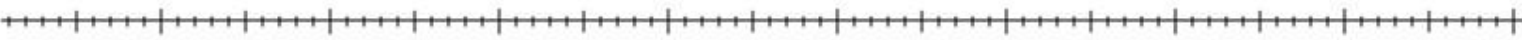
CGACAAGTGGCCCCACCACGGGTAGGACCAGCTCGACCTGCCGCTGCATTTGCCGGTGTTCAAGTCGCACAGGCCGCTCCCGCTCCCGCT

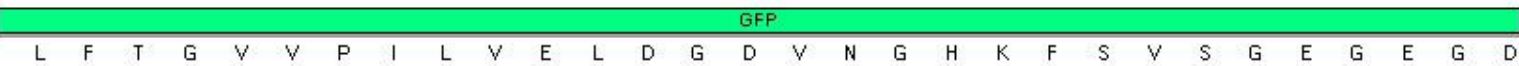

\section{b.)}

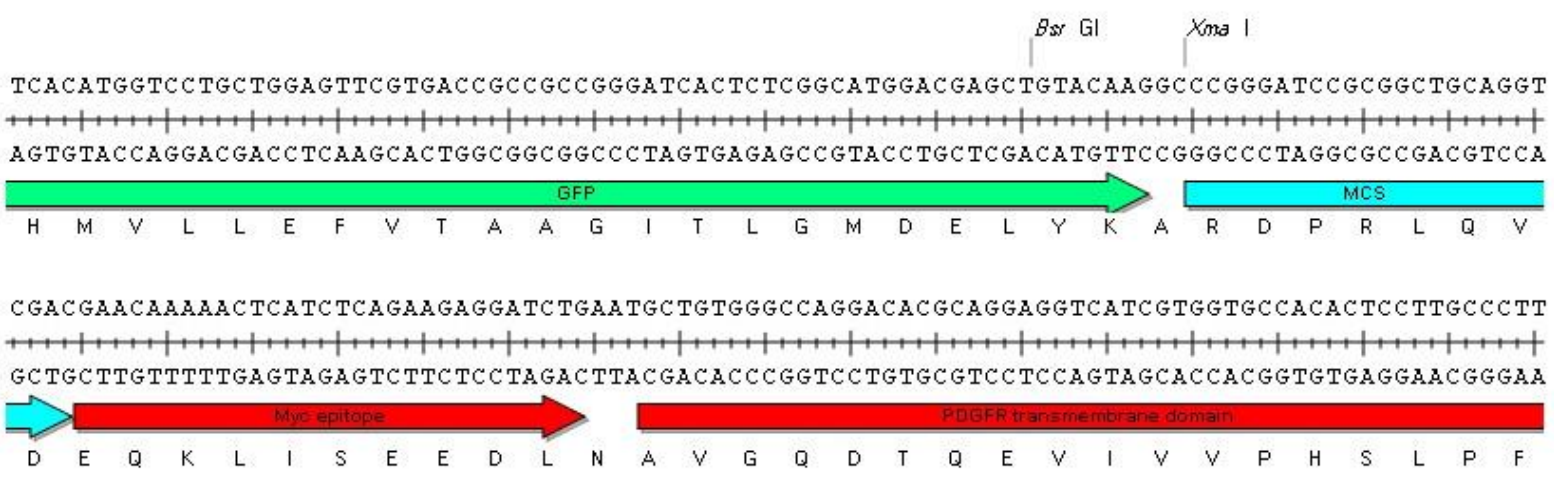
Abb. 3.5 Sequenz pDisplay+ybbR
a) Position 721-990
b) Position 1531-1710

\subsection{Virusherstellung}

Nach dem Restriktionsverdau von pCaV $2.1+798$ und $\mathrm{pCaV}_{2.1}+810$ mit den Enzymen Not I und Mfe I und einem Verdau des Vektors pTracer mit den Enzymen ECoR I und Not I wurden zunächst die 5.253 bp $\left(\mathrm{CaV}_{2.1}\right)$ und $6.354 \mathrm{bp}$ (pTracer) großen Fragmente ausgeschnitten, gereinigt und miteinander ligiert.

Die Zwischenprodukte pTracer+798 bzw. pTracer+810 wurden daraufhin mit den Restriktionsenzymen Xba I und Hind III und der Vektor pDC511 mit den Enzymen Nhe I und Hind III verdaut und die 6.657 bp (pTracer+810 bzw. pTracer+798) bzw. 4.069 bp (pDC51 1) großen Banden isoliert, gereinigt und zu den Endprodukten pDC51 1+798 bzW. pDC51 1+810 ligiert. 
Die Sequenzierung von pDC511+798 bzw. pDC511+810 bestätigte wiederum den korrekten Einbau des ybbR-Tags. Dieses war auch hier erfolgreich in die Calciumkanal-Sequenz, welche zuvor in den Vektor pDC511 hineinkloniert worden war, integriert worden (Abb. 3.6).

Hin dIII

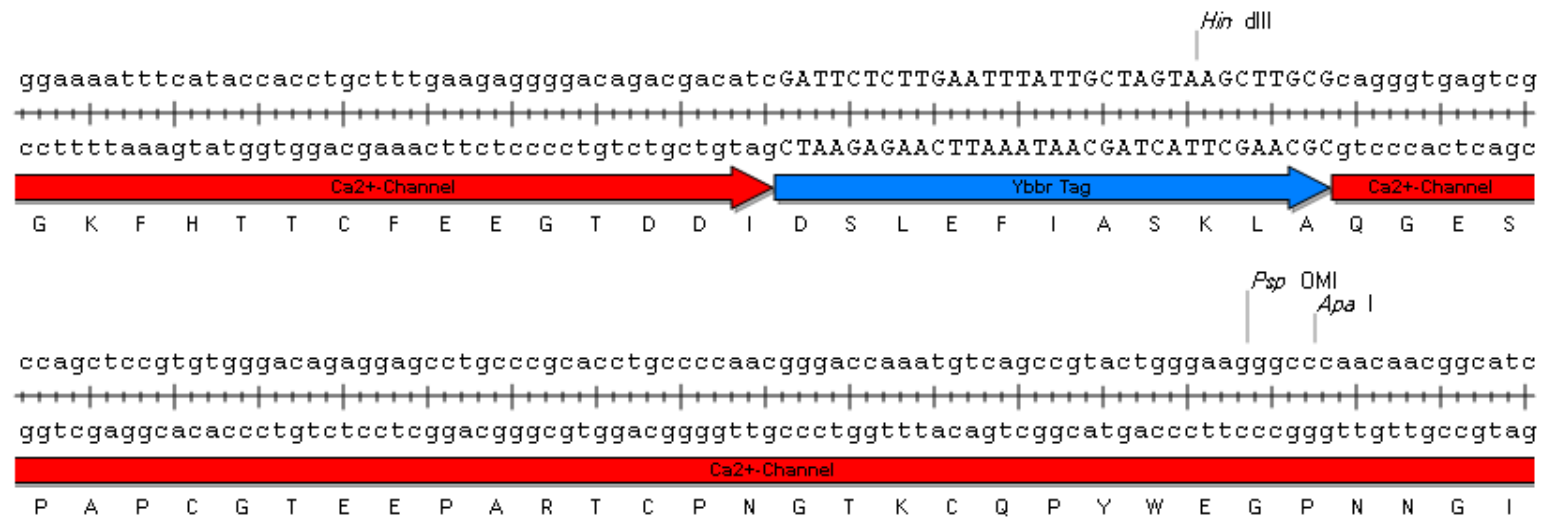

Abb. 3.6 Sequenz von pDC511+798

Daraufhin konnte der nächste Schritt der Virusherstellung, das Transfizieren der E2T-Zellen mit den Vektoren pDC511+798 bzw. pDC511+810 sowie GFPBackbone durchgeführt werden.

Ungefähr 14 Tagen nach der Transfektion ließ sich bei der Mehrzahl der Zellen der durch die Virusinfektion bedingte Zytopathologische Effekt (CPE) erkennen.

Die auf diese Weise replizierten Adenoviren dienten im Verlauf zur weiteren Infektion der mit E2T-Zellen konfluent bewachsenen $10 \mathrm{~cm}$ bzw. $20 \mathrm{~cm}$ im Diameter messenden Kulturplatten sowie der Neuronen.

Nach der Zugabe der Viren und einer Inkubationszeit von 5 Tagen war ein Großteil der Neuronen infiziert, erkennbar an der Expression des GFP der überwiegenden Mehrheit der Zellen.

Es wurde im Folgenden aufgrund der im Vorfeld vollzogenen Klonierungsschritte davon ausgegangen, dass alle fluoreszierenden Zellen auch den klonierten Calciumkanal mit dem ybbR-Tag exprimierten.

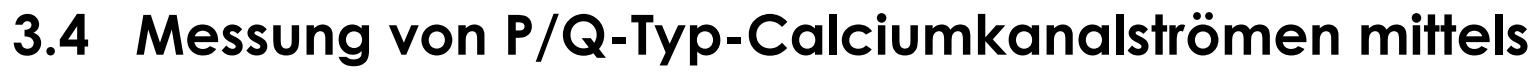 der Patch-Clamp-Technik}

Nachdem die HEK293-Zellen über die Calciumphosphat-Präzipitationsmethode mit einem der vier $\mathrm{pCaV}_{2.1}+\mathrm{ybbR}$-Vektoren $\left(\mathrm{pCaV}_{2.1}+786, \mathrm{pCaV}_{2.1}+792\right.$, $\mathrm{pCaV}_{2.1}+798, \quad \mathrm{pCaV}_{2.1}+810$ ) bzW. pCDNA3.1+CaV 2.1 (mit der Wildtyp- $\alpha_{1}$ Untereinheit) und den Calciumkanaluntereinheiten $\alpha 2 \delta$ bzw. $\beta 1 \mathrm{~b}$ sowie mit 
dem Vektor pEGFP-N 1 transfiziert worden waren, zeigte sich, dass ca. $10 \%$ der auf den Deckgläschen wachsenden HEK293-Zellen das GFP und damit höchstwahrscheinlich auch die drei Calciumkanal-Untereinheiten exprimierten, sodass von einer erfolgreichen Transfektion ausgegangen werden konnte.

Nach dem Spülen der Zellen mit PBS am Tag nach der Transfektion erfolgte am dritten Tag die Messung des durch die Calciumkanäle fließenden Stroms mithilfe der Patch-Clamp-Methode. Zu beachten war hierbei, dass der kompensierte Serienwiderstand nicht mehr als $5 \mathrm{M} \Omega$ betrug, da bei diesem Wert erfahrungsgemäß der Widerstand noch nicht so hoch ist, um den zu messenden Strom deutlich zu beeinflussen.

Der Serienwiderstand bezeichnet dabei den Zugangswiderstand zur Zelle, also den Widerstand zwischen Pipette und Zelle.

Eine Voraussetzung war, dass das Seal, das von der Pipettenspitze angesaugte Membranstück, mindestens einen Widerstand von 1 G $\Omega$ (Gigaseal) aufweisen sollte. Nach Eröffnung der Zellmembran wurde des Weiteren darauf geachtet, dass der Wert des Widerstandes möglichst nicht unter $500 \mathrm{M} \Omega$ fiel.

Für die Messung wurde die HEK293-Zelle bei einem Haltepotential von -80mV "geklemmt" (Clamp).

Die Auswertung der Messungen erfolgte unter Berücksichtigung des Parameters "Maximaler Stromfluss" sowie des Anteils der gemessenen HEK293-Zellen, in denen sich ein durch Calciumeinstrom induzierter Strom messen ließ, an der Gesamtzahl aller gemessenen HEK293-Zellen.

Insgesamt wurden 164 Zellen für die Messung von Calciumkanalströmen mittels der Patch-Clamp Technik eingesetzt und es konnten auf diese Weise 50 durch Calciumeinstrom induzierte elektrische Ströme gemessen werden.

Sowohl die gemessenen durchschnittlichen Maximalströme als auch das Verhältnis zwischen gemessenen Zellen mit und ohne durch $\mathrm{Ca}^{2+}$-Einstrom induzierten elektrischen Strom wiesen deutliche Unterschiede zwischen den jeweiligen Vektoren auf (S. 59, Tabelle 3.1 und Abbildung 3.12).

Insgesamt wurden 44 Zellen, welche mit dem Vektor $\mathrm{pCaV}_{2.1}+786$ transfiziert worden waren, gemessen, die 10 auswertbare Datensätze erbrachten. Dies entsprach einem Anteil von 0,227 der HEK293-Zellen, welche einen $\mathrm{Ca}^{2+}$-Strom aufwiesen, an der Gesamtzahl aller gemessenen Zellen.

Um 10 Datensätze für mit dem Vektor $\mathrm{pCaV}_{2.1}+792$ transfizierte Zellen zu erhalten, wurden insgesamt 31 Zellen gemessen, der Quotient betrug somit 0,323 .

HEK293-Zellen, welche mit dem Vektor $\mathrm{pCaV}_{2.1}+798$ transfiziert worden waren, wiesen einen Quotienten von 0,3125 auf. Es wurden insgesamt 32 Zellen für 10 auswertbare Datensätze gemessen.

Der Anteil der HEK293-Zellen, welche mit dem Vektor pCaV ${ }_{2.1}+810$ transfiziert wurden, betrug 0,33 , da diesmal insgesamt 30 Zellen gemessen werden muss- 
ten, um wiederum 10 Datensätze auswerten zu können.

Zur Kontrolle erfolgte die Messung der Ströme mit HEK293-Zellen, welche die $\mathrm{CaV}_{2.1}$-Calciumkanal-Wildtyp-Untereinheit exprimierten. Um hier wiederum 10 $\mathrm{Ca}^{2+}$-Ströme analysieren zu können, wurden insgesamt 27 Zellen gemessen, der Quotient betrug in diesem Fall 0,37 (S. 59, Abbildung 3.13 und Tabelle 2).

Da insgesamt 164 HEK293-Zellen gemessen wurden, um $50 \mathrm{Ca}^{2+}$-Ströme auswerten zu können, entspricht dies einem Gesamtanteil an Zellen, bei denen ein durch Calciumeinstrom induzierbarer elektrischer Strom gemessen werden konnte, von 30,5\%.

Die Analyse der Maximalströme ergab folgendes Bild: Der durchschnittliche Maximalstrom bei Benutzung des Vektors $\mathrm{pCaV}_{2.1}+786$ betrug $226 \mathrm{pA}$ (Beispiel Abb. 3.7), bei Verwendung des Vektors $\mathrm{pCaV}_{2.1}+792271 \mathrm{pA}$ (Beispiel Abb. 3.8). Mit dem Vektor $\mathrm{pCaV}_{2.1}+798$ ließ sich eine durchschnittlicher Maximalstrom von $467 \mathrm{pA}$ messen (Beispiel Abb.3.9) und der Maximalstrom beim Vektor $\mathrm{pCaV}_{2.1}+810$ betrug $491 \mathrm{pA}$ (Beispiel Abb. 3.10).

Wiederum wurde zum Vergleich der durchschnittliche Maximalstrom herangezogen, der in HEK293-Zellen gemessen wurde, die mit dem $\mathrm{pCaV}_{2.1}$-WildtypVektor $\left(\mathrm{pCDNA3.1}+\mathrm{CaV}_{2.1}\right)$ transfiziert worden waren. Dieser betrug $668 \mathrm{pA}$ (Beispiel Abb. 3.11).

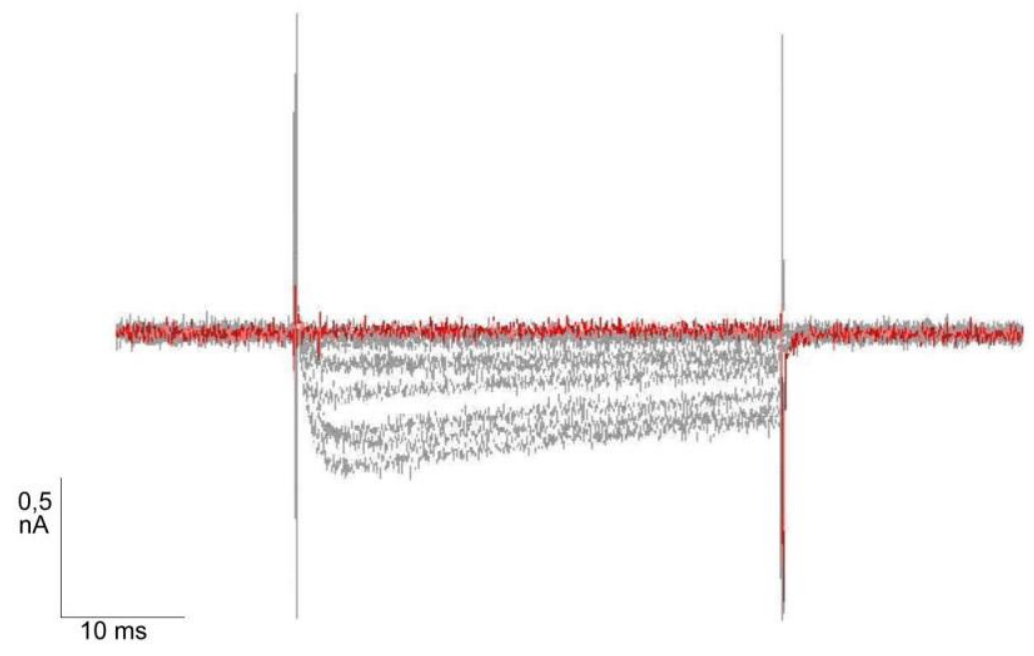

Abb. $3.7 \mathrm{pCaV}_{2.1}+786$ (Messung 5) 


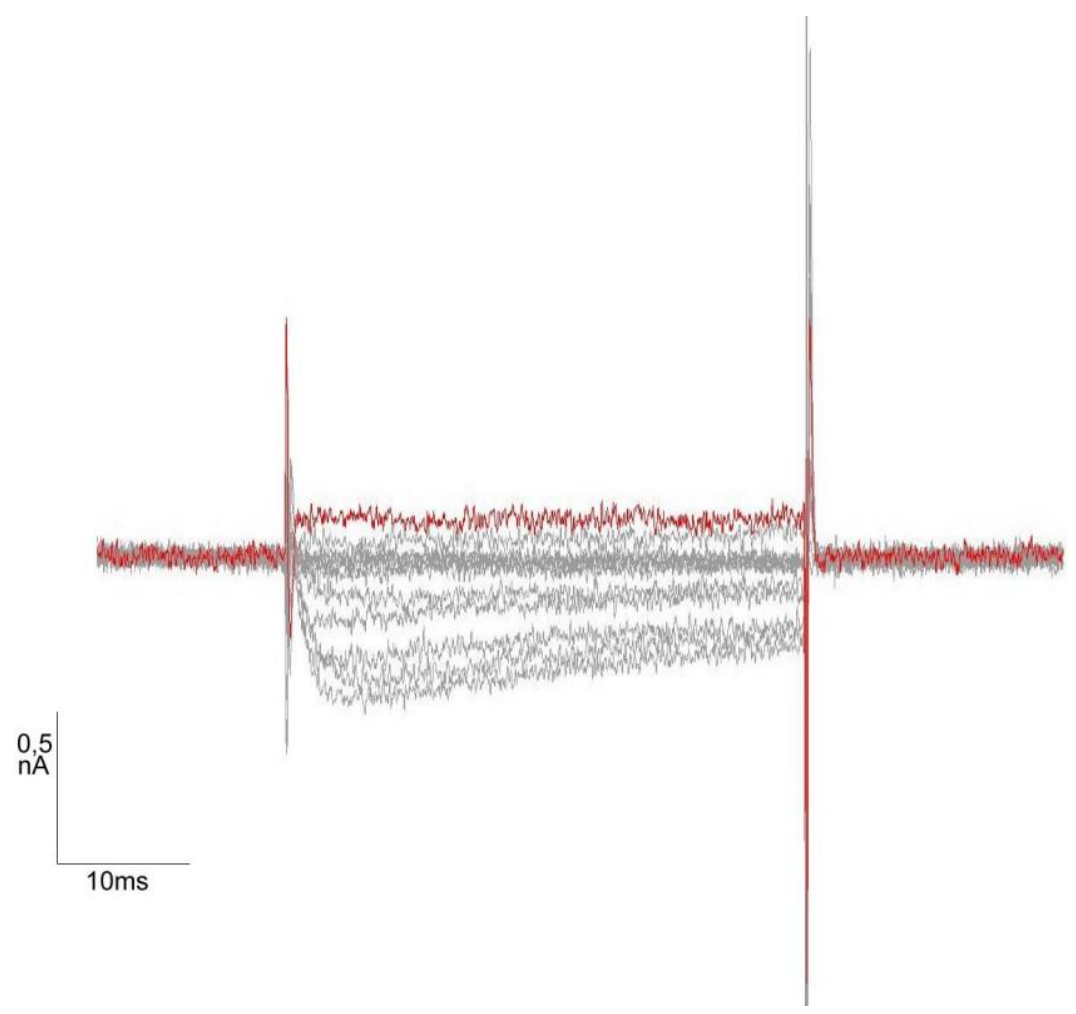

Abb. 3.8 $\mathrm{pCaV}_{2.1}+792$ (Messung 4)

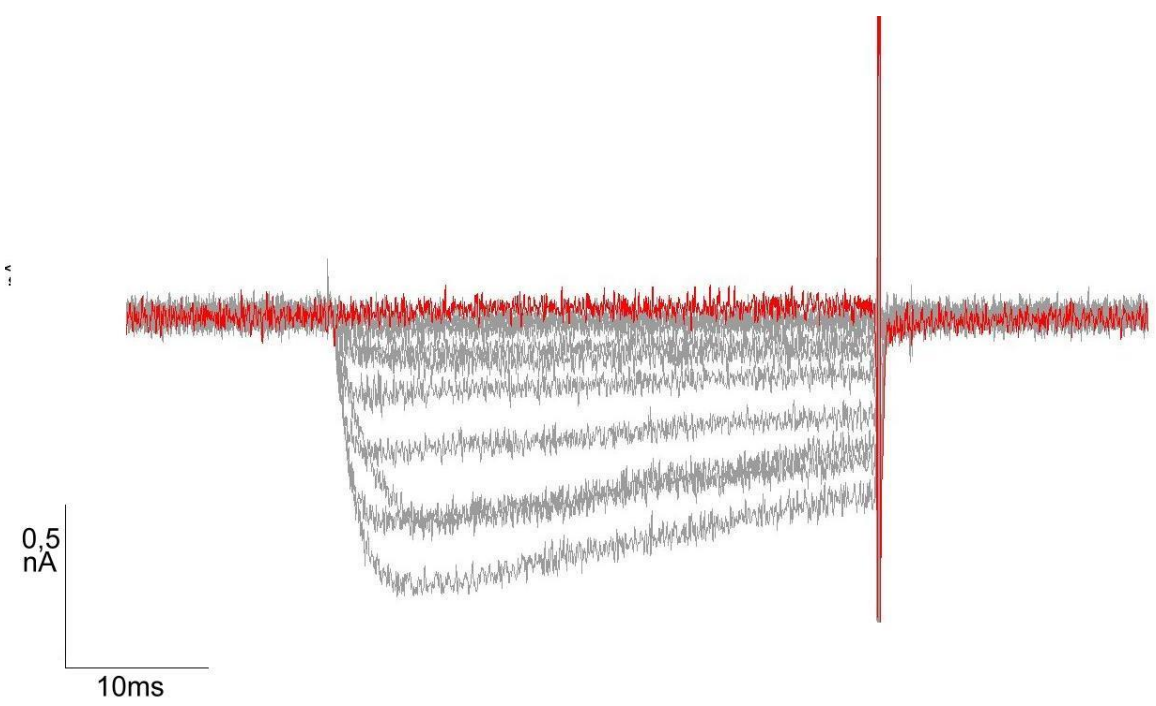

Abb. 3.9 pCaV $2.1+798$ (Messung 3) 


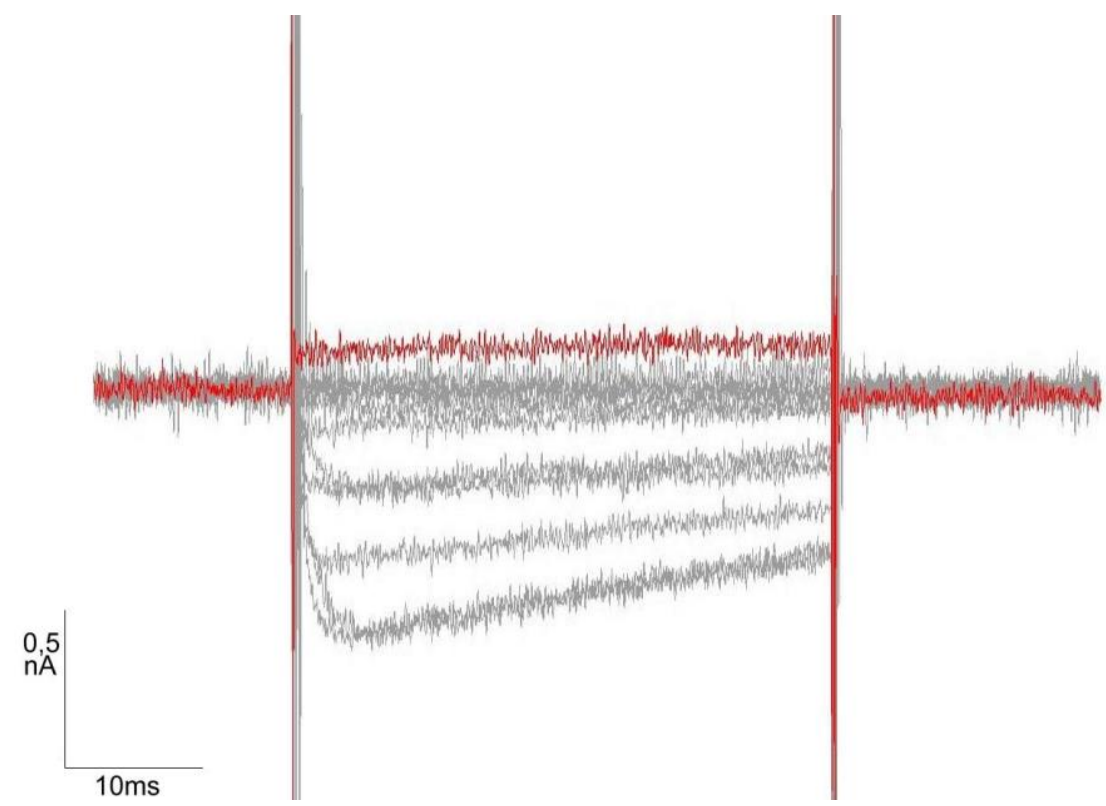

Abb. 3.10 $\mathrm{pCaV}_{2,1}+810$ (Messung 1)

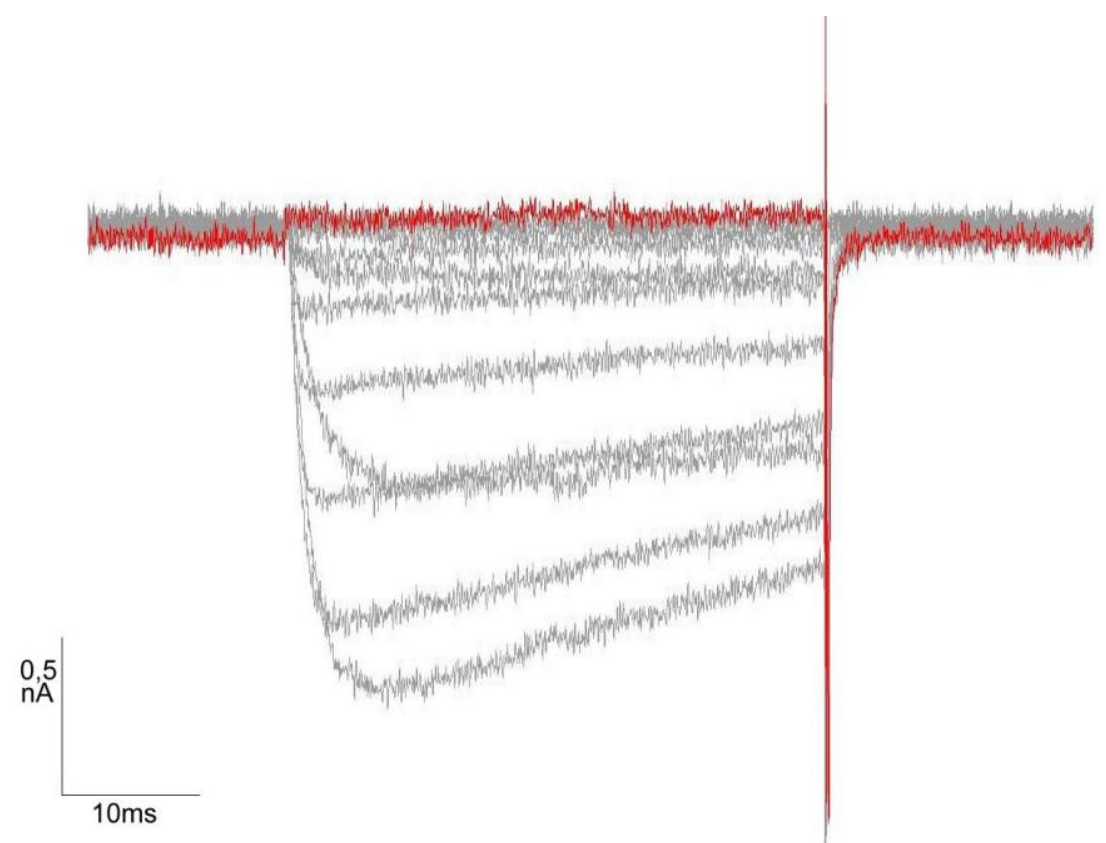

Abb. 3.11 pCaV 2.1 -Wildtyp in pCDNA3.1 (Messung 1) 


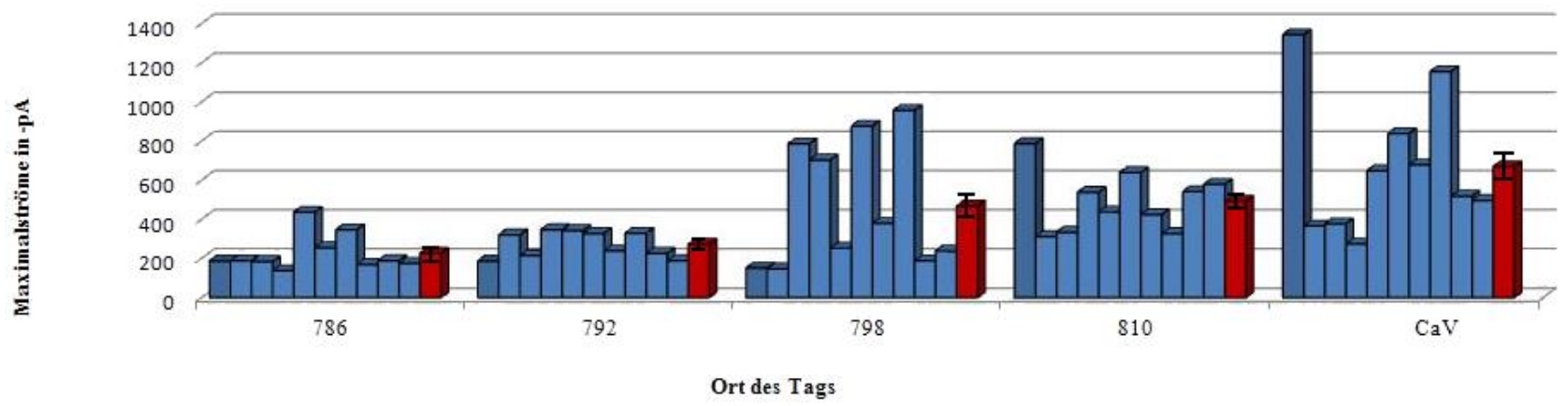

Abb. 3.12 Maximalströme und Durchschnitt der Maximalströme Die Maximalströme sind blau, die Durchschnitte der Maximalströme rot dargestellt.

Tabelle 3.1 Maximalströme, Durchschnittsstrom und Standardfehler je Tag

\begin{tabular}{lllllllllllll}
\hline Tag & Vmax 1 & $V \max 2$ & $V \max 3$ & $V \max 4$ & $V \max 5$ & $V \max 6$ & $V \max 7$ & $V \max 8$ & $V \max 9$ & Vmax 10 & Vmax $\varnothing$ fehler \\
\hline pCaV+786 & 186,7 & 187,284 & 184,136 & 137,077 & 435,563 & 254,564 & 345,455 & 168,564 & 188,345 & 174,284 & 226,1972 & 29,65 \\
pCaV+792 & 186,543 & 320,543 & 214,433 & 346,456 & 342,347 & 327,356 & 238,318 & 328,451 & 225,547 & 188,328 & 271,8322 & 21,08 \\
pCaV+798 & 150,286 & 146,988 & 785,325 & 702,154 & 252,956 & 875,453 & 378,575 & 956,327 & 187,327 & 237,487 & 467,2878 & 102,75 \\
pCaV+810 & 786,22 & 311,245 & 333,712 & 537,338 & 437,376 & 638,468 & 423,436 & 326,436 & 541,437 & 578,328 & 491,3996 & 48,62 \\
pCaV WT & 1343,124 & 365,856 & 376,454 & 273,583 & 647,376 & 837,274 & 677,654 & 1154,376 & 517,753 & 496,342 & 668,9792 & 110,83
\end{tabular}

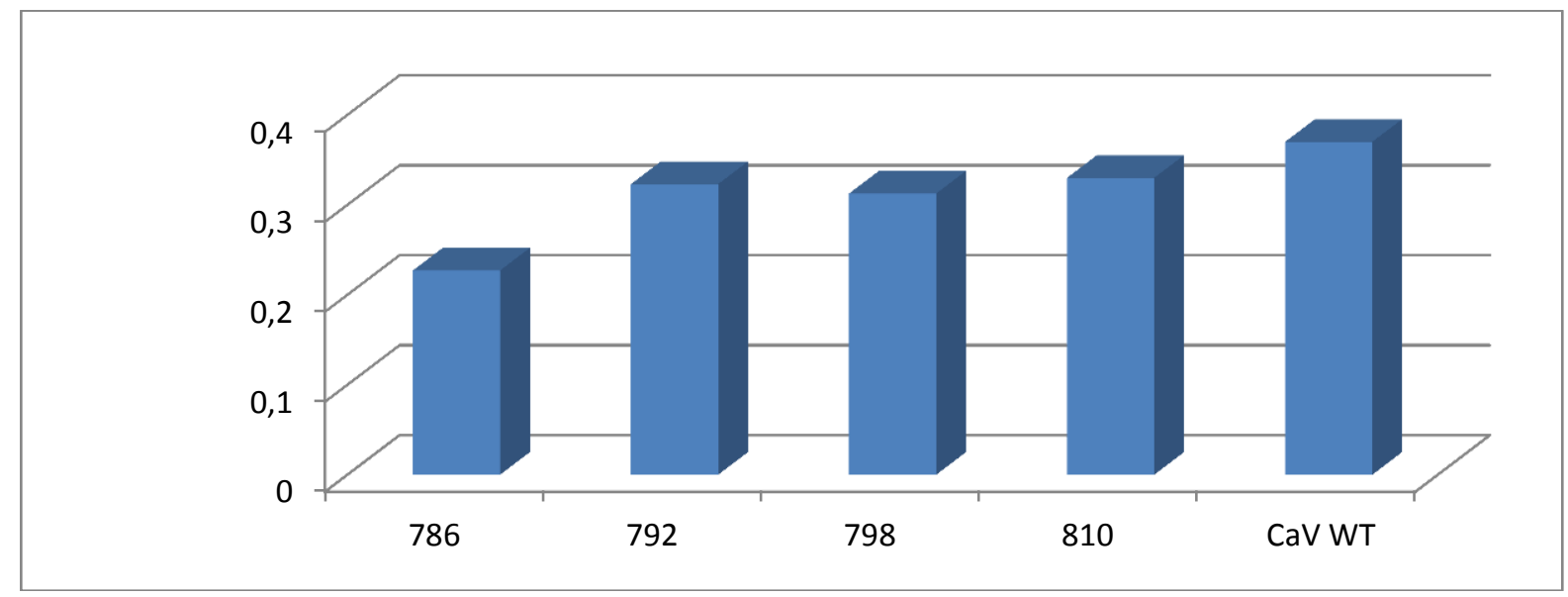

Abb. 3.13 Anteil der Zellen mit $\mathrm{V}_{\mathrm{Ca} 2+}$ an der Gesamtzahl der gemessenen Zellen

Tabelle 3.2 Verhältnis zwischen Zellen mit $\mathrm{V}_{\mathrm{Ca} 2+}$ zur Gesamtzahl der gemessenen Zellen

\begin{tabular}{|c|c|c|c|c|}
\hline 786 & 792 & 798 & 810 & CaV WT \\
\hline 0,227 & 0,323 & 0,3125 & 0,33 & 0,37 \\
\hline
\end{tabular}


Wie diese Ergebnisse zeigen, ist es trotz der Integration des ybbR-Tags in den Calciumkanal noch möglich, einen durch Calciumeinstrom induzierten Stromfluss zu messen.

Daraus ließ sich schließen, dass keines der benutzen Tags zu einer vollständigen Blockierung des Calciumkanals geführt hatte. Andererseits sind deutliche Unterschiede im Stromfluss zwischen den HEK293-Zellen, welche einen getaggten Calciumkanal exprimierten, im Vergleich zu jenen Zellen festzustellen, die mit der unmodifizierten Wildtyp-Calciumkanal-Sequenz transfiziert worden waren. Die Messungen dieser Zellen lieferten mit einem durchschnittlichen Maximalstrom von 668 pA und einen Quotienten von 0,37 die besten Ergebnisse. Dies lässt wiederum den Schluss zu, dass das integrierte ACP-ybbR-Tag den Kanal zumindest in gewisser Weise beeinflusst.

Doch auch der Vergleich der HEK293-Zellen mit getaggtem Calciumkanal untereinander zeigte, dass jene Zellen, welche mit den Vektoren $\mathrm{pCaV}_{2.1}+798$ bzw. $\mathrm{pCaV}_{2.1}+810$ transfiziert worden waren, im Vergleich zu den übrigen beiden Vektoren sowohl einen höheren Stromfluss als auch einen günstigeren Quotienten erzielten. Mit einem durchschnittlichen Maximalstrom von $491 \mathrm{pA}$ und einem Quotienten von 0,33 erzielten die mit dem Vektor $\mathrm{pCaV}_{2.1}+810$ transfizierten Zellen das beste Resultat aller getaggten Zellen.

Zusammenfassend lässt sich feststellen, dass anhand der positiven Ergebnisse in den Patch-Clamp-Versuchen alle für die Transfektion eingesetzten Vektoren auch für die folgenden, weiterführenden Experimente benutzł werden konnten.

\subsection{Färbung}

\subsubsection{Labeling der mit dem Vektor ACPerbB 1 transfizierten HEK293- Zellen und der Zelllinie ACPerbB 1 unter Verwendung des Enzyms Sfp}

Zunächst erfolgte die Transfektion der HEK293-Zellen mit dem Vektor ACPerbB 1, welcher freundlicherweise von Frau Dr. Arndt-Jovin zur Verfügung gestellt worden war, gemeinsam mit dem Vektor pEGFP-N 1.

Diese Transfektion diente als Positivkontrolle, mit der sichergestellt werden sollte, dass das ACP-Labeling bei transfizierten HEK293-Zellen unter den vorliegenden Bedingungen funktionierte.

In dem ACPerbB1-Vektor ist ein aus 78 Aminosäuren bestehendes ACP-Tag 
integriert. Da mit diesem Tag bereits umfangreiche Erfahrungen vorlagen, eignete es sich als zuverlässige Kontrolle.

Als weitere Positivkontrolle wurde außerdem von Frau Dr. Arndt-Jovin eine Zelllinie aus stabil exprimierenden ACPerbB 1-CHO-Zellen zur Verfügung gestellt.

Drei Viertel der Zellen einer Linie exprimierten das ACPerbB1-Tag, ein Viertel nicht.

Auf diese Weise wurde sichergestellt, dass im Vergleich zur Transfektion der HEK293-Zellen mit dem Vektor ACPerbB1 nun auch diejenigen Fehler, welche durch eine Transfektion per se entstehen können, ausgeschlossen werden konnten.

Aus diesem Grund erfolgte die Verwendung des Vektors ACPerbB 1 nur für die ersten Versuche. Die ACPerbB1-Zellen standen erst für spätere Experimente zur Verfügung. Dass diese Zellen nicht erst transfiziert werden mussten, ermöglichte ein effizienteres Arbeiten.

Beim Färben der Zellen wurden die Menge des eingesetzten ACP-CoASubstrates, die Menge des Enzyms Sfp, die Inkubationstemperatur und die Inkubationszeit unterschiedlich mit einander kombiniert.

Es musste darauf geachtet werden, dass die Inkubationszeit und die ACPCoA-Substratmengen ausreichend lang bzw. hoch gewählt wurden, um eine suffiziente Färbung der HEK293-Zellen zu gewährleisten. Allerdings bestand bei einer zu langen Inkubationszeit und einer zu großen Substratmenge die Gefahr einer verstärkten unspezifischen Färbung, sodass es essentiell war, diese beiden Faktoren in einem optimalen Verhältnis zueinander einzusetzen, um ein möglichst gutes Ergebnis zu erzielen.

Als Inkubationszeiten wurden versuchsweise $30 \mathrm{bzw}$. 70 min und als Inkubationstemperaturen $4{ }^{\circ} \mathrm{C}, 20^{\circ} \mathrm{C}$ bzw. $37^{\circ} \mathrm{C}$ gewählt. Vom Substrat wurden $2,5 \mu \mathrm{M}, 5 \mu \mathrm{M}, 12,5 \mu \mathrm{M}$ bzw. $25 \mu \mathrm{M}$ eingesetzt. Die Sfp-Enzymmenge wurde zwischen $0,15 \mu \mathrm{M}, 0,3 \mu \mathrm{M}, 0,5 \mu \mathrm{M}$, bzw. $1 \mu \mathrm{M}$ variiert.

Die mit den Vektoren ACPerbB1 und pEGFP-N1 transfizieren Zellen wurden nach dem Färben und dem nachfolgenden Spülen zunächst im Konfokalmikroskop unter blavem Licht analysiert, um jene Zellen zu identifizieren, welche das Protein GFP exprimierten.

Dies erfolgte wiederum in der Annahme, dass in der Zellmembran der GFPexprimierenden Zellen auch die ACP-Tag-tragenden Calciumkanäle integriert worden waren.

Die Erstellung der Bilder erfolgte im Konfokalmikroskop mithilfe eines Argonlasers bei einer Wellenlänge von $488 \mathrm{~nm}$, die zur Anregung des GFPs führte, sowie eines HeNe-Lasers bei einer Wellenlängen von $547 \mathrm{~nm}$ bzw. $647 \mathrm{~nm}$, welche für die ACP-CoA-Substrate benötigt wurden.

Durch die Variation der gewählten Parameter Inkubationszeit und -temperatur sowie Substrat- bzw. Enzymkonzentration wurden die in den 
Abbildungen 3.14 - 3.23 dargestellten Ergebnisse erzielt. Alle Bilder entstanden unter konstanten Software-Einstellungen am Konfokalmikroskop (Kontrast 422, Helligkeit 9628, Pinhole 1, Attenuation 1/1/10).

\section{Abb. 3.14 bis 3.16}

\section{HEK293-Zellen transfiziert mit ACPerbB1 und pEGFP-N1}

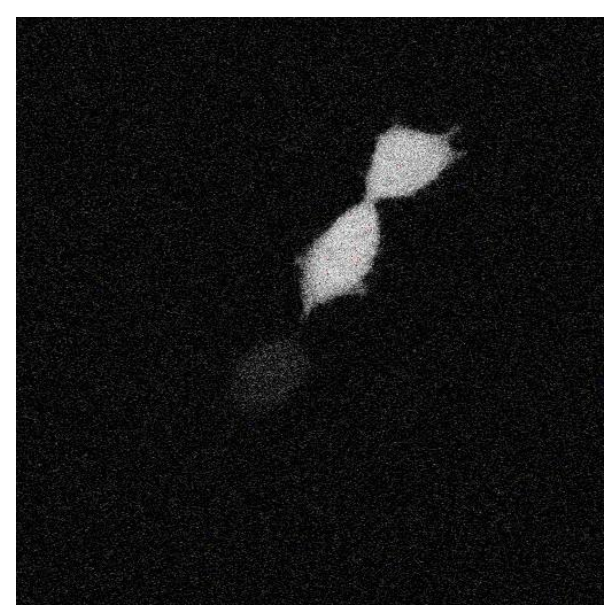

Aufnahme bei $488 \mathrm{~nm}$ (GFP)

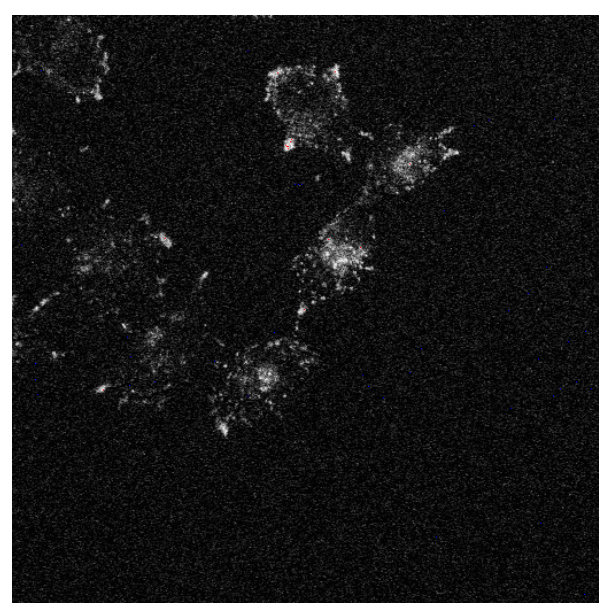

Aufnahme bei $633 \mathrm{~nm}$ (ACPerbB1-Tag)

Abb. 3.14 Inkubation $70 \mathrm{~min}, 12,5 \mu \mathrm{M}$ Substrat, $0,5 \mu \mathrm{M}$ Sfp, $37^{\circ} \mathrm{C}$

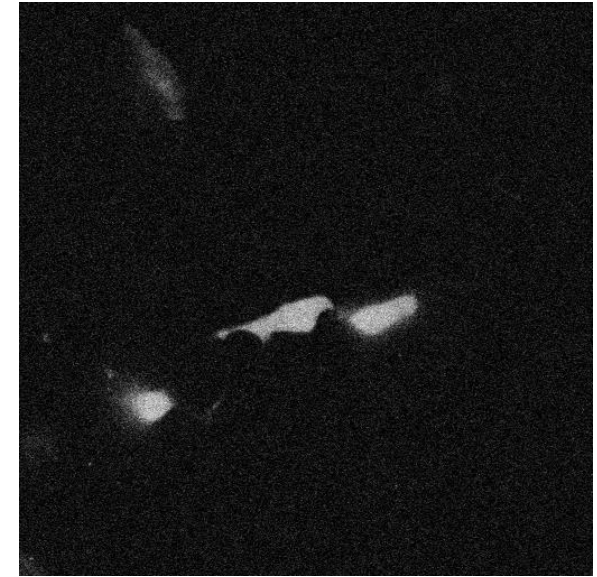

Aufnahme bei $488 \mathrm{~nm}$ (GFP)

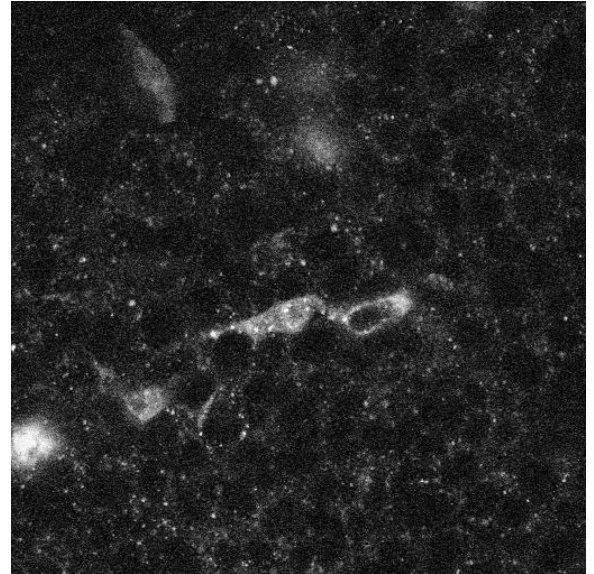

Aufnahme bei $633 \mathrm{~nm}$ (ACPerbB1 Tag)

Abb. $3.1570 \mathrm{~min}, 12,5 \mu \mathrm{M}$ Substrat, $0,5 \mu \mathrm{M}$ Sfp, $20^{\circ} \mathrm{C}$ 


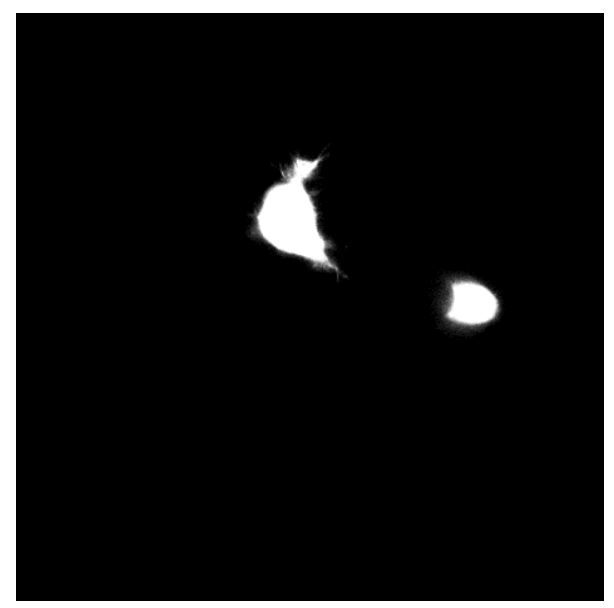

Aufnahme bei $488 \mathrm{~nm}$ (GFP)

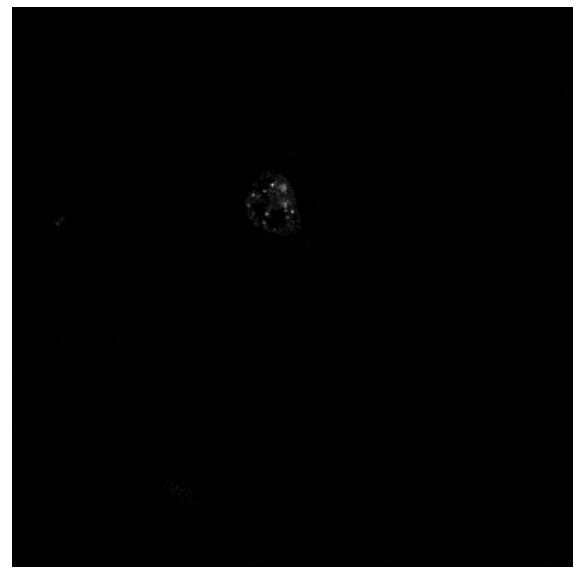

Aufnahme bei $633 \mathrm{~nm}$ (ACPerbB1 Tag)

Abb. 3.16 Inkubation $70 \mathrm{~min}, 12,5 \mu \mathrm{M}$ Substrat, 0,5 $\mu \mathrm{M}$ Sfp, $4^{\circ} \mathrm{C}$

Abb. 3.17 bis 3.24

ACPerbB1-CHO Zellen

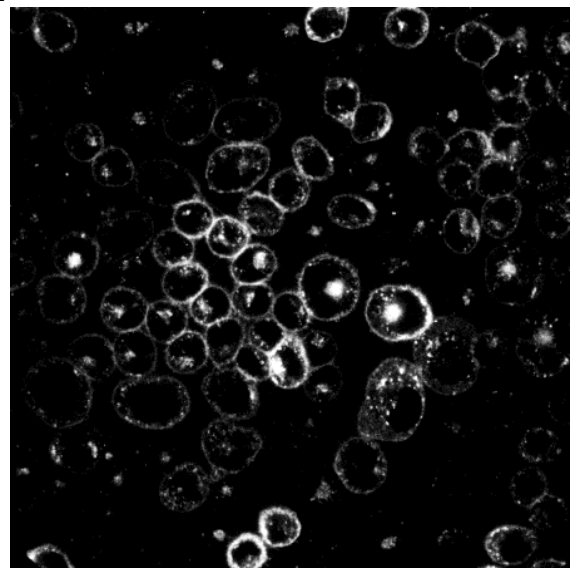

Abb. 3.17 Inkubation $30 \mathrm{~min}, 12,5 \mu \mathrm{M}$ Substrat, $0,5 \mu \mathrm{M}$ Sfp, $20^{\circ} \mathrm{C}$

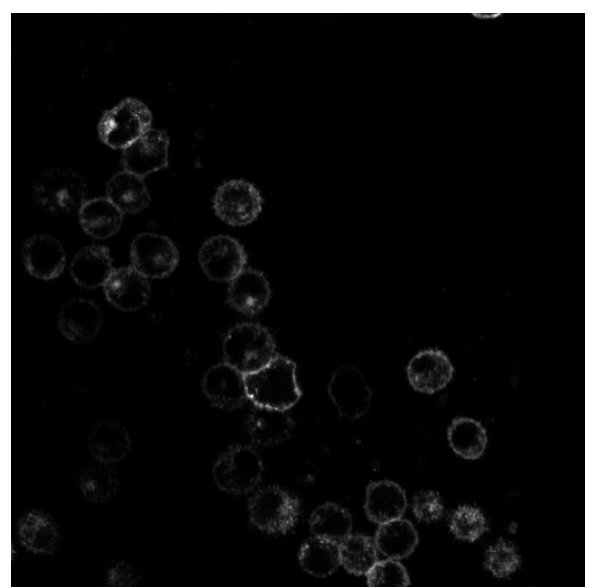

Abb. 3.18 Inkubation $30 \mathrm{~min}, 2,5 \mu \mathrm{M}$ Substrat, $0,5 \mu \mathrm{M} \mathrm{Sfp}, 20^{\circ} \mathrm{C}$ 


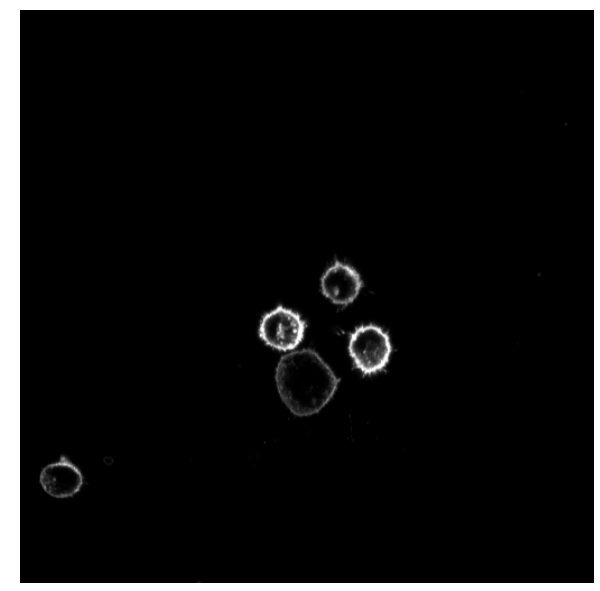

Abb. 3.19 Inkubation $30 \mathrm{~min}, 5 \mu \mathrm{M}$ Substrat, $0,5 \mu \mathrm{M} \mathrm{Sfp}, 20^{\circ} \mathrm{C}$

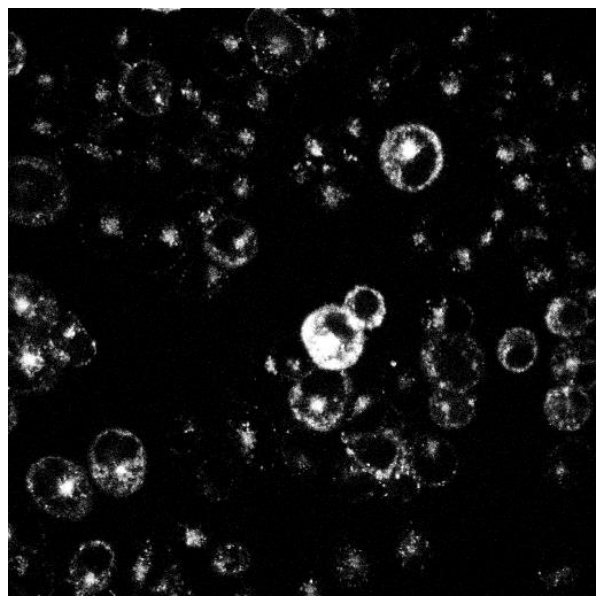

Abb. 3.20 Inkubation $30 \mathrm{~min}, 25 \mu \mathrm{M}$ Substrat, $0,5 \mu \mathrm{M} \mathrm{Sfp}, 20^{\circ} \mathrm{C}$

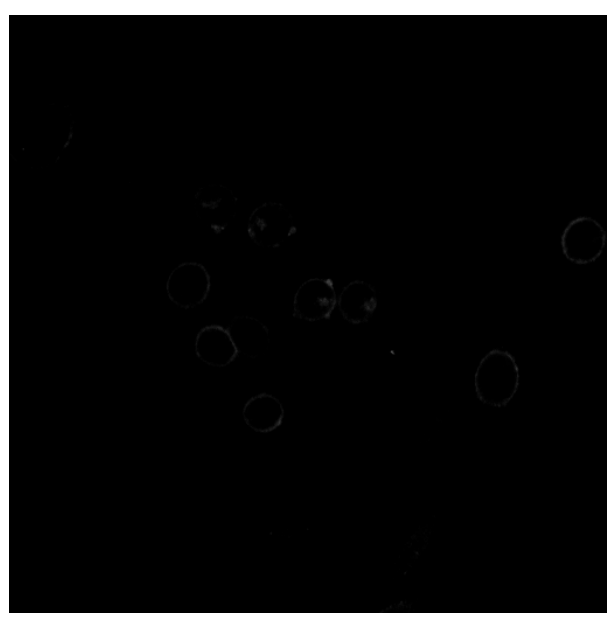

Abb. 3.21 Inkubation $30 \mathrm{~min}, 5 \mu \mathrm{M}$ Substrat, $0,15 \mu \mathrm{M} \mathrm{Sfp}, 20^{\circ} \mathrm{C}$ 


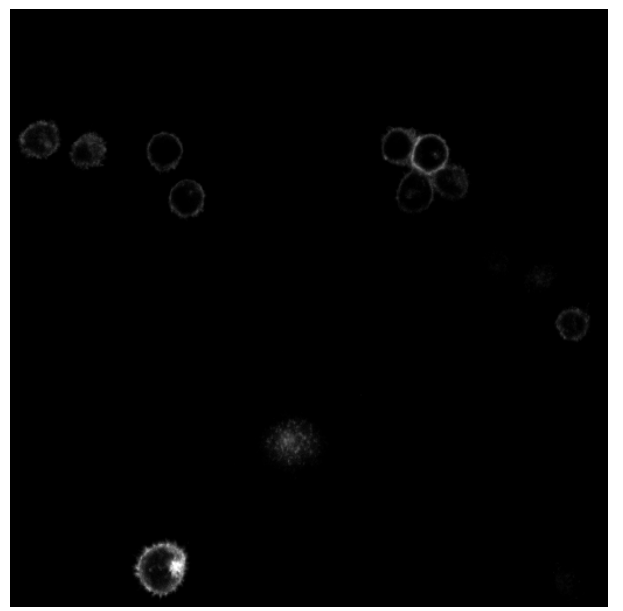

Abb. 3.22 Inkubation $30 \mathrm{~min}, 5 \mu \mathrm{M}$ Substrat, $0,3 \mu \mathrm{M}$ Sfp, $20^{\circ} \mathrm{C}$

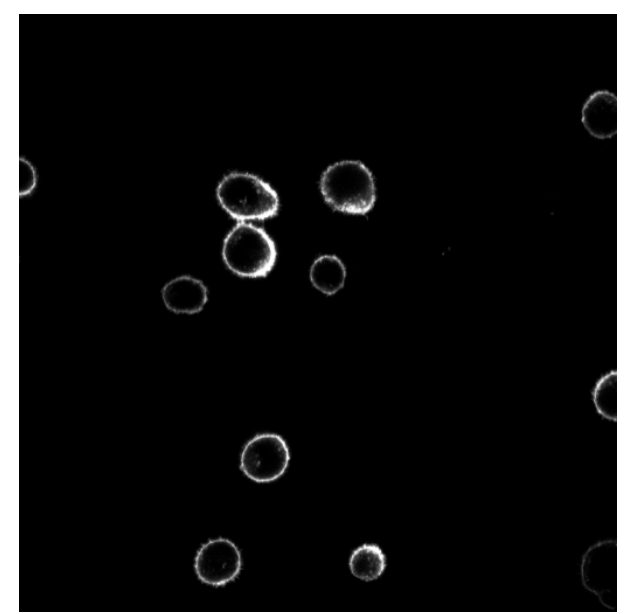

Abb. 3.23 Inkubation $30 \mathrm{~min}, 5 \mu \mathrm{M}$ Substrat, $1 \mu \mathrm{M} \mathrm{Sfp}, 20^{\circ} \mathrm{C}$

Die spezifische Membranfärbung sowohl der mit dem Vektor ACPerbB1 transfizierten HEK293-Zellen als auch der ACPerbB1-CHO-Zellen konnte erfolgreich durchgeführt werden (Abb. 3.14-3.23).

Begonnen wurden die Experimente zunächst mit einer Inkubationszeit von $70 \mathrm{~min}$, einer Inkubationstemperatur von $37^{\circ} \mathrm{C}, 12,5 \mu \mathrm{M}$ Substrat und $0,5 \mu \mathrm{M}$ $\mathrm{Sfp}$. Diese Kombination resultierte in einer sehr hellen, jedoch auch sehr unspezifischen Färbung, welche u.a. einen relativ stark ausgeprögten intrazellulären Charakter besaß (Abb. 3.14).

Es wurde vermutet, dass diese unspezifische, teilweise intrazelluläre Anfärbung darin begründet sein könnte, dass beinahe alle Zellen den Farbstoff bei einer Inkubationstemperatur von $37^{\circ} \mathrm{C}$ vermehrt durch Endozytose aufnahmen.

Daher fiel die Entscheidung, die Inkubationstemperatur auf $20^{\circ} \mathrm{C}$ zu verringern. Dies führte zu einer deutlicher Verringerung der intrazellulären Fluoreszenz, jedoch noch immer zu einer relativ unspezifischen Färbung der Zellmembran der meisten Zellen (Abb. 3.15). 
Eine weitere Absenkung der Inkubationstemperatur auf $4{ }^{\circ} \mathrm{C}$ zur potentiellen Verringerung des unspezifischen Hintergrunds resultierte jedoch in einem sehr schwachen Signal, sodass diese Maßnahme für das Durchführen der Experimente nicht zielführend war (Abb. 3.16).

Aus diesem Grund wurde eine Inkubationstemperatur von $20^{\circ} \mathrm{C}$ beibehalten und zur Verringerung der unspezifischen Färbung die Inkubationszeit auf 30 min verkürzt und damit ein etwas besseres Ergebnis erzielt (Abb. 3.17).

Da es das Ziel war, einerseits die Wahrscheinlichkeit einer unspezifischen Färbung zu minimieren, andererseits jedoch die Intensität des vom Fluoreszenzfarbstoff der getaggten Zellen ausgehenden Signals maximiert werden sollte, wurde zunächst im nöchsten Schritt die Substratkonzentration zwischen $12,5 \mu \mathrm{M}, 2,5 \mu \mathrm{M}, 5 \mu \mathrm{M}$ und $25 \mu \mathrm{M}$ variiert (Abb. 3.18 - 3.20).

Das beste Ergebnis erzielte eine Substratkonzentration von $5 \mu \mathrm{M}$, da dort das Verhältnis zwischen spezifischer Färbung und ausreichend starkem Signal am günstigsten war (Abb. 3.19).

Im letzten Schritt wurden Enzymkonzentrationen von 0,5 $\mu \mathrm{M}, 0,15 \mu \mathrm{M}, 0,3 \mu \mathrm{M}$ bzw. $1 \mu$ M getestet (Abb. 3.21 - 3.23).

Enzymkonzentrationen von 0,15 $\mu \mathrm{M}$ (Abb. 3.21) und 0,3 $\mu \mathrm{M}$ (Abb. 3.22) führten zU einer unzureichenden Anfärbung der getaggten Zellmembran. Bei einer Enzymkonzentration von $1 \mu \mathrm{M}$ zeigte sich kein signifikanter Unterschied zu den Färbungen mit 0,5 $\mu \mathrm{M}$ Enzym (Abb. 3.23).

Somit erwies sich eine Inkubationszeit von 30 min bei einer Inkubationstemperatur von $20^{\circ} \mathrm{C}$ als optimal. Die günstigste Substratkonzentration betrug $5 \mu \mathrm{M}$ und die beste Enzymkonzentration 0,5 $\mathrm{M}$. Eine Erhöhung der Substratkonzentration führte zu einem Anstieg der unspezifischen Färbung (Abb. 3.20), ein deutliches Absenken bedingte ein schwächeres Signal (Abb. 3.21).

Eine weitere Erhöhung der Enzymmenge zeigte keinen positiven Effekt (Abb. 3.23). Eine deutliche Verringerung führte zu einer Abschwächung des Signals (Abb. 3.21 bzw. 3.22).

Abschließend fertigten wurde zur Darstellung der Anfärbung der kompletten Zellmembran samt Ausläufern unter Beibehaltung der o.g. Parameter ein weiteres konfokalmikroskopisches Bild angefertigt (Abb. 3.24). 


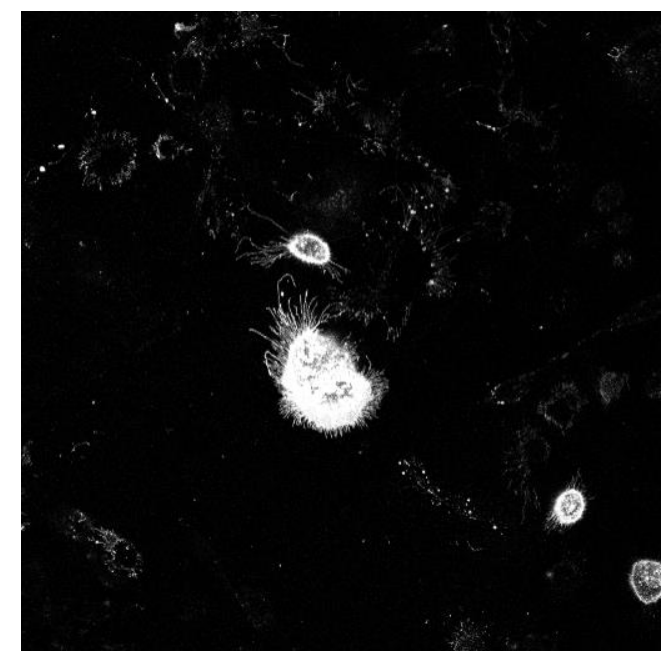

Abb. 3.24 Zellmembran, Inkubation $30 \mathrm{~min}, 5 \mu \mathrm{M}$ Substrat, $0,5 \mu \mathrm{M} \mathrm{Sfp}, 20^{\circ} \mathrm{C}$

\subsection{2 ybbR-Tag bei Verwendung des Vektors pDisplay und Sfp}

Daraufhin erfolgte das Färben der HEK293-Zellen, welche zuvor mit dem Vektor pDisplay+ybbR transfiziert worden waren.

Dieser Vektor enthielt, wie bereits beschrieben, neben einer GFP- auch die Sequenz des 11 Aminosäuren lange ACP-ybbR-Tags und diente folglich als Positivkontrolle.

Durch die Ergebnisse der vorhergehenden Experimente (Kap. 3.5.1) wurde die Färbung mit der ermittelten Kombination aus Enzym- und Substratkonzentration sowie der als optimal eingestuften Inkubationszeit von $30 \mathrm{~min}$ bei einer Inkubationstemperatur von $20^{\circ} \mathrm{C}$ durchgeführt.

Zur Kontrolle wurden dennoch drei Variationen der Substrat- bzw. Enzymmenge durchgeführt (Abb. 3.25-3.28).

\section{Abb. 3.25-3.28}

HEK293-Zellen transfiziert mit pDisplay

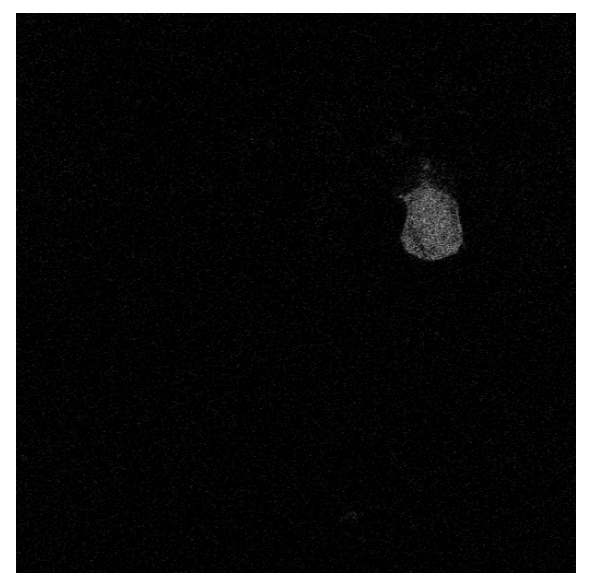

Aufnahme bei $488 \mathrm{~nm}$ (GFP)

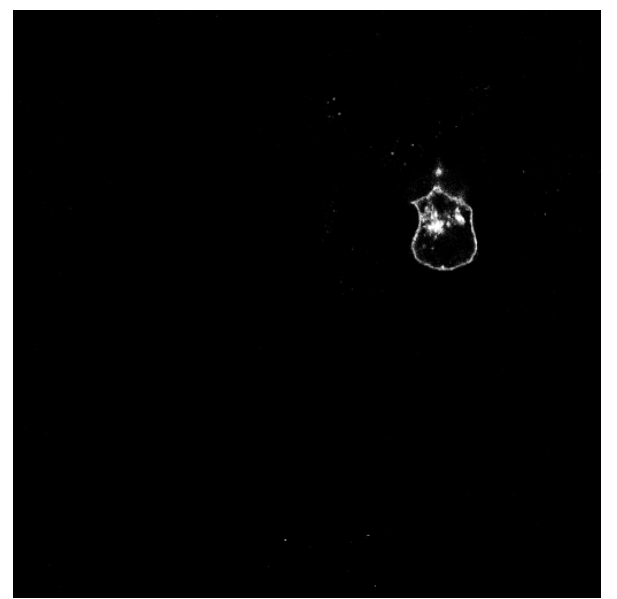

Aufnahme bei 547 nm (gefärbtes ybbR-Tag)

Abb. 3.25 Inkubation $30 \mathrm{~min}, 5 \mu \mathrm{M}$ Substrat, $0,5 \mu \mathrm{M} \mathrm{Sfp,} 20^{\circ} \mathrm{C}$ 


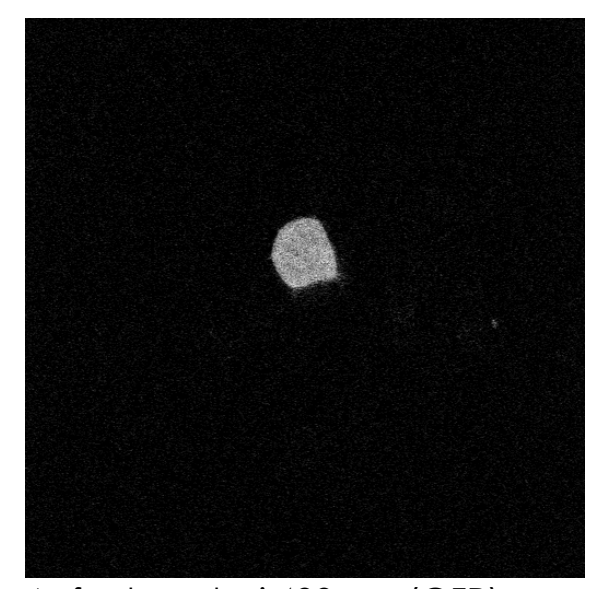

Aufnahme bei $488 \mathrm{~nm}$ (GFP)

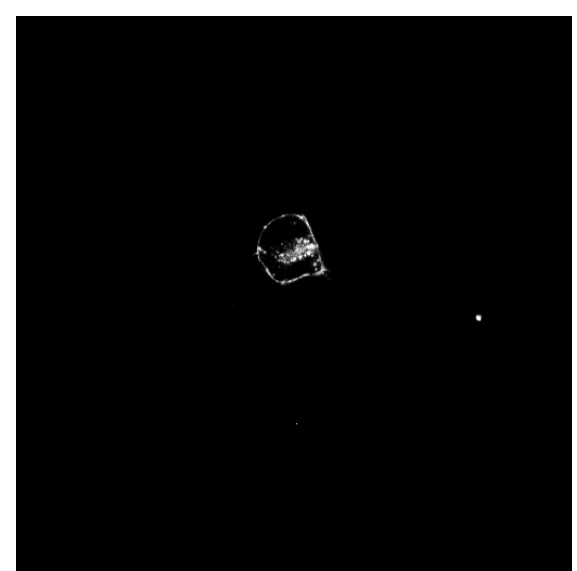

Aufnahme bei $547 \mathrm{~nm}$ (gefärbtes ybbR-Tag)

Abb. 3.26 Inkubation 30 min, $5 \mu M$ Substrat, $1 \mu M$ Sfp, $20{ }^{\circ} \mathrm{C}$

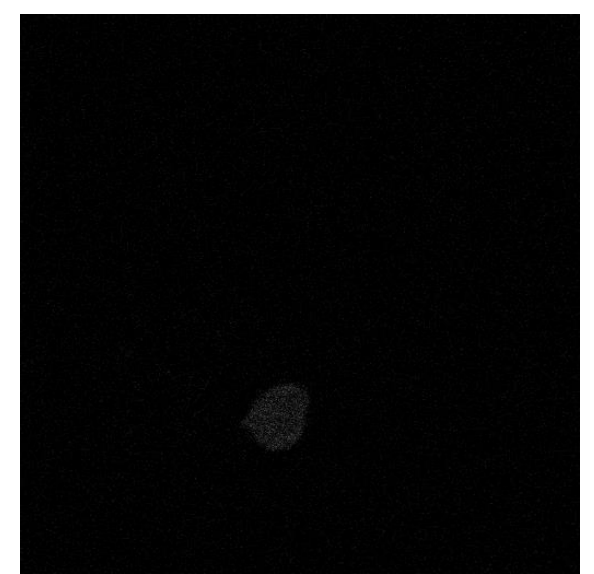

Aufnahme bei $488 \mathrm{~nm}$ (GFP)

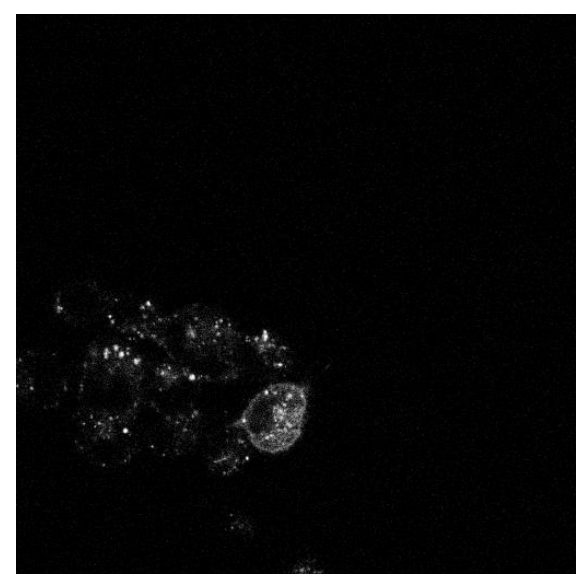

Aufnahme bei $547 \mathrm{~nm}$ (gefärbtes ybbR-Tag)

Abb. 3.27 Inkubation $60 \mathrm{~min}, 5 \mu \mathrm{M}$ Substrat, 0,5 $\mu \mathrm{M}$ Sfp, $20{ }^{\circ} \mathrm{C}$

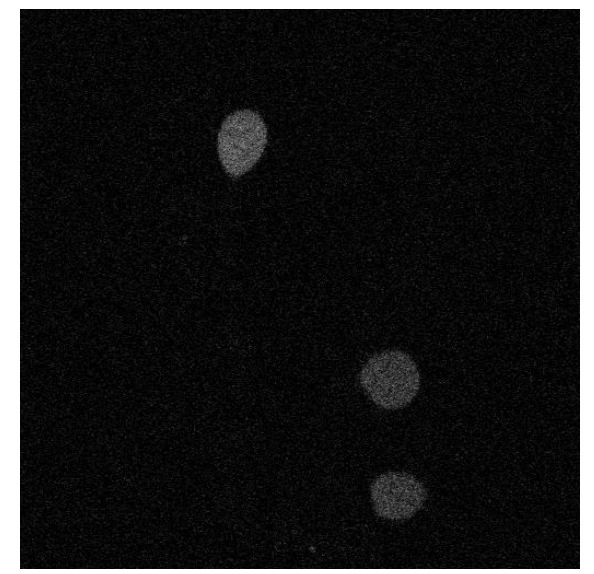

Aufnahme bei $488 \mathrm{~nm}$ (GFP)

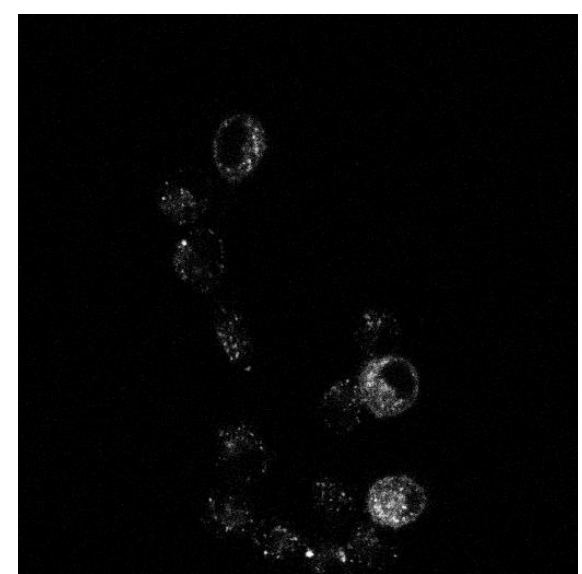

Aufnahme bei $547 \mathrm{~nm}$ (gefärbtes ybbR-Tag)

Abb. 3.28 Inkubation 30 min, 12,5 $\mu \mathrm{M}$ Substrat, 0,5 $\mu \mathrm{M}$ Sfp, $20^{\circ} \mathrm{C}$ 
Auch bei den HEK293-Zellen, welche mit dem Vektor pDisplay+ybbR transfiziert worden waren, konnte die Zellmembran spezifisch angefärbt werden (Abb. 3.25 - 3.28).

Durch die Variation der Substrat- bzw. Enzymmengen konnte bestätigt werden, dass die günstigsten Ergebnisse wiederum mit einer Kombination aus 0,5 $\mu \mathrm{M}$ Sfp und $5 \mu \mathrm{M}$ Substrat bei einer Inkubationszeit von 30 min und einer Inkubationstemperatur von $20^{\circ} \mathrm{C}$ erzielt werden konnten (Abb. 3.25). Eine Erhöhung der Enzymkonzentration ergab auch diesmal keine Verbesserung des Ergebnisses (Abb. 3.26). Die Erhöhung der Inkubationsdaver (Abb. 3.27) bzw. der Substratkonzentration (Abb. 3.28) führte erneut zu einem Anstieg der unspezifischen Färbung.

\subsubsection{HEK293-Zellen, transfiziert mit $p \mathrm{CaV}_{2.1}+y b b R$-Insert unter Ver- wendung von Sfp}

Im nächsten Schritt wurde das Ziel der Arbeit, die spezifische Färbung der $\alpha_{1^{-}}$ Untereinheit $\mathrm{pCaV}_{2.1}$ der P/Q-Typ-Calciumkanäle in der Zellmembran, in den Fokus der weiteren Experimente gerückt.

Die HEK293-Zellen wurden nach der Calciumphosphat-Präzipitationsmethode zunächst mit einem der vier Vektoren pCaV $2.1+y b b R ~(786,792,798$ bzw. 810) sowie dem Vektor pEGFP-N1 und der DNA der Calciumkanal-Untereinheiten $\alpha 2 \delta$ und $\beta 1 b$ transfiziert.

Am dritten Tag nach der Transfektion erfolgte die Durchführung der LabelingReaktion, wobei auf die Ergebnisse der vorangegangenen Experimente hinsichtlich der Vektoren pDisplay bzw. ACPerbB 1 sowohl bezüglich der Substratund Enzymmengen (5 $\mu \mathrm{M}$ bzw. 0,5 $\mu \mathrm{M}$ ) als auch der Inkubationszeit (30 min) und Inkubationstemperatur $\left(20^{\circ} \mathrm{C}\right)$, zurückgegriffen wurde (Abb. 3.29 - 3.32).

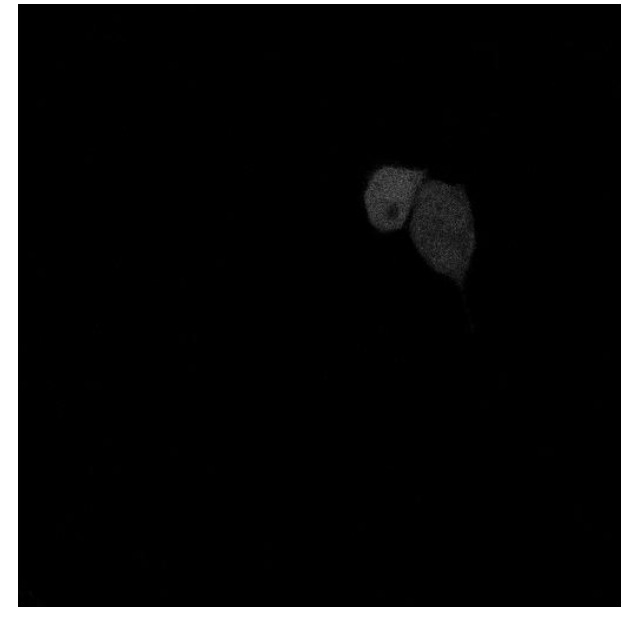

Aufnahme bei $488 \mathrm{~nm}$ (GFP)

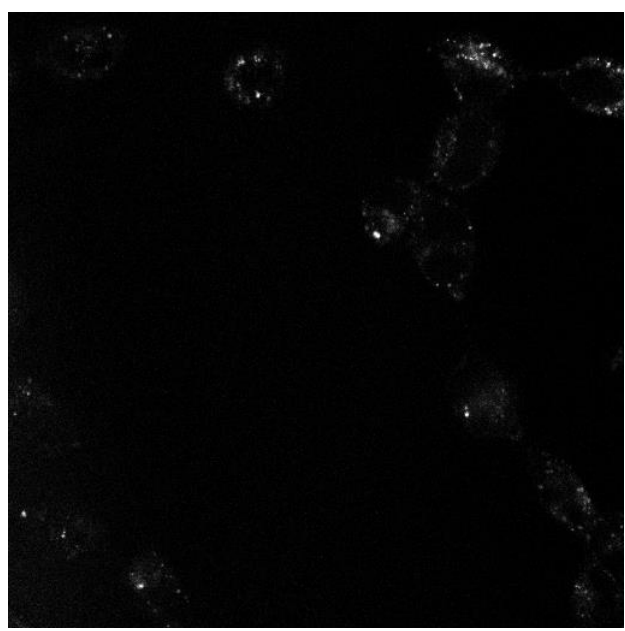

Aufnahme bei $647 \mathrm{~nm}$ (gefärbtes ybbR-Tag)

Abb. $3.29 \mathrm{pCaV}_{2.1}+786$ - Inkubation $30 \mathrm{~min}, 5 \mu \mathrm{M}$ Substrat, $0,5 \mu \mathrm{M} \mathrm{Sfp}, 20^{\circ} \mathrm{C}$ 


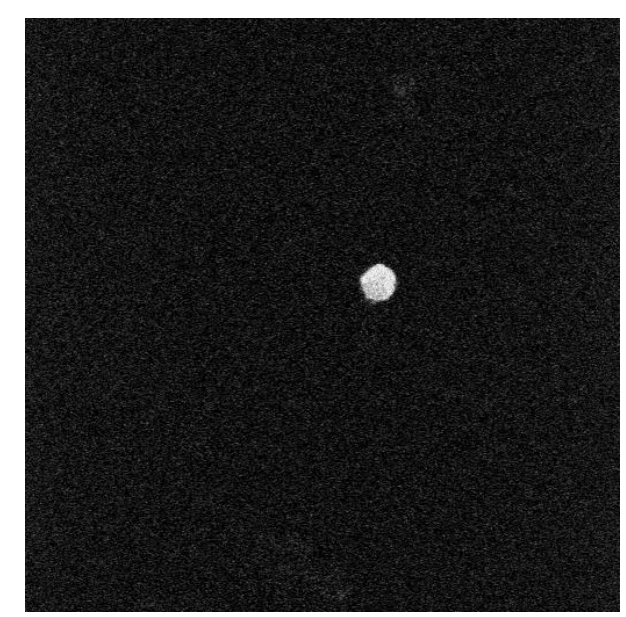

Aufnahme bei $488 \mathrm{~nm}$ (GFP)

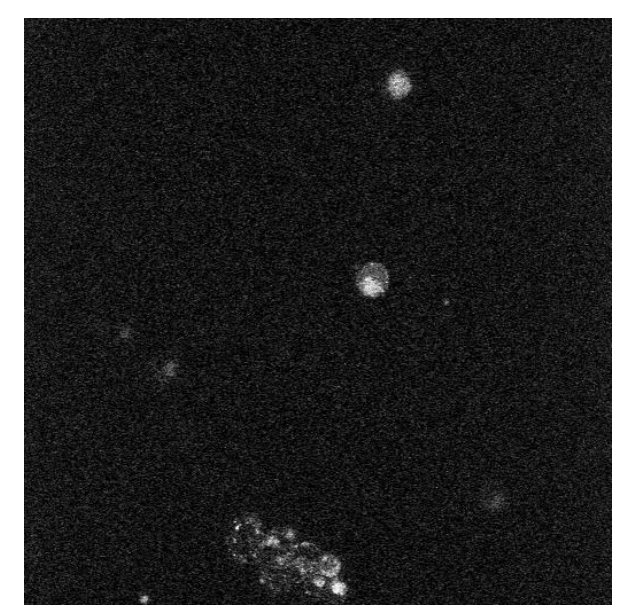

Aufnahme bei $647 \mathrm{~nm}$ (gefärbtes ybbR-Tag)

Abb. $3.30 \mathrm{pCaV}_{2.1}+792$ : Inkubation $30 \mathrm{~min}, 5 \mu \mathrm{M}$ Substrat, $0,5 \mu \mathrm{M} \mathrm{Sfp}, 20^{\circ} \mathrm{C}$

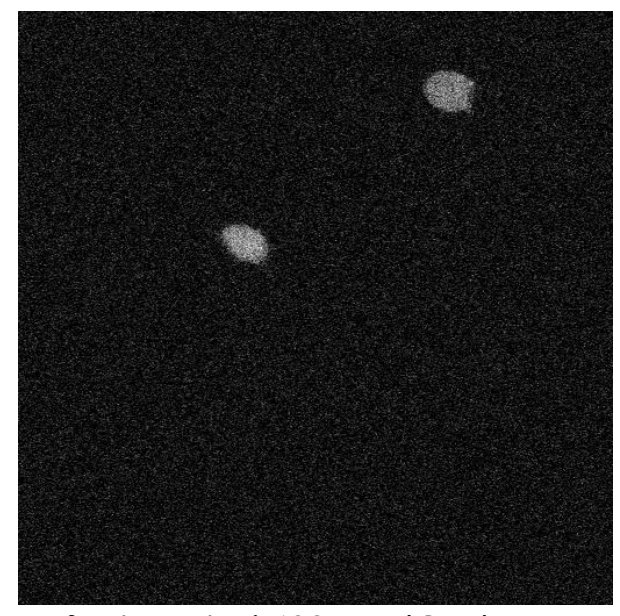

Aufnahme bei $488 \mathrm{~nm}$ (GFP)

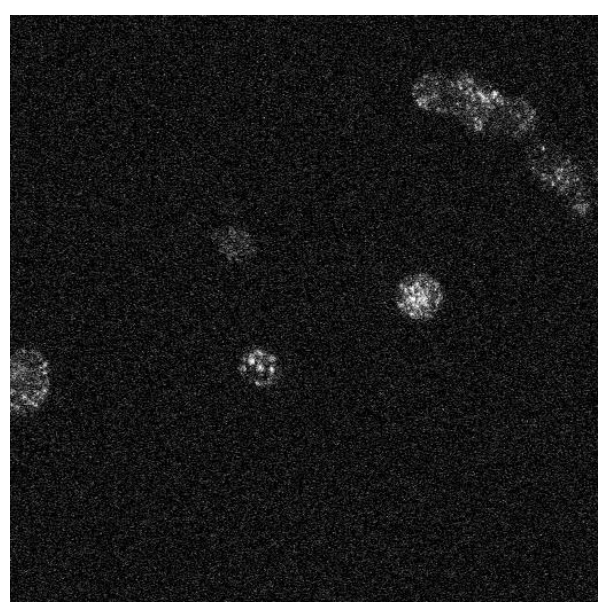

Aufnahme bei $647 \mathrm{~nm}$ (gefärbtes ybbR-Tag)

Abb. $3.31 \mathrm{pCaV}_{2.1}+798$ : Inkubation $30 \mathrm{~min}, 5 \mu \mathrm{M}$ Substrat, $0,5 \mu \mathrm{M} \mathrm{Sfp}, 20^{\circ} \mathrm{C}$

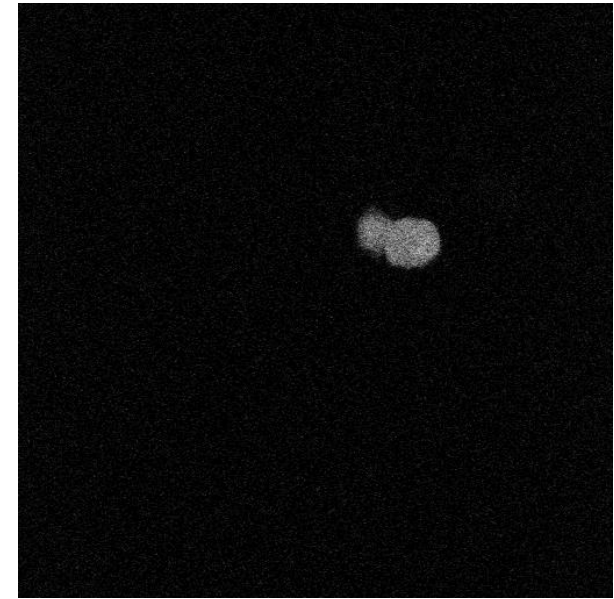

Aufnahme bei 488 nm (GFP)

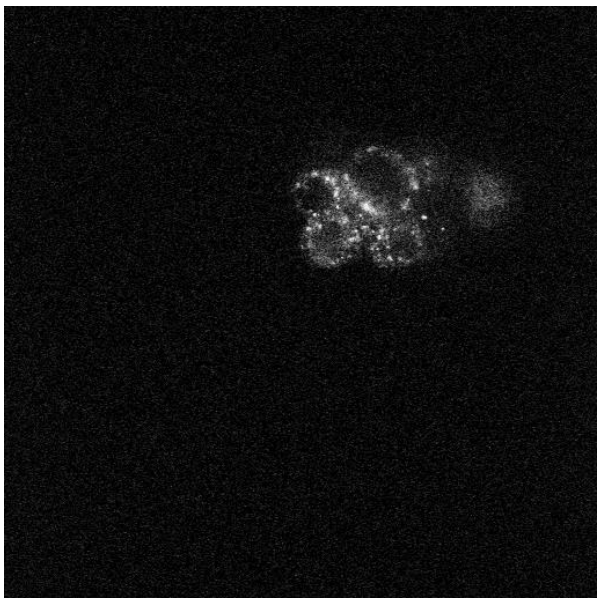

Aufnahme bei $647 \mathrm{~nm}$ (gefärbtes ybbRTag)

Abb. $3.32 \mathrm{pCaV}_{2.1}+810$ : Inkubation $30 \mathrm{~min}, 5 \mu \mathrm{M}$ Substrat, $0,5 \mu \mathrm{M}$ Sfp, $20^{\circ} \mathrm{C}$ 
Es zeigte sich, dass nicht nur jene Zellen, welche erfolgreich transfiziert werden konnten, bei einer Wellenlänge von $647 \mathrm{~nm}$ ein schwaches Fluoreszenzsignal emittierten, sondern alle beobachteten Zellen. Eine reproduzierbare Differenzierung zwischen transfizierten und nicht transfizierten Zellen ließ sich anhand dieser Resultate nicht treffen.

Unabhängig vom verwendeten Vektor waren die Resultate vergleichbar: Die Anzahl der gefärbten Zellen pro Sichtfeld (Wellenlänge $647 \mathrm{~nm}$ ) war deutlich höher als die Anzahl der tatsächlich transfizierten Zellen, erkennbar am exprimierten GFP (Wellenlänge 488 nm) (Abb. 3.29 - 3.32).

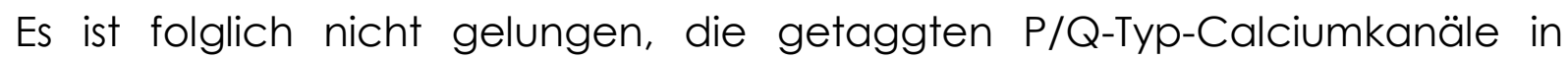
HEK293-Zellen auf diese Weise im Konfokalmikroskop darzustellen.

Auf der Suche nach möglichen Fehlerquellen wurde entschieden, das Sfp durch ein anderes Enzym zu ersetzen.

In der Literatur wurde zwar fast ausschließlich dieses Enzym in Verbindung mit dem ybbR-Tag verwendet [u.a. YIN et al. 2005a], jedoch ist es mit seinen immerhin 220-240 Aminosäuren doppelt so groß wie z.B. das Enzym AcpS [QUADRI et al. 1998; LAMBALOT, WALSH 1997].

Diese Tatsache führte zu der Annahme, dass das Sfp aufgrund seiner Masse möglicherweise zu groß sein könnte, um an die Calciumkanäle zu gelangen.

Zur Klärung dieser Hypothese wurden einige der vorangegangenen Experimente mit dem Enzym AcpS wiederholt.

\subsection{4 ybbR-Tag im Vektor pDisplay und AcpS}

Zunächst erfolgte als Positivkontrolle die Färbung der mit dem Vektor pDisplay transfizierten HEK293-Zellen mit dem Enzym AcpS unter Verwendung der als optimal eingestuften Bedingungen: Inkubationszeit 30 min, Inkubationstemperatur $20^{\circ} \mathrm{C}, 0,5 \mu \mathrm{M}$ AcpS und $5 \mu \mathrm{M}$ Substrat (Abb. 3.33).

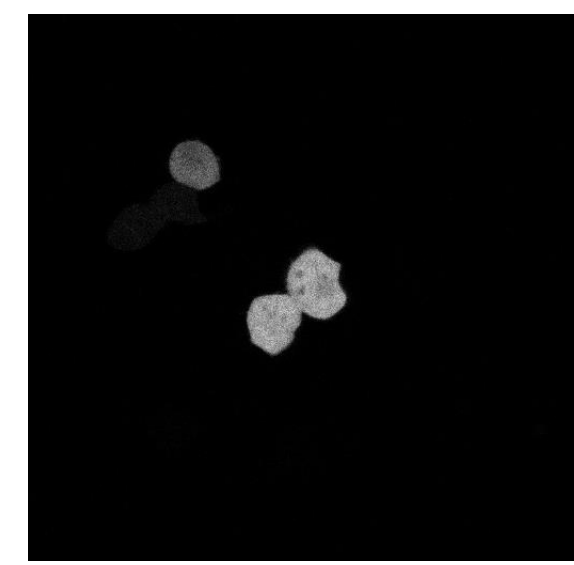

Aufnahme bei 488 nm (GFP)

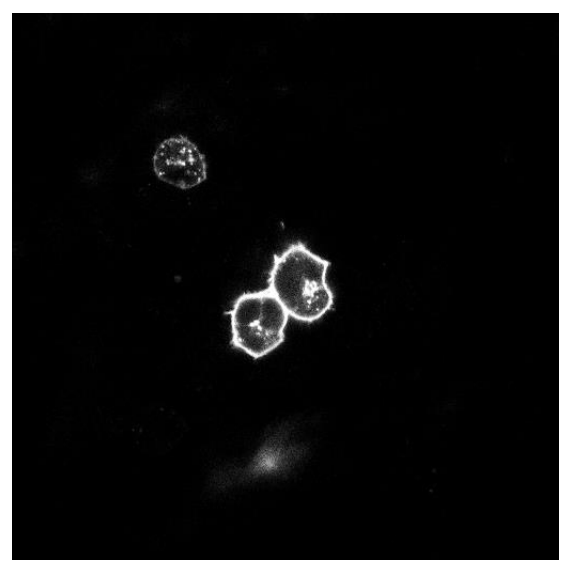

Aufnahme bei $547 \mathrm{~nm}$ (gefärbtes ybbR-Tag)

Abb. 3.33 HEK293-Zellen transfiziert mit pDisplay; Inkubation $30 \mathrm{~min}, 5 \mu \mathrm{M}$ Substrat, $0,5 \mu \mathrm{M}$ Acps, $20^{\circ} \mathrm{C}$ 
Wie in den obigen Abbildungen zu erkennen, hat eine durch AcpS katalysierte selektive Membranfärbung stattgefunden. Dies führte zu der Überzeugung, dass Zellen, in denen das 11 Aminosäuren lange ybbR-Tag integriert worden war, gleichermaßen mithilfe des Sfp als auch der AcpS gefärbt werden konnten.

\subsubsection{HEK293-Zellen, tranfiziert mit $p \mathrm{CaV}_{2.1}+y b b R$-Insert unter Ver- wendung von AcpS}

Die Reaktion erfolgte wiederum unter den oben genannten Bedingungen (Abb. 3.34 - 3.37).

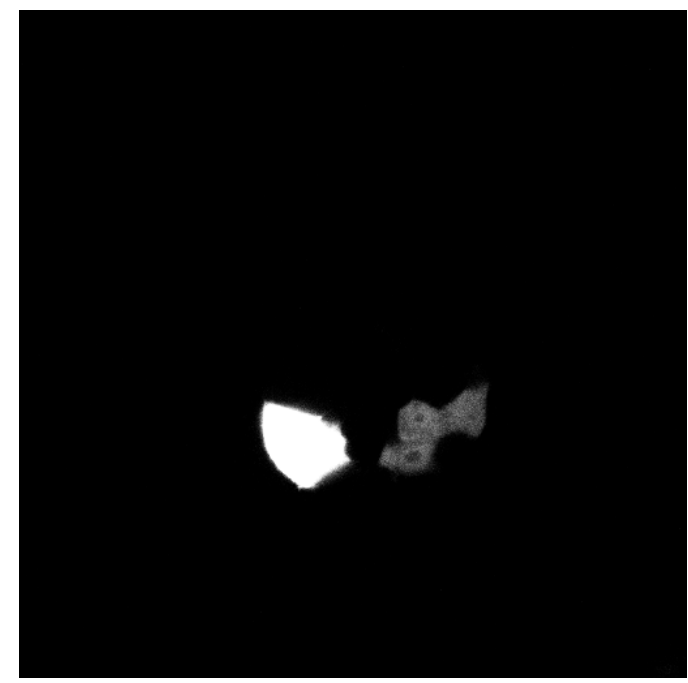

Aufnahme bei $488 \mathrm{~nm}$ (GFP)

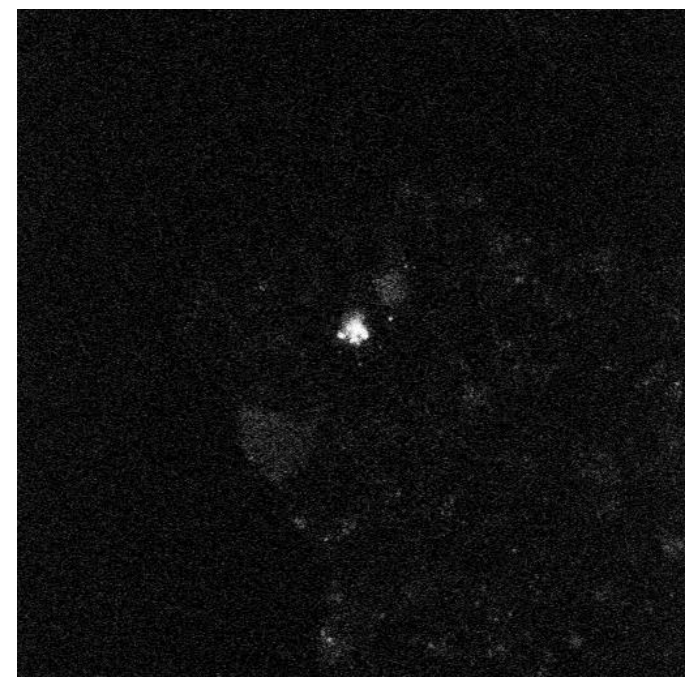

Aufnahme bei $547 \mathrm{~nm}$ (gefärbtes ybbR-Tag)

Abb. $3.34 \mathrm{pCaV}_{2.1}+786$ : Inkubation $30 \mathrm{~min}, 5 \mu \mathrm{M}$ Substrat, $0,5 \mu \mathrm{M}$ AcpS, $20^{\circ} \mathrm{C}$

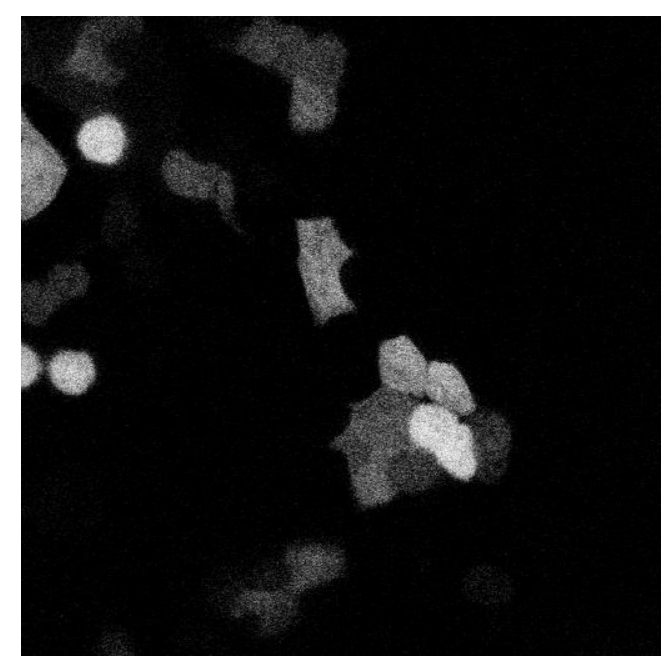

Aufnahme bei $488 \mathrm{~nm}$ (GFP)

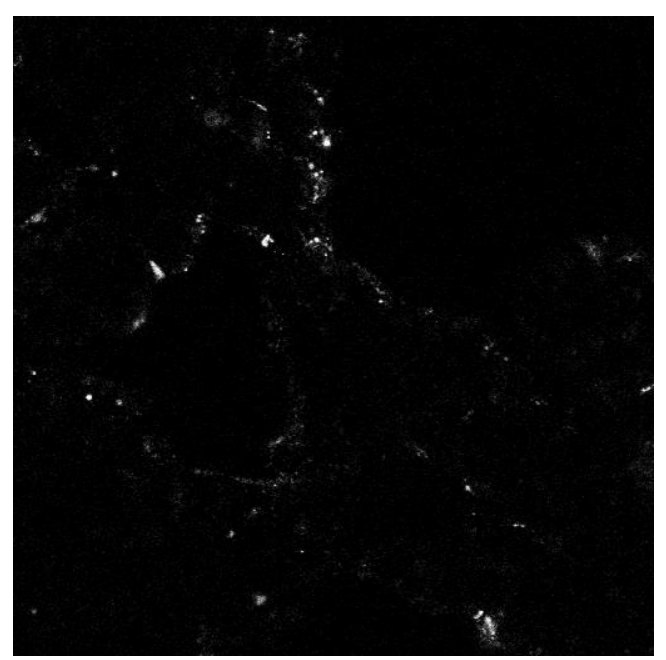

Aufnahme bei $547 \mathrm{~nm}$ (gefärbtes ybbR-Tag)

Abb. $3.35 \mathrm{pCaV}_{2.1}+792$ : Inkubation $30 \mathrm{~min}, 5 \mu \mathrm{M}$ Substrat, $0,5 \mu \mathrm{M}$ AcpS, $20^{\circ} \mathrm{C}$ 


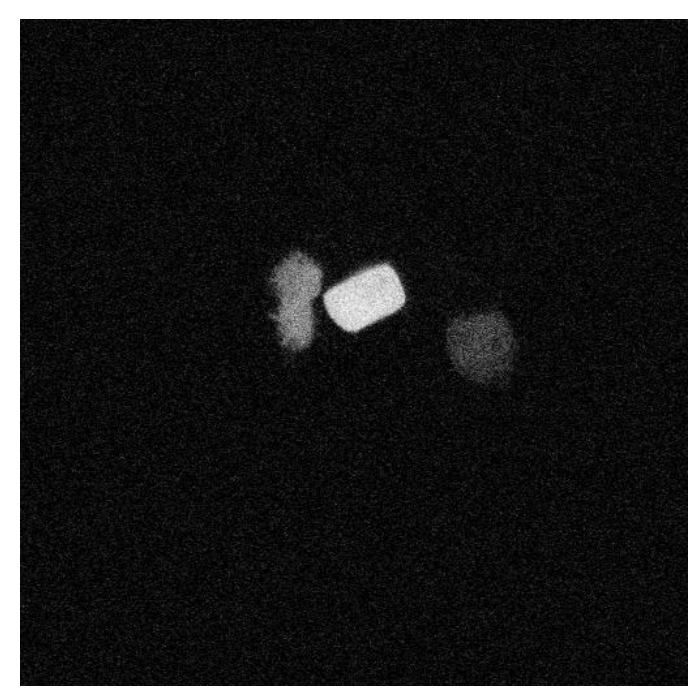

Aufnahme bei $488 \mathrm{~nm}$ (GFP)

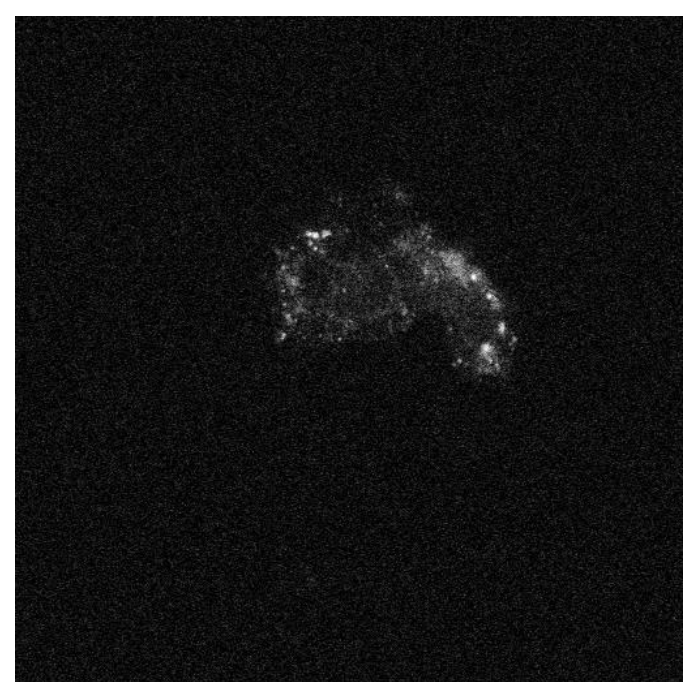

Aufnahme bei $547 \mathrm{~nm}$ (gefärbtes ybbR-Tag)

Abb. $3.36 \mathrm{pCaV}_{2.1}+798$ : Inkubation $30 \mathrm{~min}, 5 \mu \mathrm{M}$ Substrat, $0,5 \mu \mathrm{M}$ AcpS, $20^{\circ} \mathrm{C}$

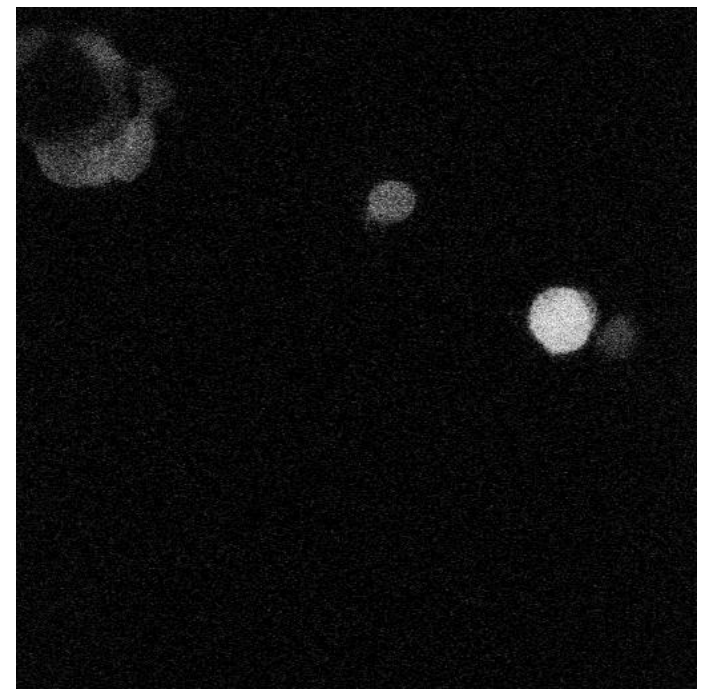

Aufnahme bei $488 \mathrm{~nm}$ (GFP)

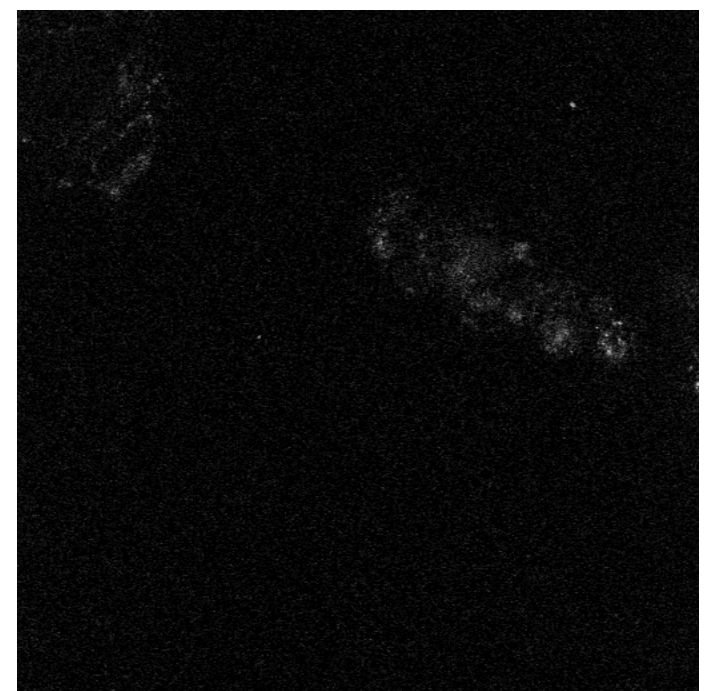

Aufnahme bei $547 \mathrm{~nm}$ (gefärbtes ybbR-Tag)

Abb. $3.37 \mathrm{pCaV}_{2.1}+810$ : Inkubation $30 \mathrm{~min}, 5 \mu \mathrm{M}$ Substrat, $0,5 \mu \mathrm{M}$ AcpS, $20{ }^{\circ} \mathrm{C}$

Als Resultat auch dieser Experimente ließ sich festhalten, dass keine sichtbar spezifische Färbung der ybbR-ACP-Tag-tragenden Calciumkanäle in HEK293Zellen stattgefunden hatte.

Zur Ursachensuche für dieses Ergebnis musste zunächst geklärt werden, ob es in der Tat zu keiner spezifischen Färbung der mit dem ybbR-Tag versehenen $\alpha_{1}$-Untereinheit $\mathrm{pCaV}_{2.1}$ der membranständigen $\mathrm{P} / \mathrm{Q}$-Typ-Calciumkanäle gekommen ist. Als weiterer Grund der nicht erfolgreichen Färbung könnte angenommen werden, dass die Dichte der P/Q-Typ-Calciumkanäle in HEK293- 
Zellen zu gering isł und sie darüber hinaus zu diffus über die gesamte Zellmembran verteilt sind, um adäquat im Konfokalmikroskop beurteilt werden zu können.

Aus diesem Grund wurde entschieden die Labeling-Reaktion ein weiteres Mal mit Primärneuronen durchzuführen. Hintergrund war die Tatsache, dass die P/Q-Typ-Calciumkanäle in Neuronen höchstwahrscheinlich eher in den aktiven Zonen konzentriert sind. Diese Konzentrierung würde die Wahrscheinlichkeit einer Darstellung der Kanäle deutlich erhöhen. Auf diese Weise könnte so eine mögliche Ursache für das negative Ergebnis des vorangegangenen Experiments aufgeklärt werden.

\subsubsection{Infektion von Neuronen}

Zur Herstellung der Viren und der nachfolgenden Infektion der Neuronen erfolgte aus Gründen der Effizienz die Beschränkung auf die beiden Vektoren $\mathrm{pCaV}_{2.1}+798$ und $\mathrm{pCaV}_{2.1}+810$. Die Reduktion auf diese beiden Vektoren erfolgte aufgrund der analysierten durch Calciumeinstrom induzierten Ströme, da Zellen, welche mit diesen beiden Vektoren transfiziert worden waren, die besten Resultate erzielt hatten.

Die infizierten Neurone wurden unter Verwendung der etablierten Parameter, Inkubationszeit $30 \mathrm{~min}$, Temperatur $20^{\circ} \mathrm{C}, 0,5 \mu \mathrm{M}$ Sfp, $5 \mu \mathrm{M}$ Substrat, gefärbt und im Konfokalmikroskop analysiert. Als Kontrolle dienten Neuronen, welche vorher nicht infiziert worden waren (Abb. 3.38 - 3.40).

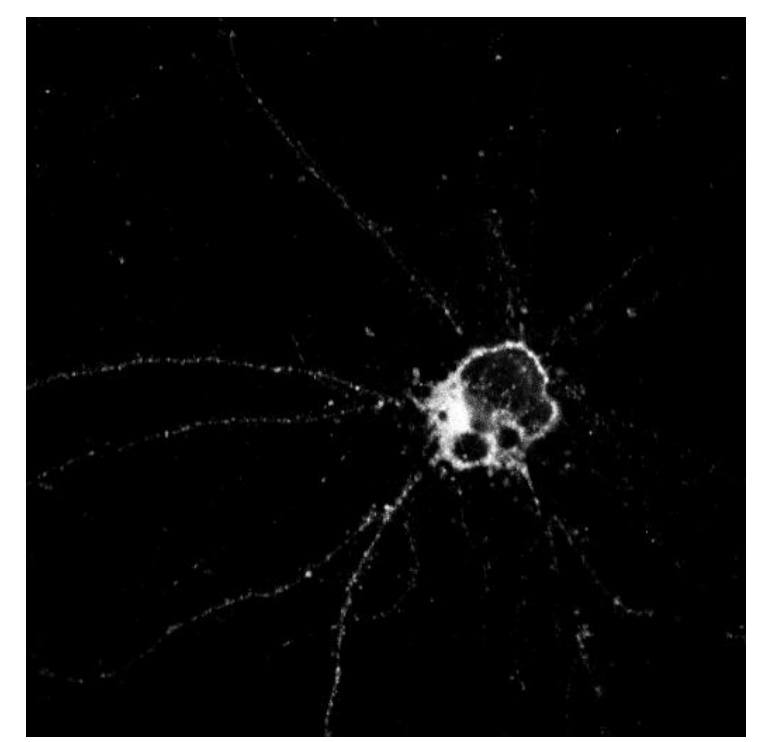

Abb. 3.38 Neuron, infiziert mit $\mathrm{pCaV}_{2.1}+798$ : Inkubation $30 \mathrm{~min}, 5 \mu \mathrm{M}$ Substrat, $0,5 \mu \mathrm{M} \mathrm{Sfp}, 20^{\circ} \mathrm{C}$ 


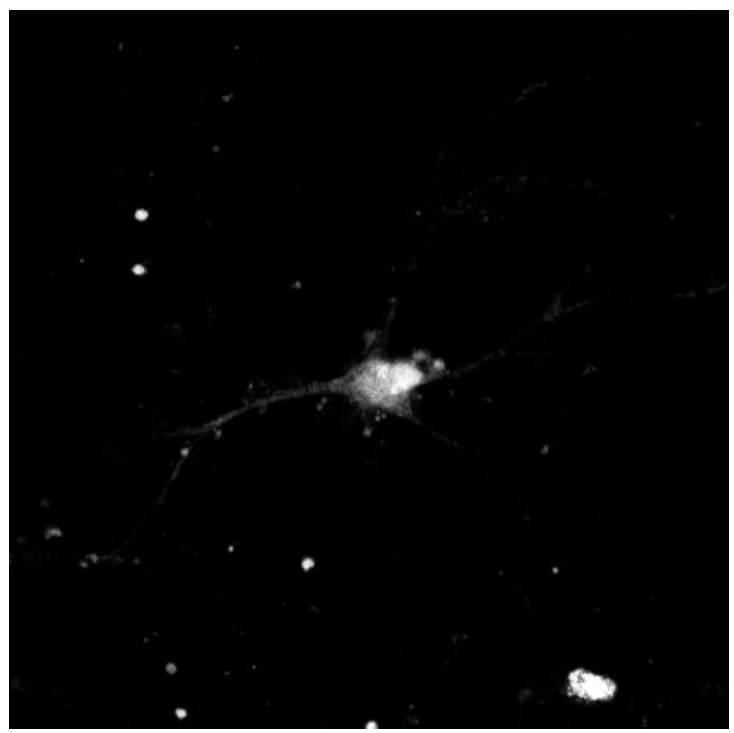

Abb. 3.39 Neuron, infiziert mit $\mathrm{pCaV}_{2.1}+810$ : Inkubation $30 \mathrm{~min}, 5 \mu \mathrm{M}$ Substrat, $0,5 \mu \mathrm{M}$ Sfp, $20^{\circ} \mathrm{C}$

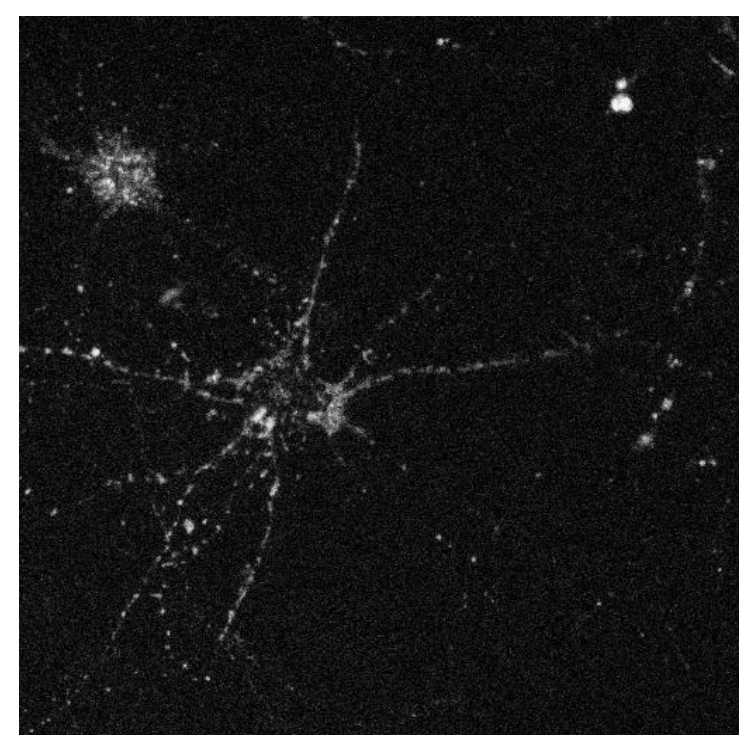

Abb. 3.40 Neuron, nicht infiziert: Inkubation $30 \mathrm{~min}, 5 \mu \mathrm{M}$ Substrat, $0,5 \mu \mathrm{M} \mathrm{Sfp}, 20^{\circ} \mathrm{C}$

Auch nach Analyse dieser Ergebnisse war es nicht möglich, sich abschließend festzulegen, ob es hierbei zu einer spezifischen Anfärbung der Calciumkanäle gekommen ist. Trotz der anfangs relativ überzeugenden Färbung der Zellmembran der Neuronen (Abb. 3.38 und 3.39) erbrachte die konfokalmikroskopische Analyse der Kontroll-Neuronen, welche nicht infiziert worden waren, dass diese ähnlich wie die infizierten Neuronen zahlreiche Fluoreszenzfarbstoffkonglomerate aufwiesen (Abb. 3.40). Aus diesem Grund war es sehr schwer zu unterscheiden, ob es sich bei den Konglomeraten der infizierten Neuronen um gefärbte Calciumkanäle oder eher um eine unspezifische Färbung handelte.

Zur Klärung des Sachverhalts wurde die Spezifität der Färbung erhöht, indem das Experiment wiederholt worden ist, es diesmal jedoch mit einer Kombinati- 
on aus zwei unterschiedlichen, parallelen Färbemethoden durchgeführt worden ist. Es wurde zu diesem Zweck allerdings das Ziel verlassen, lebende Zellen zu färben, da als zweite Färbungsmethode eine Antikörperreaktion mit fixierten Zellen gewählt wurde.

Die Neuronen wurden zunächst mithilfe des gleichen Protokolls, wie es für das Labeling der Neuronen in den vorangegangenen Experimenten benutz† worden war, gefärbt. Anschließend wurden diese Zellen fixiert. Daraufhin erfolgte die Applikation eines spezifischen Antikörpers gegen VGlutl, einen Glutamattransporter der Vesikel, in Kombination mit dem an den Sekundärantikörper GaGp gebundenen Fluoreszenzfarbstoff Alexa 647.

Auf diese Weise sollten zum einen die ACP-Tag-tragenden Calciumkanäle mithilfe des CoA-Substrates und zum anderen der Glutamattransporter VGlut1 mithilfe von Anti-VGlut1 und GaGp A647 mit Fluoreszenzmolekülen markiert werden.

Das Ziel war es, bei einer Korrespondenz der durch beide Fluoreszenzfarbstoffe angefärbten Areale der Zellmembran Rückschlüsse auf die Herkunft der Signale ziehen zu können.

Korrespondierende Fluoreszenzsignale sowohl bei $547 \mathrm{~nm}$ (ACP-Tag) als auch bei $647 \mathrm{~nm}$ (VGlutl der Vesikel) würden die Vermutung nahe legen, dass tatsächlich Calciumkanäle mit assoziierten Vesikeln markiert wurden (Abbildungen 3.41 und 3.42).
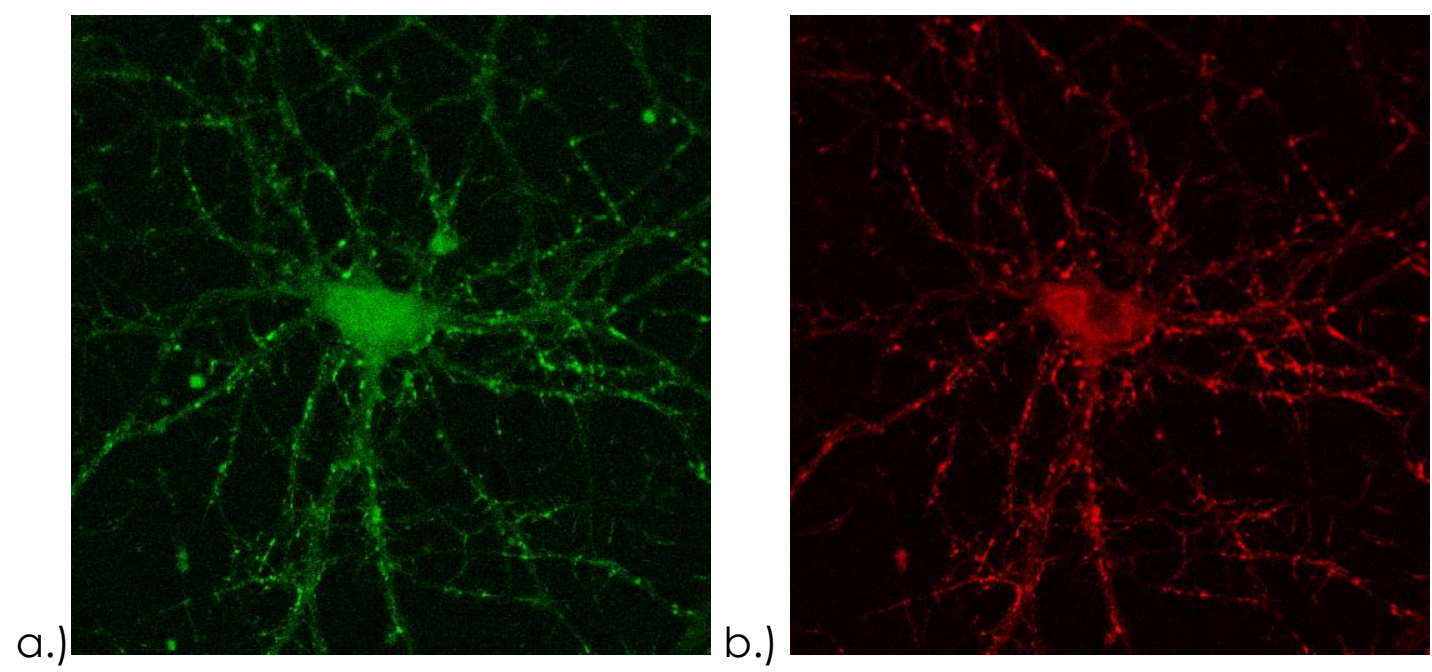

Abb. 3.41 Neuron, infiziert mit $\mathrm{pCaV}_{2.1}+798$ sowie Applikation des Antikörpers Anti-VGlut1: In-

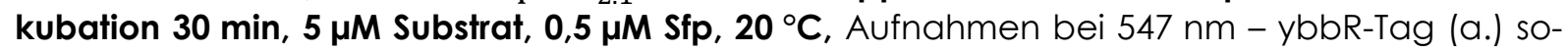
wie bei $647 \mathrm{~nm}$ - Anti-VGlutl (b.) 


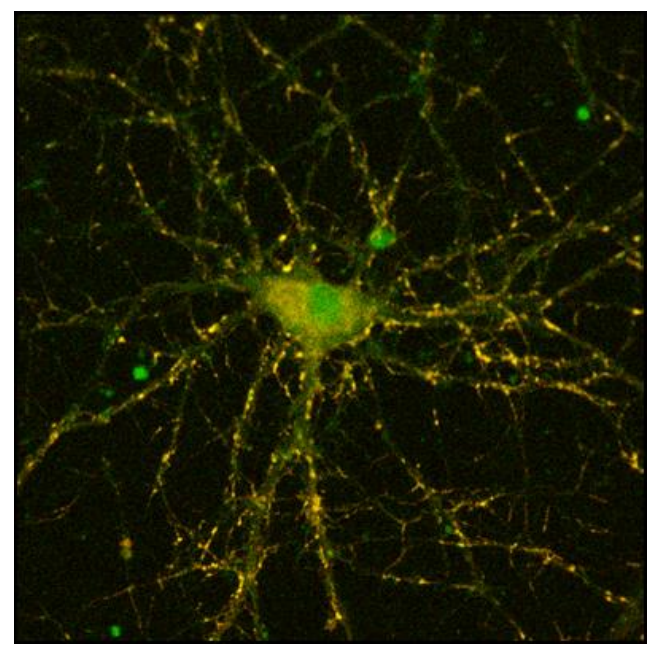

Abb. 3.42 Überlagerung der Aufnahmen bei $547 \mathrm{~nm}$ und $647 \mathrm{~nm}$ (ybbR-Tag bzw. Anti-VGlut1)
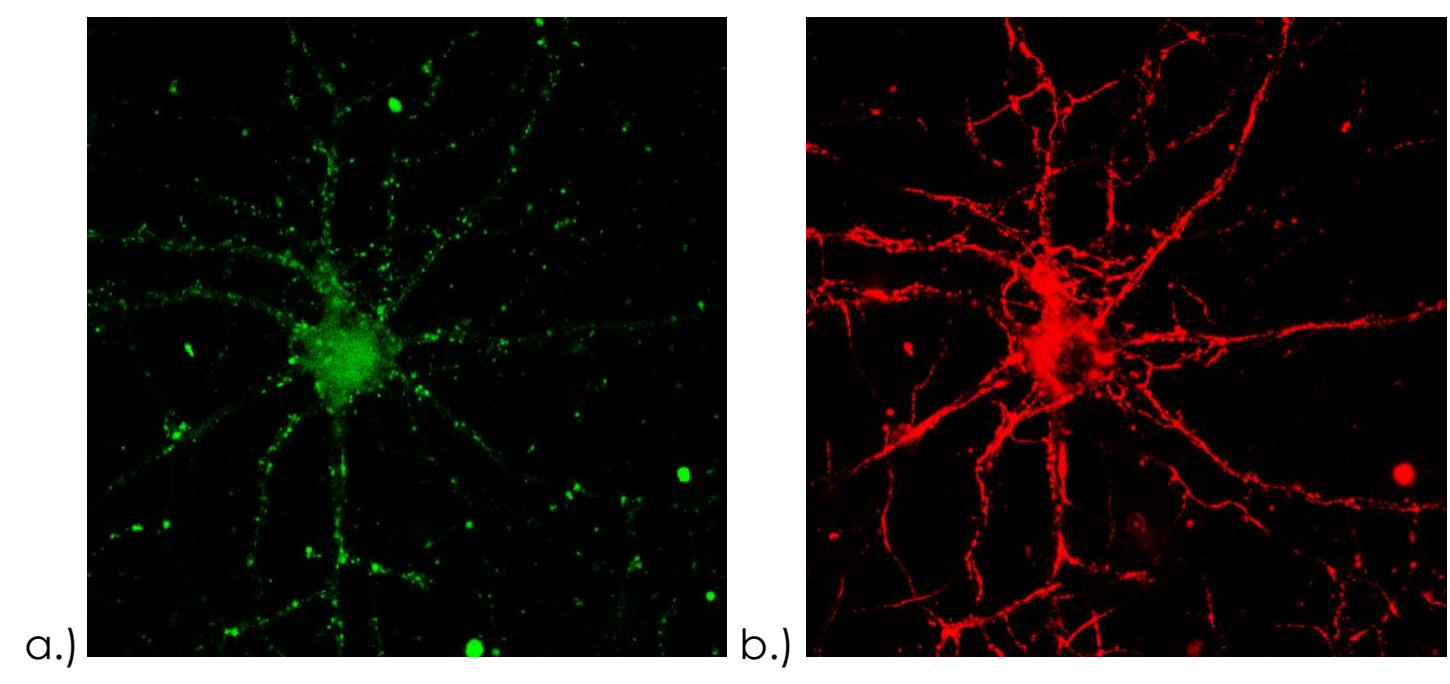

Abb. 3.43 Neuron, infiziert mit $\mathrm{pCaV}_{2.1}+\mathbf{8 1 0}$ sowie Applikation des Antikörpers Anti-VGlut1: In-

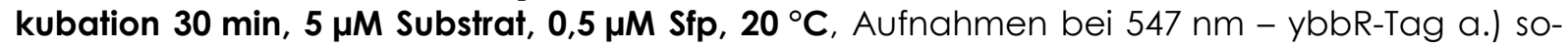
wie bei $647 \mathrm{~nm}$ - Anti-VGlutl (b.) 


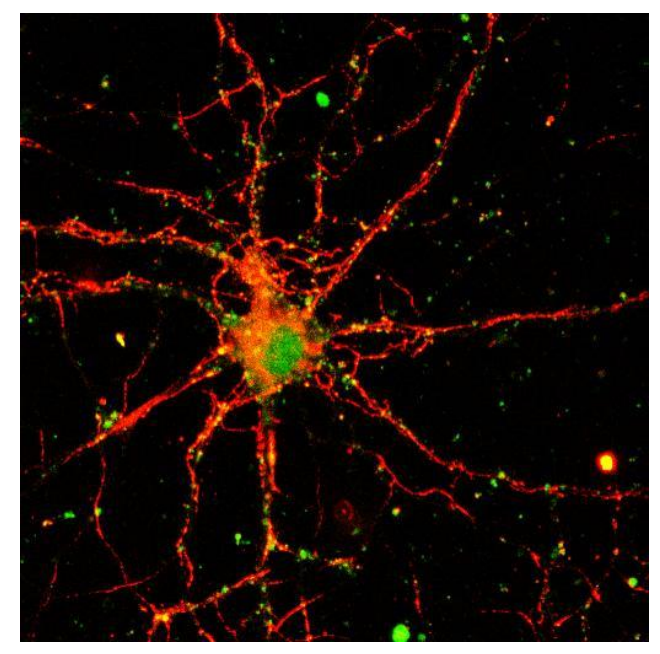

Abb. 3.44 Überlagerung der Aufnahmen bei $547 \mathrm{~nm}$ und $647 \mathrm{~nm}$ (ybbR-Tag [grün] bzw. AntiVGlut1 [rot], Überlagerung [gelb])

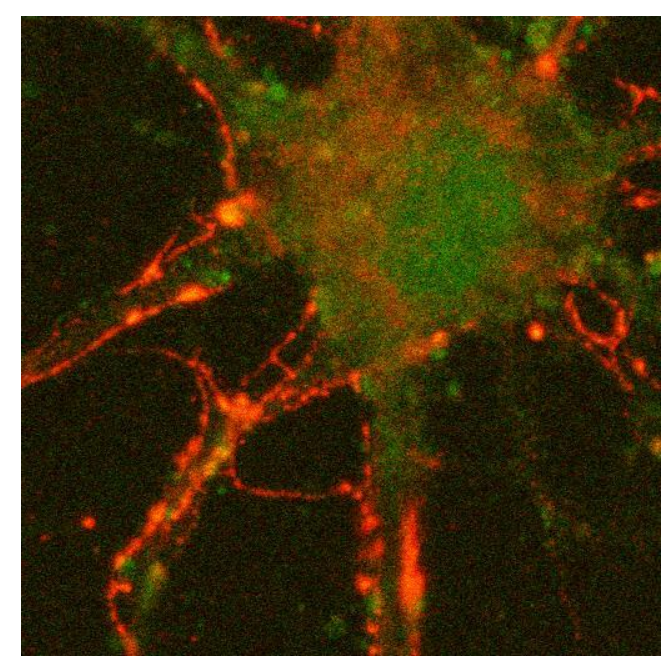

Abb. 3.45 Ausschnittsvergrößerung aus Abb. 3.44

Die ersten Bilder der auf diese Weise gefärbten Neuronen sahen zunächst sehr vielversprechend aus. Es konnten vor allem in den Dendriten und Axonen der Neuronen Bereiche mit einer starken Farbstoffanreicherung identifiziert werden, welche anfangs die Vermutung nahe legten, dass es sich hierbei um Konglomerate einer Vielzahl von Calciumkanälen samt Vesikeln handeln könnte. Dies wurde, wie weiter oben erwähnt, dadurch unterstützt, dass die Farbstoffanreicherungen bei $547 \mathrm{~nm}$, also der Wellenlänge des CoA-ACPSubstrates, sich genau an denselben Stellen befanden wie auch die Konglomerate bei $647 \mathrm{~nm}$, der Wellenlänge des VGlut1-Antikörperfarbstoffes.

Als Kontrolle erfolgte daraufhin die Färbung nicht infizierter Neurone (Abb. 3.46). 


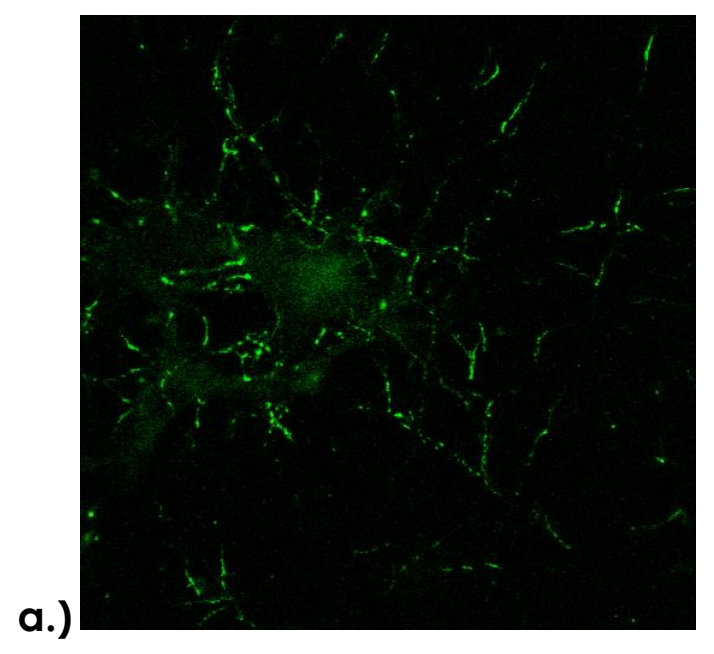

b.)

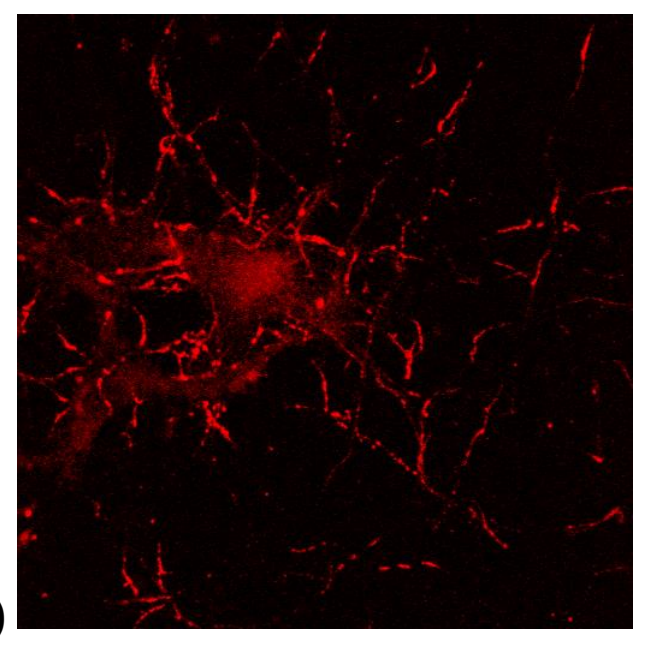

Abb. 3.46 Neuron, nicht infiziert, nicht gefärbt, Anti-VGlut1: Inkubation $\mathbf{3 0}$ min, $\mathbf{5} \mu \mathrm{M}$ Substrat, $0,5 \mu \mathrm{M}$ Sfp, $20^{\circ} \mathrm{C}$, Aufnahmen bei $547 \mathrm{~nm}$ - ybbR-Tag (a.) sowie bei $647 \mathrm{~nm}$ - VGlutl (b.)

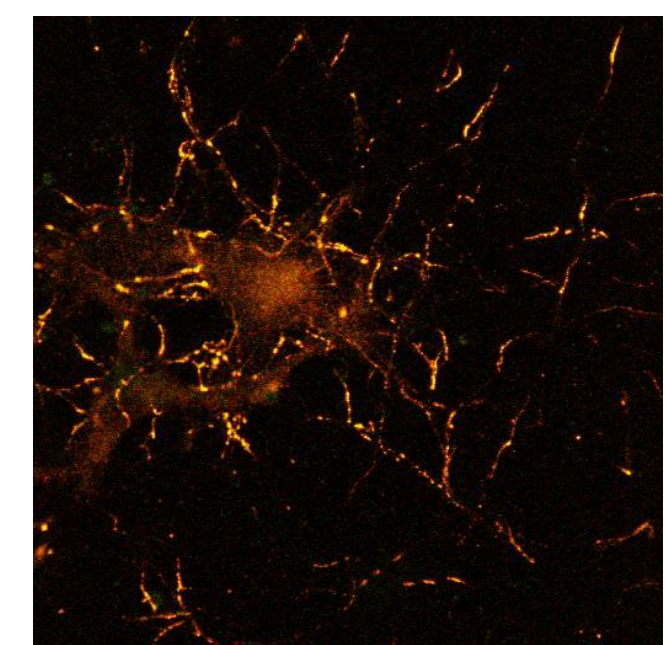

Abb. 3.47 Überlagerung der Aufnahmen bei $547 \mathrm{~nm}$ und $647 \mathrm{~nm}$ (ybbR-Tag [grün] bzw. AntiVGlut1 [rot], Überlagerung [gelb])

Bedauerlicherweise traten auch bei der Färbung der nicht infizierten Neuronen korrespondierende Farbstoffanreicherungen auf (Abb. 3.47).

Dies ließ vermuten, dass diese Anreicherungen im Bereich der Dendriten und Axone, welche bei einer Wellenlänge von $547 \mathrm{~nm}$ identifiziert werden konnten, durch eine spektrale Überlappung (blead-through) der durch die VGlut1/GaGp-A647-Antikörperfärbung entstandenen Fluoreszenzfarbstoffkonglomerate hervorgerufen werden könnten. Das würde bedeuten, dass es auch in diesem Falle zu keiner reproduzierbaren spezifischen Färbung der Calciumkanäle gekommen war.

Als Fazit aller Versuche, Calciumkanäle mithilfe der ACP-Tag-Methode anzufärben, musste leider festgehalten werden, dass dieses Verfahren für diesen 
Zweck nicht geeignet und nicht zielführend gewesen war. Es wurde daher ein alternativer Versuchsaufbau gewählt.

\subsubsection{STED-Mikroskopie}

Die Experimente wurden so modifiziert, dass sie mithilfe der STED-Mikroskopie durchgeführt werden konnten (siehe Kapitel 2.7.5 und 2.9).

Eine Infektion der Neuronen wurde nicht benötigt (Abb. 3.48-3.51).

Abb. 3.48-3.51

Primärneuronen, gefärbt mit Anti-VGlut1 (1:5.000), Anti-CaVext 1:100, Anti-Guineapig Alexa 488 (1:500) und Anti-rabbit Atto 647N (1:100), $20^{\circ} \mathrm{C}, 30 \mathrm{~min}$

a.)

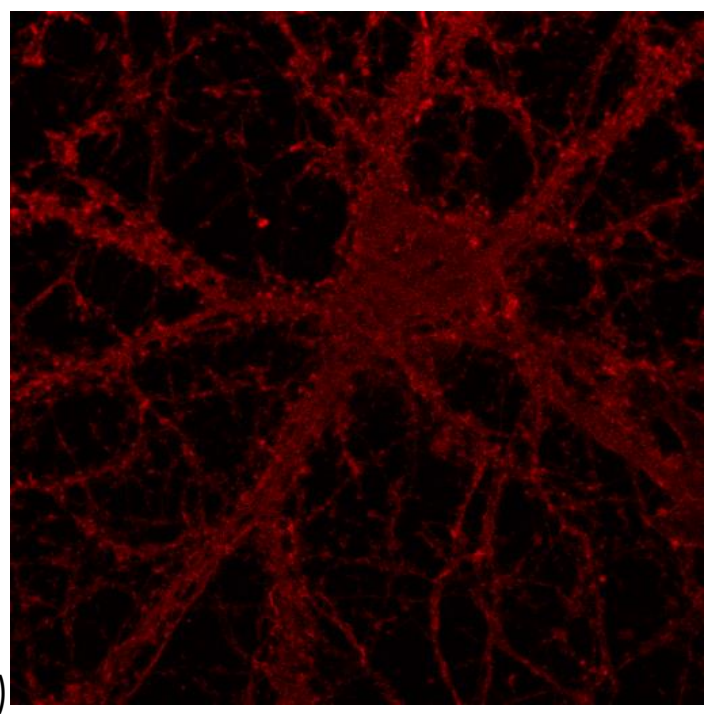

b.)

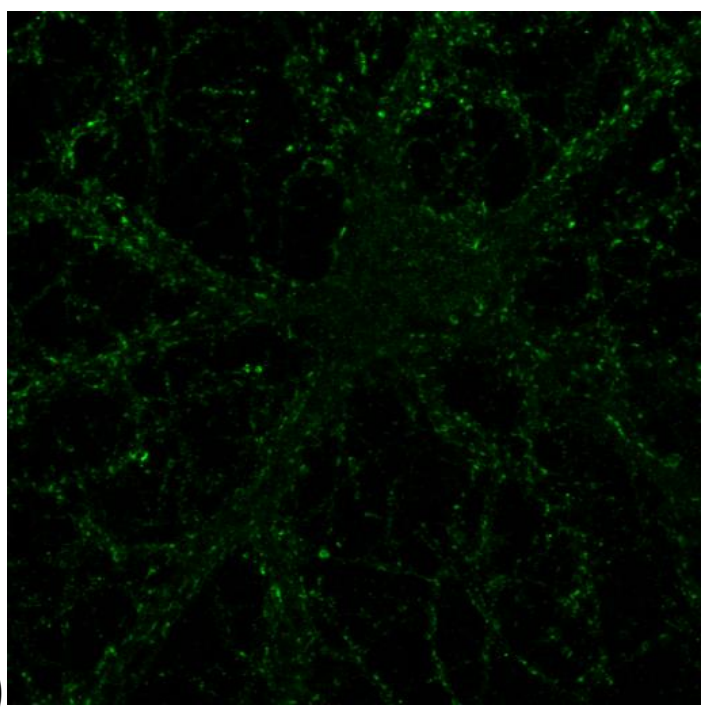

Abb. 3.48 Primärneuronen, gefärbt, konfokalmikroskopische Aufnahme: Wellenlänge $647 \mathrm{~nm}$

- CaVext (a.) sowie 488 nm - Anti-VGlutl (b.)

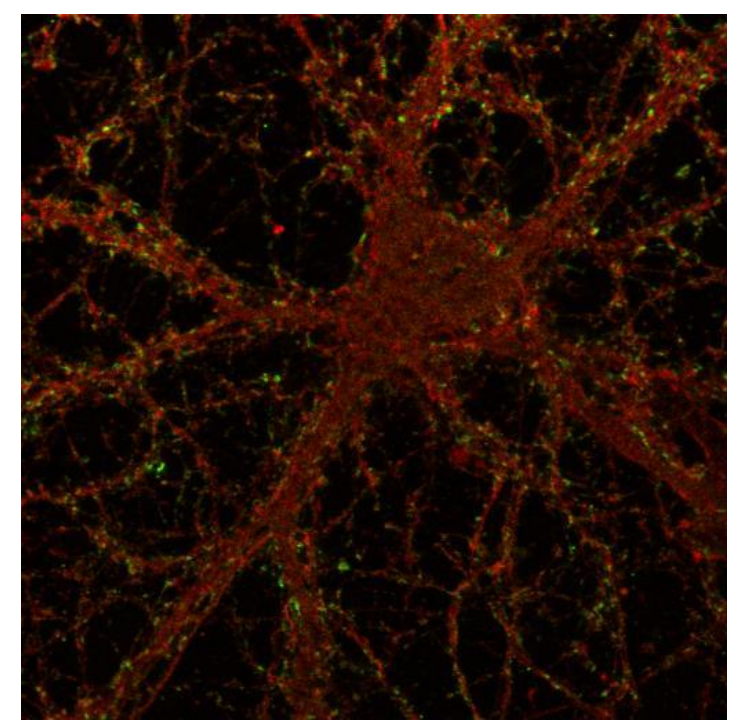

Abb. 3.49 Überlagerung der Aufnahmen bei $488 \mathrm{~nm}$ und $647 \mathrm{~nm}$ (Anti-VGlut][grün] bzW. CaVext [rot], Überlagerung [gelb]) 

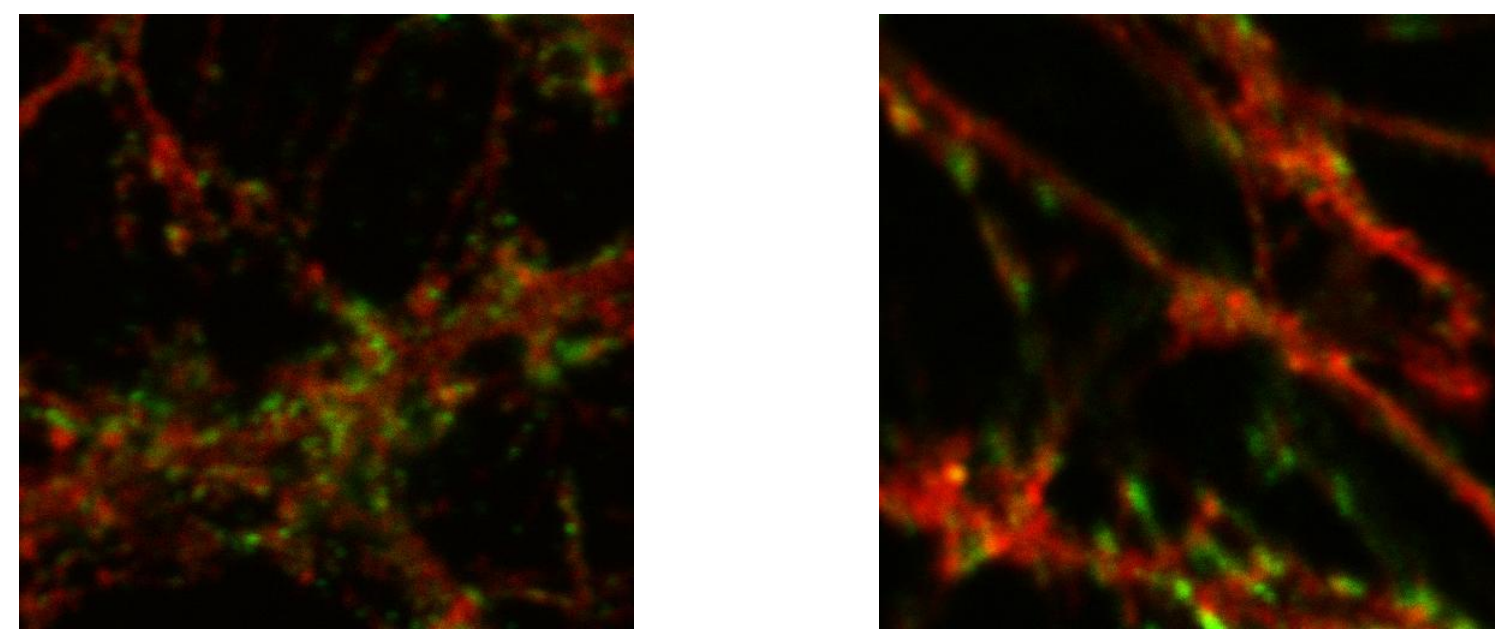

Abb. 3.50 Ausschnittsvergrößerungen aus Abb. 3.49
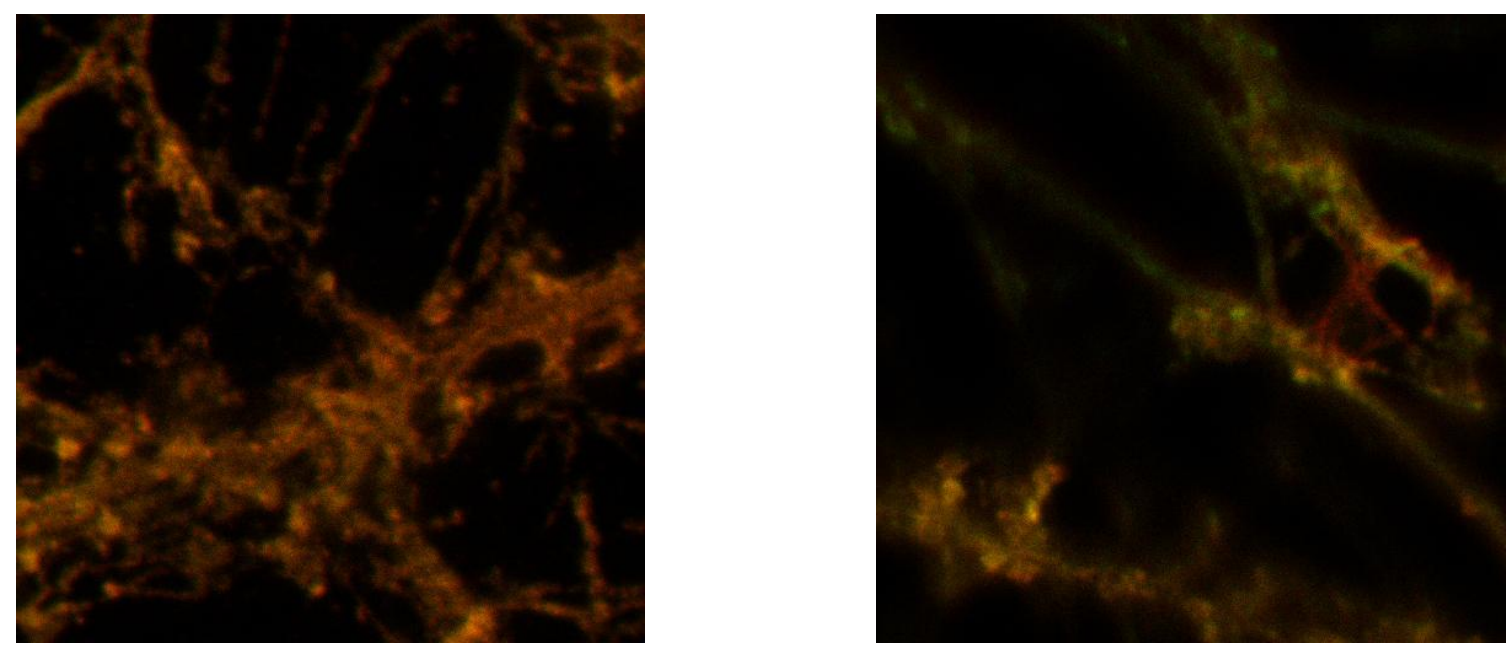

Abb. 3.51 Überlagerung der Ausschnittsvergrößerungen bei $488 \mathrm{~nm}$ und $647 \mathrm{~nm}$ im STED-

Mikoskop (Anti- VGlutl [grün] bzw. CaVext [rot]), Verwendung der Avalanche Photo Diode

Beim Betrachten der Abbildungen 3.48 - 3.51 ließ sich erkennen, dass das STED-Prinzip funktionierte. Das Auflösungsvermögen des STED-Mikroskops (Abb. 3.51) übertraf das des konventionellen Konfokalmikroskops (Abb. 3.50) deutlich.

Anfangs wurde dieses Resultat positiv bewertet, da davon ausgegangen wurde, dass mithilfe des STED-Mikroskops tatsächlich ein detailreiches Bild der Calciumkanäle erzeugt werden konnte (Abb. 3.51).

Weiterführende Untersuchungen im Elektronenmikroskop zeigten jedoch, dass die Farbstoffkonglomerate, welche im STED-Mikroskop identifiziert werden konnten, auf eine unspezifische Bindung der Antikörper innerhalb der dendriti- 
schen Dornfortsätzen der Neuronen zurückzuführen waren (Abb. 3.52) [PEDERSEN 2009].

Aufgrund dieses Resultats war wiederum davon auszugehen, dass es auch in diesem Falle zu keiner spezifischen Färbung der an der präsynaptischen Zellmembran der Neuronen befindlichen P/Q-Typ-Calciumkanäle gekommen war.

Dieses endgültig als negativ zu wertende Ergebnis führte schließlich zu dem Entschluss, alle Experimente an dieser Stelle abzubrechen. Es musste resümiert werden, dass eine Visualisierung der P/Q-Typ-Calciumkanäle mit den gewählten Methoden nicht zufriedenstellend durchführbar war.

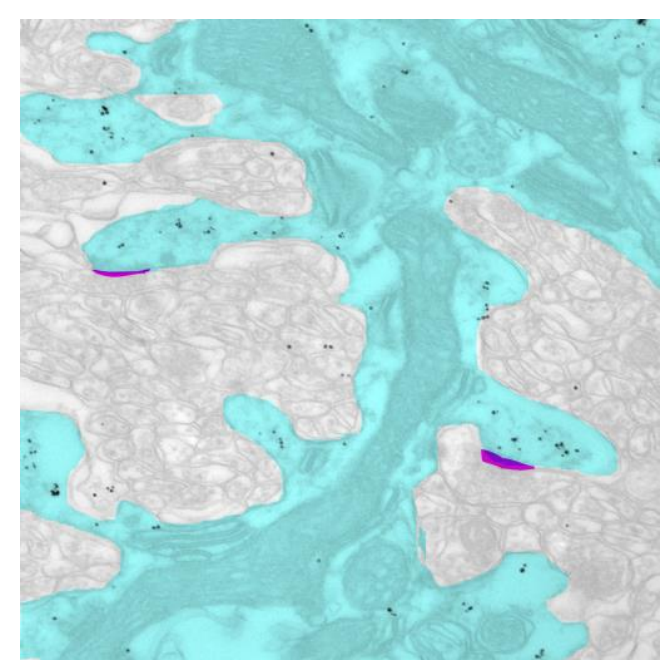

Abb. 3.52 Farbstoffkonglomerate im dendritischen Dornfortsatz (EM-Bild, Vergrößerung 30.000x) Zu erkennen sind ein Dendrit einer Purkinje-Zelle (blau), die aktiven Zonen an diesen Dendriten (lila) sowie die umgebenden Gliazellen (grau). Die Farbstoffkonglomerate (schwarz) sind nicht in den aktiven Zonen, in welcher sich die Mehrzahl der Calciumkanäle befindet, konzentriert, sondern sind relativ diffus im Dendriten verteilt. (Diese Aufnahme wurde freundlicherweise von Frau Dr. Pedersen zur Verfügung gestellt.) 


\section{Diskussion}

\section{1 Übersicht}

Das Ziel dieser Arbeit war es, die Verteilung und die Anzahl von P/Q-TypCalciumkanälen in der aktiven Zone sowie ihre örtliche Beziehung zu den synaptischen Vesikeln zu bestimmen.

Inspiriert durch mehrere Arbeiten, z.B. SAKABA und NEHER (2001b) bzw. MEINRENKEN et al. (2002), wurde versucht, diese Kanäle hinsichtlich ihrer genaven Lokalisation sowie der möglichen Existenz zweier Vesikelpopulationen mit unterschiedlichen Transmitterfreisetzungsgeschwindigkeiten näher zu charakterisieren.

Dazu war es zunächst nötig, die Calciumkanäle optisch darzustellen. Diese Darstellung erfolgte anfangs mithilfe der Konfokalmikroskopie. Für die Akquise hochauflösender Daten erfolgte der Einsatz der STED-Mikroskopie bzw. der Elektronenmikroskopie.

Für die Wahl des geeigneten Färbeverfahrens war eine grundlegende Voraussetzung, möglichst lebende Zellen färben zu können. Dadurch sollte es möglich werden, in späteren Experimenten auch dynamische Prozesse durch eine gezielte Modifikation bzw. Stimulation der lebenden Zellen analysieren zu können.

Die Darstellung und Charakterisierung von Calciumkanälen ist seit vielen Jahren Gegenstand wissenschaftlicher Arbeiten. Die Anzahl und die Ergebnisse dieser Arbeiten sind, bezogen auf die einzelnen Calciumkanal-Subtypen, allerdings ausgesprochen heterogen.

Die Mehrheit aller wissenschaftlichen Arbeiten wurde mit L-TypCalciumkanälen durchgeführt, sodass für diese die umfangreichsten Daten vorliegen.

Schwerpunkt der meisten vorangehenden Arbeiten war die selektive Färbung der Calciumkanäle in der Zellmembran. So konnte z.B. durch immunohistochemische Arbeiten von HELL et al. (1993), durch Einsatz von Antikörper gegen die Calciumkanal-Untereinheiten $\alpha_{1 \mathrm{C}}(\mathrm{CNC} 1)$ bzw. $\alpha_{1 \mathrm{D}}(\mathrm{CND} 1)$, die Verteilung von L-Typ-Calciumkanälen in Neuronen des Hippocampus, des Kortex bzw. des Cerebellums bestimmt werden.

Später erfolgten durch WESTENBROEK et al. (1998) Charakterisierungen der somatodendritischen Distribution aller bekannten $\alpha_{1}$-Untereinheiten in GABAergen Nervenzellen der spinalen Motorneuronen der Ratte.

Die Arbeit von DAVARE et al. (2001) untersuchte an adrenergen $\beta_{2}$ Rezeptoren die Lokalisation der $\alpha_{1 C}$-Untereinheit im exzitatorischen postsynaptischen Kompartment der Synapsen mithilfe einer doppelten Immunofluoreszenzförbung. 
OBERMAIR et al. (2004) führten in kultivierten Neuronen des Hippocampus der Maus eine optische Darstellung von L-Typ-Calciumkanälen mithilfe eines extrazellulären HA-Tags in Form einer Immunofluoreszenzdarstellung durch. Diese Darstellung erfolgte sowohl in Neuronen, welche vor der Färbung fixiert worden waren, als auch in Zellen, welche erst gefärbt und dann fixiert worden waren (, live cell staining").

Weitere positive Ergebnisse bezüglich der Färbung von L-Typ-Calciumkanälen erzielten ZHANG $\mathrm{H}$ et al. (2005) mithilfe der Antikörper Anti-Synapsin pAb (Synapse) und Anti-CaV ${ }_{13 a}$ pAb (Calciumkanal). Dadurch konnten Areale, in denen eine korrespondierende Bindung beider Antikörper registriert werden konnte, als Calciumkanalakkumulationen in den aktiven Zonen der Synapsen identifiziert werden.

Neben den wissenschaftlichen Abhandlungen über L-Typ-Calciumkanäle erfolgten einige Arbeiten an T-Typ- und N-Typ-Calciumkanälen [z.B. MAXIMOV und BEZPROZVANNY 2002], jedoch ist die genaue Lokalisationsbestimmung dieser Kanäle noch nicht so weit fortgeschritten, wie dies bei L-TypCalciumkanälen der Fall ist.

Dies gilt auch für die nähere Untersuchung der P/Q-Typ-Calciumkanäle, welche die Grundlage für die vorliegende Arbeit bildeten.

TIMMERMANN et al. (2002) verwendeten z.B. zur Calciumkanaldarstellung von Neuronen des zerebralen Cortex der Maus zwei Antikörper, Anti-CNA5 und Anti-CNA6, welche selektiv gegen verschiedene Splicevarianten der $\alpha_{1 A}$ Untereinheit von P/Q-Typ-Calciumkanälen gerichtet waren [SAKURAI et al. 1996].

In jener Arbeit wurde die genaue Distribution dieser Splicevarianten in den unterschiedlichen Kompartimenten eines Neurons analysiert.

Zuvor gelang WU et al. (1999) unter Verwendung der Antikörper Anti-CNA5 (gegen die $\alpha_{1 \mathrm{~A}}$-Untereinheit), Anti-CNE2 (gegen die $\alpha_{1 \mathrm{E}}$-Untereinheit) und Anti-CNB2 (gegen die $\alpha_{1 \mathrm{~B}}$-Untereinheit) in Verbindung mit Anti-Synaptotagmin eine Darstellung der Distribution von P/Q-Typ-, N-Typ- bzw. R-TypCalciumkanälen an der Held'schen Calyx der Ratte.

HEBLICH et al. (2008) führten eine Darstellung der P/Q-Typ-Calciumkanäle in tsA201-HEK293-Zellen mithilfe eines doppelten HA-Tags durch, welches vorher in einen extrazellulären Loop der $\alpha_{1 \mathrm{~A}}$-Untereinheit $\mathrm{CaV}_{2.1}$ integriert worden war. Diese Färbung wurde sowohl an permeabilisierten als auch an nicht permeabilisierten fixierten Zellen durchgeführt.

WATSCHINGER et al. (2008) verwendeten eine ähnliche Methode zur Darstellung von P/Q-Typ-Calciumkanälen. Jedoch wurden in dieser Arbeit Hippocampusneuronen der Maus benutzt. Neben des Labelings vorher fixierter und permeabilisierter bzw. nicht permeabilsierter Neuronen wurden auch Versuche unternommen, die Calciumkanäle in Neuronen zu identifizieren, welche erst nach der Färbereaktion fixiert worden waren (,live cell staining"). 
Aufgrund der Bedingung, lebende Zellen ohne vorangegangene Fixierung darzustellen, wurde zur optischen Darstellung der Kanäle das ACP-Tag verwendet.

Neben der Wahl des Tags unterschied sich der gewählte Ansatz von den o.g. Arbeiten dahingehend, dass es das Bestreben war, hochauflösende Daten mithilfe der STED-Mikroskope bzw. der Elektronenmikroskopie zU akquirieren.

Mithilfe des SFPs bzw. der AcpS wäre es z.B. möglich gewesen, an Coenzym A gekoppelte Goldpartikel an die P/Q-Typ-Calciumkanäle zu binden. Auf diese Weise hätte eine elektronenmikroskopische Analyse der Kanäle mit einer genaveren Lokalisationsbestimmung durchgeführt werden können.

Trotz eines von diesen Vorgaben abweichenden Ergebnisses lassen sich aus der vorliegenden Arbeit jedoch die folgenden Aussagen ableiten.

\subsection{Interpretation der Ergebnisse}

\section{Das ACP-Tag lässt sich erfolgreich in die $\alpha_{1}$-Untereinheit $\mathrm{CaV}_{2.1}$ integrieren, ohne die Funktion des Calciumkanals zu stören.}

Die durchgeführte Gelelektrophorese der Vektoren pUC19+ybbR (Abb. 3.1) und $\mathrm{pCaV}_{2.1}+\mathrm{ybbR}$ (Abb. 3.3) sowie die Sequenzierungen von pUC19+ybbR (Abb. 3.2) bestätigten die korrekte Integration des ybbR-Tags in die $\alpha_{1}$ Untereinheit $\mathrm{CaV}_{2.1}$.

Zur geplanten späteren Durchführung dynamisch-optischer Darstellungen an lebenden Zellen war es eine grundlegende Voraussetzung, dass die Calciumkanäle trotz integriertem Tag in ihrer Funktionsfähigkeit nicht entscheidend eingeschränkt werden durften. Aus diesem Grund war eine Überprüfung der Ionenströme, welche die Kanäle passierten, mittels der Patch-Clamp-Technik von großer Bedeutung.

Die Analyse der durch $\mathrm{Ca}^{2+}$-Einstrom induzierten Ströme in HEK293-Zellen mit integriertem ACP-Tag ergab, dass alle Zellen funktionsfähige Calciumkanäle exprimierten. Der Vergleich der Messwerte dieser Zellen mit jenen, welche die Wildtyp- $\alpha_{1}$-Untereinheit exprimierten, ließ des Weiteren auf eine Beeinflussung der Kinetik der Calciumkanäle schließen. Dies lieferte einen Hinweis darauf, dass das ACP-Tag mit großer Wahrscheinlichkeit zusammen mit dem Calciumkanal exprimiert worden war.

Auch der Vergleich der HEK293-Zellen, in welche jeweils Tags an verschiedenen Positionen innerhalb der DNA der $\mathrm{CaV}_{2.1}$-Untereinheit integriert worden waren, untereinander ergab unterschiedliche Ergebnisse (Abb. 3.12, 3.13 und Tabellen 3.1, 3.2).

Die besten Resultate bei der Analyse der HEK293-Zellen mit integriertem ACPTag ergaben sich bei jenen Zellen, welche mit den Vektoren $\mathrm{pCaV}_{2.1}+798$ bzw. $\mathrm{pCaV}_{2.1}+810$ transfiziert worden waren. 
Diese Ergebnisse standen im Einklang mit den Arbeiten, welche Frau Dr. Pedersen am Max-Planck Institut für biophysikalische Chemie zuvor durchgeführt hatte [PEDERSEN 2008].

Der Versuchsaufbau sah dort den Einbau eines HA-Tags in die $\mathrm{CaV}_{2.1^{-}}$ Untereinheit vor. Auch die Ergebnisse von PEDERSEN (2008) ergaben, dass ein Tag, welches zwischen den Basenpaaren 798/799 bzw. 810/811 (gezählt vom $\mathrm{N}$-Terminus aus) integriert worden war, die besten Ergebnisse aufwies.

\section{Mithilfe des adenoviralen Expressionssystems lassen sich Primärneuronen infi- zieren, sodass sie GFP und das ybbR-ACP-Tag exprimieren.}

Mithilfe der Sequenzierung des Vektors pDC511 konnte ein korrekter Einbau des ybbR-Tags bestätigt werden (Abb. 3.6).

Fünf Tage nach der Infektion der Neuronen emittierte die überwiegende Anzahl ein grünes Fluoreszenzsignal unter blavem Licht, sodass von einer erfolgreichen Expression des GFPs und damit auch der getaggten $\mathrm{CaV}_{2.1^{-}}$ Untereinheit ausgegangen werden konnte.

\section{Mithilfe des ACP-Tags lassen sich selektive Membranproteinfärbungen durch- führen.}

Zur Determination der optimalen Kombination der Parameter Inkubationszeit und Inkubationstemperatur bzw. Enzym- und Substratkonzentration sowie zur Überprüfung der prinzipiellen Durchführbarkeit dieses Verfahrens unter den im Labor herrschenden Bedingungen wurde zunächst eine Färbungen mithilfe transfizierter HEK293- bzw. ErbB 1-CHO-Zellen durchgeführt, in welche zuvor ein 78 Aminosäuren langes ACP-Tag in unmittelbarer Nähe zum EGFR kloniert worden war.

Mit der als am günstigsten zu wertenden Kombination aus einer Enzymkonzentration des $\mathrm{Sfp}$ bzw. AcpS von $0,5 \mu \mathrm{M}$, einer Substratkonzentration von $5 \mu \mathrm{M}$, einer Inkubationstemperatur von $20^{\circ} \mathrm{C}$ sowie einer Inkubationsdaver von 30 min, wurden gute Ergebnisse bezüglich der Membranfärbung erzielt (Abb. 3.19).

Das ybbR-Tag eignet sich, um selektive Membranproteinfärbungen durchzuführen.

Der Vektor pDisplay wurde verwendet, um das ybbR-Tag in der Plasmamembran von HEK293-Zellen exprimieren zu können. Dabei wurden die Eigenschaften dieses Vektors genutzt, exprimierte Proteine unter Verwendung des sekretorischen Pfades an die Zellmenbran zu befördern, um diese mithilfe des PDGFRs in der Zellmembran zU verankern.

Die nach Integration der GFP- und ybbR-Sequenzen in den Vektor pDisplay (Abb.3.5) sowie nach Transfektion der HEK-Zellen durchgeführte Färbung 
ergab, dass mithilfe des ybbR-Tags eine selektive Membranfärbung möglich war. Diese Ergebnisse waren unabhängig vom verwendeten Enzym, Sfp bzw. AcpS, miteinander vergleichbar (Abb. 3.25 und 3.33).

Diese Resultate suggerierten, dass das ybbR-Tag geeignet sein könnte, in P/QTyp-Calciumkanäle integriert zu werden und dass diese so optisch dargestellt werden könnten.

\section{Die Integration des ybbR-Tags in die $\alpha_{1}$-Untereinheit $\mathrm{CaV}_{2.1}$ führte weder in HEK293-Zellen noch in Primärneuronen zu einer spezifischen und reproduzier- baren Färbung von Calciumkanälen.}

Auf Basis der Daten, welche mithilfe des Vektors pDisplay+ybbR akquiriert worden waren, wurde zunächst eine Transfektion der HEK293-Zellen mit den jeweiligen Vektoren $\mathrm{CaV}_{2.1}+786, \mathrm{CaV}_{2.1}+792, \mathrm{CaV}_{2.1}+798$ bzw. $\mathrm{CaV}_{2.1}+810$ durchgeführt. Im Anschluss erfolgte die Färbung mit einer Inkubationszeit von 30 min bei $20^{\circ} \mathrm{C}$ und $5 \mu \mathrm{M}$ des ACP-Substrats bzw. 0,5 $\mu \mathrm{M}$ des jeweiligen Enzyms.

Weder die Sfp- noch die AcpS-katalysierte Reaktion führte zu einem zufriedenstellenden Ergebnis (Abb. 3.29 - 3.32 bzw. 3.34 - 3.37). Auch eine weitergehende Variation der Inkubationsparameter erbrachte keine deutlichen Verbesserungen. Bei den durchgeführten Experimenten kam es zu einer nicht selektiven, unspezifischen Färbung aller Zellen, unabhängig davon, ob diese transfiziert worden waren oder nicht.

Nach dem erfolglosen Versuch, die in HEK293-Zellen exprimierten, getaggten Calciumkanäle optisch darzustellen, wurden die Experimente auf Primärneuronen ausgeweitet.

Da eine Transfektion nach der Calciumphosphat-Präzipitationsmethode bei Primärneuronen nicht ohne weiteres möglich ist, wurde ein adenovirales Expressionssystem angewandt [YOUNG und NEHER 2009], um Calciumkanäle mit der getaggten $\mathrm{CaV}_{2.1}$-Untereinheit gemeinsam mit GFP in Neuronen exprimieren zu können. Zwar verlief die Infektion erfolgreich (Kap. 3.5.6), jedoch wurde auch diesmal keine eindeutige, selektive Färbung erzielt, da sich diese Resultate nicht deutlich von denen bei Verwendung nicht infizierter Neuronen unterschieden (Abb. 3.40).

Als nächste Variation erfolgte neben der ACP-Labeling-Reaktion eine Fixierung der Neuronen sowie die Applikation des Antikörpers Anti-VGlutl gemeinsam mit dem Sekundärantikörper GaGp A647, um auf diese Weise einen besseren Kontrast zwischen infizierten und nichtinfizierten Neuronen zu erreichen. Jene Bereiche der Zellmembran, die sowohl bei Verwendung von GaGp A647 (Vesikel) als auch vom ACP-Substrat $\left(\mathrm{CaV}_{2.1}\right)$ eine hohe Signalintensität aufwiesen, würden auf eine tatsächliche Anfärbung von membranständigen Calciumkanälen hinweisen. 
Zwar konnten bei der Analyse dieser Färbung tatsächlich korrespondierende Signalverstärkungen sowohl bei einer Wellenlänge von 647 nm (GaGp A647), als auch von $547 \mathrm{~nm}$ (ACP-Substrat) registriert werden, jedoch waren diese Signalverstärkungen ebenso bei nicht infizierten Neuronen erkennbar (Abb. 3.47). Dies führte zusammenfassend zu der Annahme, dass diese Korrespondenz höchstwahrscheinlich zum größten Teil durch eine spektrale Überlappung (,,blead-through") entstanden war, sodass auch diesmal keine eindeutigen Aussagen über ein erfolgreiches Labeling der P/Q-TypCalciumkanäle getroffen werden konnten.

\section{Mithilfe des STED-Mikroskops lassen sich Strukturen in einer höheren Auflösung darstellen.}

Als abschließendes Experiment erfolgte zur Analyse der P/Q-TypCalciumkanäle eine Antikörperfärbung mithilfe der Primärantikörper AntiVGlut1 bzw. Anti-CaVext und der Sekundärantikörper Anti-Guineapig Alexa 488 und Anti-Rabbit Atto 647N durch.

Der Vergleich der konfokalmikroskopischen Aufnahmen (Abb. 3.50) mit den Bildern aus dem STED-Mikroskop (Abb. 3.51) ließ eine deutliche Zunahme des Auflösungsvermögens bei Verwendung der STED-Technologie erkennen. Jedoch war es auch mit dieser Methode nicht möglich, eine genaue Darstellung der P/Q-Typ-Calciumkanäle zu erzielen, obwohl in früheren Experimenten u.a. nachgewiesen werden konnte, dass die verwendeten Antikörper zumindest P/Q-Typ-Calciumkanäle inhibieren können und damit auch binden sollten [LIAO et al. 2008].

Es lassen sich im STED-Mikroskop zwar Calciumkanal-typische Strukturen erkennen, jedoch zeigten weiterführende elektronenmikroskopische Experimente, dass es sich bei diesen Strukturen höchstwahrscheinlich um eine nicht näher definierte Materie handelte, welche sich in den dendritischen Dornfortsätzen befand (Abb. 3.52).

Als Schlussfolgerung aus allen durchgeführten Experimenten musste leider zur Kenntnis genommen werden, dass es nicht gelungen war, P/Q-TypCalciumkanäle mit den gewählten Methoden adäquat anzufärben, um sie optisch und möglichst hochauflösend darstellen zu können. Dies führte zu der Frage:

Was könnte die wahrscheinlichste Ursache gewesen sein, die ein positives Ergebnis verhinderte? 


\subsection{Ursachensuche}

Zur Beantwortung dieser Frage lassen sich einige Hypothesen formulieren, welche es erlauben, mögliche Ursachen zu diskutieren.

\subsubsection{Inaktivierung und Konfirmationsänderung}

Zum einen besteht die Möglichkeit, dass die Labeling-Reaktion infolge einer Inaktivierung der Calciumkanäle gestört wurde.

Die Inaktivierung von Calciumkanälen kann sowohl auf einem calciumabhängigen als auch auf einem spannungsabhängigen Mechanismus beruhen. Gemein ist beiden Prozessen, dass sie höchstwahrscheinlich zu einer Konformationsänderung des Kanals führen [ECKERT und CHAD 1984]. Beide Mechanismen sind gemeinsam für eine Inaktivierung der Kanäle verantwortlich. Je nach Zelltyp ist der Anteil des jeweiligen Mechanismus an der Gesamtinaktivierung unterschiedlich groß [BROWN et al. 1981; JONES und MARKS 1989].

Durch diese Inaktivierungsmechanismen wird verhindert, dass es bei langanhaltenden bzw. stark repetitiven Depolarisationen zu einer toxischen Akkumulation von intrazellulärem Calcium kommt [CENS et al 2006]. Sie tragen außerdem fast ausschließlich zur posttetanischen Depression der EPSPs bei und spielen dadurch eine tragende Rolle bei der synaptischen Plastizität [FORSYTHE et al. 1998].

Bei der calciumabhängigen Inaktivierung besitz† Calmodulin eine zentrale Funktion, indem es von der intrazellulären Seite aus zusammen mit Calcium an der IQ-Sequenz, welche sich hinter der sog. „EF hand" des C-Terminus der $\alpha_{1}$ Untereinheit befindet, bindet und so als wichtiger Calciumsensor dient [PETERSON BZ et al. 1999; QIN et al. 1999; PITT et al. 2001] (Abb. 4.1). 


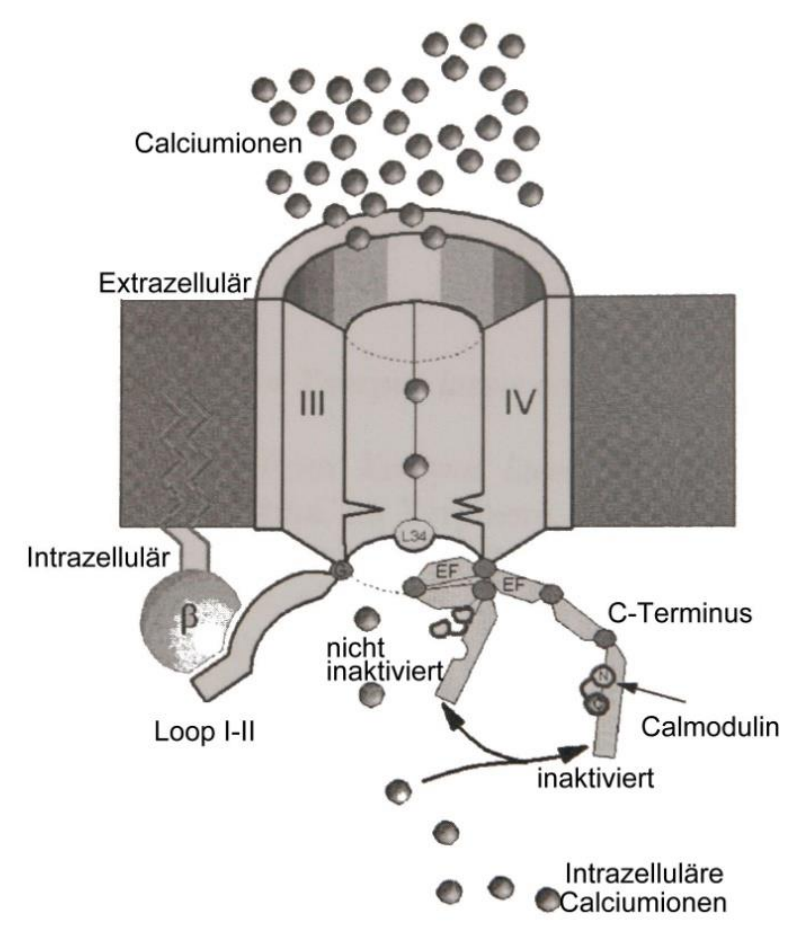

Abb. 4.1 Schematische Darstellung der Inaktivierung eines Calciumkanals (adaptiert nach CENS et al. 2006, S. 112)

Das Calmodulin ist bereits vor der Bindung des Calciums mit der $\alpha_{1}$ Untereinheit $\mathrm{CaV}_{2.1}$ assoziiert und nimmt somit auch funktionell die Rolle einer zusätzlichen Calciumkanaluntereinheit war [ERICKSON et al. 2001].

Bindet das Calcium an das N-terminale Ende des Calmodulins, führt dies bei P/Q-Typ-Calciumkanälen zu einer Konformationsänderung des Kanals [LEE et al. 1999; CHAUDHURI et al. 2004].

Da das N-terminale Ende des Calmodulins eine geringe Affinität für Calcium besitzt, kommt es vor allem bei einer Erhöhung des sog. globalen Calciums (s.o.) zu dieser Bindung, sodass hohe Calciumkonzentrationen benötigt werden [DEMARIA et al. 2001; SOONG et al. 2002].

Diese werden wiederum bei schnell aufeinanderfolgenden Aktionspotentialen erreicht und führen so verstärkt zu einer calciumabhängigen Inaktivierung [CHAUDHURI et al. 2007].

Durch eine Hyperpolarisation wird die calciumabhängige Inaktivierung im Verlauf wieder aufgehoben, da man davon ausgehen kann, dass eine $\mathrm{Hy}$ perpolarisation die Sensitivität des an die IQ-Sequenz gebundenen Calciumsensors herabsetz† [IMREDY und YUE 1994; PETERSON BZ et al. 1999]. Calmodulin erhält daher eine regulierende Funktion, indem es sowohl zur Inaktivierung der Calciumkanäle als auch zur Aufhebung der Inaktivierung beiträgt [ZÜHLKE et al. 1999].

Die zusätzlichen Untereinheiten $\beta 2$ a und $\beta 4$ wirken ebenfalls regulatorisch auf die calciumabhängige Inaktivierung [CATTERALL 2000; GEIB et al. 2002].

Wie eine durch diesen Mechanismus hervorgerufene Konformationsänderung im Detail aussehen könnte, ist aktuell noch Gegenstand der Forschung. 
Denkbar wäre z.B., dass es zU einem Umklappen des Loops I-II in Richtung der Kanalpore kommen könnte, was eine Obstruktion dieser herbeiführen würde.

Weiterhin möglich wäre auch eine Konstriktion der Pore, worin das Segment S6 involviert wäre. Diese Konstriktion wäre durch eine Lösung der Bindung des Loop I-Il bedingt, da diese im Ruhezustand die Konstriktion verhindert [CENS et al. 2006]. Hierdurch könnte das Calcium den Kanal dann nicht mehr passieren.

Eine andere, jedoch stark vereinfachte Theorie der calciumabhängigen Inaktivierung besagt, dass diese durch eine intrazelluläre Akkumulation des Calciums verursacht wird. Erreicht das Calcium demnach eine bestimmte Konzentration, können Calciumionen als divalente Kationen von der intrazellulären Seite aus in größerer Anzahl an der Pore binden und sie auf dieses Weise reversibel verstopfen, sodass kein weiteres Calcium den Kanal passieren kann [FORSYTHE et al. 1998].

Die spannungsabhängige Inaktivierung wird analog zur calciumabhängigen Inaktivierung durch eine Depolarisation hervorgerufen und führt höchstwahrscheinlich ebenfalls zu einer Konformationsänderung des Kanals [ECKERT und CHAD 1984].

Bei dieser Inaktivierung spielt die $G$-Protein-Untereinheit $\mathrm{G}_{\beta \gamma}$ eine tragende Rolle [HERLITZE et al. 1996; ZAMPONI und SNUTCH 1998]. Bei einer Depolarisation kommt es zu einer Dissoziation der $\mathrm{G}_{\beta \gamma}$-Untereinheit vom Calciumkanal und damit zu einer Aufhebung der Calciumkanal-inaktivierung. Eine fortschreitende Negativierung des Membranpotentials führt im weiteren Verlauf jedoch $\mathrm{zU}$ einer erneuten Bindung der $\mathrm{G}_{\beta \gamma}$-Untereinheit an den Calciumkanal und damit zu dessen erneuter Inaktivierung [FOX et al 2008].

Auch bei diesem Mechanismus ist die genave Morphologie der Konformationsänderung noch nicht bekannt. Es wird jedoch davon ausgegangen, dass es auf diese Weise zu einer Änderung in den $\alpha$-Helices der $\alpha_{1}$-Untereinheit kommt, was wiederum eine Veränderung der Morphologie der Kanalpore zur Folge hätte. Dadurch wird gleichzeitig der Spannungssensor des Kanals verändert. An der Pore findet sich unter anderem auch die sog. „LoopDomäne". Sie liegt zwischen den Segmenten S5 und S6 der Domäne I der $\alpha_{1}$ Untereinheit und bildet eine Art Schlaufe, welche konvex in Richtung der Pore gebogen ist und diese teilweise ausfüllt (Abb. 1.3).

Weiterhin ist denkbar, dass der Mechanismus der Inaktivierung zu einer Konstriktion der inneren Kanalpore führt, sodass durch diese kein Calcium mehr passieren kann [STOTZ et al. 2000; HERING et al. 2000; SHI und SOLDATOV 2002].

Der Mechanismus der spannungsabhängigen Inaktivierung nimmt im Allgemeinen für P/Q-Typ-Calciumkanäle einen höheren Stellenwert ein, als dies z.B. für L-Typ-Calciumkanäle der Fall ist [CENS et al. 2006]. 
Die spannungsabhängige Inaktivierung verläuft jedoch 6-10-mal langsamer als die calciumabhängige Inaktivierung [KIM et al. 2004]. Aus diesem Grund kommt es unter bestimmten Umständen, z. B. bei einem sehr starken Calciumeinstrom, eher zu einer calciumabhängigen Inaktivierung, da diese dann den langsameren Mechanismus der spannungsabhängigen Inaktivierung inhibiert. Diese Inhibition erfolgt durch eine Bindung von Calcium an die LASequenz am C-Terminus der $\alpha_{1}$-Untereinheit [SOLDATOV 2003].

Die Calciumkanal-Untereinheiten $\alpha 2 \delta$ und $\beta 1 \mathrm{~b}$ sind für die Regulation der spannungsabhängigen Inaktivierung zuständig [ARIKKATH und CAMPBELL 2003]. Das Fehlen der Untereinheit $\alpha 2 \delta$ würde zum Beispiel zu einer drei- bis vierfachen Verlangsamung der Inaktivierung sowie zu einer ca. fünffach schnelleren Reaktivierung der Kanäle führen [SHIROKOV et al. 1998].

HEK293-Zellen besitzen kein stabiles Membranpotential, da sie relativ zur Zellmembranoberfläche zu wenige membranständige Ionenkanäle besitzen. Das Membranpotential fluktuiert daher sehr stark und erreicht im Allgemeinen lediglich Werte von -10 mV. Dieser Umstand führt dazu, dass es permanent zu Depolarisationen kommt und demzufolge die spannungsabhängigen Calciumkanäle verstärkt im Zustand der spannungsabhängigen Inaktivierung vorliegen. Die dadurch bedingte Konformationsänderung könnte zu einer morphologischen Veränderung der "Loop-Domäne" (s.o.) und somit auch zu einer Verformung des darin eingeschlossenen ACP-Tags geführt haben.

Dies hätte möglicherweise zur Folge, dass das Sfp bzw. die AcpS das Tag nicht mehr erkennen konnte und es somit zu keiner Färbung der Calciumkanäle kam.

Dieser Mechanismus könnte einen Hinweis liefern, warum ein Labeling in HEK293-Zellen nicht erfolgreich war. Es lässt sich auf diese Weise jedoch nicht ausreichend begründen, warum die Färbung in Neuronen ebenfalls nicht möglich war.

Neuronen besitzen im Gegensatz zU HEK293-Zellen ein stabiles Membranpotential. Ihre Depolarisation setzt eintreffende Aktionspotentiale voraus, sodass einer spannungsabhängigen Inaktivierung, verglichen mit HEK293-Zellen, eine deutlich geringere Bedeutung zukommen sollte. Durch die enge Vernetzung der einzelnen Neuronen untereinander kann es zwar für den Fall, dass ein Neuron spontan depolarisiert und sich diese Erregung auf die umliegenden Zellen überträgt, auch zu einer dadurch bedingten spontanen Depolarisationen aller Neuronen eines Wells kommen. Diese spontanen Depolarisationen, welche eine spannungsabhängige Inaktivierung begünstigen könnten, treten jedoch deutlich seltener auf, als dies bei HEK293-Zellen der Fall ist.

Bezüglich der Neuronen wäre zu diskutieren, ob dem Mechanismus der calciumabhängigen Inaktivierung eine bedeutende Funktion zukommen könnte, da diese durch die Konformationsänderung eine mögliche Deformierung des Tags verursachen könnte.

Allerdings bleibt ungeklärt, woher das Calcium, welches eine calciumabhängige Inaktivierung verursacht hätte, stammen konnte. Eine denkbare Quelle hätte z.B. das Calciumchlorid als Bestandteil des Neurobasal-A-Mediums, in welchem die Neuronen gefärbł wurden, sein können. Ein hierdurch entstan- 
dener Calciumüberschuss wäre jedoch sofort durch eine direkte Aufnahme des überschüssigen Calciums in die internen Calciumspeicher der Zellen abgebaut worden, um die intrazelluläre Calciumkonzentration konstant zu halten. Es wäre dadurch nicht mehr in der Lage gewesen, den Kanal zu inaktivieren. Ein plötzliches Austreten von Calcium aus den internen Speichern scheidet als mögliche Ursache ebenso aus, da dieses nicht spontan erfolgt.

In HEK293-Zellen, welche sich unter anderem durch eine relativ ausgeprägte Expression von Calmodulin auszeichnen [DEMARIA et al. 2001], wäre die calciumabhängige Inaktivierung als zusätzliches Erklärungsmodell für eine ungenügende Färbung der Calciumkanäle denkbar. Diese Erklärung scheidet allerdings aus, da die Kanäle aufgrund der oben erwähnten spannungsabhängigen Inaktivierung schon im Vorfeld für Calcium nicht mehr durchgängig gewesen wären, sodass sich dieses Calcium nicht in einem für die calciumabhängige Inaktivierung benötigten Maße in der Zelle akkumulieren könnte.

Zusammenfassend lässt sich festhalten, dass jede Art von Konformationsänderung ursächlich für eine nicht erfolgreiche Färbung der Kanäle gewesen sein könnte, da diese zum einen bewirken kann, dass das Tag so stark deformiert wurde, dass es durch das Enzym nicht mehr erkannt werden konnte.

Weiterhin wäre auch denkbar, dass das Tag per se nicht beeinflusst wurde, sich jedoch der Calciumkanal als Ganzes so in seiner Konformation verändert hatte, dass das Enzym das Tag zwar erkennen könnte, es für dieses aber nicht mehr zugänglich war.

Dieses könnte, wie oben beschrieben, durch eine spannungsabhängige bzw. eine calciumabhängige Inaktivierung erfolgt sein, jedoch verursacht bereits jedes Öffnen und Schließen des Kanals eine gewisse Konformationsänderung. Dies würde freilich auch eine mögliche Interferenz mit der Labeling-Reaktion bedeuten, da vor allem in Neuronen die Kanäle fortwährend zwischen offenem und geschlossenem Zustand fluktuieren.

\subsubsection{Signalintensität}

Des Weiteren ist zu diskutieren, ob es auch möglich wäre, dass das ACPSubstrat zwar adäquat am Tag gebunden hatte, jedoch das Signal, welches vom ACP-Fluoreszenzfarbstoff emittiert wurde, in seiner Intensität nicht ausreichte, um im Konfokalmikroskop dargestellt zu werden.

Nimmt man beispielsweise an, dass die Calciumkanäle nicht in Clustern akkumuliert an relativ wenigen Stellen der Zellmembran vorliegen, sondern vielmehr diffus über die gesamte Zellmembran verteilt sind und so pro Flächeneinheit nur wenige Fluoreszenzfarbstoffe binden können, besteht die Möglichkeit, dass diese wenigen Farbstoffmoleküle nicht ausreichen, um ein adäquates Signal zu emittieren. Dies könnte vor allem bei HEK293-Zellen der Fall sein. 
In Gegensatz zu Antikörpern ist bei Verwendung des ACP-Tags keine Signalverstärkung (signal enhancement) möglich. Dies bedeutet, dass pro Tag nur ein Farbstoffmolekül binden kann.

Bei Antikörperfärbungen hingegen wird das Epitop bzw. das Tag zunächst durch einen Primärantikörper besetzt. An diesen können jeweils zwei Sekundörantikörper binden, an denen wiederum jeweils 2-3 Fluoreszenzmoleküle gebunden sein können. Dies führt dazu, dass ein Epitop bzw. Antikörper-Tag von bis zu 6 Farbstoffmolekülen besetzł werden kann, sodass theoretisch ein deutlich stärkeres Signal erzeugt wird, als es durch ein einziges, an ein ACPTag gebundenes Fluoreszenzfarbstoffmolekül möglich wäre.

Es könnte so z.B. angenommen werden, dass die Infektion der Neuronen zwar erfolgreich war, also eine Integration des ACP-Tag-tragenden Calciumkanals durchgeführt werden konnte und eine Sfp- bzw. AcpS-katalysierte selektive Färbereaktion stattgefunden hat. Möglich wäre jedoch, dass das Signal, welches von nur einem an das ACP-Tag gebundenen Fluoreszenzfarbstoffmolekül emittiert wurde, nicht nur zu schwach gewesen ist, um detektiert zu werden, sondern darüber hinaus könnte dies durch eine spektrale Überlappung („,blead-through") überstrahlt worden sein, welche von den am Antikörper Anti-VGlutl gebundenen Farbstoffmolekülen ausging. Diese fehlende Differenzierbarkeit der beiden Färbungen würde eine Aussage über Erfolg oder Misserfolg der selektiven Färbung der Calciumkanäle stark erschweren.

Mit dieser Tatsache ließe sich dann erklären, warum beim Vergleich der konfokalmikroskopischen Analysen von infizierten versus nicht infizierten Neuronen, welche außer mit dem ACP-Verfahren auch jeweils mithilfe des Antikörpers Anti-VGlutl gefärbt wurden, keine signifikanten Unterschiede erkannt werden konnten.

\subsubsection{Färbeverfahren}

Zu diskutieren wäre weiterhin, ob die gewählte Färbemethode bzw. die gewählten Enzyme und Substrate tatsächlich geeignet waren, die gewünschte Färbung durchzuführen.

Das ACP-Labeling-Verfahren wurde mit dem Ziel ausgewählt, Färbungen an lebenden Zellen durchzuführen.

Es stellte sich als weiterer Vorteil des ACP-Labeling-Verfahrens heraus, dass die Bindung der Substrate an das Tag durch einen einzigen Reaktionsschritt bewerkstelligt werden konnte. Dies unterscheidet diese Methode von anderen Färbetechniken, z.B. der Reaktion mit Streptavidinen, bei welchen zumeist zwei Reaktionsschritte benötigt werden.

Des Weiteren musste das gewählte Verfahren potentiell hochauflösende AnaIysen z.B. per Elektronenmikroskop ermöglichen. Da es dank des ACP auch möglich ist, Goldpartikel enzymatisch an ein Protein zu binden, war diese Bedingung ebenfalls erfüllt.

Eine weitere Voraussetzung war, dass das Tag den Calciumkanal funktionell nicht stark beeinflussen durfte, sodass weiterhin Calciumionen in einer adäquaten Menge durch den Kanal strömen konnten. Um dieses Ziel zu errei- 
chen, war es von größter Bedeutung, dass das gewählte Tag möglichst klein war. Zur Erfüllung dieser Vorgabe schien das nur 11 Aminosäuren lange ybbRTag die richtige Wahl gewesen zu sein.

Das ybbR-Tag ist jedoch nicht das einzige ACP-Tag, auf welches die oben beschriebenen Eigenschaften zutreffen.

An dieser Stelle sollen beispielhaft das S6- und das A1-Tag erwähnt werden.

Beide Tags setzten sich aus 12 Aminosäuren zusammen und besitzen so eine vergleichbare Größe wie das ybbR-Tag. Auch strukturell ähneln das S6- bzw. Al-Tag dem ybbR-Tag. Alle drei Tags nehmen beispielsweise eine $\alpha$-helikale Struktur an, welche die Bindung des Sfp und auch der AcpS fördert.

Das A 1- und das S6-Tag unterscheiden sich jedoch deutlich in ihrer Enzymspezifität. Die katalytische Effektivität $\left(k_{c a t} / K_{m}\right)$ des S6-Tags ist bei Verwendung von Sfp beispielsweise 442-fach höher als für die AcpS, wohingegen das Al-Tag eine 30-fach höhere katalytische Effektivität bezogen auf die AcpS vorzuweisen hat.

Verglichen mit dem ybbR-ACP-Tag besitz† das S6-Tag in Kombination mit Sfp eine etwa halb so große $\mathrm{K}_{\mathrm{m}}$ sowie eine ca. doppelt so hohe katalytische Effektivität.

Wird die Reaktion durch die AcpS katalysiert, beträgt auch in diesem Fall die $\mathrm{K}_{\mathrm{m}}$ bei Verwendung des A 1-Tag verglichen mit dem ybbR-Tag weniger als die Hälfte und die katalytische Effektivität ist etwa um das Fünffache erhöht [zur Übersicht ZHOU Z et al. 2007].

Die niedrigere $\mathrm{K}_{\mathrm{m}}$ sowie die deutlich höhere katalytische Effektivität, die eine Verwendung des S6- bzw. Al-Tags mit sich bringen würden, hätten im Vergleich zum ybbR-Tag den Vorteil, dass ein niedrigerer Substrateinsatz sowie eine kürzere Inkubationszeit nötig gewesen wären. Dies hätte die Wahrscheinlichkeit einer unspezifischen Färbung deutlich reduziert.

Fraglich wäre jedoch, ob eine solche Reduktion des unspezifischen Hintergrundes in der Tat zu einer selektiven Färbung der Calciumkanäle geführt hätte.

Als weitere Färbemethode war auch ein Labeling mithilfe des Antikörpers AntiCaVext durchgeführt worden. Denkbar wäre jedoch auch die Verwendung eines HA-Tags gewesen [WATSCHINGER et al. 2008].

Da das HA-Tag aus nur 9 Aminosäuren zusammengesetzt ist, besteht analog zum ybbR-Tag der Vorteil, dass elektrophysiologische Störungen bezüglich der Kanalfunktionalität minimiert werden könnten.

Des Weiteren wäre es auch möglich gewesen, ein Histidin-Tag als AntikörperTag an die $\mathrm{CaV}_{2.1}$-Untereinheit zu koppeln. Dieses Tag besitzt mit 6 bzw. 9 Aminosäuren zwar auch eine geringe Größe, führt jedoch zu einer deutlich stärkeren Restriktion der Kanalfunktion [WATSCHINGER et al. 2008].

Die Verwendung von Antikörpern besitzt im Vergleich zu den Sfp- bzw. AcpSkatalysierten Reaktionen den Vorteil, dass diese, wie oben erwähnt, ein „signal enhancement" ermöglichen, was in einem stärkeren Fluoreszenzsignal resultieren würde. 
Die meisten Antikörperreaktionen setzen jedoch vor der Färbung eine Fixation der Zellen voraus. Diese könnte unter Umständen problematisch werden, da auch durch eine Fixation per se eine Modifikation des Tags denkbar wäre.

Möglicherweise könnte es durch die Fixation des Weiteren auch zu einer Permeabilisierung der Zellmembran kommen. So wäre eine streng extrazelluläre Färbung nicht mehr gewährleistet.

Führt man hingegen Lebendzellfärbungen durch, welche voraussetzen, dass das zu färbende Epitop extrazellulär liegt, kann sich bei Verwendung von Antikörpern gegebenenfalls ein weiteres Problem ergeben:

Da Antikörper zwei Bindestellen besitzen und zudem relativ große Komplexe darstellen, kann es vorkommen, dass die verwendeten Antikörper zwei vormals voneinander getrennte Proteine miteinander aggregieren. Binden nun Sekundörantikörper an diese Primärantikörper, welche wiederum weitere Proteine aggregieren können, kann es U.U. zU einer artifiziellen Entstehung von Proteinkonglomeraten kommen, die "Cluster" vortäuschen könnten.

Des Weiteren stellen Antikörper im Vergleich zum AcpS bzw. Sfp mit einer Masse von über $150 \mathrm{kDa}$ sehr schwere und große Komplexe dar, sodass es möglich ist, dass diese das Tag überhaupt nicht erreichen bzw. nicht in den synaptischen Spalt gelangen (s.u.).

Alternativ zur Verwendung von Antikörper-Tags bestehen jedoch noch weitere Optionen.

Es gäbe zum Beispiel die Möglichkeit, ein Bungarotoxin-Tag zu verwenden [WATSCHINGER et al. 2008]. Dieses Protein-Tag zeichnet sich auch durch seine geringe Länge von 13 Aminosäuren aus.

Mit diesem Tag könnten dann Fluoreszenzfarbstoffe, welche an ein aus 66 Aminosäuren zusammengesetztes $\alpha$-Bungarotoxin gebunden sind, selektiv reagieren [TSETLIN et al. 2009].

Diese Reaktion führt jedoch zu nichtkovalenten Bindungen, welche unter Umständen in relativ instabilen Komplexen resultieren könnten und so die Gefahr einer erneuten Dissoziation der Farbstoffmoleküle von den getaggten Membranproteinen besteht [YIN et al. 2005b].

Weiterhin ist auch bekannt, dass das Bungarotoxin-Tag in Ionenkanälen zu einer deutlich funktionseinschränkenden biophysikalischen Modifikation der Kinetik führen kann. Es kann zum Beispiel eine Verschiebung des Schwellenwertes, ab dem eine spannungsabhängige Inaktivierung der Kanäle in Kraft tritt, beobachtet werden [WATSCHINGER et al. 2008]. Bedingt durch diesen Umstand scheint dieses Tag, wie auch das Histidin-Tag, verglichen mit dem ACP-bzw. HA-Tag die gewünschten Zwecke unpassend zu sein.

\subsubsection{Wahl der Position zur Tag-Integration}

Neben der Art des Tags wäre weiterhin zu ervieren, ob die gewählte Position innerhalb der Sequenz des Calciumkanals, an welcher das ACP-Tag integriert worden war, einen Einfluss auf das Ergebnis der Färbung genommen haben 
könnte. Die Integration der jeweiligen ACP-Tags erfolgte hinter den Basenpaaren 786, 792, 798 bzw. 810 (vom N-Terminus aus gezählt) in der codierenden Sequenz. Die Wahl dieser Positionen erfolgte in Anlehnung an Daten, welche Frau Dr. Pedersen am Max-Planck-Institut für biophysikalische Chemie in früheren Arbeiten unter Verwendung eines HA-Tags elektrophysiologisch akquirieren konnte [PEDERSEN 2008].

Alle diese Positionen liegen in der Domäne I der $\alpha_{1}$-Untereinheit im extrazellulären flexiblen Loop zwischen S5 und S6, welcher gleichzeitig am Aufbau der Kanalpore beteiligt ist. Wichtig war, dass die Integration des ACP-Tags außerhalb des für die Kanalfunktion kritischen Bereiches erfolgte.

Denkbar wäre allerdings auch, das Tag an einer anderen Position zu platzieren, um das Ergebnisse der Färbung zu optimieren. Theoretisch ließen sich die Tags an allen Positionen innerhalb der $\alpha_{1}$-Untereinheit platzieren. Als ungünstige Position kann jedoch der Abschnitt, welcher sich zwischen den Basenpaaren 903 und 1006 befindet, definiert werden. Hier liegt ein stark konservierter Abschnitt der DNA-Sequenz, welcher unter anderem für die Transmembranhelix sowie für ein Glutamat, an welchem Calciumionen binden können, codiert. Daher muss davon ausgegangen werden, dass jegliche Modifikation in diesem Abschnitt in einer starken Beeinflussung der Kanalkinetik resultieren würde bzw. diesen funktionsunfähig machen könnte.

In einigen Arbeiten wurde z.B. ein HA-Tag in der Domäne I hinter den Basenpaarpositionen 840 und 1008 bzw. in der Domäne IV hinter den Basenpaarpositionen 5166 und 5196 integriert. Auch die Integration der jeweiligen Tags an diesen Positionen führte zu einer Expression funktionsfähiger Calciumkanäle, bei welchen die elektrophysiologischen Eigenschaften nicht bedeutend beeinflusst wurden [WATSCHINGER et al. 2008].

Es lässt sich jedoch anhand der Ergebnisse, welche an diesen alternativen Tagpositionen erzielt worden sind, nicht erkennen, ob diese grundsätzlich zu besseren Resultaten führen würden als die in der vorliegenden Arbeit gewählten Positionen.

\subsubsection{Struktur der Synapse}

Ist folglich davon auszugehen, dass für das Resultat dieser Arbeit weder die Art des Tags noch die gewählte Position kausal verantwortlich ist, könnte des Weiteren angenommen werden, dass das Enzym zwar potentiell in der Lage gewesen wäre, das Tag zu erkennen, es jedoch keine Möglichkeit hatte, dieses zu erreichen.

Als Ursache für diesen Umstand könnte zum Beispiel bei der versuchten Färbung der Neuronen angenommen werden, dass das Enzym keine Möglichkeit besaß, in den synaptischen Spalt zu gelangen.

Wie zuvor beschrieben, befinden sich am synaptischen Spalt unter anderem zwei Proteine, welche eine direkte Verbindung zwischen zwei Neuronen her- 
stellen. Dies ist auf der postsynaptischen Seite das Neuroligin und auf der präsynaptischen das Neurexin [SCHEIFFELE et al. 2000; Ll et al. 2006]. Beide Proteine bilden gemeinsam eine sehr stabile Barriere, die es dem Sfp bzw. der AcpS unmöglich gemacht haben könnte, diese zu passieren und in den synaptischen Spalt zu gelangen. Ursächlich hierfür könnte der Aufbau dieser Enzyme aus immerhin 120-140 (AcpS) bzw. 220-240 (Sfp) Aminosäuren und einer Masse von $13 \mathrm{kDa}$ bzw. $26 \mathrm{kDa}$ sein, da diese somit relativ große Komplexe darstellen.

Im Gegensatz dazu hätte das ACP-Substrat aufgrund seiner deutlich geringeren Größe die Barriere aus Neuroligin und Neurexin zwar frei passieren müssen, jedoch ohne die enzymkatalysierte Reaktion nicht selektiv an das ACP-Tag binden können.

\subsubsection{Struktur des Calciumkanals}

Anzunehmen wäre jedoch auch, dass die molekulare Struktur der $\alpha_{1}$ Untereinheit, an welcher das Tag gebunden war, zu einer Veränderung des Tags geführt hat.

Im Gegensatz zu anderen lonenkanälen ist die genaue molekulare Struktur der P/Q-Typ-Calciumkanäle derzeit noch nicht bekannt.

Strukturanalysen anderer Ionenkanäle ergaben, dass einige dieser Kanäle über eine ausgeprägte Sekundärstruktur mit starker Faltung verfügen. Ein Beispiel für einen lonenkanal mit einer solchen Eigenschaft stellt der ClcChloridkanal dar [FENG et al. 2010]. Auch wenn nicht direkt davon auszugehen ist, dass sich Calciumkanäle analog zu Clc-Chloridkanälen verhalten, besteht jedoch die Wahrscheinlichkeit, dass auch diese eine ausgeprägte Sekundärstruktur besitzen.

Dieser Umstand könnte dazu geführt haben, dass die Form des Tags durch eine ausgeprägte Faltung des gesamten Proteins dermaßen verändert wurde, dass das Enzym für die Labeling-Reaktion das Tag nicht mehr erkannte und es daher zu keiner Färbung kommen konnte.

Eine weitere Ursache für eine Verformung des Tags könnte auch in dessen Interaktion mit den umliegenden Proteinen begründet sein. Entscheidend ist hierfür die Interaktion des Tags mit allen Kanalproteinen und vor allem mit den einzelnen Calciumkanaluntereinheiten. Möglicherweise bildeten die Proteine in der Umgebung des Tags stärkere Wasserstoffbrückenbindungen aus als jene, welche die Sekundärstruktur des Tags bilden, und hätten womöglich dazu beigetragen, dieses so weit zu deformieren, dass es seine Funktion nicht mehr wahrnehmen konnte.

Ein weiteres Problem könnte die Anordnung der einzelnen CalciumkanalUntereinheiten zueinander sowie deren Morphologie darstellen.

Obwohl die Struktur der P/Q-Typ-Calciumkanäle noch nicht genau bekannt ist, existieren Erkenntnisse aus der Strukturanalyse von L-Typ-Calciumkanälen, 
welche einige Rückschlüsse auf den Aufbau von P/Q-Typ-Calciumkanälen erlauben.

WOLF et al. (2003) analysierten z.B. die Struktur der L-Typ-Calciumkanäle mithilfe der Elektronenkryomikroskopie.

Durch diese Analyse ist es u.a. gelungen, Strukturen unterschiedlicher Dichte zu charakterisieren, welche so eine Abgrenzung der einzelnen Untereinheiten erlaubte. Der L-Typ-Calciumkanal als $550 \mathrm{kDa}$ schweres und ca. $12 \mathrm{~nm}$ großes Protein konnte demnach in die fünf Einheiten $\alpha_{1}, \alpha_{2}, \delta, \gamma$ und $\beta$ unterteilt werden, wobei die $\alpha_{1}$-Untereinheit die anderen Untereinheiten größenmäßig dominiert.

Die Untereinheiten $\alpha_{1}, \delta$ und $\beta$ bilden zusammen den unteren Teil des Calciumkanals, wohin gegen sich die Untereinheit $\gamma$ oberhalb von $\beta$ und die Untereinheit $\alpha_{2}$ oberhalb von $\delta$ befindet (Abb. 4.2).

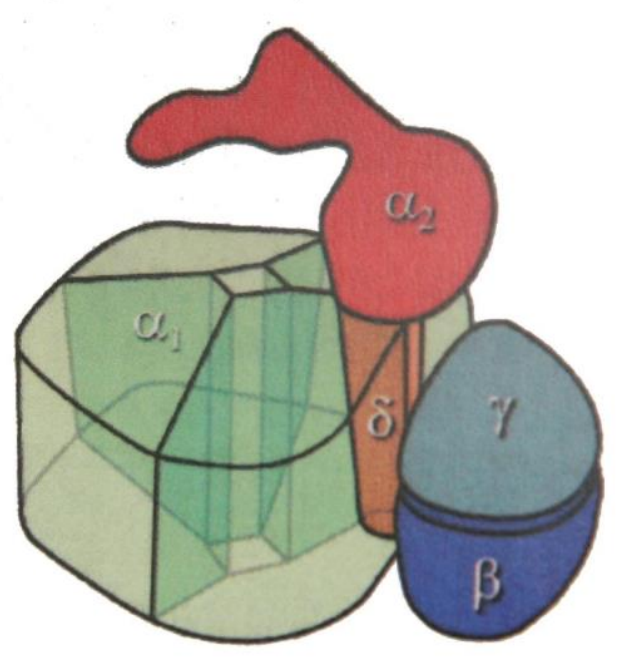

Abb 4.2. Schematische Anordnung der Untereinheiten des L-Typ-Calciumkanals (adaptiert nach WOLF et al. 2003, S. 175)

Wie auf der Abbildung 4.2. angedeutet, überragt die $\alpha_{2}$-Untereinheit die $\alpha_{1}$ Untereinheit in Form eines langgestreckten Ausläufers und überspannt auf diese Weise die Kanalpore, sodass diese nur durch einen relativ engen Spalt mit der Umgebung kommunizieren kann.

P/Q-Typ-Calciumkanäle sind wie L-Typ-Calciumkanäle aus den gleichen fünf Untereinheiten aufgebaut, sodass man unter Umständen von einer analogen Anordnung der Untereinheiten ausgehen kann.

Es könnte folglich angenommen werden, dass auch bei P/Q-Typ-Calciumkanälen nur ein sehr enger Spalt zwischen der $\alpha_{2}$ - und der $\alpha_{1}$-Untereinheit existiert, durch den Moleküle an die Kanalpore gelangen können. Dies könnte bedeuten, dass das Sfp bzw. die AcpS zu groß waren, um diesen Spalt zu passieren und das Tag in unmittelbarer Nähe der Kanalpore zu erreichen. 
Dies hätte dazu geführt, dass zwar höchstwahrscheinlich das deutlich kleinere CoA-Substrat das Tag erreichte, jedoch wiederum ohne eine Katalyse durch Sfp bzw. AcpS nicht selektiv an diesem binden konnte.

\subsection{Bewertung der Ergebnisse im Kontext mit Arbeiten anderer Arbeitsgruppen}

Verglichen mit WATSCHINGER et al. (2008) ergeben sich einige Parallelen zU der vorliegenden Arbeit. Von dieser Arbeitsgruppe wurde hinter der Basenpaarposition 5166 in Domäne IV ein HA-Tag sowie am N-Terminus ein GFP-Tag integriert. Dies resultierte bei Verwendung von Anti-GFP- bzw. Anti-HAAntikörpern in Hippocampusneuronen, welche zuvor permeabilisiert und fixiert worden waren, in Färbungen, welche aufgrund einer "clusterartigen", vor allem im Soma und den Dendriten auftretenden Anordnung auf eine Anfärbung von Calciumkanälen schließen ließen.

Die Wiederholung dieses Labelings mit fixierten, jedoch diesmal nicht permeabilisierten Neuronen führte wiederum zu einer Färbung "clusterartiger" Strukturen, welche sich diesmal entlang der Zellmembran erstreckten.

Abschließend zeigte sich jedoch beim „live cell staining", also bei einer Färbung vor der Fixation, dass nun keine selektive Darstellung der zuvor analysierten Membranstrukturen mehr möglich war.

Als Schlussfolgerung aus diesem Ergebnis wurde angenommen, dass es sich bei den vorangegangenen Färbungen mit fixierten Zellen höchstwahrscheinlich um eine Anfärbung intrazellulärer Calciumkanäle gehandelt haben könnte. Als mögliche Erklärung hierfür wurde erwogen, dass der Farbstoff aufgrund einer durch die Fixierung bedingten, ungewollten Permeabilisierung der Zellmembran in die Zelle gelangen konnte.

Warum diese intrazellulärern Calciumkanäle im Gegensatz zu den extrazellulären gefärbt werden konnten, ließe sich mit der oben erwähnten angenommenen Molekularstruktur der P/Q-Typ-Calciumkanäle erklären. Es wäre möglich, dass die Antikörper zwar an die im endoplasmatischen Retikulum noch separat vorliegenden $\alpha_{1}$-Untereinheiten binden konnten, dies jedoch aufgrund des Vorhandenseins der $\alpha_{2}$-Untereinheit in kompletten, aus fünf Untereinheiten bestehenden Membrankanälen nicht mehr möglich ist.

Da auch das in der Arbeit von WATSCHINGER et al. verwendete Verfahren, vor bzw. Ohne Fixation zu färben, zu keinem positiven Resultat geführt hat, stehen diese Ergebnisse im Einklang mit der vorliegenden Arbeit.

WATSCHINGER et. al überprüften des Weiteren, ob es generell zu einer Bindung des Antikörpers an das Tag gekommen ist. Durch Applikation eines AntiHA-Antikörpers konnte eine partielle Inhibition des Kanals nachgewiesen werden, sodass davon ausgegangen werden konnte, dass der Antikörper erfolgreich binden konnte.

Warum es zu einer Inhibition, jedoch nicht zu einer Färbung gekommen ist, ließe sich mit der Tatsache erklären, dass der Kanal zu diesem Zweck daver- 
haft offen sein müsste, damit nicht eine durch das permanente Öffnen und Schließen des Kanals bedingte Konformationsänderung die Morphologie des Kanals fortwährend verändert.

Denkbar wäre unter anderem auch, dass trotz einer Konformationsänderung die Sequenz des Kanals zwar erkannt wurde, der Antikörper sogar binden und somit auch inhibieren konnte, diese Bindung jedoch nur reversibel verlief. Dies hätte dazu geführt, dass der Antikörper kurze Zeit später wieder von der Erkennungssequenz wegdiffundierte und somit eine daverhafte Färbung unmöglich machte.

Um eine solche reversible Bindung handelte es sich höchstwahrscheinlich auch bei der Verwendung des Primärantikörpers Anti-CaVext für die STEDMikroskopie, welcher auf dem DIII-Antikörper basierte [LIAO et al. 2008]. Da Antikörper in der Regel jedoch irreversibel binden, könnte dieser Umstand mit einer leichten, durch eine Konformationsänderung begünstigten Verformung des P/Q-Typ-Calciumkanals erklärt werden, welche zwar die Erkennung der Antikörperbindungsstelle ermöglichte, jedoch keine feste Bindung des Antikörpers gewährleistete.

Analog zU WATSCHINGER et al. (2008) gelang HEBLICH et al. (2008) die Darstellung von P/Q-Typ-Calciumkanälen in transfizierten HEK-Zellen, welche vor der Färbung fixiert worden waren. Jedoch wurden auch in dieser Arbeit, ähnlich wie z.B. bei den Arbeiten von TIMMERMANN et al. (2002) oder MEZGHRANI et al. (2008), keine hochauflösenden Daten akquiriert, sodass keine Aussagen über die genaue Lokalisation der Calciumkanäle gemacht werden konnten.

Es wurde des Weiteren auch versucht, nicht nur P/Q-Typ-Calciumkanäle, sondern auch die übrigen Calciumkanaltypen optisch darzustellen.

MAXIMOV und BEZPROZVANNY (2002) gelang beispielsweise die Darstellung von intrazellulären N-Typ-Calciumkanälen. Jedoch vermochten auch sie nicht, membranständige lonenkanäle in lebenden Zellen, also vor der Fixation, zU färben. Ein an der Untereinheit $\alpha_{1 B}$ gebundenes Myc-Epitop-Tag führte zU keiner Bindung des spezifischen myc-Antikörpers, sodass angenommen wurde, dass dieses Epitop höchstwahrscheinlich für den Antikörper nicht zugänglich war.

Verglichen mit Arbeiten, welche sich mit der Analyse von P/Q-Typ- bzw. NTyp-Calciumkanälen beschäftigten, existiert für L-Typ-Calciumkanäle eine deutlich größere Anzahl an Resultaten, welche eine erfolgreiche Färbung der jeweiligen Calciumkanaluntereinheiten zeigen.

So konnte beispielsweise nachgewiesen werden, dass L-Typ-Calciumkanäle in Hippocampusneuronen in kleinen Clustern in der Zellmembran vorliegen. Die Distribution ist jedoch nicht gleichmäßig. Die Mehrheit der Cluster ist im Soma und den Dendriten konzentriert, am Axon finden sie sich nur im proximalen Abschnitt sowie im Bereich des Axonhügels.

Es wird angenommen, dass jedes Cluster aus ungefähr acht L-TypCalciumkanälen besteht. Weiterhin gibt es Hinweise darauf, dass auch außerhalb von Synapsen Calciumkanäle in Clustern organisiert sein könnten [OBERMAIR et al. 2004]. 
Diese Resultate wurden ebenfalls mit Neuronen erzielt, welche HA-getaggte Calciumkanäle exprimierten und mit einem an den Antikörper Anti-HA gebundenen Fluoreszenzfarbstoff gefärbt worden waren. 


\section{Zusammenfassung}

Zusammenfassend lässt sich festhalten, dass es bisher weder in dieser Arbeit noch in Arbeiten anderer Forschungsgruppen gelungen ist, hochauflösende Daten über P/Q-Typ-Calciumkanäle zu akquirieren, welche es erlauben würden, verbindliche Aussagen über deren genaue Distribution an der Zellmembran zu treffen. Daher war es auch nicht möglich, belastbare Informationen über das Vorhandensein und die genaue Lokalisation der "langsam" bzw. "schnell freisetzenden" Vesikelpopulationen zu erhalten.

Es konnte mithilfe der vorliegenden Arbeit allerdings gezeigt werden, dass eine spezifische Färbung von Zellmembranen mithilfe einer enzymatisch katalysierten Reaktion sowohl unter Verwendung des 78 Aminosäuren großen ACPTags als auch mithilfe des nur 11 Aminosäuren kleinen ybbR-Tags unter den im Labor vorhandenen Bedingungen erfolgreich durchgeführt werden konnte. Des Weiteren gelang es im Rahmen der vorliegenden Arbeit, das ybbR-Tag erfolgreich in die Sequenz der P/Q-Typ-Calciumkanäle zu integrieren ohne diese grundlegend in ihrer Funktion zu beeinträchtigen. Auch konnten mithilfe des adenoviralen Expressionssystems Primärneuronen infiziert werden, sodass diese neben GFP auch das ybbR-Tag exprimierten.

Allerdings war es mit dem gewählten Verfahren unter Verwendung des ACPTags weder in Neuronen noch in HEK293-Zellen möglich, verwertbare Daten an P/Q-Typ-Calciumkanälen zu akquirieren.

Auch wenn es durch einen modifizierten Versuchsaufbau gelungen war, durch die STED-Mikroskopie Strukturen in einer höheren Auflösung als konfokalmikroskopisch möglich darzustellen, erbrachte der Versuch, ein positives Resultat mithilfe des Antikörpers Anti-CaVext zu erzielen, kein zufriedenstellendes Ergebnis.

Die genauen Gründe für dieses Ergebnis bleiben weiterhin unklar, könnten jedoch durch verschiedene Ursachen erklärt werden.

Denkbar wäre neben einer Konformationsänderung des Calciumkanals eine zU starke Faltung des exprimierten ACP-Tags, welche eine Erkennung durch das Enzym oder eine ausreichende Bindung des Antikörpers Anti-CaVext unmöglich machten. Zu diskutieren wäre weiterhin eine fehlende Eignung des gewählten Färbeverfahrens aufgrund nicht optimaler intrinsischer Eigenschaften. Begründet durch die Molekularstruktur des P/Q-Typ-Calciumkanals, könnte es womöglich auch für das Enzym oder einen farbstofftragenden Antikörper unmöglich gewesen sein, das Tag bzw. das Epitop zu erreichen und damit eine erfolgreiche Färbung zu gewährleisten. Diese Molekularstruktur, vor allem die Anordnung der $\alpha_{2}$-Untereinheit in Bezug zur $\alpha_{1}$-Untereinheit, wurde als die wahrscheinlichste Ursache der erfolglosen spezifischen Färbung der Calciumkanäle betrachtet. 
Somit kann diese Arbeit dazu beitragen, einen weiteren Teil der "Sackgassen im Labyrinth" aufzuzeigen und Teilschritte im Bereich der Anfärbbarkeit von P/Q-Typ-Calciumkanälen erfolgreich darzustellen.

Welche schlussendlich die wahren Gründe der nicht in allen Bereichen der experimentellen Fragestellung zufriedenstellenden Resultate waren, bleibt jedoch weiter ungewiss. Diese Gründe zu ervieren, ggf. zu beseitigen und dann aufbavend auf den vorliegenden Ergebnissen eine zielführende Methode zu entwickeln, bleibt die Aufgabe zukünftiger Forschung auf diesem Gebiet. 


\section{Literatur}

Adams SR, Campbell RE, Gross LA, Martin BR, Walkup GK, Yao Y, Llopis J, Tsien RY (2002): New biarsenical ligands and tetracysteine motifs for protein labeling in vitro and in vivo: synthesis and biological applications. J Am Chem Soc $\underline{124}, 6063-6076$

Akbergenova Y, Bykhovskaia M (2010): Synapsin regulates vesicle organization and activity-dependent recycling at Drosophila motor boutons.

Neuroscience $\underline{170}, 441-452$

Andrews-Zwilling YS, Kawabe H, Reim K, Varoqueaux F, Brose N (2006): Binding to Rab3A-interacting molecule RIM regulates the presynaptic recruitment of Munc13-1 and ubMunc13-2. J Biol Chem 281, 19720-19731

Aravamudan B, Fergestad T, Davis WS, Rodesch CK, Broadie K (1999): Drosophila UNC-13 is essential for synaptic transmission. Nat Neurosci 2, 965-971

Arikkath J, Campbell KP (2003): Auxiliary subunits: essential components of the voltage-gated calcium channel complex. Curr Opin Neurobiol 13, 298-307

Ashery U, Varoqueaux F, Voets T, Betz A, Thakur P, Koch H, Neher E, Brose N, Rettig J (2000): Munc 13-1 acts as a priming factor for large dense-core vesicles in bovine chromaffin cells. EMBO J 19, 3586-3596

Augustin I, Rosenmund C, Südhof TC, Brose N. (1999): Munc13-1 is essential for fusion competence of glutamatergic synaptic vesicles. Nature $\underline{400}, 457-461$

Ausubel FM, Brent R, Kingston RE, Moore DD, Seidman JG, Struhl K: Current Protocols in Molecular Biology. Current protocols (2009); John Wiley \& Sons Inc., Hoboken, USA 2009

Baloh RW, Yue Q, Furman JM, Nelson SF (1997): Familial episodic ataxia: clinical heterogeneity in four families linked to chromosome 19p. Ann Neurol 41 , $8-16$

Barnes DW, Sirbasky DA, Sato GH: Cell Culture Methods for Molecular and Cell Biology; Alan R. Liss Inc., New York, USA 1984

Bech-Hansen NT, Naylor MJ, Maybaum TA, Pearce WG, Koop B, Fishman GA, Mets M, Musarella MA, Boycott KM (1998): Loss-of-function mutations in a calcium-channel 1-subunit gene in Xp1 1.23 cause incomplete X-linked congenital stationary night blindness. Nat Genet 19, 264-267 
Betz A, Ashery U, Rickmann M, Augustin I, Neher E, Südhof TC, Rettig J, Brose, N (1998): Munc 13-1 is a presynaptic phorbol ester receptor that enhances neurotransmitter release. Neuron $\underline{21}, 123-136$

Bischofberger J, Geiger JR, Jonas P (2002): Timing and efficacy of $\mathrm{Ca}^{2+}$ channel activation in hippocampal mossy fiber boutons. J Neurosci 22, 1059310602

Bohn G, Moosmang S, Conrad H, Ludwig A, Hofmann F, Klugbauer N (2000): Expression of T- and L-type calcium channel mRNA in murine sinoatrial node. FEBS Lett $481,73-76$

Borst JG, Sakmann B (1999): Effect of changes in action potential shape on calcium currents and transmitter release in a calyx-type synapse of the rat auditory brainstem. Philos Trans R Soc Lond B Biol Sci 354, 347-355

Bretschneider S, Eggeling C, Hell SW (2007): Breaking the diffraction barrier in fluorescence microscopy by optical shelving. Phys Rev Lett 98, 218103

Brown AM, Morimoto IC, Tsuda Y, Wilson DL (1981): Calcium currentdependent and voltage-dependent inactivation of calcium channels in Helix aspersa. J Physiol 320, 193-218

Bucurenciu I, Kulik A, Schwaller B, Frotscher M, Jonas, P (2008): Nanodomain coupling between $\mathrm{Ca}^{2+}$ channels and $\mathrm{Ca}^{2+}$ sensors promotes fast and efficient transmitter release at a cortical GABAergic synapse. Neuron 57, 536-545

Cane DE, Walsh CT (1999): The parallel and convergent universes of polyketide synthases and nonribosomal peptide synthetases. Chem Biol $\underline{6}$, 319-325

Cantí C, Nieto-Rostro M, Foucault I, Heblich F, Wratten J, Richards MW, Hendrich J, Douglas L, Page KM, Davies A, Dolphin AC (2005): The metal-iondependent adhesion site in the von Willebrand factor-A domain of alpha2delta subunits is key to trafficking voltage-gated Ca2 channels. Proc Natl Acad Sci USA 102, 11230-11235.

Catterall WA (2000): Structure and regulation of voltage-gated Ca2 channels. Annu Rev Cell Dev Biol 16, 521-555

Catterall WA, Perez-Reyes E, Snutch TP, Striessnig J (2005): International Union of Pharmacology. XLVIII. Nomenclature and structure-function relationships of voltage-gated calcium channels. Pharmacol Rev $\underline{57}, 411-425$ 
Cens T, Rousset M, Leyris JP, Fesquet P, Charnet P (2006): Voltage- and calci-

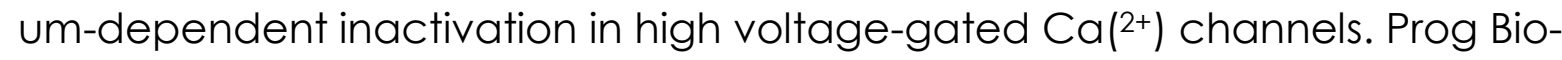
phys Mol Biol $\underline{90}, 104-117$

Chapman ER (2002): Synaptotagmin: a Ca $\left({ }^{2+}\right)$ sensor that triggers exocytosis? Nat Rev Mol Cell Biol 3 , 498-508

Chaudhuri D, Chang SY, DeMaria CD, Alvania RS, Soong TW, Yue DT (2004): Alternative splicing as a molecular switch for $\mathrm{Ca}^{2+} / \mathrm{calmodulin}^{-d e p e n d e n t ~ f a-~}$ cilitation of P/Q-type $\mathrm{Ca}^{2+}$ channels. J Neurosci 24, 6334-6342

Chaudhuri D, Issa JB, Yue DT (2007): Elementary mechanisms producing facilitation of Cav2.1 (P/Q-type) channels. J Gen Physiol 129, 385-401

Chen CA, Okayama H (1988): Calcium phosphate-mediated gene transfer: a highly efficient transfection system for stably transforming cells with plasmid DNA. Biotechniques $\underline{6}, 632-638$

Chen YA, Scheller RH (2001): SNARE-mediated membrane fusion. Nat Rev Mol Cell Biol 2, 98-106

Chen I, Howarth M, Lin W, Ting AY (2005): Site-specific labeling of cell surface proteins with biophysical probes using biotin ligase. Nat Methods 2 ,99-104

Cho WJ, Jeremic A, Jena BP (2005): Size of supramolecular SNARE complex: Membrane-directed self-assembly. J Am Chem Soc 127, 10156-10157

Cribbs LL, Lee JH, Yang J, Satin J, Zhang Y, Daud A, Barclay J, Williamson MP, Fox $M$, Rees $M$, et al. (1998): Cloning and characterization of $1 \mathrm{H}$ from human heart, a member of the T-type Ca2 channel gene family. Circ Res 83, 103-109.

Davare MA, Avdonin V, Hall DD, Peden EM, Burette A, Weinberg RJ, Horne MC, Hoshi T, Hell JW (2001): A beta2 adrenergic receptor signaling complex assembled with the $\mathrm{Ca}^{2+}$ channel Cav1.2. Science 293, 98-101

Davies A, Hendrich J, Van Minh AT, Wratten J, Douglas L, Dolphin AC (2007): Functional biology of the a2d subunits of voltage-gated calcium channels. Trends Pharmacol Sci $\underline{28}, 220-228$

DeMaria CD, Soong TW, Alseikhan BA, Alvania RS, Yue DT (2001): Calmodulin bifurcates the local Ca2 signal that modulates P/Q-type Ca2 channels. Nature $\underline{411}, 484-489$

Denier C, Ducros A, Vahedi K, Joutel A, Thierry P, Ritz A, Castelnovo G, Deonna T, Gérard P, Devoize J, et al. (1999): High prevalence of CACNAIA trunca- 
tions and broader clinical spectrum in episodic ataxia type 2. Neurology $\underline{52}$, 1816-1821

Dietrich D, Kirschstein T, Kukley M, Pereverzev A, von der Brelie C, Schneider T, Beck H (2003): Functional specialization of presynaptic Cav2.3 Ca2 channels. Neuron $\underline{39}, 483-496$

Dittman JS, Regehr WG (1998): Calcium dependence and recovery kinetics of presynaptic depression at the climbing fiber to purkinje cell synapse. J Neurosci $18,6147-6162$

Dolphin, AC (2003): $\beta$-subunits of voltage-gated calcium channels. J Bioenerg Biomembr 35, 599-620

Dragulescu-Andrasi A, Rao J (2007): Chemical labeling of protein in living cells. Chembiochem $\underline{8}, 1099-1101$

Ducros A, Denier C, Joutel A, Cecillon M, Lescoat C, Vahedi K, Darcel F, Vicaut E, Bousser MG, Tournier-Lasserve E (2001): The clinical spectrum of familial hemiplegic migraine associated with mutations in a neuronal calcium channel. N Engl J Med $\underline{345}, 17-24$

Dulubova I, Lou XL, Lu J, Huryeva I, Alam A, Schneggenburger R, Sudhof TC, Rizo J (2005): A Munc13/RIM/Rab3 tripartite complex: from priming to plasticity? EMBO J 24, 2839-2850

Dulubova I, Khvotchev M, Liu S, Huryeva I, Südhof TC, Rizo J (2007): Munc18-1 binds directly to the neuronal SNARE complex. Proc Natl Acad Sci USA 104, 2697-2702

Dunlap K, Luebke Jl, Turner TJ (1995): Exocytotic calcium channels in mammalian central neurons. Trends Neurosci 18, 9-98

Eaton L, Lambert E (1957): Electromyography and electric stimulation of nerves in diseases of motor units; observations on myasthenic syndrome associated with malignancy. J Am Med Assoc 163, 1117-1 124

Eckert R, Chad JE (1984): Inactivation of Ca channels. Prog Biophys Mol Biol $\underline{44}, 215-267$

Edwards FA, Konnerth A, Sakmann B, Takahashi T (1989): A thin slice preparation for patch clamp recordings from neurones of the mammalian central nervous system. Pflugers Arch 414, 600-612 
Erickson MG, Alseikhan BA, Peterson BZ, Yue DT (2001): Preassociation of calmodulin with voltage-gated $\mathrm{Ca}^{2+}$ channels revealed by FRET in single living cells. Neuron $\underline{31}, 973-985$

Fanning AS, Mitic LL, Anderson JM (1999): Transmembrane proteins in the tight junction barrier. J Am Soc Nephrol 10, 1337-1345

Farinas J, Verkman AS (1999): Receptor-mediated targeting of fluorescent probes in living cells. J Biol Chem $\underline{274}$,

7603-7606

Fatt P, Katz B (1953): The electrical properties of crustacean muscle fibres. J Physiol 120, 171-204

Feng L, Campbell EB, Hsiung Y, MacKinnon R (2010): Structure of a eukaryotic $\mathrm{CLC}$ transporter defines an intermediate state in the transport cycle. Science 330, 635-641

Fernández-Chacón R, Königstorfer A, Gerber SH, García J, Matos MF, Stevens CF, Brose N, Rizo J, Rosenmund C, Südhof TC (2001): Synaptotagmin I functions as a calcium regulator of release probability. Nature $\underline{410}, 41-49$

Ferris CD, Snyder SH (1992): Inositol phosphate receptors and calcium disposition in the brain. J Neurosci 12 , 1567-1574

Fesce R, Grohovaz F, Valtorta F, Meldolesi J (1994): Neurotransmitter release: fusion or 'kiss-and-run'? Trends Cell Biol 4 , 1- 4

Field J, Nikawa J, Broek D, MacDonald B, Rodgers L, Wilson IA, Lerner RA, Wigler M (1988): Purification of a RAS-responsive adenylyl cyclase complex from Saccharomyces cerevisiae by use of an epitope addition method. Mol Cell Biol $\underline{8}, 2159-2165$

Flucher BE, Franzini-Armstrong C (1996): Formation of junctions involved in excitation-contraction coupling in skeletal and cardiac muscle. Proc Natl Acad Sci USA $\underline{93}, 8101-8106$

Flugel RS, Hwangbo Y, Lambalot RH, Cronan Jr JE, Walsh CT (2000): Holo-(acyl carrier protein) synthase and phosphopantetheinyl transfer in Escherichia coli. J Biol Chem 275, 959-968

Forsythe ID, Tsujimoto T, Barnes-Davies M, Cuttle MF, Takahashi T (1998): Inactivation of presynaptic calcium current contributes to synaptic depression at a fast central synapse. Neuron $\underline{20}, 797-807$ 
Fox AP, Cahill AL, Currie KP, Grabner C, Harkins AB, Herring B, Hurley JH, Xie Z (2008): $\mathrm{N}$ - and $\mathrm{P} / \mathrm{Q}$-type $\mathrm{Ca}^{2+}$ channels in adrenal chromaffin cells. Acta Physiol (Oxf) 192, 247-261

Garner CC, Kindler S, Gundelfinger ED (2000): Molecular determinants of presynaptic active zones. Curr Opin Neurobiol 10, 321-327

Geib S, Sandoz G, Cornet V, Mabrouk K, Fund-Saunier O, Bichet D, Villaz M, Hoshi T, Sabatier JM, De Waard M (2002): The interaction between the I-II loop and the III-IV loop of Cav2.1 contributes to voltagedependent inactivation in a $\beta$-dependent manner. J Biol Chem 277, 10003-10013

George N, Pick H, Vogel H, Johnsson N, Johnsson K (2004): Specific labeling of cell surface proteins with chemically diverse compounds. J Am Chem Soc $\underline{126}, 8896-8897$

Georgiev D, Glazebrook J: Subneuronal processing of information by solitary waves and stochastic processes; in: Nano and Molecular Electronics Handbook; hrsg. v. Lyshevski SE; CRC Press, Boca Raton, USA 2007, 401-441

Geppert M, Goda Y, Hammer RE, Li C, Rosahl TW, Stevens CF, Sudhof TC (1994). Synaptotagmin I: A major $\mathrm{Ca}^{2+}$ sensor for neurotransmitter release at a central synapse. Cell $\underline{79}, 717-727$

Geschwind DH, Perlman S, Figueroa KP, Karrim J, Baloh RW, Pulst SM (1997): Spinocerebellar ataxia type 6. Frequency of the mutation and genotypephenotype correlations. Neurology 49 , 1247-1251

Glossmann H, Striessnig J (1990): Molecular properties of calcium channels. Rev Physiol Biochem Pharmacol 114, 1-105

Graus F, Lang B, Pozo-Rosich P, Saiz A, Casamitjana R, Vincent A (2002): P/Qtype calciumchannel antibodies in paraneoplastic cerebellar degeneration with lung cancer. Neurolog 59, 764-766

Green N, Alexander H, Olson A, Alexander S, Shinnick TM, Sutcliffe JG, Lerner RA (1982): Immunogenic structure of the influenza virus hemagglutinin. Cell $\underline{28}$, 477-487

Griffin BA, Adams SR, Tsien RY (1998): Specific covalent labeling of recombinant protein molecules inside live cells. Science $\underline{281}$, 269-272

Guignet EG, Hovius R, Vogel H (2004): Reversible siteselective labeling of membrane proteins in live cells. Nat Biotechnol 22, 440-444 
Gundelfinger ED, Kessels MM, Qualmann B (2003): Temporal and spatial coordination of exocytosis and endocytosis. Nat Rev Mol Cell Biol 4, 127-139

Hamill OP, Marty A, Neher E, Sakmann B, Sigworth FJ (1981): Improved patchclamp techniques for high-resolution current recording from cells and cell-free membrane patches. Pflugers Arch 391, 85-100

Hang HC, Yu C, Kato DL, Bertozzi CR (2003): A metabolic labeling approach toward proteomic analysis of mucin-type O-linked glycosylation. Proc Natl Acad Sci USA 100, 14846-14851

He LM, WU XS, Mohan R, WU LG (2006): Two modes of fusion pore opening revealed by cell-attached recordings at a synapse. Nature 444, 102-105

Heady TN, Gomora JC, Macdonald TL, Perez-Reyes E (2001): Molecular pharmacology of T-type Ca2channels. Jpn J Pharmacol $\underline{85}$, 339-350

Heblich F, Tran Van Minh A, Hendrich J, Watschinger K, Dolphin AC (2008): Time course and specificity of the pharmacological disruption of the trafficking of voltage-gated calcium channels by gabapentin.

Channels $\underline{2}, 4-9$

Hell JW, Westenbroek RE, Warner C, Ahlijanian MK, Prystay W, Gilbert MM, Snutch TP, Catterall WA (1993): Identification and differential subcellular localization of the neuronal class $C$ and class D L-type calcium channel alpha 1 subunits. J Cell Biol 123, 949-962

Helton TD, Kojetin DJ, Cavanagh J, Horne WA (2002): Alternative splicing of a beta4 subunit proline-rich motif regulates voltage-dependent gating and toxin block of Cav2.1 $\mathrm{Ca}^{2+}$ channels. J Neurosci 22, 9331-9339

Hendrich J, Van Minh AT, Heblich F, Nieto-Rostro M, Watschinger K, Striessnig J, Wratten J, Davies A, Dolphin AC (2008): Pharmacological disruption of calcium channel trafficking by the alpha2delta ligand gabapentin. Proc Natl Acad Sci USA 105, 3628-3633

Hering S, Berjukow S, Sokolov S, Marksteiner R, Weiss RG, Kraus R, Timin EN (2000): Molecular determinants of inactivation in voltage-gated $\mathrm{Ca}^{2+}$ channels. J Physiol $\underline{528}$, 237-249

Herlitze S, Garcia DE, Mackie K, Hille B, Schever T, Catterall WA (1996): Modulation of $\mathrm{Ca}^{2+}$ channels by $\mathrm{G}$-protein beta-gamma subunits. Nature $\underline{380}, 258-$ 262 
Hess P, Lansman JB, Tsien RW (1984): Different modes of Ca channel gating behaviour favoured by dihydropyridine $\mathrm{Ca}$ agonists and antagonists. Nature $\underline{311}, 538-544$

Heuser JE, Reese TS (1973): Evidence for recycling of synaptic vesicle membrane during transmitter release at the frog neuromuscular junction. J Cell Biol 57, 315-44.

Heuser JE, Reese TS, Landis DM (1974): Functional changes in frog neuromuscular junctions studied with freeze-fracture. J Neurocytol $\underline{3}, 109-131$

Hille B: Ion Channels of Excitable Membranes. 3. Auflage; Sinauer Associates Inc, Sunderland, Massachusetts, USA 2001

Hillyard DR, Monje VD, Mintz IM, Bean BP, Nadasdi L, Ramachandran J, Miljanich G, Azimi-Zoonooz A, McIntosh JM, Cruz LJ, et al. (1992): A new conus peptide ligand for mammalian presynaptic calcium channels. Neuron $\underline{9}$, 9-77

Ho A, Morishita W, Hammer RE, Malenka RC, Südhof TC (2003): A role for Mints in transmitter release: Mint 1 knockout mice exhibit impaired GABAergic synaptic transmission. Proc Natl Acad Sci USA 100, 1409-1414

Hockerman GH, Peterson BZ, Johnson BD, Catterall WA (1997): Molecular determinants of drug binding and action on L-type calcium channels. Annu Rev Pharmacol Toxicol 37, 361-396

Hofmann F, Biel M, Flockerzi V (1994): Molecular basis for Ca2 channel diversity. Annu Rev Neurosci 17, 399-418

Hopwood DA (1997): Genetic contributions to understanding polyketide synthases. Chem ReV 97, 2465-2497

Howarth M, Ting AY (2008): Imaging proteins in live mammalian cells with biotin ligase and monovalent streptavidin. Nat Protoc $\underline{3}, 534-545$

Imredy JP, Yue DT (1994): Mechanism of $\mathrm{Ca}\left({ }^{2+}\right)$-sensitive inactivation of L-type $\mathrm{Ca}^{2+}$ channels. Neuron 12, 1301-1318

Jahn R, Sudhof TC (1999): Membrane fusion and exocytosis. Annu Rev Biochem $68,863-911$

Jen J, Yue Q, Nelson S, Yu H, Litt M, Nutt J, Baloh R (1999): A novel nonsense mutation in CACNA 1 A causes episodic ataxia and hemiplegia. Neurology $\underline{53}$, $34-37$ 
Jiang H, Tang B, Xia K, Zhou Y, Xu B, Zhao G, Li H, Shen L, Pan Q, Cai F (2005): Spinocerebellar ataxia type 6 in Mainland China: molecular and clinical features in four families. J Neurol Sci $\underline{236}, 25-29$

Johnsson N, George N, Johnsson K (2005): Protein chemistry on the surface of living cells. Chem Bio Chem $\underline{6}, 47-52$

Jones SW (1998): Overview of voltage-dependent calcium channels. J Bioenerg Biomembr 30, 299-312

Jones SW, Marks TN (1989): Calcium currents in bullfrog sympathetic neurons. II. Inactivation. J Gen Physiol 94, 169-182

Jouvenceau A, Eunson LH, Spauschus A, Ramesh V, Zuberi SM, Kullmann DM, Hanna MG (2001): Human epilepsy associated with dysfunction of the brain P/Q-type calcium channel. Lancet 358, 801-807

Juillerat A, Heinis C, Sielaff I, Barnikow J, Jaccard H, Kunz B, Terskikh A, Johnsson K (2005): Engineering substrate specificity of O6-alkylguanine-DNA alkyltransferase for specific protein labeling in living cells. Chem Bio Chem $\underline{b}$, 1263-1269

Keppler A, Gendreizig S, Gronemeyer T, Pick H, Vogel H, Johnsson K (2003): A general method for the covalent labeling of fusion proteins with small molecules in vivo. Nat Biotechnol 21, 86-89

Keppler A, Pick H, Arrivoli C, Vogel H, Johnsson K: (2004): Labeling of fusion proteins with synthetic fluorophores in live cells. Proc Natl Acad Sci USA 101, 9955-9959

Khanna R, Li Q, Schlichter LC, Stanley EF (2007): The transmitter release-site CaV2.2 channel cluster is linked to an endocytosis coat protein complex. Eur J Neurosci $\underline{26}, 560-574$

Kim J, Ghosh S, Nunziato DA, Pitt GS (2004): Identification of the components controlling inactivation of voltage-gated $\mathrm{Ca}^{2+}$ channels. Neuron $\underline{41}, 745-754$

Kleinkauf $\mathrm{H}$ (2000): The role of 4'-phosphopantetheine in t' biosynthesis of fatty acids, polyketides and peptides. Biofactors 11, 91-92

Klinke R, Silbernagel S: Lehrbuch der Physiologie. 3. Auflage; Georg Thieme Verlag, Stuttgart 2001

Krueger BK, Forn J, Greengard P (1977): Depolarization-induced phosphorylation of specific proteins, mediated by calcium ion influx, in rat brain synaptosomes. J Biol Chem 252, 2764-2773 
La Clair JJ, Foley TL, Schegg TR, Regan CM, Burkart MD (2004): Manipulation of carrier proteins in antibiotic biosynthesis. Chem Biol 11, 195-201

Lai CY, Cronan JE (2004): Isolation and characterization of beta-ketoacyl-acyl carrier protein reductase (fabG) mutants of Escherichia coli and Salmonella enterica serovar Typhimurium. J Bacteriol 186, 1869-1878

Lambalot RH, Walsh CT (1997): Holo-[acyl-carrier-protein] synthase of Escherichia coli. Methods Enzymol 279, 254-262

Lambalot RH, Gehring AM, Flugel RS, Zuber P, LaCelle M, Marahiel MA, Reid R, Khosla C, Walsh CT (1996): A new enzyme superfamily - the phosphopantetheinyl transferases. Chem Biol $\underline{3}, 923-36$

Lee A, Wong ST, Gallagher D, Li B, Storm DR, Schever T, Catterall WA (1999): $\mathrm{Ca}^{2+} /$ calmodulin binds to and modulates P/Q-type calcium channels. Nature 399, 155-159

Lennon VA, Kryzer TJ, Griesmann GE, O'Suilleabhain PE, Windebank AJ, Woppmann A, Miljanich GP, Lambert EH (1995): Calcium-channel antibodies in the Lambert-Eaton syndrome and other paraneoplastic syndromes. N Engl J Med 332, 1467-1474

Li X, Zhang J, Cao Z, Wu J, Shi Y (2006): Solution structure of GOPC PDZ domain and its interaction with the C-terminal motif of neuroligin. Protein Sci 15 , 2149-2158

Liao YJ, Safa P, Chen YR, Sobel RA, Boyden ES, Tsien RW (2008): Anti-Ca ${ }^{2+}$ channel antibody attenuates $\mathrm{Ca}^{2+}$ currents and mimics cerebellar ataxia in vivo. Proc Natl Acad Sci USA 105, 2705-2710

Lippincott-Schwartz J, Patterson GH (2003): Development and use of fluorescent protein markers in living cells. Science $\underline{300}, 87-91$

Llinas R, Sugimori M, Silver RB (1992): Microdomains of high calcium concentration in a presynaptic terminal. Science 256 , 677-679

Los GV, Encell LP, McDougall MG, Hartzell DD, Karassina N, Zimprich C, Wood MG, Learish R, Ohana RF, Urh M, Simpson D, et al. (2008): HaloTag: a novel protein labeling technology for cell imaging and protein analysis. ACS Chem Biol $\underline{3}, 373-382$ 
Lykke Thomsen L, Kirchmann Eriksen M, Faerch Romer S, Andersen I, Ostergaard E, Keiding N, Olesen J, Russell M (2002): An epidemiological survey of hemiplegic migraine. Cephalalgia 22, 361-375

Mangoni ME, Couette B, Bourinet E, Platzer J, Reimer D, Striessnig J, Nargeot J (2003): Functional role of L-type Cav1.3 Ca2 channels in cardiac pacemaker activity. Proc Natl Acad Sci USA 100, 5543-5548

Mareska M, Gutmann L (2004): Lambert-Eaton myasthenic syndrome. Semin Neurol 24, 149-153

Marks KM, Rosinov M, Nolan GP (2004): In vivo targeting of organic calcium sensors via genetically selected peptides. Proc Natl Acad Sci USA 101, 99829987

Marty A, Neher E: Tight-seal whole-cell recording; in: Single Channel Recording; hrsg. v. Sakmann B und Neher E; Plenum Publishing Co., New York, USA 1983, 56-74

Maximov A, Bezprozvanny I (2002): Synaptic targeting of N-type calcium channels in hippocampal neurons. J Neurosci 22, 6939-6952

Meinrenken CJ, Borst JG, Sakmann B (2002): Calcium secretion coupling at calyx of Held governed by nonuniform channelvesicle topography. J Neurosci 22, $1648-1667$

Meldolesi J, Ceccarelli B (1981): Exocytosis and membrane recycling. Phil Trans R Soc Lond $\underline{296}$, 55-65

Meyer BH, Segura JM, Martinez KL, Hovius R, George N, Johnsson K, Vogel H (2006): FRET imaging reveals that functional neurokinin-1 receptors are monomeric and reside in membrane microdomains of live cells. Proc Natl Acad Sci USA 103, 2138-2143

Mezghrani A, Monteil A, Watschinger K, Sinnegger-Brauns MJ, Barrère C, Bourinet $E$, Nargeot J, Striessnig J, Lory P (2008): A destructive interaction mechanism accounts for dominant-negative effects of misfolded mutants of voltage-gated calcium channels. J Neurosci 28 , 4501-4511

Miljanich GP, Ramachandran J (1995): Antagonists of neuronal calcium channels: structure, function and therapeutic implications. Annu Rev Pharmacol Toxicol 35, 707-734 
Miller LW, Sable J, Goelet P, Sheetz MP, Cornish VW (2004): Methotrexate conjugates: a molecular in vivo protein tag. Angew Chem Int Ed Engl 43, 16721675

Missler M, Zhang W, Rohlmann A, Kattenstroth G, Hammer RE, Gottmann K, Sudhof TC (2003): a-neurexins couple $\mathrm{Ca}^{2+}$ channels to synaptic vesicle exocytosis. Nature $\underline{424}, 939-948$

Mofid MR, Finking R, Marahiel MA (2002): Recognition of hybrid peptidyl carrier proteins/acyl carrier proteins in nonribosomal peptide synthetase modules by the 4'-phosphopantetheinyl transferases AcpS and Sfp. J Biol Chem $\underline{277}$, 17023-17031

Mofid MR, Finking R, Essen LO, Marahiel MA (2004): Structure-based mutational analysis of the 4'-phosphopantetheinyl transferases Sfp from Bacillus subtilis: carrier protein recognition and reaction mechanism. Biochemistry $43,4128-36$

Monahan SL, Lester HA, Dougherty DA (2003): Site-specific incorporation of unnatural amino acids into receptors expressed in mammalian cells. Chem Biol 10, 573-580

Moss FJ, Viard P, Davies A, Bertaso F, Page KM, Graham A, Cantí C, Plumpton M, Plumpton C, Clare JJ, Dolphin AC (2002): The novel product of a five exon stargazin-related gene abolishes CaV2.2 calcium channel expression. EMBO J 21, 1514-1523

Murthy VN, Stevens CF (1999): Reversal of synaptic vesicle docking at central synapses. Nat Neurosci $\underline{2}, 503-507$

Nakano MM, Corbell N, Besson J, Zuber P (1992): Isolation and characterization of sfp: a gene that functions in the production of the lipopeptide biosurfactant, surfactin, in Bacillus subtilis. Mol Gen Genet 232, 313-321

Naylor MJ, Rancourt DE, Bech-Hansen NT (2000): Isolation and characterization of a calcium channel gene, Cacnalf, the murine orthologue of the gene for incomplete X-linked congenital stationary night blindness. Genomics $\underline{66}$, 324-327

Neher E (2006): A comparison between exocytic control mechanisms in adrenal chromaffin cells and a glutamatergic synapse. Pflugers Arch $\underline{453}, 261-$ 268

Neher E (2010): Complexin: does it deserve its name? Neuron $\underline{68}, 803-806$ 
Neher E, Sakaba T (2008): Multiple roles of calcium ions in the regulation of neurotransmitter release. Neuron $\underline{59}, 861-872$

Neher E, Sakmann B (1976): Single-channel currents recorded from membrane of denervated frog muscle fibres. Nature $\underline{260}, 799-802$

Newcombe R, Szoke B, Palma A, Wang G, Chen XH, Hopkins W, Cong R, Miller J, Urge L, Tarczy-Hornoch K, et al. (1998): Selective peptide antagonist of the class $\mathrm{E}$ calcium channel from the venom of the tarantula Hysterocrates gigas. Biochemistry $\underline{37}$, 15353-15362

Noren CJ, Anthony-Cahill SJ, Griffith MC, Schultz PG (1989): A general method for site-specific incorporation of unnatural amino acids into proteins. Science $\underline{244}, 182-188$

Obermair GJ, Szabo Z, Bourinet E, Flucher BE (2004): Differential targeting of the L-type $\mathrm{Ca}^{2+}$ channel alpha $1 \mathrm{C}$ (CaV 1.2) to synaptic and extrasynaptic compartments in hippocampal neurons. Eur J Neurosci 19, 2109-2122

Ophoff RA, Terwindt GM, Vergouwe MN, van Eijk R, Oefner PJ, Hoffman SM, Lamerdin JE, Mohrenweiser HW, Bulman DE, Ferrari M, et al. (1996): Familial hemiplegic migraine and episodic ataxia type-2 are caused by mutations in the $\mathrm{Ca}^{2+}$ channel gene CACNL1A4. Cell 87, 543-552

Ophoff RA, Terwindt GM, Ferrari MD, Frants RR (1998): Genetics and pathology of voltage-gated $\mathrm{Ca}^{2+}$ channels. Histol Histopathol 13 , 827-836

Parris KD, Lin L, Tam A, Mathew R, Hixon J, Stahl M, Fritz CC, Seehra J, Somers WS (2000): Crystal structures of substrate binding to Bacillus subtilis holo-(acyl carrier protein) synthase reveal a novel trimeric arrangement of molecules resulting in three active sites. Structure $\underline{8}, 883-895$

Parrott MB, Barry MA (2001): Metabolic biotinylation of secreted and cell surface proteins from mammalian cells. Biochem Biophys Res Commun 281, 9931000

Pedersen M: Investigation localization of Calcium channels and vesicles at the Calyx of Held; Vortrag gehalten am 01.12.2008 auf EU Synapse Annual Meeting 2008 in Amsterdam

Pedersen M: Progress report; Vortrag gehalten am 03.12.2009 auf EU Synapse Annual Meeting 2009 in Göttingen 
Pelucchi A, Ciceri E, Clementi F, Marazzini L, Foresi A, Sher E (1993): Calcium channel autoantibodies in myasthenic syndrome and small cell lung cancer. Am Rev Respir Dis 147, 1229-1232

Peterson BZ, DeMaria CD, Adelman JP, Yue DT (1999): Calmodulin is the $\mathrm{Ca}^{2+}$ sensor for $\mathrm{Ca}^{2+}$-dependent inactivation of L-type calcium channels. Neuron $\underline{22}, 549-558$

Peterson K, Rosenblum MK, Kotanides, H, Posner JB (1992): Paraneoplastic cerebellar degeneration. I. A clinical analysis of 55 anti-Yo antibody-positive patients. Neurology $\underline{42}, 1931-1937$

Perez-Reyes E (2003): Molecular physiology of low-voltageactivated T-type calcium channels. Physiol Rev 83, 117-161

Pitt GS, Zuhlke RD, Hudmon A, Schulman H, Reuter H, Tsien RW (2001): Molecular basis of calmodulin tethering and $\mathrm{Ca}^{2+}$-dependent inactivation of L-type $\mathrm{Ca}^{2+}$ channels. J Biol Chem 276, 30794-30802

Pourmand R (2009): Lambert-eaton myasthenic syndrome. Front Neurol Neurosci $\underline{26}, 120-125$

Prescher JA, Dube DH, Bertozzi CR (2004): Chemical remodelling of cell surfaces in living animals. Nature $\underline{430}, 873-877$

Pusch M, Neher E (1988): Rates of diffusional exchange between small cells and a measuring patch pipette. Pflugers Arch 411, 204-211

Qin N, Platano D, Olcese R, Costantin JL, Stefani E, Birnbaumer L (1998):

Unique regulatory properties of the type $2 a \mathrm{Ca}^{2+}$ channel $b$ subunit caused by palmitoylation. Proc Natl Acad Sci USA $\underline{95}, 4690-4695$

Qin N, Olcese R, Bransby M, Lin T, Birnbaumer L (1999): Ca2+-induced inhibition of the cardiac Ca2+ channel depends on calmodulin. Proc Natl Acad Sci USA $\underline{96}, 2435-2438$

Quadri LE, Weinreb PH, Lei M, Nakano MM, Zuber P, Walsh CT (1998): Characterization of Sfp, a Bacillus subtilis phosphopantetheinyl transferase for peptidyl carrier protein domains in peptide synthetases. Biochemistry 37, 1585-1595

Rang HP, Dale MM, Ritter JM, Moore PK: Pharmacology. 5. Auflage; Churchill Livingstone, Edinburgh, Großbritannien 2003

Reid CA, Bekkers JM, Clements JD (2003): Presynaptic Ca²+ channels: a functional patchwork. Trends Neurosci $\underline{26}, 683-687$ 
Reuter K, Mofid MR, Marahiel MA, Ficner R (1999): Crystal structure of the surfactin synthetase-activating enzyme sfp: a prototype of the 4'phosphopantetheinyl transferase superfamily. EMBO J 18, 6823-6831

Rios E, Pizarro G, Stefani E (1992): Charge movement and the nature of signal transduction in skeletal muscle excitation-contraction coupling. Annu Rev Physiol $\underline{54}$, 109-133

Rizzoli SO, Betz WJ (2005): Synaptic vesicle pools. Nat Rev Neurosci $\underline{6}$, 57-69

Roberts WM, Jacobs RA, Hudspeth AJ (1990): Colocalization of ion channels involved in frequency selectivity and synaptic transmission at presynaptic active zones of hair cells. J Neurosci 10, 3664-3684

Rosenmund C, Sigler A, Augustin I, Reim K, Brose N, Rhee JS (2002): Differential control of vesicle priming and short-term plasticity by Munc 13 isoforms. Neuron $33,411-424$

Rossier MF, Ertel EA, Vallotton MB, Capponi AM (1998): Inhibitory action of mibefradil on calcium signaling and aldosterone synthesis in bovine adrenal glomerulosa cells. J Pharmacol Exp Ther 287, 824-831

Saiki RK, Scharf S, Faloona F, Mullis KB, Horn GT, Erlich HA, Arnheim N (1985): Enzymatic amplification of beta-globin genomic sequences and restriction site analysis for diagnosis of sickle cell anemia. Science 230, 1350-1354

Sakaba T (2006): Roles of the fast-releasing and the slowly releasing vesicles in synaptic transmission at the calyx of Held. J Neurosci $\underline{26}, 5863-5871$

Sakaba T, Neher E (2001 a): Quantitative relationship between transmitter release and calcium current at the calyx of Held synapse. J Neurosci, 21, 462476

Sakaba T, Neher E (2001b): Calmodulin mediates rapid recruitment of fastreleasing synaptic vesicles at a calyx-type synapse. Neuron 32, 1119-1131

Sakaba T, Neher E (2001c): Preferential potentiation of fast-releasing synaptic vesicles by CAMP at the calyx of Held. Proc Natl Acad Sci USA 98, 331-336

Sakaba T, Neher E (2003): Direct modulation of synaptic vesicle priming by GABA(B) receptor activation at a glutamatergic synapse. Nature $424,775-$ 778 
Sakurai T, Westenbroek RE, Rettig J, Hell J, Catterall WA (1996): Biochemical properties and subcellular distribution of the $\mathrm{BI}$ and $\mathrm{rbA}$ isoforms of alpha $1 \mathrm{~A}$ subunits of brain calcium channels. J Cell Biol 134, 511-528

Sambrook J, Russell DW: Molecular Cloning. A laboratory manual. 3. Auflage; Cold Spring Harbor Laboratory Press, Cold Spring Harbor, New York, USA 2001

Satoyoshi E, Kowa H, Fukunaga N (1973): Subacute cerebellar degeneration and Eaton-Lambert syndrome with bronchogenic carcinoma: A case report. Neurology $23,764-768$

Saxon E, Bertozzi CR (2000): Cell surface engineering by a modified Staudinger reaction. Science 287, 2007-2010

Scheiffele P, Fan J, Choin J, Fetter R, Serafini T (2000): Neuroligin expressed in nonneuronal cells triggers presynaptic development in contacting axons. Cell 101, 657-669

Schikorski T, Stevens CF (1997): Quantitative ultrastructural analysis of hippocampal excitatory synapses. J Neurosci 17, 5858-5867

Schulman H, Greengard P (1978): Stimulation of brain membrane protein phosphorylation by calcium and an endogenous heat-stable protein. Nature $\underline{271}, 478-479$

Sculimbrene BR, Imperiali B (2006): Lanthanide-binding tags as luminescent probes for studying protein interactions. J Am Chem Soc 128, 7346-7352

Shams'ili S, Grefkens J, De Leeuw B, van den Bent M, Hooijkaas H, van der Holt B, Vecht C, Sillevis Smitt P (2003): Paraneoplastic cerebellar degeneration associated with antineuronal antibodies: analysis of 50 patients. Brain 126, 14091418

Sharma SK, Modak R, Sharma S, Sharma AK, Sarma SP, Surolia A, Surolia N (2005): A novel approach for over-expression, characterization, and isotopic enrichment of a homogeneous species of acyl carrier protein from Plasmodium falciparum. Biochem Biophys Res Commun 330,1019-1026

Sheng M (2001): Molecular organization of the postsynaptic specialization. Proc Natl Acad Sci USA $\underline{98}, 7058-7061$

Sheng M, Kim MJ (2002): Postsynaptic signaling and plasticity mechanisms. Science $\underline{298}, 776-780$ 
Shenk T, Horwitz MS: Adenoviridae: the viruses and their replication, adenoviruses; in: Fields virology, 4. Auflage, hrsg. v. Fields BN, Knipe DM, Howley PM; Lippincott-Raven Publishers, Philadelphia, USA 2001, 2265-2326

Shi C, Soldatov NM (2002): Molecular determinants of voltage-dependent slow inactivation of the $\mathrm{Ca}^{2+}$ channel. J Biol Chem 277, 6813-6821

Shimomura O, Johnson FH, Saiga Y (1961): Purification and properties of Cypridina luciferase. J Cell Comp Physiol 58, 113-123

Shirokov R, Ferreira G, Yi J, Ríos E (1998): Inactivation of gating currents of Ltype calcium channels. Specific role of the alpha 2 delta subunit. J Gen Physiol $\underline{111}, 807-823$

Sinnegger-Brauns MJ, Hetzenauer A, Huber IG, Renstrom E, Wietzorrek G, Berjukov S, Cavalli M, Walter D, Koschak A, Waldschutz R, et al. (2004): Isoformspecific regulation of mood behavior and pancreatic cell and cardiovascular function by L-type Ca2-channels. J Clin Investig 113, 1430-1439

Smith S (1994): The animal fatty acid synthase: one gene, one polypeptide, seven enzymes. FASEB J $\underline{8}, 1248-1259$

Soldatov NM (2003): $\mathrm{Ca}^{2+}$ channel moving tail: link between $\mathrm{Ca}^{2+}$-induced inactivation and $\mathrm{Ca}^{2+}$ signal transduction. Trends Pharmacol Sci $\underline{24}$, 167-171

Soong TW, DeMaria CD, Alvania RS, Zweifel LS, Liang MC, Mittman S, Agnew W, Yue DT (2002): Systematic identification of splice variants inhuman P/Qtype channel $\alpha_{1-2.1}$ subunits: implications for current density and Ca2dependent inactivation. J Neurosci 22, 10142-10152

Sorensen JB, Nagy G, Varoqueaux F, Nehring RB, Brose N, Wilson MC Neher E (2003): Differential control of the releasable vesicle pools by SNAP-25 splice variants and SNAP-23. Cell 114, 75-86

Stevens CF, Wesseling JF (1998): Activity-dependent modulation of the rate at which synaptic vesicles become available to undergo exocytosis. Neuron $\underline{21}$, 415-424

Stotz SC, Hamid J, Spaetgens RL, Jarvis SE, Zamponi GW (2000): Fast inactivation of voltage-dependent calcium channels: a hinged-lid mechanism. J Biol Chem $\underline{275}$, 24575-24582

Striessnig J (1999): Pharmacology, structure and function of cardiac L-type calcium channels. Cell Physiol Biochem 9 , 242-269 
Striggow F, Ehrlich BE (1996): Ligand-gated calcium channels inside and out. Curr Opin Cell Biol $\underline{8}, 490-495$

Subramony SH, Schott K, Raike RS, Callahan J, Langford LR, Christova PS, Anderson JH, Gomez CM (2003): Novel CACNA IA mutation causes febrile episodic ataxia with interictal cerebellar deficits. Ann Neurol 54, 725-731

Sudhof TC (1995): The synaptic vesicle cycle: a cascade of protein-protein interactions. Nature $\underline{375}, 645-653$

Takamori M. (2008): Lambert-Eaton myasthenic syndrome: search for alternative autoimmune targets and possible compensatory mechanisms based on presynaptic calcium homeostasis. J Neuroimmunol 201, 145-152

Takimoto K, Li D, Nerbonne JM, Levitan ES (1997): Distribution, splicing and glucocorticoid-induced expression of cardiac 1C and 1D voltage-gated calcium channel mRNAs. J Mol Cell Cardiol 29, 3035-3042

Talley EM, Cribbs LL, Lee JH, Daud A, Perez-Reyes E, Bayliss DA (1999): Differential distribution of three members of a gene family encoding low voltageactivated (T-type) calcium channels. J Neurosci 19, 1895-1911

Tian GW, Mohanty A, Chary SN, Li S, Paap S, Drakakaki G, Kopec CD, Li J, Ehrhardt D, Jackson D, Rhee SY, Raikhel NV, Citovsky V (2004): Highthroughput fluorescent tagging of full-length Arabidopsis gene products in planta. Plant Physiol $\underline{135}, 25-38$

Timmermann DB, Westenbroek RE, Schousboe A, Catterall WA (2002): Distribution of high-voltage-activated calcium channels in cultured gammaaminobutyric acidergic neurons from mouse cerebral cortex. J Neurosci Res 67, 48-61

Tsetlin V, Utkin Y, Kasheverov I (2009): Polypeptide and peptide toxins, magnifying lenses for binding sites in nicotinic acetylcholine receptors. Biochem Pharmacol $\underline{78}, 720-731$

Tsien RY (1998): The green fluorescent protein. Annu Rev Biochem 67, 509-544

Vivero-Pol L, George N, Krumm H, Johnsson K, Johnsson N (2005): Multicolor imaging of cell surface proteins. J Am Chem Soc 127, 12770- 12771

Von Brederlow B, Hahn AF, Koopman WJ, Ebers GC, Bulman DE (1995): Mapping the gene for acetazolamide responsive hereditary paryoxysmal cerebellar ataxia to chromosome 19p. Hum Mol Genet 4, 279-284 
Wadel K, Neher E, Sakaba T (2007): The coupling between synaptic vesicles and $\mathrm{Ca}^{2+}$ channels determines fast neurotransmitter release. Neuron $\underline{53}, 563-$ 575

Walsh CT, Gehring AM, Weinreb PH, Luis EN, Flugel RS (1997): Post-translational modification of polyketide and nonribosomal peptide synthases. Curr Opin Chem Biol 1, 309-315

Wang LY, Kaczmarek LK (1998): High-frequency firing helps replenish the readily releasable pool of synaptic vesicles. Nature 394, 384-388

Wang LY, Fedchyshyn MJ, Yang YM (2009): Action potential evoked transmitter release in central synapses: insights from the developing calyx of Held. Mol Brain (nur online) 2:36

Wappl E, Koschak A, Poteser M, Sinnegger MJ, Walter D, Eberhart A, Groschner K, Glossmann H, Kraus RL, Grabner M, Striessnig J (2002): Functional consequences of $\mathrm{P} / \mathrm{Q}$-type $\mathrm{Ca}^{2+}$ channel Cav2.1 missense mutations associated with episodic ataxia type 2 and progressive ataxia. J Biol Chem $\underline{277}$, 6960-6966

Watschinger K, Horak SB, Schulze K, Obermair GJ, Wild C, Koschak A, Sinnegger-Brauns MJ, Tampé R, Striessnig J (2008): Functional properties and modulation of extracellular epitope-tagged $\mathrm{Ca}(\mathrm{V}) 2.1$ voltage-gated calcium channels. Channels 2 , 461-473

Westenbroek RE, Hell JW, Warner C, Dubel SJ, Snutch TP, Catterall W (1992): Biochemical properties and subcellular distribution of an $\mathrm{N}$-type calcium channel 1 subunit. Neuron $\underline{6}$, 1099-1115

Westenbroek RE, Hoskins L, Catterall WA (1998): Localization of $\mathrm{Ca}^{2+}$ channel subtypes on rat spinal motor neurons, interneurons, and nerve terminals. J Neurosci 18, 6319-6330

Wienisch M, Klingauf J (2006): Vesicular proteins exocytosed and subsequently retrieved by compensatory endocytosis are nonidentical. Nat Neurosci $\underline{q}$, 1019-1027

Wightman RM, Haynes CL (2004): Synaptic vesicles really do kiss and run. Nat Neurosci $\underline{7}, 321-322$

Willig KI, Keller J, Bossi M, Hell SW (2006): STED microscopy resolves nanoparticle assemblies. New J Phys (nur online) 8106 
Wölfel M, Lou XL, Schneggenburger R (2007): A mechanism intrinsic to the vesicle fusion machinery determines fast and slow transmitter release at a large CNS synapse. J Neurosci 27, 3198-3210

Wolf M, Eberhart A, Glossmann H, Striessnig J, Grigorieff N (2003): Visualization of the domain structure of an L-type $\mathrm{Ca}^{2+}$ channel using electron cryomicroscopy. J Mol Biol 332, 171-182

Wu LG, Borst JG (1999): The reduced release probability of releasable vesicles during recovery from short-term synaptic depression. Neuron $\underline{23}, 821-832$

Wu LG, Westenbroek RE, Borst JG, Catterall WA, Sakmann B (1999): Calcium channel types with distinct presynaptic localization couple differentially to transmitter release in single calyx-type synapses. J Neurosci 19, 726-736

XU J, Mashimo T, Sudhof TC (2007): Synaptotagmin-1, -2, and -9: $\mathrm{Ca}^{2+}$ sensors for fast release that specify distinct presynaptic properties in subsets of neurons. Neuron $\underline{54}, 567-581$

Xue L, Mei YA (2011): Synaptic vesicle recycling at the calyx of Held. Acta Pharmacol $\sin \underline{32}, 280-287$

Xue MS, Stradomska A, Chen HM, Brose N, Zhang WQ, Rosenmund C, Reim K (2008): Complexins facilitate neurotransmitter release at excitatory and inhibitory synapses in mammalian central nervous system. Proc Natl Acad Sci USA $\underline{105}, 7875-7880$

Yabe I, Sasaki H, Takeichi N, Takei A, Hamada T, Fukushima K, Tashiro K (2003): Positional vertigo and macroscopic downbeat positioning nystagmus in spinocerebellar ataxia type 6 (SCA6). J Neurol 250, 440-443

Yanisch-Perron C, Vieira J, Messing J (1985): Improved M13 phage cloning vectors and host strains: nucleotide sequences of the M13mp18 and pUC19 vectors. Gene 33, 103-119

Yin J, Liu F, Li X, Walsh CT(2004): Labeling proteins with small molecules by sitespecific posttranslational modification. J Am Chem Soc 126, 7754-7755

Yin J, Straight PD, McLoughlin SM, Zhou Z, Lin AJ, Golan DE, Kelleher NL, Kolter R, Walsh CT (2005a): Genetically encoded short peptide tag for versatile protein labeling by Sfp phosphopantetheinyl transferase. Proc Natl Acad Sci USA 102, 15815-15820 
Yin J, Lin AJ, Buckett PD, Wessling-Resnick M, Golan DE, Walsh CT (2005b): Single-cell FRET imaging of transferrin receptor trafficking dynamics by Sfpcatalyzed, site-specific protein labeling. Chem Biol 12,999-1006

Young SM Jr, Neher E (2009): Synaptotagmin has an essential function in synaptic vesicle positioning for synchronous release in addition to its role as a calcium sensor. Neuron $\underline{63}, 482-496$

Yu FH, Catterall WA (2004): The VGL-chanome: a protein superfamily specialized for electrical signaling and ionic homeostasis. Sci STKE 253, 15

Zamponi GW, Snutch TP (1998): Modulation of voltagedependent calcium channels by $G$ proteins. Curr Opin Neurobiol $\underline{8}$, 351-356

Zhang H, Maximov A, Fu Y, Xu F, Tang TS, Tkatch T, Surmeier DJ, Bezprozvanny I (2005): Association of CaV1.3 L-type calcium channels with Shank. J Neurosci $\underline{25}, 1037-1049$

Zhang W, Efanov A, Yang SN, Fried G, Kolare S, Brown H, Zaitsev S, Berggren PO, Meister B (2000): Munc-18 associates with syntaxin and serves as a negative regulator of exocytosis in the pancreatic beta-cell. J Biol Chem $\underline{275}$, $41521-41527$

Zhou H, Beaudet AL (2000): A new vector system with inducible E2a cell line for production of higher titer and safer adenoviral vectors. Virology $275,348-$ 357

Zhou Z, Cironi P, Lin AJ, XU Y, Hrvatin S, Golan DE, Silver PA, Walsh CT, Yin J (2007): Genetically encoded short peptide tags for orthogonal protein labeling by Sfp and AcpS phosphopantetheinyl transferases. ACS Chem Biol $\underline{2}$, 337-346

Zhu XD, Sadowski PD (1995): Cleavage-dependent ligation by the FLP recombinase. J Biol Chem 270, 23044-23054

Zhuchenko O, Bailey J, Bonnen P, Ashizawa T, Stockton DW, Amos C, Dobyns WB, Subramony SH, Zoghbi HY, Lee CC (1997): Autosomal dominant cerebellar ataxia (SCA6) associated with small polyglutamine expansions in the 1Avoltage-dependent calcium channel. Nat Genet 15, 62-69

Zucchi R, Ronca-Testoni S (1997): The sarcoplasmic reticulum Ca+ channel/ ryanodine receptor: modulation by endogenous effectors, drugs and disease states. Pharmacol Rev $\underline{49}, 1-51$ 
Zühlke RD, Pitt GS, Deisseroth K, Tsien RW, Reuter H (1999): Calmodulin supports both inactivation and facilitation of L-type calcium channels. Nature $\underline{399}$, 159-162 


\section{Danksagung}

Allen, die mich bei der Verwirklichung dieser Arbeit unterstütz† haben, danke ich herzlich.

Ich möchte mich zunächst sehr bei Herrn Prof. Dr. Erwin Neher bedanken, der mir dieses interessante Thema zur Verfügung gestellt hat und in dessen Abteilung ich die Arbeit durchführen durfte.

Mein außerordentlicher Dank gilt Frau Dr. Meike Pedersen, die meine Arbeit betreute und jederzeit für Diskussionen, Fragen und konstruktive Kritik zur Verfügung stand. Des Weiteren bedanke ich mich für die geduldige Einarbeitung und Unterstützung sowie viele gewinnbringende Diskussionen.

Allen Mitarbeitern der Abteilung für Membranbiophysik danke ich für ihre Unterstützung.

Dr. Ralf Mohrmann danke ich für viele Anregungen bei der Lösung einiger experimenteller Herausforderungen.

Weiterhin möchte ich an dieser Stelle meiner Familie, insbesondere meiner Frau danken. Ihre fortwährende Unterstützung und Bereitschaft, einige familiäre Mühen wie auch Lasten schwerpunktmäßig auf sich zu nehmen, ermöglichte die Durchführung dieser Arbeit. 


\section{Lebenslauf}

Am 18.02.1981 wurde ich in Wilhelmshaven als Sohn der Tierärztin Dr. med. vet. Alena Juha, geb. Hrebik, und des Arztes Dr. med. Adalbert Juha geboren. Ich habe einen älteren Bruder. Am 11.11.2008 sind meine beiden Söhne, Lucas Jonathan und Raphael Maximilian, geboren. Seit September 2009 bin ich mit meiner Frau Dipl. Kauffrau cand. med. Bianca Juha, geb. Braun, verheiratet.

1987 wurde ich an der Grundschule Glarum in Schortens, Niedersachsen, eingeschult. Von 1991 bis 1993 besuchte ich die Orientierungsstufe der Franziskusschule Wilhelmshaven und anschließend das Gymnasium Cäcilienschule in Wilhelmshaven, an dem ich 2001 mein Abitur ablegte. Ergänzt wurde meine schulische Ausbildung in den Jahren 1997 bzw. 1998 durch ein Auslandsjahr an der Van Buren Highschool in Van Buren, Arkansas, USA.

Von 2001 bis 2002 erfolgte die Absolvierung des Zivildienstes beim Malteser Hilfsdienst in Wilhelmshaven.

Im Jahr 2002 nahm ich das Studium der Betriebswirtschaftslehre an der Katholischen Universität Eichstätt-Ingolstadt auf, welches ich ab 2004 an der Fernuniversität Hagen fortsetzte.

Von 2004 bis 2010 studierte ich Humanmedizin an der Georg-AugustUniversität Göttingen.

Im Jahr 2006 absolvierte ich den 1. Teil der Ärztlichen Prüfung und im Mai 2007 begann ich den experimentellen Teil meiner Dissertation am Max-PlanckInstitut für biophysikalische Chemie in Göttingen in der Abteilung Membranbiophysik (Prof. Dr. Erwin Neher). Im Mai 2010 waren meine Experimente abgeschlossen.

Über weite Abschnitte meines Studiums in Göttingen hinweg war ich Mitglied der Fachschaft sowie leitendes Mitglied der Lokalvertretung Göttingen der Bundesvertretung Medizinstudierender in Deutschland, Sparte Famulantenund Forschungsaustausch. Des Weiteren war ich von 2007 bis 2010 Mitglied der Forschungskommission der Universitätsmedizin Göttingen.

Während meines Studiums absolvierte ich meine Famulaturen in Wilhelmshaven; Prag, Tschechien; Van Buren, USA und Kobe, Japan.

Von August 2009 bis März 2010 verbrachte ich meine ersten beiden Tertiale am St. Martini Krankenhaus Duderstadt in der Abteilung für Chirurgie bzw. Innere Medizin. Anschließend absolvierte ich von März bis Juli 2010 mein Wahl- 
tertial am Universitätsklinikum der Universität Göttingen in der Klinik für Radiologie bzw. in der Klinik für Strahlentherapie und Radioonkologie.

Im November 2010 legte ich erfolgreich den 2. Teil der Ärztlichen Prüfung ab und erhielt kurz danach die Approbation als Arzt.

Seit dem 01.04.2011 arbeite ich als Assistenzarzt im Klinikzentrum für Strahlentherapie, Hämatologie und Onkologie im Pius Hospital Oldenburg, wo ich zunächst auf Station und später in der Patientenbetreuung an den Linearbeschleunigern tätig war. Ab dem 01.05.2013 führe ich meine Weiterbildung zum Facharzł für Strahlentherapie an der Klinik und Poliklinik für Strahlentherapie der Universitätsmedizin Rostock fort. 